\title{
Japanese Electoral Politics
}

The old Japanese single-party system collapsed in 1993, but a new system has not yet fully evolved.

Following the most significant party reform in Japanese history, this book analyses the most recent national elections, examining voter behaviour and how it is influenced. It provides a comprehensive overview of Japanese politics from 1955 to 1993 and a detailed historical study of events leading up to the 1996 and 2000 elections, before presenting statistical analysis of the elections themselves. The authors then look to the future, anticipating what form the new political system will take.

Japanese Electoral Politics contains four very detailed case studies and a wealth of new data. It will appeal to students and researchers of Japanese politics and elections and electoral systems.

Steven R. Reed is Professor of Modern Government at Chuo University, Japan. His major areas of research include elections, electoral systems and Japanese politics. His recent publications include 'The Causes of Political Reform in Japan' and 'The Consequences of Political Reform in Japan' with Michael F. Thies in Mixed-Member Electoral Systems. 


\title{
The Nissan Institute/RoutledgeCurzon Japanese Studies Series
}

\begin{abstract}
Editorial Board
J.A.A. Stockwin, Nissan professor of modern Japanese studies, University of Oxford and director, Nissan Institute of Japanese Studies; Teigo Yoshida, formerly professor of the University of Tokyo; Frank Langdon, professor, Institute of International Relations, University of British Columbia; Alan Rix, executivedean, faculty of arts, The University of Queensland; Junji Banno, formerly professor of the University of Tokyo, now professor, Chiba University; Leonard Schoppa, associate professor, department of government and foreign affairs, and director of the East Asia Center, University of Virginia.
\end{abstract}

Other titles in the series:

The Myth of Japanese Uniqueness

Peter Dale

The Emperor's Adviser: Saionji

Kinmochi and Pre-war Japanese

Politics

Lesley Connors

\author{
A History of Japanese Economic \\ Thought \\ Tessa Morris-Suzuki
}

The Establishment of the Japanese Constitutional System

Junji Banno, translated by J. A. A.

Stockwin

Industrial Relations in Japan: The Peripheral Workforce

Norma Chalmers

Banking Policy in Japan: American Efforts at Reform During the Occupation

William M. Tsutsui

Educational Reform in Japan Leonard Schoppa
How the Japanese Learn to Work: Second Edition

Ronald P. Dore and Mari Sako

Japanese Economic Development: Theory and Practice, Second Edition

Penelope Francks

Japan and Protection: The Growth of Protectionist Sentiment and the Japanese response

Syed Javed Maswood

The Soil, by Nagatsuka Takashi: A Portrait of Rural Life in Meiji Japan

Translated and with an introduction by Ann Waswo

Biotechnology in Japan

Malcolm Brock

Britain's Educational Reform: A

Comparison with Japan

Michael Howarth

Language and the Modern State: The Reform of Written Japanese Nanette Twine 
Industrial Harmony in Modern

Japan: The Intervention of a

Tradition

W. Dean Kinzley

Japanese Science Fiction: A View of a Changing Society

Robert Matthew

The Japanese Numbers Game: The Use and Understanding of Numbers in Modern Japan

Thomas Crump

Ideology and Practice in Modern Japan

Edited by Roger Goodman and Kirsten Refsing

Technology and Industrial Development in Pre-war Japan: Mitsubishi Nagasaki Shipyard, 1884-1934

Yukiko Fukasaku

Japan's Early Parliaments, 1890-1905: Structure, Issues and Trends

Andrew Fraser, R. H. P. Mason and Philip Mitchell

Japan's Foreign Aid Challenge:

Policy Reform and Aid Leadership Alan Rix

Emperor Hirohito and Shōwa Japan: A Political Biography Stephen S. Large

Japan: Beyond the End of History David Williams
Ceremony and Ritual in Japan:

Religious Practices in an Industrialized Society

Edited by Jan van Bremen and D. P. Martinez

Understanding Japanese Society: Second Edition

Joy Hendry

The Fantastic in Modern Japanese Literature: The Subversion of Modernity

Susan J. Napier

Militarization and Demilitarization in Contemporary Japan

Glenn D. Hook

Growing a Japanese Science City: Communication in Scientific

Research

James W. Dearing

Architecture and Authority in Japan

William H. Coaldrake

Women's Gidayü and the Japanese Theatre Tradition

A. Kimi Coaldrake

Democracy in Post-war Japan:

Maruyama Masao and the Search for Autonomy

Rikki Kersten

Treacherous Women of Imperial Japan: Patriarchal Fictions, Patricidal Fantasies

Hélène Bowen Raddeker 
Japanese-German Business

Relations: Competition and

Rivalry in the Inter-war Period

Akira Kudō

Japan, Race and Equality: The Racial Equality Proposal of 1919

Naoko Shimazu

The Making of Urban Japan: Cities and Planning from Edo to the Twenty-first Century

Andre Sorensen

Public Policy and Economic

Competition in Japan: Change and Continuity in Antimonopoly Policy, 1973-1995

Michael L. Beeman

Modern Japan: A Social and Political History

Elise K. Tipton
Men and Masculinities in Contemporary Japan: Dislocating the Salaryman Doxa

Edited by James E. Roberson and

Nobue Suzuki

The Voluntary and Non-profit

Sector in Japan: The Challenge of Change

Edited by Stephen P. Osborne

Japan's Security Relations with

China: From Balancing to

Bandwagoning

Reinhard Drifte

Understanding Japanese Society: Third Edition

Joy Hendry

Japanese Electoral Politics: Creating a New Party System Edited by Steven R. Reed 


\title{
Japanese Electoral Politics Creating a new party system
}

\author{
Edited by Steven R. Reed
}


First published 2003 by Routledge

Published 2017 by Routledge

2 Park Square, Milton Park, Abingdon, Oxon OX14 4RN

711 Third Avenue, New York, NY 10017, USA

Routledge is an imprint of the Taylor \& Francis Group, an informa business

Copyright (C) 2003 Steven R. Reed for selection and editorial material; individual contributors their contributions

Typeset in Times by

Rosemount Typing Services, Thornhill, DG3 5LS

The Open Access version of this book, available at www.tandfebooks.com, has been made available under a Creative Commons Attribution-Non Commercial-No Derivatives 4.0 license.

British Library Cataloguing in Publication Data

A catalogue record for this book is available from the British Library

Library of Congress Cataloging in Publication Data

Japanese electoral politics : creating a new party system / edited by Steven R. Reed.

p. $\mathrm{cm}$.

Includes bibliographical references and index.

1. Political parties-Japan. 2. Elections-Japan. 3. Japan-Politics and government-1989- I. Reed, Steven R., 1947-

JQ1698.A1 J364 2003

324. $952^{\prime} 049-\mathrm{dc} 21$

2002154264

ISBN 978-0-415-31140-3 (hbk) 


\section{Contents}

List of figures $\quad$ ix

List of tables $\quad \mathrm{x}$

Notes on contributors $\quad$ xi

Preface xii

Acknowledgements xiv

Note on romanisation $\quad \mathrm{XV}$

List of abbreviations $\quad$ xvi

\section{PART I}

The political context of the 1996 and 2000 elections 1

1 The 1993 election and the end of LDP one-party dominance 7 STEVEN R. REED

2 Realignment between the 1993 and 1996 elections 24 STEVEN R. REED

3 Realignment between the 1996 and 2000 elections 40 STEVEN R. REED

\section{PART II}

Four prefectural case studies

4 Political realignment in Nagano: Hata Tsutomu and the new opposition challenge the LDP

ETHAN SCHEINER

5 A local five-party alliance challenges the LDP in Hyogo KAREN E. COX 
viii Contents

6 Inheriting the 'Conservative Kingdom' in Ibaraki 105 Hulda THÓRA SVEINSDÓTTIR

7 Kagoshima: the prefecture that realignment forgot 122 ROBERT WEINER

\section{PART III}

Statistical analysis

8 Who won the 1996 election?

SteVen R. REED

9 Who won the 2000 election?

SteVen R. ReED

10 Conclusions

178

Steven R. Reed

References

202

Index

209 


\section{Figures}

3.1 The LDP regains its majority

9.1 Support for the Hashimoto administration

9.2 Support for the Obuchi administration

9.3 Support for the DPJ

10.1 Changes in the effective number of parliamentary parties since political reform 


\section{Tables}

II.1 The prefectures included 66

8.1 Determinants of a candidate's vote in $1996 \quad 152$

$\begin{array}{lll}8.2 & \text { Determinants of the vote by party, } 1996 & 154\end{array}$

$\begin{array}{lll}\text { 8.3 The determinants of turnout in } 1996 & 158\end{array}$

$\begin{array}{lll}9.1 & \text { Mean change in vote percentage by party } & 167\end{array}$

$\begin{array}{lll}9.2 & \text { Determinants of a candidate's vote in } 2000 & 168\end{array}$

$\begin{array}{ll}9.3 \text { The fate of the } 1996 \text { NFP candidates } & 170\end{array}$

$\begin{array}{lll}9.4 & \text { Determinants of the LDP vote, } 2000 & 172\end{array}$

$\begin{array}{lll}9.5 & \text { Determinants of the DPJ vote, } 2000 & 173\end{array}$

$\begin{array}{lll}\text { 9.6 Determinants of the JCP vote, } 2000 & 174\end{array}$

10.1 Movement toward equilibrium between the first and second 188

10.2 Competitiveness in urban and rural districts 189 


\section{Notes on contributors}

Karen E. Cox is a PhD candidate in the Woodrow Wilson Department of Politics, University of Virginia, USA. Her recent publications include 'Interaction Effects in Mixed-Member Electoral Systems: Theory and Evidence from Germany, Japan, and Italy' (with Leonard J. Schoppa, Comparative Political Studies 35: 9). Her dissertation examines the influence of local factors on party system change in Japan.

Steven R. Reed is professor of modern government at Chuo University in Japan, where all his classes are taught in Japanese. His major areas of interest include elections, electoral systems and Japanese politics. His recent publications include 'The Causes of Political Reform in Japan' and 'The Consequences of Political Reform in Japan' with Michael F. Thies in Mixed-Member Electoral Systems.

Ethan Scheiner is a Postdoctoral Fellow in the Institute for Studies at Stanford University, USA. His major areas of interest include political parties, elections, electoral systems and Japanese politics. He is currently completing a book manuscript entitled Democracy Without Competition: Opposition Failure in One-Party Dominant Japan.

Hulda Thóra Sveinsdóttir is a $\mathrm{PhD}$ candidate in the Department of Politics, University of Newcastle-upon-Tyne, UK. Her thesis examines the development of factionalism within the conservative parties in Japan between 1945 and 1964. Her main research interests include political parties, party organisation, factionalism, electoral systems and Japanese politics.

Robert Weiner is a $\mathrm{PhD}$ candidate in the Department of Political Science, University of California at Berkeley, USA. 


\section{Preface}

I took on this project for four reasons. First, the 1996 and 2000 elections were the first two to be held under the new electoral system and represent the first steps toward creating a new Japanese party system. These were two very important elections indeed. For political scientists these two elections rank with the 1994 and 1996 Italian elections as natural experiments that provide invaluable data on a wide range of theoretical issues. For students of Japanese politics, these elections rank with the 1955 and 1958 elections as elections in which major decisions about the future of Japanese politics were made, though we still await an election like the 1960 election that solidified the previous party system. In these two elections, we are watching the early stages of the birth of a new party system.

Second, I would very much like to start a series on Japanese elections. My model is the British Nuffield series. Other countries have also seen book-length studies of specific elections. Why not Japan? Japan has an active political science community studying elections but most of the literature is published in Japanese only. A second barrier to a series on Japanese elections was the fact that, until recently, comparative political scientists were more interested in Japanese economic policy than in elections. Moreover, earlier books on specific Japanese elections had trouble because not much was happening in Japanese politics at the time. Recently, Japanese electoral politics has become much more interesting, more comparativists are interested in Japanese elections, and I read the Japanese literature but write in English. A series on Japanese elections is now possible. Reader response to this volume will tell us whether such a series would also be desirable.

Third, since I now work in Japan, the cost of collecting the necessary materials has dropped to virtually nothing. It is quite difficult to keep up with all the twists and turns of Japanese politics when living somewhere else but, especially for an elections junkie like myself, easy to do so when living in Japan. My daughter tells me that I act as though the morning newspaper were some kind of wonderful gift. TV talk shows keep me stimulated, and discussions with Japanese political scientists keep me well informed. It may not be too much to claim that this book could only have been written while living in Japan. Finally, I was lucky to find four excellent graduate students who shared my advantage of 
being in Japan because each of them was doing his or her dissertation research. Anyone who plans to study Japanese elections would be well advised to study at least one case in detail. Such case studies provide the context necessary to interpret events and statistical data. Each of these graduate students had, or was developing, expertise in the politics of some prefecture and was thus able to write one of the prefectural case studies for Part II of this volume. Japanese specialists who already have a firm grasp of the context of these two elections may find these case studies to be excessively detailed. I doubt that any future volume on Japanese elections will require similar case studies. However, for the first two elections under a new electoral system, I hope they prove helpful to election specialists who study other countries and to those just starting their study of Japanese politics. I know that I found the district case studies in the British election series to be useful for precisely this kind of contextual knowledge. 


\section{Acknowledgements}

I would like to thank first and foremost my seminar students for their participation in this project. Two seminar participants deserve special mention. Koyano Hiromi and Sugibayashi Tooru co-authored prefectural case studies that were not included in the final volume. I appreciate their efforts even though I proved unable to reward them.

I must also thank Japanese newspapers, especially local newspapers, for the rapid development of their respective home pages. It is now possible to follow many different local races in quite some detail without leaving the office.

The editor and publishers would also like to thank Cambridge University Press for kindly granting permission to reproduce extracts from 'Evaluating Political Reform in Japan: A Midterm Report' by S. R. Reed, originally published in Japanese Journal of Political Science 33 (2): November 2002.

Finally, I could never get anything done without the support of my wife, Michiko. 


\section{Note on romanisation}

Many different romanisations are used to make the Japanese language available to Western readers. In this volume we use the romanisation that would, if entered into a Japanese word processor, produce the proper Chinese characters. I chose this romanisation for three reasons. First, because I now teach in Japan I am forced to use a Japanese word processor. This romanisation is now second nature to me, as it is for most Japanese. Second, I see no reason to use a romanisation that looks familiar to English speakers. In fact, many of the more common romanisations give the false impression that English speakers can easily produce the proper Japanese pronunciation. I prefer to make English speakers feel the need to ask someone who speaks Japanese about the proper pronunciation. 


\section{List of abbreviations}

\section{Main political parties}

LDP Liberal Democratic Party (Joyuu Minshu-tou/Jimintou)

DPJ The Democratic Party of Japan/the Democrats (Minshutou)

NFP The New Frontier Party (Shinshintou)

Koumei, The Clean Government Party

Sakigake/Shintou Sakigake, The New Party Harbinger

The Liberals (Jiyuutou)

The Conservatives (Hoshutou)

LA The Liberal Alliance (Jiyuu Rengou)

SDP Social Democratic Party of Japan (Shakai Minshutou)

JCP Japan Communist Party

JSP Japan Socialist Party (Nihon Shakaitou)

JNP Japan New Party (Nihon Shintou)

SNS Shinsei $=$ Shinseitou, The Renewal Party

DRA Democratic Reform Alliance (Minkairen)

\section{Newspapers}

$\begin{array}{ll}\text { AS } & \text { Asahi Shinbun } \\ \text { HS } & \text { Hokkaido Shinbun } \\ \text { IS } & \text { Ibaraki Shinbun } \\ \text { KS } & \text { Kobe Shinbun } \\ \text { MNS } & \text { Minami Nihon Shinbun } \\ \text { MS } & \text { Mainichi Shinbun } \\ \text { NN } & \text { Niigata Nippou } \\ \text { SMS } & \text { Shinano Mainichi Shinbun } \\ \text { YNS } & \text { Yamanashi Nichinichi Shinbun } \\ \text { YS } & \text { Yomiuri Shinbun }\end{array}$

Note

Many of the citations of newspapers come from their respective web pages. In some cases the date listed on the web page is a day earlier than the date when the article appeared in the newspaper. 
Part I

The political context of the 1996 and 2000 elections 

The most important events that determine the results of an election occur between, not during, the election campaigns. When a campaign begins, the choices offered to the voters have already been winnowed down to a very few parties and a very few potential leaders. The public images of those parties and candidates have already been established and cannot be radically altered during the several weeks of an electoral campaign. The primary function of the campaign is to focus the public's attention on politics and inform them about those choices (Gelman and King 1993; Huckfeldt and Sprague 1995). Of course, important events do sometimes occur during the campaign. On occasion, some candidate will make a dramatic statement (most often a mis-statement) which changes the tenor of the campaign. Moreover, a well-run campaign communicates a party's message and enhances its image more efficiently than does a poorly run campaign. Nevertheless, by the time the campaign begins, the fundamentals have been determined and all that remains is for each party to make the best of the hand it has been dealt. In Part I, I focus on the 'hands' held by each party in the 1996 and the 2000 elections. The story must thus begin with the 1993 election because events between the 1993 and 1996 elections determined the context of the 1996 election.

One common image of elections portrays the process as taking place in three stages. First, the parties present their policy proposals in clear and coherent manifestos. Next, voters study these documents in detail and decide which of the manifestos comes closest to their own individual policy preferences. Finally, the election results are translated into a government that implements its promised policy proposals. While this picture has some normatively attractive characteristics in democratic theory, it has very little empirical validity in democratic practice. Parties seldom present clear alternatives and often suffer at the polls if they do. Neither do voters study the policy proposals that are available. For Japan, the classic statement comes from Miyake: 'If over a quarter of the voters have no positions on the issues, over half are unable to identify any party that represents their views, and over three-quarters fail to link their issue preferences with the party they voted for, then it seems unlikely that a study of issues will contribute greatly to an explanation of voting outcomes' (1991: 284). 
If elections are conceived of as civics tests or examinations on current events, voters fail miserably. Democratic practice falls far short of the expectations of democratic theory but democracy continues to function. If one starts with a model of an ideal democracy and asks whether reality lives up to the ideal, the answer is a clear 'No'. If, however, one starts by analysing how democracy works in practice and then asks how that reality should be evaluated, the answer is, 'Democracy is working surprisingly well' (Popkin 1991; Page and Shapiro 1992).

My interpretations of the 1996 and 2000 elections are based (albeit informally) on the 'on-line model of voting behaviour' (Lodge, Steenbergen and Brau 1995). Voters pay little attention to politics but occasionally pick up various pieces of information from their friends and from the mass media. They do not analyse this information or even store it for future reference. Rather, they adjust their opinion of political entities on the basis of the new information. If a voter hears that a particular candidate has been implicated in a scandal, he will revise his opinion of that candidate downward but will not necessarily remember that the candidate was involved in a scandal. If a candidate is seen on television doing something dramatic, some voters will revise their opinion of that candidate upward while others revise their opinion downward. At any given time, a voter's evaluation of a candidate or a party is the current sum of the bits of information she has collected over the years. The 'on-line model of voting behaviour' implies that events between elections influence public opinion as much as do the arguments and drama of the election campaign. It also implies that the ignorance found by Miyake and other survey researchers does not necessarily indicate that issues are irrelevant to voting behaviour. Survey research merely mis-specifies the mechanism through which issues affect voting.

In Chapter 1, I briefly present the 'deep' historical background to the 1996 and 2000 elections, focusing on the 1993 election. The 1993 election ended the party system that had characterised Japanese politics since 1955. In 1993 the LDP was excluded from power for the first time in its history by several new parties formed from defections from the LDP. The 1993 election ended the 1955 party system but did not replace it with a new party system.

The 1993 election was also the last to be held under the multimember electoral system that had been used to elect the Japanese House of Representatives since 1947. I describe that electoral system and the new system that has replaced it. For Japanese politics, the 1996 and 2000 elections are the beginning of a process that will produce a new party system. For political scientists, however, these elections also represent a rare experiment in changing electoral systems. An electoral system is part of the path to power and therefore cannot help but influence the practice of politics. Though political scientists know that electoral systems are important, we disagree among ourselves on how important the electoral system is and how it affects politics. The 1996 and 2000 elections thus provide us with data which should help us to resolve these arguments. 
Chapters 2 and 3 are the core of Part I. In these chapters I will tell the story of political events as they appeared in the mass media, primarily the newspapers. I have done very few elite interviews and have made no effort to obtain inside information. I try to focus on the information available to voters as they entered the voting booth. I will use the available secondary literature but do my best to note what information was available to the voters at the time and what was not. Readers interested in an interpretation of these events based more on elite interviews and inside information would be well advised to read Gerald Curtis's (1999) excellent study. In Japanese, we are also lucky to have Sasaki Takeshi's edited volume (1999a).

All of the information presented in Chapters 2 and 3 was available to the ordinary voter if she had been paying close attention to politics. Of course, very few voters pay nearly as much attention to political events as do political scientists. There is no reason to believe that voters actually remembered many of the details or even the order of events but, based on the on-line model of voting behaviour, there is every reason to believe that each of the events reported in the mass media left an impression on public opinion. Moreover, there is good reason to believe that the aggregate result of all the impressions left by press reports accurately reflects the information available to the voters in the mass media (Kabashima and Reed 2000). However public opinion is formed, the aggregate results tend to be remarkably accurate. The events I describe were the main political stories of the day and all voters were exposed to them. My presentation will be chronological. The purpose is to give the reader a 'feel' for the context in which voters went to the polls first in 1996 and again in 2000. 



\title{
1 The 1993 election and the end of LDP one-party dominance
}

\author{
Steven R. Reed
}

After a post-war record of 38 years of continuous rule, the Liberal Democratic Party (LDP) was finally unseated in the 1993 general election. The Japanese electorate did indeed vote for change but the felling of the LDP was not accomplished by an electoral earthquake analogous to the 1992 Italian election (Pasquino and McCarthy 1993). Voting followed patterns and trends that have been in place since at least the 1970s. In terms of voting behaviour, the 1993 election was a 'normal' scandal election, similar to the previous scandal elections of 1976, 1983 and 1990. The difference this time was the defection of 46 LDP incumbents and the creation of three new non-socialist opposition parties. The LDP was defeated by the interaction between voter dissatisfaction and the attractive alternatives offered by three new parties. Dissatisfaction had come about in the past with each of the periodic scandals suffered by the LDP regime. Attractive alternatives have been less common.

\section{Alternatives to the LDP}

In the past, whenever voters were angered by one of the LDP's scandals, they were faced with a narrow and uninspiring set of alternatives. Since the founding of the LDP after the 1955 election, the largest opposition party had always been the Japan Socialist Party (JSP). ${ }^{1}$ The JSP had fought against rearmament and constitutional revision in the 1940s and 1950s, winning votes as the party of peace rather than as a party of the left (Curtis 1988: Chapter 4). This stance was electorally productive as long as the conservatives continued to stand for rearmament and constitutional revision. Except for the disaster of 1949, when the JSP was severely punished for its role in an ineffectual and scandal-ridden coalition government, the socialist vote grew continuously from the 1946 through the 1960 elections. In 1960, however, the LDP changed its strategy, emphasising its economic policies instead of its stance on rearmament.

The year 1960 was a traumatic one in Japanese politics. LDP Prime Minister Kishi Nobusuke, a pre-war bureaucrat who had been arrested (though never tried) by the American Occupation on charges of being a Class-A war criminal, attempted to force an amended version of the US-Japan Security Treaty (Ampou) 


\section{The political context}

through the Diet (Packard 1966). The socialists opposed this move with every means at their disposal, within the Diet and outside it, using both legislative manoeuvres and extraparliamentary demonstrations. The bill was passed and the Security Treaty was revised but Prime Minister Kishi was forced to resign and the LDP dropped talk of rearmament and constitutional revision. Ikeda Hayato, the new prime minister, appealed to the public on the basis of economic growth with his well-known 'income doubling policy'. The JSP continued to stand for peace but the LDP had stopped taking the other side of the issue. The appeals that had worked so well for the JSP from 1952 through 1960 proved ineffective thereafter, but the party never adjusted to this new reality. The JSP never recovered from a disastrous defeat in 1969 and its vote declined steadily thereafter through 1986.

Though the JSP failed to refurbish its image, attract new voters, or increase its vote in general elections, it was not inactive during this period. Soon after the 1969 defeat, the party began seeking co-operative arrangements with other parties, including some reasonably effective agreements on electoral cooperation. The choice between a leftist coalition with the Communists and a centrist coalition, however, posed a vexing and shifting strategic dilemma. In the 1970s the Socialists experienced some success with leftist coalitions in gubernatorial elections and with centrist coalitions in Upper House elections (Christensen 2000). However, the party failed to make a clear strategic choice or to build upon any of these relative successes.

The only Socialist victories since the 1969 disaster occurred in 1989 and 1990. Led by Doi Takako, the first female leader of a major Japanese political party, the JSP defeated the LDP in the 1989 House of Councillors elections and the 1990 general elections. These two elections were dominated by the 'Recruit scandal' and by the introduction of a new consumption tax (Reed 1991). The House of Councillors election also featured electoral co-operation with the centre parties under the auspices of the newly reunified union movement, Rengou (Christensen 2000: 111ff). Again, however, the party proved unable to build upon this success. In 1993, it returned to the previous trend towards decline as if the 'Doi boom' had never existed (Reed 1994a).

The Ampou cleavage faded after 1960 but continued to be the single strongest predictor of the vote (Flanagan 1984). Voters were ready for something new but the JSP continued to symbolise the old Ampou cleavage. Both the LDP vote and the JSP vote declined in the 1960s and 1970s and the votes freed up by the decline of both major parties were picked up by several small new parties. None of these new parties, however, attracted broad support. In a process the Japanese called tatouka (literally 'multipartisation'), new parties were periodically established to take advantage of otherwise unoccupied niches in the Japanese electorate. Precisely because they were 'niche parties', 2 however, they could not expand much beyond their respective constituencies and had no prospects of ever winning a majority in the Diet.

The JSP split in 1960 and, in a process analogous to the formation of the SDP in Britain, the Democratic Socialist Party (DSP) was formed from a group of 
defectors from the JSP (Steel and Tsurutani 1986; Hrebenar 1992a). The DSP failed to make serious inroads into the socialist vote in its first election and thereafter settled into a niche provided by Doumei, the less ideological of the two main labour union federations. By 1993 the DSP had drifted to the right of the LDP on the rearmament issue while maintaining moderate left-wing stances on most other issues.

In 1967 Koumei (usually translated as the 'Clean Government Party'), a local party based on the Souka Gakkai Buddhist sect, entered the national arena (White 1970; Hrebenar 1992b). Koumei mobilised many new voters who had otherwise tended not to vote at all. Though only about half of their vote comes from members of the Souka Gakkai (Watanuki 1991: 77), the organisation has proven remarkably effective, turning out not only to support Koumei candidates but also to support candidates from other parties as directed by party leaders. However, the party has not been able to attract many voters from other parties, even in exchange for the disciplined support of Koumei voters in other elections (Christensen 2000: 95). Koumei has one of the most negative images of any party in Japan, second only to that of the communists.

The Japan Communist Party (JCP) had run in every post-war election, indeed in every electoral district since 1960, but experienced little success until 1972 (Berton 1992). In the 1960s and 1970s the JSP allied itself with the JCP, winning several major gubernatorial elections (Maeda 1995). However, neither the DSP nor Koumei would accept JCP co-operation. Forced to choose between a leftist alliance with the JCP and a centrist alliance with the DSP and Koumei, the JSP finally chose the latter and the JCP was forced back into its ghetto. By 1993 no party considered the JCP an acceptable coalition partner. There was no reason to expect a vote for the JCP to contribute to replacing the LDP with a coalition of opposition parties. A vote for the JCP was a 'wasted' protest vote. ${ }^{3}$

In 1976, during the Lockheed scandal involving ex-Prime Minister Tanaka, five members of the Lower House of the Diet defected from the LDP to form the New Liberal Club (NLC) (Pharr 1982). This was the first time a defection threat had been carried out and the electorate responded enthusiastically (Reed 1997b). The problem was that only a very small proportion of the electorate was given the opportunity to respond at all. The NLC fielded candidates in only 25 districts, the minimum requirement for legal recognition as a political party. With only five incumbents (defectors from the LDP) and candidates in only 25 districts, the NLC failed to unseat the LDP despite an enthusiastic response from voters. Nevertheless, the 'NLC boom' of 1976 provided the reformers of 1993 with many valuable lessons, both positive and negative (Otake 1999: 70). The most positive lesson learned from the NLC was that the electorate was ready for a change and a new reformist party could expect a boom in its first election. The most negative lesson was that a party could be 'new' only once. The NLC faded in its second election and finally returned to the LDP fold after the 1986 election.

In 1978 Eda Saburou finally gave up his attempts to reform the JSP from the inside and defected to form the Social Democratic League (SDL, Shaminren). 
Unfortunately, Eda died soon afterward and the SDL never developed into a significant force in Japanese politics.

In 1993 the traditional opposition to the LDP included the JSP, DSP, Koumei, JCP, and SDL. There was widespread appreciation within the opposition camp that none of these parties offered much hope of taking power away from the LDP. There was much discussion of a new opposition party that could defeat the LDP but it was hard to imagine winning without breaking up the LDP to some degree. Thus, Curtis argued that, 'For the foreseeable future at least, the end of LDP rule, if it is to occur at all, is most likely to result from a split in the LDP itself' (Curtis 1988: 240). There were two glimmers of hope, the NLC boom of 1976 and the Doi boom of 1989-1990. Each fed a dream that had been bandied about since the LDP was founded in 1955, a centre-right dream and a centre-left dream.

If the LDP could be split to form a new conservative party, but learn from the mistakes of the NLC and do it right this time, perhaps the centre-right dream of a second conservative party, perhaps including some sympathetic socialists, could be realised. The leaders of the centre-right dream in the 1990s were Kanemaru Shin and Ozawa Ichirou (Christensen 2000: 152). Before the centre-right dream could be realised, however, Kanemaru was arrested in a major corruption scandal. Presumably, he had never planned to leave the LDP but had collected those huge sums of money to fund a new party. Though things did not go as planned, the Kanemaru scandals kept the impetus for reform alive by providing a very bad example of how the old system worked. Ozawa was to play a major, albeit problematic, role in the events that led to the defeat of the LDP.

The centre-left dream involved reforming or splitting the JSP to produce a new party consisting of the best of the opposition parties, and perhaps even including some sympathetic members of the LDP. ${ }^{4}$ This seemed the only way the JSP could finally follow the path pioneered by European socialist parties and begin to compete with the LDP. Flanagan saw potential in this scenario: 'Should the ruling party fall short of a majority, the most likely scenario would be that it would continue to govern in coalition with one of the small centre parties. However, a dramatic elite realignment could occur. Already the centre parties have taken steps toward establishing the building blocks of a larger centrist coalition that might draw support from both defecting LDP factions and the moderate wing of the JSP' (Flanagan 1984: 203). Yamahana Sadao led the most recent version of the centre-left dream from inside the JSP and Yamagishi Akira, head of the Rengou labour federation, led the movement from outside the party. Both envisioned the core of the new centre-left party to be formed from reuniting the two socialist parties, the JSP and the DSP, backed by a unified labour movement. Both were ready to split the JSP and discard the left wing in order to achieve their objectives. Despite their best-laid plans, the JSP stubbornly refused to split and the DSP continued to go its separate way. Though their plans failed, both men were to play major roles in the political realignments that followed.

The two dreams overlapped and were not mutually exclusive. The centre-right dream had long included the right wing of the JSP, while pointedly excluding the 
left, and the centre-left dream included the more compatible members of the LDP. All earlier attempts to realise these dreams failed.

Both dreams required a split in the LDP. Rumours and threats of a split recurred throughout the LDP's existence. It is a highly factionalised party and some faction or other was almost always threatening to leave and start a new party of its own. Splitting the LDP thus seemed a perfectly feasible strategy, but when LDP reformers looked outside the LDP for potential allies, they found few attractive partners. Cross-party alliances were discussed and came close to fruition in the process that led to the selection of Miki Takeo as the president of the LDP in 1974 and during the complex 'Nikaidou affair' of 1983 (Christensen 2000: 143-150). The LDP managed to hang together each time, overcoming an even greater challenge to its unity in 1980 (Curtis 1999: 67-69). Though one may dispute the importance of ideological differences in preventing these cross-party alliances, the end of the Cold War certainly made cross-party alliances easier to imagine (Curtis 1999: 78-79).

As the major opposition party under the old party system, the JSP would also have to change, and perhaps split, before a new party system could be formed. Though the internal dynamics of the JSP have not been as thoroughly analysed as those of the LDP, the party had a long history of failed reform movements and party splits. There were groups inside the JSP which were satisfied to stay in opposition as long as they could prevent any revision of the constitution. Other groups were more ambitious and less tied to the old Ampou cleavage.

The historic victory of the JSP in the 1989 House of Councillors election both gave the socialists hope and offered a glimpse of a path leading towards power. First, socialist reformers learned that the corruption issue would win more votes than the peace issue. Second, they received an object lesson in the working of electoral systems (Sasaki 1999b). The Doi boom gave socialist candidates a boost both in the 1989 House of Councillors election and in the 1990 general election, but that increase in votes produced a much bigger increase in seats in the singlemember districts of the Upper House election. The JSP was much less able to convert votes into seats in the multimember districts of the Upper House or in the Lower House. The party's attitude toward reform of the electoral system had been negative since its unpleasant experience with the 'Hato-mander' (a gerrymander which took its name from LDP Prime Minister Hatoyama) in 1955 (Kusunoki 1997). The experience of the Doi boom forced party members to rethink their position and made them more open to political reform.

\section{The Reform Movement and the new parties}

A window of opportunity for breaking the mould of post-war Japanese politics opened with the string of scandals, which began in 1988 with the 'Recruit scandal' (Curtis 1999: 75-76). The Recruit scandal was followed in 1992 by the Sagawa Kyuubin scandal which led to a steady stream of revelations, many concerning the incredible feats of fund-raising by Kanemaru Shin (Curtis 1999: 


\section{The political context}

86-87). These scandals opened another window of opportunity for reform similar to those which had resulted in the NLC boom of 1976 and the Doi boom in the 1989 House of Councillors election (Reed 1999). Though both previous movements had failed, both came close enough to offer some hope and teach some lessons to the reformers of 1993 . The scandals and the failures to address the problems seen as causing them produced a series of reform movements within both the LDP and the opposition and even in cross-party reform groups.

After the Recruit scandal and the 1990 election, Prime Minister Kaifu promised political reform. Intra-party squabbling prevented him from keeping his promise. After the Sagawa scandal and the revelations concerning Kanemaru Shin, Prime Minister Miyazawa again promised political reform, and this time made the promise on national television. Once again, he failed to deliver as a result of opposition within the LDP. Two successive broken promises opened wide the window of opportunity for reform, if only someone had the initiative to climb through it. In the event, three different new parties seized that initiative.

The 1993 election was precipitated by the decision of 39 members of the LDP to vote in favour of a motion of no confidence against its own government. Eighteen more abstained by absenting themselves from the vote. The inability to enact political reform frustrated the public and fractured the LDP. A total of 46 defectors formed two new parties. First, on 21 June 1993, Takemura Masayoshi led a group of reformers out of the LDP and founded the New Party Harbinger (Shintou Sakigake, hereafter Sakigake) (Otake 1997). Takemura had started his career in the Ministry of Home Affairs, had been elected governor of rural Shiga prefecture with opposition party support, the LDP climbing aboard his bandwagon in his second term, and was serving in the House of Representatives in the LDP at the time. Two days later, on 23 June 1993, the faction led by Hata Tsutomu and Ozawa Ichirou defected en masse to form the Renewal Party (Shinseitou, hereafter Shinsei). They were joined by the Japan New Party (JNP, Nihon Shintou) which had been founded before the 1992 House of Councillors election by Hosokawa Morihiro, the governor of rural Kumamoto prefecture. Though the JNP had been founded first, it was the 'newest' of the new parties in the sense that it included no defectors and therefore no incumbents. Hosokawa had served in the House of Councillors for the LDP before being elected governor and the party recruited from a pool of conservatives who would previously have run for the LDP, but the JNP projected an image of political amateurs, outsiders attacking the political establishment (Nakai 1997). The key word in each of the party names was 'new' (shin in Japanese).

\section{The 1993 election}

The main event of the 1993 election was the 'new party boom'. All three new parties gained votes and, even more significantly, the 'newer' the party's image, the better it fared at the polls. The average change in vote by candidate gives us a simple estimate of how many votes a given party label was worth. The JNP 
label was worth 42,000 votes per candidate, while the other two new party labels were both worth over 30,000 votes. Only a very few JNP candidates had run in the previous election so the number of observations for this calculation is small but other analyses confirm this result (Kabashima 1998: 33-38). The JNP had no incumbents and few politicians with experience at the national level but still managed to have 35 candidates elected. In Shinsei and Sakigake almost all of the incumbents who ran were re-elected and their new candidates also fared quite well. The message was clear: the Japanese electorate wanted change.

The big loser in 1993 was the JSP, the average candidate losing almost 40,000 votes and the party losing almost half its seats. The Socialists had been the symbols of change in the previous 1990 election and they lost all of the changeoriented voters to the new parties. The correlation between the increase in JSP votes in 1990 and the decrease in 1993 is 0.56 and rises to over 0.80 if we eliminate the complication of the changing number of JSP candidates in a district. The JSP lost votes in 1993 in precisely those districts where it had gained votes in 1990. Voters did not reject the JSP. They had moved to the Doi-led JSP hoping for a change and in 1993 they moved on to other, more promising, agents of change.

Similarly, the voters did not abandon the LDP. The LDP label lost each candidate only about 5,000 votes on average. If all of the defectors had run under the LDP label and lost 5,000 votes each, the LDP would have finished with 29 per cent of the electorate and 43 per cent of the vote. With no defectors, the LDP would have lost votes but would probably have maintained its majority in the Diet. The defections were a necessary condition of unseating the LDP. The LDP was defeated by the interaction between the LDP defections and the response of the electorate represented by the new party boom.

The smaller established opposition parties were not much affected by the 1993 election. Koumei strategically reduced the number of candidates nominated, replaced many of its incumbents, and was thus able to increase its seats from 45 to 51 while maintaining its overall vote. The Democratic Socialist Party (DSP) did the same, though somewhat less successfully, gaining a single seat. The Communist vote dropped slightly. The only large-scale movement of votes was from the Socialists to the new parties.

The most surprising aspect of the election was the low turnout, the lowest in post-war history to that point. Perhaps the voters had been lulled into complacency by the fact that the media had predicted the historic defeat of the LDP many times before. Probably more important was the infighting among the new parties. The new parties failed to offer the electorate a clear alternative to the LDP. In 1990 Doi Takako had symbolised the forces of change, but this time there was no single non-LDP leader upon whom voters could focus their hopes. 


\section{The political context}

\section{Forming a non-LDP government}

After the election, independents who won joined parties and a few more defections occurred, leaving the line-up in the new Diet as follows: LDP: 228 seats plus 5 independent conservatives; JSP: 77 seats; Shinsei: 60 seats; Koumei: 52 seats; the JNP and Sakigake acting as a single parliamentary faction within the Diet: 52 seats; DSP: 19 seats; Communists: 15 seats; and three non-LDP independents. The non-LDP, non-communist forces had a majority of 260 seats to the LDP's 233. However, the non-LDP forces were divided into five major groupings and a total of eight parties. In a normal process of coalition formation, one would expect the LDP to be able to find a coalition partner. The non-LDP parties were united on nothing except the necessity of political reform and the LDP was now expressing a commitment to enact political reform, expressing a particular interest in the reform proposals of the JNP and Sakigake (Iwai 1999: 162-163). Even Watanabe Michio, in a bid to become the next leader of the LDP, suddenly expressed an interest in reform. The LDP could thus play the role of centre party, necessary to any policy-based coalition. In the event, however, the non-LDP parties were able to form a coalition and establish a government led by the JNP's Hosokawa. The logic of coalition formation was overpowered by the logic of preparing for the next election and the logic of grasping a historical opportunity. That the latter logics prevailed was hardly inevitable but it had a skilled and tireless advocate in Ozawa Ichirou (Curtis 1999: 11-114).

The electorate was demanding change and any party which ran against the LDP and then delivered more of the same by allowing the LDP to stay in power could expect to face an angry electorate at the next election. The DSP had made overtures to the LDP in the past and was often seen as the LDP's most natural coalition partner among the traditional opposition parties. Chairman Oouchi Keigo considered a coalition with the LDP but received a visit from the head of the Yuuai Kaigi, successor to the Doumei labour federation and the DSP's primary base of support. He was told that if the DSP joined the LDP in coalition it would mean the end of the party. The labour unions were 'non-LDP' and would not support the DSP if it opted for joining an LDP-led coalition (YS 15 August 1993). Similarly, both the JNP and Sakigake received a stream of phone calls urging them not to rescue the LDP (YS 3 August 1993). As importantly, the LDP had been in power for 38 years. If the opposition parties missed this chance, when could they expect to get another? The JSP, DSP, Shinsei and Koumei had been discussing the possibility of a coalition since the election began, but the JNP and Sakigake refused to participate in those talks (Iwai 1999: 160). The two parties had co-operated during the election and formed a joint parliamentary faction within the Diet. They seemed compatible coalition partners both to the LDP and to the LDP's opponents so the two sides competed for its support (YS 16 July 1993). There were those inside the LDP, however, who did not like the idea of any coalition. Led by secretary-general Kajiyama, they argued that the LDP should try to establish a one-party minority government and go into opposition if that were not possible (YS 23 July 1993). 
Hosokawa of the JNP had stated that the main issue of the campaign was a change in power, and he would have had trouble leading his party into coalition with the LDP under any circumstances. Takemura of Sakigake found it more difficult to abandon the reformers who stayed inside the LDP. He thus indicated his willingness to join a coalition with any party that supported political reform including a new electoral system, the Mixed-Member Majoritarian (MMM, heiritsu-sei in Japanese) electoral system. This proposal opened the door to the LDP, or at least to the reformers within the LDP, and seemed to close the door to the JSP. The JSP had opposed enactment of MMM under the Kaifu administration and was now asked to reverse its position. The JSP faced the facts, however, and quickly agreed to support MMM (YS 23 July 1993). The final key to excluding the LDP from government was Ozawa's decision to support Hosokawa as the person most likely to unify the non-LDP forces (YS 31 July 1993). The new coalition promised to enact political reform, including a new MMM electoral system, within a year. The JSP was left with few options but to join the coalition. It would have to abandon several of its past policy positions, but that would have been true in any coalition it chose to enter. Yamahana Sadao, JSP leader at the time and leader of the reform group inside the JSP, was appointed minister in charge of political reform. If the coalition government could deliver on its promise of political reform, it could justly claim to have succeeded where the LDP had repeatedly failed. The coalition needed to enter the next election able to say, 'Unlike the LDP, we keep our promises.'

The two parties which had 'lost' the 1993 election, the LDP and JSP, chose new leaders right after that election. In both cases, the dominant issue was political reform.

LDP reformers considered supporting either Gotouda Masaharu, the grand old man of political reform, or Oota Seiichi, one of the young turks. Opponents of reform backed Hashimoto Ryuutarou or Watanabe Michio. Gotouda withdrew in favour of Kouno Youhei, the man who had led the New Liberal Club out of the LDP in 1976, and the race came down to Kouno versus Watanabe. On 30 July Kouno won with 208 votes to Watanabe's 159. Though Kouno could be considered a reformer and Watanabe an opponent of reform, the race was determined more by traditional factional politics than by the reform issue (Iwai 1999: 166).

The JSP chose Murayama Tomoichi, grand old man of the left wing and opponent of reform, to lead them. As soon as he was elected, however, he declared his support for the MMM electoral system that the party, and particularly its left wing, had fought so hard to defeat during the Kaifu administration.

\section{Toward a new party system}

The 1993 election ended the 1955 party system. The LDP was out of power for the first time in its history. More importantly, the election had produced three new alternatives to the LDP. The mould had been broken but what would replace it? 
After the 1993 general election, Japanese politics entered a phase of remarkable fluidity. As I shall detail below, many new parties were founded and many more proposed. The LDP remained basically intact and the largest party in the system. As should have been expected, the new parties and the traditional opposition parties had trouble running a government together. Great expectations were dashed and many frustrated reformers reluctantly returned to the LDP. The LDP welcomed them back and found a way to regain power. The story is, however, still far from finished. We are witnessing an unfolding drama. We can expect a lot of change but cannot yet clearly see the outlines of a new party system.

\section{Changing electoral systems}

Between the 1993 and 1996 elections, Japan changed the electoral system used to elect the Lower House of the Diet (Christensen 1994; Reed and Thies 2001a). States seldom change their electoral systems. Politicians are extremely sensitive to any issue that might affect their chances of being elected and re-elected. Japan is one of the very few countries to enact a major change in its electoral system since the end of the Second World War. Along with Italy (Donovan 1995; Katz 2001) and New Zealand (Vowles 1995; Barker et al. 2001), Japan has become a laboratory for studying the effects of electoral systems. In order to interpret the 1996 and 2000 elections, therefore, we need to understand both the old and the new electoral systems.

\section{Classifying electoral systems}

Classifying electoral systems has been a favourite pastime of political scientists since modern democratic states emerged to be studied, but it has also been enjoying a particularly impressive resurgence in recent years (Grofman and Lijphart 1986; Grofman et al. 1999; Shugart and Wattenberg 2001). This resurgence has been due both to advances in analytic techniques (Taagepera and Shugart 1989) and to experimentation in the practical world of politics. Political reform, often involving changes in the electoral system, had become a major issue in many of the developed democracies during the 1990s. Democratisation in Eastern Europe, and in several other countries around the world, necessarily involved the selection of an appropriate electoral system. The demand for expert advice on electoral systems has stimulated research.

Political science knows quite a lot about electoral systems and can offer useful advice to democratisers and reformers, but there is no reason to think we will ever reach a consensus on an ideal electoral system. Indeed, we are still far from reaching a consensus on the classification of electoral systems. Out of the various classificatory schemes, I choose to focus on three interrelated dimensions particularly relevant to the Japanese case: (1) majoritarian versus consensus democracy; (2) candidate-centred versus party-centred politics; and (3) the 
incentives for opposition parties to co-ordinate their efforts to unseat the party in power.

\section{Majoritarian versus consensus democracy}

Normative theories of democracy can usefully be divided into two camps (Lijphart 1999). Majoritarians define democracy as majority rule. They tend to think of alternation in power as the essence of democracy. The key weapon given to the electorate is the power to 'kick the rascals out', putting the other rascals in. Majoritarians prefer a system with no more than two parties, one party of government and one of opposition. With only two parties, one is guaranteed a majority (assuming no ties). Whenever the party in power fails to satisfy, however, there is an alternative ready at hand, constantly trying to unseat it.

Consensus theorists, on the other hand, define democracy as a means of representing the 'will of the people'. They argue that the essence of democracy is that each individual voter should have an equal voice in government. Thus, voters should have a wide variety of options from which to choose, maximising the probability that one of those options will be close to their own individual set of policy preferences. In majoritarian theory, voters choose governments which then rule. In consensus theory, voters express their preferences for the policy packages offered by parties, which are then reflected in the laws enacted by parliament.

In terms of electoral systems, majoritarians support single-member districts (SMD) and consensus theorists support proportional representation (PR).

SMD is a simple system under which the state is divided into districts, each district electing one representative. Whoever gets the most votes in a district wins the seat and represents the district. Historically, SMD is the electoral system of Great Britain and its former colonies. In perhaps the best-known hypothesis in political science, Maurice Duverger suggested that the SMD electoral system tends to produce a two-party system (Duverger 1954). Duverger's Law has generated a huge literature, much of it critical, but it remains one of the most reliable generalisations in political science (Riker 1986). Controversy has produced much heat but also a significant amount of light. The theory has been refined by noting that the effect is felt primarily at the district level, not at the national level (Wildavsky 1959; Chhibber and Kollman 1998; Gaines 1999; Reed 2001b). Political science has also made significant progress in explaining the mechanisms which produce the observed effect (Cox 1997).

SMDs produce powerful incentives to move toward no more than two candidates per district. These incentives operate at the level of voters, candidates and parties, but the best understood effect is that upon voters. Voters who prefer a candidate with no realistic chance of winning the seat have an incentive to vote for one of the top two candidates because those two do have a chance to win. Instead of expressing their preferences, the voters have an incentive to vote strategically, thus trying to affect the election outcome (Riker 1986). Consensus theorists want to reflect the will of the people and therefore need voters to vote 
sincerely, not strategically. Majoritarian theorists want voters to choose a government and prefer that they vote responsibly for one of the two parties capable of forming a government and thus tend to think of strategic voting as wise voting.

Proportional representation (PR) is a more complex system designed to ensure that a party's percentage of the seats in the legislature equals its percentage of the vote in the election, i.e., that seats in the legislature reflect support in the electorate. This is normally accomplished through a list system. Parties present an ordered list of names. Voters choose a party, not a candidate. Seats are allocated to parties on the basis of one of several available mathematical formulae. Finally, each party's seats are awarded to their candidates beginning at the top of the list. If a party is allocated 10 seats in a district, the top 10 candidates on the list take those seats while the eleventh candidate and lower do not win a seat.

The debate between advocates of PR and advocates of SMD is perhaps the oldest and most intractable in democratic theory. All attempts to find an alternative that combines the attractive characteristics of the two systems have failed. Most theorists now agree that such a combination is, in fact, not possible. The choice is one of the two extremes or some compromise between them. The old Japanese system was just such a compromise.

From 1947 through 1993, Japan used the single non-transferable vote (most often called SNTV (Grofman et al. 1999)) in multimember districts (MMD) to elect the Lower House of the Diet. In this volume, the term MMD is preferred, for three reasons. First, the Japanese call their own system 'medium-sized districts' (chuusenkyokusei) to distinguish it from small-sized districts (SMDs) and large-sized districts. Second, the Japanese labels make good theoretical sense. The most important variable determining the proportionality of an electoral system is the district magnitude (M), the number of seats per district (Taagepera and Shugart 1989). Third, classifications should be shorter for simpler systems and longer for more complex systems. The norm should be non-transferable votes, not the more complex system of the single transferable vote (STV) required to make votes transferable from one candidate to another. The only reason to give transferable votes priority is that STV was on the agenda of political debate in English-speaking countries before political scientists studying electoral systems became interested in SNTV.

Because the primary determinant of proportionality is $\mathrm{M}$, district magnitude, countries where $\mathrm{M}$ ranges from three to five tend to have medium proportionality. Lijphart (1999) calls Japanese MMD a semiproportional system. Only Japan and Ireland feature this particular range of $\mathrm{M}$ and they have quite a lot in common, including one large party surrounded by several smaller parties (Reed 1994c). Both countries have experienced mild multipartyism. The barriers to entry for a new party are much lower than the barriers under SMD but much higher than those under pure PR. Though MMD offers a compromise between the majoritarian and consensus camps, there is no reason to think it combines either the best or the worst of both worlds. It merely contains a bit of both. 


\section{Party or candidate}

Under pure PR, voters choose a party but cannot choose a particular candidate within that party. Consensus theory suggests that voters should choose among policy packages represented by party platforms so there is no need to offer voters a choice among particular candidates.

Under SMD, voters typically have two choices, each representing a different party. In deciding how to cast their vote, citizens may weigh both the party platform and characteristics of the individual candidate. SMD gives candidates powerful incentives to develop their own personal support (Cain, Ferejohn and Fiorina 1987). In electoral systems that force large parties to run multiple candidates in each district and force voters to choose from among candidates from the same party, the incentives to develop a personal vote are even stronger (Katz 1986; Cain, Ferejohn and Fiorina 1987: 224 ff.; Carey and Shugart 1995).

As understood in Great Britain and in Ireland, proportional representation refers not to list-PR but to the single transferable vote (STV). Under STV, voters choose candidates but also vote for more than one candidate in their order of preference. A mathematical process is applied to the vote returns to ensure, first, that all candidates with a sufficient number of votes are elected and, second, that the number of wasted votes (votes cast for losing candidates) is minimised. Votes for losing candidates and excess votes for winning candidates are transferred to the voter's second and lower-order preferences (Laver and Marsh 1996). The goal is to produce a proportional result while allowing voters to vote for candidates, not parties. In practice, STV reduces the ability of a candidate to rely on the party vote because she needs to garner enough of it to be among the members of her party who win a seat. STV in multimember districts virtually forces candidates to build a personal vote because, 'As members of the same party and as supporters of a common party program, the individual candidates are unable to compete on grounds of policy or ideology. Rather, they compete in terms of individual effectiveness or competence in a manner which does much to depoliticise electoral competition' (Mair 1986: 293).

This phenomenon of candidates competing against candidates from their own party has been even stronger under Japan's MMD because it is like the Irish system except that votes are not transferable. If votes cannot be transferred, the relationship between votes and seats in a particular district can be warped beyond recognition (Cox and Niou 1994). A party that nominates too many candidates risks splitting the vote too thinly and finishing, for example, fourth and fifth in a three-member district and getting no seats. Similarly, a party that runs two candidates might have both elected if the vote were evenly divided between them but win only one if one of its candidates were too popular and received the lion's share of the vote. I know of no other electoral system that can punish a party for fielding a very popular candidate. These anomalies drew criticism, of course, but the primary problem with MMD was that it promoted competition among candidates from the same party. 
A democracy based on candidates competing to build up a base of personal votes by doing favours for their individual constituents and their geographical constituency is a very different system from a democracy based on unified parties competing for votes by proposing coherent party platforms. In the former system, voters may simultaneously have their most concrete demands met and yet justifiably feel that the government is unresponsive. They may come to have strongly negative feelings about the legislature but positive feelings about their own representative. In Japan, voters were often angry at the ruling Liberal Democratic Party, but continued to vote for particular LDP candidates. The popularity of the party and the legitimacy of the government aggregates to much less than the sum of its parts.

Moreover, campaigning under MMD cost a lot of money (Cox and Thies 2000). As the largest party, the LDP put forward multiple candidates in most districts. Each LDP candidate built up his own personal support organisation, a political machine called a kouenkai, to organise his personal vote. Gerald Curtis puts it best:

The fundamental reason for the high cost of campaigning in Japan is that every LDP politician must build and maintain his own political machine. He can rely neither on party organisation, which hardly exists on the local level, nor on party loyalties among the electorate which, to the extent that they do exist, are effectively neutralised by an electoral system that forces candidates from the same party to compete with one another. Maintaining one's own political machine means helping prefectural and local assemblymen with their election campaigns, employing one large staff in the district to look after one's support organisation, and another large staff in Tokyo to handle constituent requests and to raise money to make all other activities possible.

(Curtis 1988: 177)

The need to develop and sustain one's personal vote is the main cause of Japan's problems with the high cost of campaigning which, in turn, is a primary cause of political corruption.

\section{Co-ordination among opposition parties}

SMDs produce powerful incentives to reduce competition to no more than two candidates per district. The process of reducing candidates is one of co-ordination among potential candidates and parties. When one candidate withdraws from a district in favour of another, that act implies an alliance between the two candidates and/or the two parties. When more than two candidates compete, it indicates a failure of co-ordination which often leads to one-party dominance (Cox 1997). How did the LDP maintain its dominance for so long despite falling below 50 per cent of the vote? The most fundamental answer lies in the failure of 
the opposition parties to co-operate in order to defeat the LDP and one reason for this failure lies in the MMD electoral system.

Once LDP predominance was firmly established after 1969, elections tended to turn into referenda on the performance of the LDP government. Voters who wished to express disapproval were offered the option of voting for any of several different parties. One secret to the LDP's longevity then, was the splitting of the anti-LDP vote among several opposition parties. Dissatisfied voters also had, and exercised, the option of voting for a different LDP candidate or a conservative independent who would join the LDP if elected. That voters could express their dissatisfaction without depriving the LDP of a seat was another secret of LDP longevity. While the LDP stayed in power for 38 years, the rate of re-election for incumbents, at around 85 per cent, was one of the lowest in the democratic world (Reed 1994b).

The opposition parties competed with each other for the anti-LDP vote but they were perfectly aware of the need for electoral co-operation. Electoral co-operation, especially that between Koumei and the DSP, threatened LDP dominance in the 1970s (Christensen 2000). However, if one opposition party grew, it was usually at the expense of other opposition parties, not of the LDP. The test case was the 1990 general election (Reed 1991). In the 1989 House of Councillors election the LDP suffered its first ever defeat. It received fewer votes in the PR tier than the Socialists but was devastated in the single-member districts. The key, precisely as Cox (1997) would have predicted, was cooperation among the opposition parties. Despite this clear object lesson in the merits of co-operation, the opposition parties were unable to reproduce their cooperation in the 1990 general election (Taniguchi 1999: 271). As a result, the LDP squeaked out yet another election victory. Whereas the SMDs in the Upper House produced incentives for co-operation, MMDs in the Lower House produced incentives for the opposition parties to compete among themselves. The lessons of these two elections were not lost on the opposition parties, especially the JSP. The experience of winning in House of Councillors SMDs and then losing in House of Representatives MMDs softened attitudes toward SMDs.

\section{Changing the electoral system}

MMD had served Japan reasonably well from the 1950s through the 1970s by producing a moderate multiparty system and a stable majority in the Diet but had also produced several festering problems. The system failed to produce alternation in power because it hindered co-operation among the opposition parties. The flip side of a stable government majority was long-term dominance by the LDP. The opposition could not overcome its co-ordination problems in order to mount a credible threat to the LDP, and the LDP got quite good at breaking up nascent moves toward effective co-ordination. The LDP regularly coopted the most popular opposition policy positions around which all opposition parties might rally (Pempel 1975) and brought up issues that divided the 


\section{The political context}

opposition when its members co-operated. Most clearly, the system had fostered expensive, personal vote campaigning which was a major factor producing the rising number of corruption scandals after 1974 and particularly after 1989. Commentators criticised money politics and yearned for low-cost, party-centred elections.

Despite widespread dissatisfaction with MMD, there was little agreement on what should replace it. Large parties favoured SMD and small parties favoured PR. Fearing a gerrymander, no party would allow any other party to draw the new district boundaries. Electoral systems are hard to change. I will describe those circumstances in Chapter 2. Here I will briefly describe the operation of the new system.

\section{The new system: MMM}

Japan's new electoral system combines SMD and PR. The Japanese call it the parallel system (heiritsu-sei), quite an appropriate label, but I will follow Shugart and Wattenberg (2001) in calling it the Mixed-Member Majoritarian system (MMM) even though that leaves us with an unfortunate similarity between the old MMD and the new MMM labels. Combinations of SMD and PR have become quite popular lately, and it is important to distinguish between the two main types of mixed-member systems.

Germany uses Mixed-Member Proportional Representation (MMPR), a form of PR. When originally adopted it was called 'PR with a human face'. Seats are allocated to party lists and the SMD tier can affect the distribution of seats among parties only in unusual circumstances. The primary purpose of the SMD election is to provide voters with an identifiable representative, a face they can recognise as their own Member of Parliament.

MMPR has been very popular among political scientists, especially those who prefer PR. New Zealand has also recently adopted it. Among the industrialised states, only Japan and Italy have adopted MMM (on the Italian system see Katz 2001). Under MMM, the SMDs play a large role in allocating seats among the parties. The SMD tier and PR tiers are less closely linked and more parallel, as in the Japanese name for the system.

Under Japan's new MMM system, voters first cast a ballot for a candidate in their single-member district and then cast a ballot for a party in their PR bloc. The 130 old multimember districts have been redrawn into 300 new SMDs. The PR votes allocate 200 seats in 11 blocs ranging in magnitude from seven to 33 seats. Before the 2000 election, the PR tier was reduced to 180 seats. The only point of contact between the PR and SMD tiers is the 'double-candidacy' (choufuku rikkouho) provision that allows a candidate to run in both one SMD and one PR bloc. In the translation of votes into seats, the two halves are perfectly independent, making Japan's MMM the simplest combination of PR and SMD.

Double-candidacy involves placing an SMD candidate on the PR list, the candidate being deleted from the party's PR list if she wins the SMD race. A more 
complex option involves listing multiple SMD candidates in the same position on the PR list, the tie to be broken by relative performance in the SMD races. The candidate with the highest sekihairitsu (the losing candidate's vote calculated as a percentage of the winner's vote) is assigned priority over those with lower sekihairitsu. Double candidacy opens up many strategic options which are not yet fully understood.

\section{Notes}

1 The JSP has adopted three different official English translations of its party name in the post-war period while leaving the Japanese name (Nihon Shakaitou) unchanged. I will use JSP because it is the most direct translation of the Japanese. I will use SDP after the party changed its official Japanese name to the Social Democratic Party (Shakai Minshutou) in January of 1996.

2 The concept of a 'niche party' was developed by John Creighton Campbell.

3 A vote for the communists was 'wasted' only in the sense that few communists were elected and the JCP had no chance either of winning a majority or of serving in a coalition government. As a protest vote, however, voting for the JCP was quite effective. The LDP was very sensitive to any change in the communist vote (Calder 1988).

4 The centre-left dream in Japan is analogous to the Liberal dream in Britain. In the 1950s the Liberals considered themselves the natural majority party and dreamed of splitting the Labour Party, incorporating the right wing and excluding the left wing. As in Japan, the dream began in the 1950s and only neared realisation in the late 1980s (Butler and King 1999, Chapter VI). 


\title{
2 Realignment between the 1993 and 1996 elections
}

\author{
Steven R. Reed
}

The Japanese electorate was treated to a bewildering series of new parties forming and failing between the 1993 and 1996 elections. In this chapter I will trace the various proposals for new parties, party mergers and party splits. It is important to examine the proposals and movements that failed as well as those that succeeded. We learn about what reformers sought from their attempts, including their failures. Failures also tell us a great deal about what was possible and what was not. Some movements succeeded after multiple failures. Others proved impossible even after multiple attempts. The reorganisation of the opposition camp evolved in a process of interaction between what various reformers believed to be desirable and what they learned to be feasible.

Neither the JSP nor the LDP were unitary actors. Both parties were split between reformers and non-reformers. Reformers were optimistic about the possibility of splitting the JSP and had high hopes of further splitting the LDP. Both Takemura of Sakigake and Ozawa of Shinsei pursued seemingly inconsistent strategies, appealing both to the left and to the right. Takemura was closely linked to the JNP and to the Kitagawa reform group inside the LDP from the conservative camp but was also looking for allies inside the JSP. Ozawa was linked to Watanabe Michio from the right wing of the LDP but was also trying to develop alliances with the JNP, with LDP reform groups and with JSP candidates who had lost the 1993 election. The reform issue cross cut the left-right cleavage.

The confusion is illustrated by the case of Watanabe Michio, who had just lost his bid to become president of the LDP. He had been the candidate of the old guard and had lost to Kouno Youhei (Iwai 1999: 166). The LDP thus chose 'reformer' Kouno over 'conservative' Watanabe but 'reformer' Ozawa was trying to draw 'conservative' Watanabe out of the LDP on the possibility that Watanabe could be prime minister of a 'reform' administration. Watanabe was also critical of Koumei, which was close to Ozawa. One can hardly blame the public for being confused and cynical.

The first, and seemingly most sensible, proposal for a new party soon failed. Sakigake and the JNP had supported each other in every district where only one fielded a candidate and formed a single parliamentary group after the election. The two parties shared the image of being pure reform parties and supporters of 
one had very positive evaluations of the other (Kabashima and Reed 2000). The problem arose from the difference in the composition of the parties. As a group of LDP defectors, Sakigake sported a high proportion of incumbents, most in their third terms and many second- or third-generation Diet members from established political families. They were proud of their status as political professionals. JNP Diet members, however, were all first-termers and prided themselves on being political amateurs (YS 8 September 1993). The JNP members justifiably felt that they had been the biggest winners in the election and were upset that they had not been rewarded with proportionate influence within the coalition government. Seniority continued to rule in the Diet despite the fact that voters seemed to prefer the outsiders and amateurs. Moreover, at the leadership level, Takemura and Ozawa proved incompatible both in policy and in personality. As Hosokawa moved toward Ozawa and away from Takemura, plans for a merger between Takemura's Sakigake and Hosokawa's JNP became harder to imagine.

The failure of the JNP-Sakigake merger was not primarily a matter of policy differences, but policy disputes inside the coalition government influenced perceptions of the realignments which were possible or desirable. The first major dispute was over the liberalisation of rice imports. The JSP, which was already dissatisfied with the influence of the Shinsei-Koumei alliance inside the coalition, defended Japan's rice farmers, thus offering the LDP a possible wedge for breaking up the coalition. Farmers were angry and rice liberalisation produced a drop in support for the Hosokawa administration, from 73.5 per cent to 65.9 per cent (YS 23 December 1993). The fall in support proved temporary but caused a flurry of debate at the time.

Both the LDP and the JSP had lost urban votes during the 1970s and 1980s, leaving them the two most rural of Japan's political parties. The LDP considered proposing a motion of no confidence on the issue of rice import liberalisation, expecting some JSP Diet members to abandon the party line and perhaps bring the government down (YS 9 December 1993). In the event the JSP managed to put down its internal rebellion and rice liberalisation was enacted into law. The rice liberalisation debate placed the two traditional and 'rural' parties, the LDP and the JSP, on the same side of a policy debate and this led some to suggest a motion of no confidence to be followed by a coalition between the LDP and the JSP (YS 24 December 1993). The idea attracted little attention at the time. Throughout this process of realignment, the JSP repeatedly defied predictions that the party would soon fall apart or be easily broken up (Kato 1998). Internal policy and strategic differences were repeatedly suppressed in the name of party unity.

The most prominent version of the centre-left new party dream was the idea of a 'social-liberal' party. On 21 December 1993, several groups which had earlier supported Kubo Wataru against Murayama Tomoichi in the election for chairperson of the JSP formed the 'Demokurattsu' (Democrats), a study group which represented the centre-left dream (Taniguchi 1999: 294-295). Though the policy of such a party was never defined with any clarity, there was broad 
agreement among socialist proponents on who should lead the new party: Hokkaido Governor Yokomichi Takahiro. Yokomichi was a successful governor of a major prefecture and was friendly with Hosokawa and Takemura, the two exgovernors then playing leading roles in the coalition government. That Yokomichi planned to return to the Diet in the upcoming general election generated considerable excitement. The Demokurattsu saw the JNP, Sakigake and some members of the LDP as potential allies (YS 22 December 1993).

Hoping to prevent a split, Chairman Murayama proposed an alternative vision for the future of the JSP, and the 'Murayama vision' was announced in January 1994. Murayama saw the JSP as one pole in a 'moderate multiparty system' (Shinkawa 2000: 195). The aim would then be to support socialist policy goals as a member of a coalition government. That the new electoral system contained a PR bloc, in addition to single-member districts, made the dream of moderate multipartyism seem possible, but the dominant discourse focused on which party would become the second in a two-party system, which would become the opposition to the LDP.

\section{Enacting political reform}

Proposals for new parties were based on presumed agreement on a wide variety of issues and strategies, but the immediate problem was political reform. The Hosokawa government's political destiny depended on enacting political reform. Once the coalition was formed, momentum toward political reform would prove irreversible. Although many difficulties had to be overcome, two facts made some type of reform virtually inevitable. First, too many members of the Diet, including many still inside the LDP, were committed to reform and willing to break party discipline, if necessary, in order to achieve it. If an acceptable political reform bill came to a vote, it would likely pass no matter what position the leadership of the various parties chose to take. Second, no party wanted to enter the next election as the party that had killed reform (Reed and Thies 2001a). Most notably, many socialists who doubted the wisdom of changing the electoral system also feared to face the electorate having voted against reform (Iwai 1999: 179, 195).

The Hosokawa coalition began with the highest popularity rating ever recorded, 71.9 per cent, as opposed to only 13.2 per cent who did not support the new government (YS 30 September 1993). The previous record had been held by the Kaifu administration, also welcomed as a reform government at the time with 62.5 per cent support. The primary reason given for supporting the government was the expectation that it would do 'something different' ( 60.7 per cent) and the primary reason for failing to support the government was that it seemed unstable (35.2 per cent). However, the secondary reasons on both sides concerned political reform: 32.4 per cent of those who supported the government did so because they thought it would enact political reform and 33.5 per cent of those who did not support the government made this choice because they did not believe it could 
enact political reform (YS 30 September 1993). Political reform was near the top of the political agenda and enjoyed strong, if amorphous, popular support (see the list of opinion poll results in Sasaki 1999a, appendix 4).

The process of enacting political reform was, however, complicated by the fact that both the coalition and the opposition LDP were divided on the issue. Inside the LDP, a group of urban Diet members led by Ishihara Shintarou of Tokyo (elected governor of Tokyo in 1999) and Nakayama Tarou of Osaka opposed reform because they doubted the ability of the LDP to win many SMDs in urban areas (YS 5 November 1993). They went so far as to propose an 'urban LDP' new party, which would still be the LDP but would project an image more attractive to urban voters (YS 2 June 1994).

Inside the coalition, the primary question was how many socialists would defy the party line and vote against reform. The party line held in the House of Representatives, but 17 JSP defectors (against only five defectors from the LDP) defeated political reform in the House of Councillors (YS 22 January 1994). The conference committee failed to reach agreement and the bill was returned to the Lower House. Prime Minister Hosokawa decided to negotiate with LDP president Kouno. Both needed to enact reform, Hosokawa to save his government, Kouno to prevent defections, estimated to be between 80 and 100 with only around 70 necessary to pass the bill (YS 28 January 1994). The proposal was amended slightly in favour of the LDP and against the preferences of the JSP and passed the Lower House, again with reluctant JSP support (Kawato 2000; Reed and Thies 2001a). The Japanese experience clearly confirms the hypothesis that changing an electoral system can only be achieved under extraordinary circumstances.

\section{After political reform}

With political reform passed, the Hosokawa coalition lost what cohesion it had until then possessed and its popular support waned. The public welcomed reform. Almost 63 per cent evaluated the reform positively (although only 18.7 per cent were strongly positive) against only 25 per cent who were negative. The primary reason for a positive evaluation was a belief that reform would reduce corruption (31.7 per cent) and the primary reason for a negative evaluation was a belief that it would not (39.8 per cent) (YS 25 December 1993). The Hosokawa administration was closely identified with reform. When voters were asked what they liked about the Hosokawa administration, political reform consistently headed the list, often with over 45 per cent choosing this response. Dissatisfaction focused on economic policy and taxes. Nevertheless, Prime Minister Hosokawa chose as his next major policy proposal a tax increase, the 'national welfare tax' (kokumin fukushi zei).

The JSP had won the 1989 Upper House and 1990 general elections on a platform of opposing the consumption tax and faced serious defections if the party went along with a tax increase (YS 4 February 1994). Takemura of Sakigake also opposed the idea, in part because it had originated with Ozawa of Shinsei and 
Ichikawa of Koumei. The Shinsei-Koumei axis was coming to dominate the coalition government (Iwai 1999: 180). Infighting within the coalition and the idea of a tax increase resulted in a drastic drop in support for the Hosokawa administration, from 72.4 to 58.0 per cent (YS 2 March 1994). In the end Hosokawa was forced to drop the proposal and was never to regain the policy initiative.

Opposition to the Shinsei-Koumei axis produced co-ordination among the JSP, the DSP and Sakigake within the coalition. They proposed a new Social Democratic Liberal Party which would exclude the far left (defined as those who had voted against political reform) and the far right (defined as those who sought co-operation with Shinsei) (YS 19 and 27 February 1994). Prime Minister Hosokawa, on the other hand, proposed merging his JNP with Shinsei. The proposal seemed destined to split the JNP and was therefore dropped. Thus, both JNP-Sakigake and JNP-Shinsei mergers were proposed but failed. The idea of a Sakigake-Shinsei merger was never proposed, presumably because Takemura and Ozawa had very different visions of reform (Otake 1997: 73). In the 1993 election, the voters flocked to the three new parties. There is every reason to believe that a combination of new parties would have been popular. Nevertheless, the three new parties proved incompatible at the elite level. Instead of seeking a merger with one of the other new parties, Shinsei sought to build on its alliance with Koumei and to attract further defectors from the LDP, focusing again on Watanabe Michio. An Ozawa-Watanabe alliance made sense on several levels, but it would clearly not have been an alliance of reformers.

\section{Hosokawa resigns}

In April of 1994 Hosokawa unexpectedly resigned as prime minister over a relatively minor scandal involving a large loan he had received from Sagawa Kyuubin (YS 8 April 1994). Because the resignation seemed unnecessary, it produced speculation that Hosokawa was ready to resign for other reasons or that he was afraid that more damaging revelations might follow. The public was harsh, almost 60 per cent calling his resignation irresponsible. Yet 64.5 per cent gave the eight-month Hosokawa administration a positive evaluation, both because of political reform (33.9 per cent) and because it had ended the long reign of the LDP (37.2 per cent) (YS 20 April 1994).

The Hosokawa resignation threw the political world into confusion again as the various forces manoeuvred to form a new coalition. The two socialist parties and Sakigake competed with the Shinsei-Koumei bloc, each hoping to attract the bulk of the JNP. The wild card was the Watanabe faction: would he really leave the LDP and, if he did, how many from his faction would follow? In the event, Watanabe announced his intention to leave but his faction proved unwilling to follow (YS 18 April 1994). Nevertheless, six of his supporters, a group known as the liberals within the LDP, defected from the LDP later to form the Liberal Party led by Oota Seiichi and Kakizawa Hiroharu. (This Liberal Party, Jiyuutou, should 
not be confused with the party of the same name formed by Ozawa Ichirou after the 1996 election). Five other LDP incumbents defected to form the 'Future Party' (Shintou Mirai) led by Kano Michihiko (YS 18 April 1994). In April, the Diet set a new record for the number of parliamentary factions at 12 . These micro-new parties left the LDP in the hope of joining or forming a new centreright reform party.

The only viable option that remained after all of this manoeuvring was a continuation of the old coalition led by Hata Tsutomu, the leader of Shinsei. The public had no clear preferences during the process of forming the Hata coalition government. Whereas 21.3 per cent supported a continuation of a coalition excluding the LDP and the JCP and 13.7 per cent supported a coalition centred on the LDP, 42.1 per cent supported a coalition of one sort or another which included only part of the LDP (YS 20 April 1994). On the other hand, 60 per cent said they would support a new administration led by Hata and 56.8 per cent actually did support it after it was formed.

The JSP voted for Hata as prime minister, giving him a higher total than Hosokawa had received a year earlier. However, only a few hours after Hata had been chosen as prime minister, Shinsei, the JNP and the DSP announced that they would form a new joint parliamentary faction to be called Reform (Kaishin). The move was part of Ozawa's movement toward forming a new party which could compete with the LDP. His efforts were aided by the resignation of DSP chairman Oouchi Keigo and his replacement by Yonezawa Takashi. Oouchi had long opposed Koumei in his own electoral district and therefore posed a barrier to any co-operation between the DSP and the Shinsei-Koumei alliance. ${ }^{1}$ The selection of Yonezawa removed this barrier. Under Yonezawa, the DSP led the movement to form the new parliamentary faction. The formation of Reform was a straightforward step toward realising the centre-right dream, but the timing of the move proved crucial. Since cabinet posts are allocated to parliamentary factions, not to political parties, Reform replaced the JSP as the largest faction within the coalition before the Hata cabinet was formed. The JSP felt it had been stabbed in the back. Before the Reform incident, the JSP could not have left the coalition government without suffering major defections. The incident unified the party behind the leadership, who led the members out of the coalition (Curtis 1999: $182-188)$. The JSP decision to leave the coalition was not popular. Almost 57 per cent of the public were critical and only 28 per cent supported the move (YS 30 April 1994). Nevertheless, once again the JSP managed to execute a complex and controversial manoeuvre without breaking apart.

After the JSP left the anti-LDP coalition, study groups which included representatives from both LDP and JSP proliferated (YS 5 June 1994); Watanabe continued to discuss the possibility of some sort of coalition with Ozawa (YS 19 June 1994); and Hata searched for ways of bringing the JSP back into an antiLDP coalition (YS 22 June 1994).

Events were brought to a head, however, when the LDP tabled a motion of no confidence in the Hata coalition government. LDP president Kouno had been 
criticised within the party for failing to take more aggressive action to regain power and the motion of no confidence was his way of silencing his critics. The JSP again came close to breaking apart because many reformers in the Demokurattsu preferred a return to the Hata coalition to a coalition with the LDP (YS 26 June 1994). Prime Minister Hata was faced with a difficult decision. Should he dissolve the Diet and call an election or should he resign and allow the LDP to form a coalition government? Letting the LDP back into power was not an attractive option, but the prospect of another election under MMD would probably have sounded the death knell for several of the smaller parties in the coalition, most notably the JNP and the DSP (YS 26 June 1994). An earlier poll had found that 94 per cent of the coalition parties favoured holding the next election under the new system and none favoured another election under the old system (YS 21 May 1994). The party most fearful of the new system was the JSP. Only 25 per cent favoured an election under the new system and 70 per cent thought an election under the old system was either desirable or unavoidable. In the event, Hata chose to resign and the LDP began looking for ways of forming a coalition with its traditional enemies, the JSP.

A key factor in getting the LDP and JSP together in a coalition was to make Murayama Tomoichi, the leader of the JSP and hero of the left, the new prime minister. The left-wing socialists most likely to oppose coalition with the LDP on policy grounds were also the most likely to support Murayama as prime minister. A second key factor was to bring Sakigake into the coalition to serve as a bridge between the traditional enemies.

The LDP suffered three more defections, including ex-Prime Minister Kaifu, over the decision to support a left-wing socialist for prime minister. Kaifu then became the anti-LDP coalition's candidate for prime minister, drawing 19 votes from the LDP, one from Sakigake and seven from the left wing of the JSP. On 29 June 1994 the LDP-JSP-Sakigake coalition maintained sufficient cohesion to elect Murayama the first socialist prime minister since 1949, though by a very small margin and with several Diet members voting against their own parties. The Demokurattsu split, some voting for Murayama and others voting for Kaifu, and the group stopped functioning with the formation of the Murayama government. As Curtis puts it, 'Everyone, even the leaders of the parties involved, seemed stunned by what had happened' (1999: 191).

New administrations are usually helped by being given the benefit of the doubt and vague expectations of change also work in their favour, but expectations for the LDP-JSP-Sakigake coalition were low from the beginning. Only 37 per cent supported the Murayama administration against 44 per cent who did not (YS 2 July 1994). Large majorities did not think the administration could achieve much either on the foreign policy front, over which the LDP and the JSP had long fought, nor on the issue of political reform. Over 46 per cent considered the LDP-JSP combination a bad idea, with only 29 per cent approving of it. Not surprisingly, the percentage of voters unable to answer these questions was relatively high. Among those who did not support the administration, 49.7 per 
cent gave the 'unprincipled' LDP-JSP combination as a reason (YS 20 July 1994).

The behind-the-scenes story of the formation of the LDP-JSP coalition became public in December of 1994. According to documents uncovered by the press (YS 28 December 1994), several attempts had been made before the final attempt succeeded. Although the formation of this coalition of 'strange bedfellows' (yagou in Japanese) surprised the public and most observers, discussions had been going on behind the scenes for several months.

The first impetus for a new coalition came from the rivalry between Takemura of Sakigake and Ozawa of Shinsei, which initiated moves toward an LDP coalition government including the JSP. Angered over the Hosokawa government's plans for the welfare tax, Takemura proposed an anti-Ozawa alliance among Sakigake, the JSP and the DSP. The Japanese public, however, knew nothing of these manoeuvres and was shocked when presented with the fact of the LDP-JSP coalition government.

Curtis argues (1999: 187) and I agree that the return of the LDP to power in coalition with the JSP was far from inevitable. If the Reform incident had never happened or had been better timed or better executed, the JSP could not have left the Hata coalition without suffering serious defections and might well have stayed in the coalition in order to prevent these. The LDP's return to power, far from being inevitable, was an undeserved stroke of luck. Strategic errors by the founders of Reform, most notably the excessive manoeuvring of Ozawa, allowed the LDP to return to government.

From a policy perspective, the LDP-JSP-Sakigake coalition made little sense. During its term in government, the JSP abandoned all of its historical policy positions. It no longer opposed the existence of the Self Defence Forces (as the military is called in Japan), the security treaty with the United States, the national flag and national anthem, or nuclear power plants. On the other hand, the coalition accomplished several goals that had long been on the JSP policy agenda. Most notable were compensation for foreign 'comfort women' used by the Japanese military during the Second World War, a law guaranteeing compensation for victims of the atomic bomb, and compensation for victims of the environmental mercury poisoning known as 'Minamata disease'. The LDP also had to remove several items from its policy agenda lest it drive the JSP out of the coalition. Among the issues in this category were the problem of North Korea's nuclear capacity and the revision of guidelines for military co-operation between the United States and Japan. In the end, however, the policy of the coalition government reflected little of traditional JSP concerns and, in fact, represented the removal of those concerns from the national policy agenda (see Nonaka 1998 and Shinkawa 2000: 198-205 for evaluations).

The three-party coalition was not primarily about policy substance, but about policy-making procedures. The LDP's goal was simply to get back into power and the party was willing to compromise almost any policy stance in order to accomplish that goal. As a classic catch-all party, the LDP has few, if any, 


\section{The political context}

inviolable principles. The JSP, for its part, had no more policy in common with the LDP than with the Hosokawa or Hata coalition parties. What drove the JSP from one coalition to the other was the style of decision making in the Hosokawa coalition. Ozawa's aggressive style was particularly galling but Hosokawa also tried to exercise 'leadership' by skirting the normal requirements of Japanesestyle consensus decision making. The LDP and JSP had been bitter rivals for almost 40 years but they had also learned to work together during that time (Nonaka 1998). They shared the traditional Japanese consensus decision-making style (Campbell 1984; Krauss 1984). Between 1960 and 1993, the LDP consulted the opposition JSP thoroughly and, after having had its say, the JSP supported most of the bills presented by the LDP (Iwai 1988a: 102-108). The first thing the new LDP-JSP-Sakigake coalition did was to establish a new system for coalition decision making which would ensure the full participation of all three parties (YS 5 July 1994).

All this may sound exotic, oriental and perhaps even irrational. Where else would procedural issues cause so much trouble and policy issues so little? The answer is Great Britain and Austria (and probably elsewhere as well). The story of the formation of the Liberal Democratic Party (called the Lib Dems, not the LDP) in Britain from a merger of the Liberals and the Alliance would sound quite familiar to the Japanese politicians who struggled to form a new party between 1993 and 1996 (Denver 1992). If the Hosokawa and Hata coalitions broke up primarily over procedural, not policy, issues, the end of the 20 years of grand coalition government in Austria was also brought about by procedural disagreement (Muller 1999). Though democratic theory focuses on policy preferences, democratic practice is often about procedural issues, not 'What shall we do?' but 'How shall we decide what to do?'.

\section{The new-new parties}

Back in opposition, momentum toward reforming the old opposition and the three new parties into a 'new-new party' (Shinshintou, or the New Frontier Party) accelerated. Ozawa worked toward his goal of a large party based on Shinsei and Koumei while others pursued alternative visions. Most notable was Kaifu's founding of the Liberal Reform Alliance (Jiyuu Kaikaku Rengou) in August of 1994. The group attracted 22 members, 20 of whom had defected from the LDP after the 1993 election (YS 1 August 1994). The group planned to join a new-new party but its members wanted to do so on their own terms, and certainly not on Ozawa's. Kaifu was seen as the potential leader of the new-new party and he hoped to be able to draw further defectors from the LDP. Kaifu then joined Hosokawa of the JNP, Hata of Shinsei, Ishida of Koumei, and Yonezawa of the DSP in declaring their intention to form a new-new party (YS 6 August 1994). One problem was that, unlike the other parties, Koumei had a large membership, powerful local organisations, and a great deal of money. It wanted to join the new 
party in stages, national Diet members first and local organisations later (YS 7 August 1994).

The coalition of strange bedfellows placed many politicians in strangely conflicting situations. The right wing of the JSP was ideologically closer to the LDP, its new coalition partner, but more interested in forming a new-new party with the participation of parties then in opposition. The left wing of the JSP supported its prime minister but felt uncomfortable both with the coalition and with the progressive abandonment of the JSP's traditional policy stances. Groups inside the JSP had to be reorganised after the LDP coalition (YS 11 August 1994). Rengou's dream of a new socialist party including the JSP and the DSP had in effect been destroyed by the LDP-JSP alliance (YS 23 August 1994). In September, the JSP conference confirmed the major changes in policy that had been taking place during the party's two coalition experiences. After the conference, Yamagishi Akira retired as chairman of Rengou and the labour federation never again played a prominent role in development of new political parties and alignments.

At this time the centre-right dream was represented by Ozawa's attempt to form a second conservative party (YS 29 September 1994). Ozawa was still a controversial figure, however, and his methods repeatedly drove potential participants away. In November Shinsei dissolved itself in order to move toward a broader party which became the New Frontier Party (NFP, Shinshin, a pun on 'new-new party' which is written with different characters but pronounced the same). The NFP seemed to have a good chance of becoming the number two party but many politicians declared their intention not to participate, largely because of Ozawa's leadership style (YS 7, 8 and 11 December 1994).

The NFP was officially founded on 10 December 1994, opening with 13.1 per cent support in the polls, only 9 percentage points behind the LDP though it dropped back to around 10 per cent in the next month and thereafter (YS 22 December 1994). Factions soon formed, primarily around the old party groups, to compete for control over the party. Ozawa's plans for creating a new party involved further splitting the LDP whereas Hata's plans entailed reaching out to the right wing of the JSP. Ozawa challenged Hata in the party's first election to select a new leader. Even Koumei was not unified, with 23 supporting Ozawa, 20 supporting Hata and 25 straddling the fence (YS 25 December 1995). In the event, Ozawa was elected leader of the party he had done so much to create. His legacy also included, however, many personal enemies and serious political divisions within the party.

After the failure of the Demokurattsu, the centre-left dream inside the JSP was reorganised under the leadership of Yamahana Sadao. He planned to hold a 'meeting to prepare for a new party' (shintou junbikai, a term which had been used during the party realignments of the 1950s which had resulted in the formation of the LDP as well as during the party realignment of the 1990s). The key was how many members of the Diet would attend (YS 10 January 1995). The NFP did what it could to help, promising electoral co-operation to any democratic 


\section{The political context}

liberal group which would defect from the JSP (YS 13 January 1995). Participation in the preparatory meeting was indeed influenced not only by ideological principles and preferred coalition partners but also by prospective opponents in the SMDs created by the new electoral system. Fourteen of 27 prospective members expected to face either an LDP or a Sakigake opponent in the next election (YS 15 January 1995). The influence of labour unions was also evident. Members supported by the local government unions were conspicuously absent, while members supported by the postal workers' union were well represented (YS 15 January 1995). Some regions of the country were more enthusiastic than were others. The Kinki region (around Osaka and Kyoto) moved ahead by forming 'Liberal Kinki', a proto-party group, to fight upcoming local elections in preparation for a national liberal party whenever it was formed (YS 5 February 1995). All of these plans came to nothing, however, when the great Hanshin earthquake struck. A national disaster was not a propitious time for splitting the JSP and starting a new party. The centre-left dream failed again, but most of the Yamahana group would later be found in the Democratic Party of Japan, a subsequent incarnation of the same dream.

The JSP also continued to reform itself, officially changing its name to the Social Democratic Party of Japan (Shakai Minshutou, SDP) in January of 1996. However, the new image never caught on with the public. Political commentators on the talk shows had trouble remembering to say SDP instead of JSP. The longanticipated moderation of the JSP, the Japanese version of the German socialists' Bad Godesburg, fizzled out and had no significant effect on the party's image. Also in January, a group of left-wingers who were dissatisfied with the moderating trend formed the New Socialist Party (Shin Shakaitou, NSP) which clung to the old ideals of the party, the Japanese equivalent of the Refounded Communist Party in Italy. Later, as the 1996 election approached, the SDP worried that many of its traditional supporters would mistakenly vote for the NSP because they would not recognise the SDP as the new name of the JSP (YS 17 September 1996).

\section{The 1995 House of Councillors election}

The NFP did quite well in its first several electoral tests. In February the NFP won its first gubernatorial election in Aomori Prefecture and, in the unified local elections of April, the party won two of the three gubernatorial races in which it faced the LDP directly. These local elections also featured spectacular results in Japan's two largest prefectures. In both Tokyo and Osaka, comedic actors running without party support defeated traditional establishment candidates supported by all of the major parties. Previously 'unbeatable' candidates were being beaten. Change seemed possible. In the Diet, the NFP adopted a confrontational stance toward the Murayama government and saw its support in the polls rise to 17.2 per cent in July before the House of Councillors election. 
Both the LDP and the NFP had trouble attracting new candidates (YS 15 October 1995). Two of the traditional recruitment sources for conservative parties, large interest groups and retiring bureaucrats, had dried up considerably. Neither group wanted to offend the NFP because the NFP might soon become the party in power. Many potential candidates decided to sit out the election until they could determine which way the electoral winds were blowing.

The LDP and the JSP were in coalition and thus, technically, should co-operate during the election as well. In most cases, however, the prefectural organisations of both parties simply refused to consider the idea. The primary effect of the coalition on nominations was that the LDP nominated only one candidate in each of the two-member districts, giving the JSP a free run at the second seat (YS 9 November 1994). Most two-member districts traditionally elected either one LDP and one JSP candidate or two LDP candidates. The NFP, however, decided to challenge the JSP for the second seat and, in the 13 two-member districts, the LDP won 10 seats, the NFP 11, and the JSP only five. Co-operation between the LDP and the JSP was accomplished in only three districts and only one joint candidate was elected. He was the JSP candidate in Prime Minister Murayama's home district of Oita. Candidates supported jointly by the NFP and the JSP fared no better.

As expected, the JSP was the big loser. In the PR vote, the JSP finished first only in Oita, Murayama's home district, and in Hokkaido. The party finished second only in Akita. In 44 of Japan's 47 prefectures, the JSP was no longer the main opposition party. The NFP was declared the big winner, outperforming expectations and, with 20 seats at risk, it won 40 seats. It also won the largest share of the PR vote, only the second time the LDP had failed to take the top spot (Thies 1995). There were, however, two flies in the ointment. First, if one looks at the geographical distribution of the NFP vote, three prefectures stand out: Iwate (home of Ozawa Ichirou), Nagano (home of Hata Tsutomu) and Kumamoto (home of Hosokawa Morihiro). The NFP appeared excessively dependent upon the personal popularity of its leaders. Second, the party also appeared excessively dependent upon Koumei. Turnout in this election was the lowest in post-war history, the first time turnout in a national election had fallen below 50 per cent. Organisational strength tends to win elections which have a low turnout and, with unions and other groups on the sidelines to some degree, Koumei activated the only disciplined voting bloc available.

The House of Councillors by-election held in Saga Prefecture in November signalled a shift in the political winds, though this was not clearly recognised at the time. The LDP Councillor who had died had been a strong advocate of the farmers, loudly opposing his own government's moves toward liberalising the importation of agricultural products. Agricultural interests dominate Saga politics and in previous elections the recommendation of the Agricultural Co-operative (Noukyou) had often proved a more valuable electoral asset than the LDP nomination. The LDP nominated a prefectural assemblyman, Iwanaga Hiromi, and this did not please the Noukyou (YS 6 October 1995). However, the NFP was 
led by the people who had liberalised rice imports under the Hosokawa administration. The Noukyou thus declared a free vote, supporting neither candidate. With the major concern of Saga voters deleted from the electoral agenda, the LDP decided to focus on the issue of the separation of church and state (seikyo bunri). The Diet was debating a proposed revision of the law on religious institutions (shuukyou houjin hou), and the public was strongly in favour of strengthening the regulation of religion. The bill was later dropped but at the time over 80 per cent favoured stricter regulation and less than 10 per cent opposed it (YS 23 November 1995). The primary focus of public ire was Aum Shinrikyou, the sect that had released poisonous gas into the Tokyo subways in March of 1995. However, Koumei could be tarred with the same brush. The LDP attacked the NFP as 'Koumei in disguise'. The 'religious card' seemed to work and the LDP won. Katou Kouichi, secretary-general of the LDP, attributed the victory to the voters' dislike of mixing religion with politics (YS 20 November 1995), and the media wondered if the NFP's momentum had been halted.

The religious card was to play a large role in the 1996 election and in Japanese politics thereafter. Japanese society has never seemed fertile ground for developing a cleavage along religious lines. Not only are most Japanese Buddhist, few identify strongly with any religion and many identify with more than one (Reader 1991, chapter 1). The other major Buddhist organisations dislike the Souka Gakkai because it is aggressive and exclusive and because it favours active involvement in politics. Under MMD, voters and groups who opposed Koumei could vote for almost any other party. Only the JCP was clearly opposed to Koumei and no other party was closely linked to it. Candidates who accepted Koumei support might lose the support of other Buddhist groups but the division of the party vote was seldom affected. When the NFP was formed with Koumei as a major participant, other Buddhist groups chose to support the LDP more strongly than they ever had before. For the first time, the religious issue began to move votes from one party to another. The religious issue was to become the major axis of coalition formation in 1998 and 1999, but all anyone knew at the end of 1995 was that the LDP had found a new strategy for dealing with the NFP.

\section{Prime Minister Murayama retires}

One result of the House of Councillors defeat of the coalition parties were loud calls for Prime Minister Murayama's resignation. In August, the month after the election, over half of the public said they did not support the Murayama cabinet (YS 2 August 1995). The prime minister was perfectly willing to retire, but the coalition partners still needed him so he stayed on. At the beginning of the new year, however, Prime Minister Murayama announced his firm intention to retire (YS 3 January 1996). He had originally planned to retire before the 1993 election, running again only because the JSP had no one to replace him in his district, then accepting the leadership of the JSP because no one else could have held the party 
together, and accepting the prime ministership because he was the only one the socialists would follow into coalition with the LDP. Finally, his health and his patience ran out and he could no longer be talked out of retirement. He was replaced by Hashimoto Ryuutarou, leader of the LDP. The new administration was greeted with a 56.9 per cent support rate, and only 25.6 per cent non-support (YS 31 January 1996). Within a month, however, support had dropped to 49.9 per cent and non-support had risen to 34.1 per cent. Though there were some fluctuations, these were to be the figures as the election approached.

The change in national leadership spurred the Hata group inside the NFP, which had been progressively distancing itself from Ozawa, to consider entering a coalition with the LDP in a conservative coalition (ho-ho rengou) (YS 6 January 1996). The NFP was further shaken by the formation of another group, led by Kano Michihiko, opposed to Ozawa.

The change in national leadership also spurred those socialists who were dissatisfied with being in coalition with the LDP to move toward a new social democratic liberal party. In April this movement received an unexpected boost from Hatoyama Yukio. He and Hatoyama Kunio were grandsons of Hatoyama Ichiro, the founder of the Liberal Party just after the end of the Second World War and the leader of the Democratic Party in 1955. Their grandfather had thus played a major role in creating both of the parties that had merged in 1955 to form the LDP. Both brothers had originally been elected for the LDP, but in 1993 Hatoyama Yukio won for Sakigake and Hatoyama Kunio won as an independent who later joined the NFP. They were joined by Funada Hajime, also an ex-LDP Diet member who had run for Shinsei in 1993 and who was also in the NFP at the time. These three planned to start a new party from several of the anti-LDP, antiNFP fragments. They wisely decided to begin by building a liberal image, leaving the difficult task of hammering out policy stances to a later date (YS 29 April 1996). They were given a boost when Kan Naoto, popular Minister of Health and Welfare, decided to participate (YS 21 May 1996). In May the plan was to pull together anti-Ozawa parts of the NFP, the Yamahana group from the SDP, as much of the Sakigake as possible, Kaieda's Citizens' League, and ex-governor of Hokkaido Yokomichi Takahiro. The most controversial decision was to exclude the left wing of the SDP under former Prime Minister Murayama and Takemura Masayoshi, leader of Sakigake. This decision appears to have been a matter of excluding anyone who felt comfortable in coalition with the LDP (Otake 1999: 100). This party became the Democratic Party of Japan (DPJ) in September of 1996, only a month before the election. The DPJ started with 50 members, 29 from the SDP and 14 from Sakigake. It was able to establish only five SMD branches before the election and thus was forced to campaign on the basis of prefectural branches (Ushiro 1999: 149).

The NFP had not been idle during this period. In March it chose to make an issue of the Juusen problem. Juusen are financial institutions specialising in housing loans. They had lost a great deal of money when the bubble burst and were now in need of public assistance. The LDP-led coalition proposed a bailout 
and the NFP saw an opportunity to make some political hay. It boycotted the proceedings and picketed the committee rooms, bringing deliberations to a halt. This seemed an issue well designed for an opposition party and the NFP appeared to gain support when it began using obstruction tactics. However, the party could not find a graceful way of ending the boycott and wound up boring and confusing the public, losing whatever gains it had made in the polls.

After the 1993 election, 27 Diet members defected from the LDP. As the 1996 election approached, however, the LDP began to put electoral pressure on the defectors by threatening to run against them in their own districts. These pressures worked. A total of six incumbent Diet members returned to the LDP before the 1996 election. Several leaders of the reform movement, including Oota Seiichi, Kakizawa Kouji and Funada Hajime, were among those who came back. Tochigi Prefecture was either blessed or cursed with a surplus of reformers. Funada Hajime of Shinsei and potential founder of the DPJ competed with Yanase Susumu of Sakigake for the new party nomination in the new Tochigi $1^{\text {st }}$ district. In the end Funada ran as an LDP-supported independent, defeating Yanase who ran for the Democrats. Funada's reform credentials were impeccable but the logic of electoral politics proved too strong to ignore.

\section{The campaign}

Prime Minister Hashimoto faced a serious problem when, in an advisory referendum, Okinawans voted to reduce the US presence on their island. He handled it well, acknowledging the problem and promising future action, and the LDP was ready for the campaign. The opposition chose to focus on the government's plans to raise the consumption tax from 3 to 5 per cent, a strategy employed most effectively by the JCP. Late in the campaign, the LDP took out a full-page advertisement in the newspapers pointing out the inconsistencies in the NFP's position on taxes over time. The advert was effective, though one may doubt how many voters noticed it. In any case, none of the issues raised by the opposition had much of an impact.

The LDP's share of the vote rose by 2 percentage points but its share of the electorate fell by 2 percentage points because the turnout was so much lower. The media declared the LDP the winner because it picked up seats, largely as a result of its advantage in the SMDs. The NFP gained votes but lost four seats relative to the number held at the time of dissolution. Because the party's declared aim was a majority, this was counted as a defeat. The Democrats lost one seat, failing to live up to expectations. The 'new party boom' of 1993 was not repeated for either of the major new parties in 1996. The big winner was the JCP and the big losers were the SDP and Sakigake, the LDP's coalition partners.

Though the LDP won, its coalition partners lost. The lesson was not wasted on either previous or potential coalition members. The Democrats debated whether or not to join the LDP but decided to stay in opposition. The SDP and Sakigake both decided to co-operate with the LDP but to stay outside the coalition. Even 
conservative independents, who traditionally join the LDP right after the election, decided to form their own group in the Diet and co-operate with the LDP on a case-by-case basis. The 1996 election answered few questions about the future of the Japanese party system.

I will analyse these electoral results in more detail in Chapter 8.

\section{Notes}

1 Oouchi was supported by anti-Gakkai Buddhist religious groups and had run his election campaign on the issue of mixing politics with religion to win his first election in 1976. Later, Oouchi refused to follow his party into the New Frontier Party because it included Koumei. Instead he ran for the LDP in the 1996 election.

2 Otake (1999: 82-83) argues that a JSP-Takemura-Kouno coalition made reasonably good sense in terms of foreign policy. 


\title{
3 Realignment between the 1996 and 2000 elections
}

\author{
Steven R. Reed
}

The LDP emerged from the 1996 election as the largest party but without a majority in either house of the Diet. Both of the LDP's coalition partners, the SDP and Sakigake, had been devastated by the electoral result. Both had run against the LDP in the 1993 election and then joined a coalition led by the LDP after that election. It was only natural to attribute their losses in 1996 to their dramatic strategic reversals between elections. Doi Takako led the SDP toward re-establishing an independent image of its own but also agreed to continue supporting the LDP. Sakigake also agreed to continue its support but both of the LDP's former coalition partners refused to enter into a formal coalition or to accept any cabinet posts. Prime Minister Hashimoto's government limped along with the external support of the SDP and Sakigake.

The election result also forced the LDP to reconsider its strategic options. While the leadership opted to continue co-operation with the SDP and Sakigake, others within the party called for a conservative alliance between the LDP and the NFP (or, at least, with some elements within the NFP). The 'YKK' group (Yamazaki, Katou and Koizumi) supported continued co-operation with the SDP and Sakigake while Kamei Shizuka led the 'conservative alliance' camp (ho-ho rengou) (YS 28 January 1997). In the short term, however, the LDP opted for a third strategic option: picking up independents and defectors one or two at a time in order to regain its majority. This strategy was made more effective by trouble within the NFP.

The NFP had lost its first general election and was immediately beset by serious internal tensions. The primary problem was the party leader Ozawa. Many were dissatisfied both with his strategic choices and with his autocratic style of leadership. Members of the other parties which had joined the NFP, most notably the DSP and Koumei, began to organize factions within the party and many of the conservatives began to consider returning to the LDP. Ozawa sought closer ties with the 'conservative alliance' camp within the LDP, many of whom were vociferous critics of Koumei.

Three NFP conservatives voted for Hashimoto for prime minister, left the NFP and returned to the LDP soon thereafter. Other conservatives, most notably the NFP's two former prime ministers, Hosokawa and Hata, looked for a way to 
leave the NFP without returning to the LDP. Hata, in particular, was determined to leave the NFP despite the fact that few seemed likely to follow him out. He formed the Sun Party (Taiyoutou) on 26 December 1996 with 13 defectors from the NFP. Hosokawa failed to follow at that point, waiting until 18 June 1997 and then leaving in an anticlimactic move that had little effect. The YKK group inside the LDP saw the Sun Party as a potential ally and the LDP left the door open by not nominating LDP candidates in those districts which had Sun Party incumbents (YS 26 June 1997). Hata steadfastly refused to consider an alliance with the LDP. He could not, however, pursue an alliance with the Democrats due to resistance within his own party.

The NFP's image was further damaged by a serious scandal, the Orange Friendly Society Affair, which involved an NFP member of the House of Councillors. Then the party received a major shock in the July election of the Tokyo Metropolitan Assembly, winning not a single seat. Not surprisingly, given these problems, the party continued to suffer a slow but steady stream of defections. In addition, Koumei was losing interest in merging into the NFP, seeing little reason to board a sinking ship. The national leadership continued to promise an eventual merger but local organisations showed strong resistance to any merger with the NFP (YS 16 February 1997). Koumei also faced serious internal divisions within the Diet over the merger issue (YS 21 June 1997).

Inside the SDP Doi Takako led the party toward re-establishing its own identity, while Kubo Wataru looked for a way to reunify the political wing of the labour movement by starting a new centre-left party from parts of the SDP, the Democrats and the NFP (YS 25 December 1996). Kubo had earlier chosen to stay in the SDP when his ally, Yamahana, had left to join the Democrats. Finally, on 6 January 1997, far too late to have a significant effect, he led seven members out of the SDP. On the same day, five prominent union leaders formally attended the LDP's annual conference. Political unity in the labour movement moved yet further from realisation.

The Democrats (DPJ), having failed to get their 'new party boom', had nevertheless become the third largest party in the Diet. Their first strategic move was to seek to create a joint Diet faction with the SDP, Sakigake, and Hata's Sun Party. They even expressed a willingness to consider a coalition with the LDP (YS 20 February 1997). However, the Democrats would have to wait until the NFP drama had played itself out before they could take centre stage.

Right after the election, I wrote 'There appear to be ten to twenty Diet members poised to join the LDP as soon as they can manage to do so without appearing excessively cynical. The LDP may be able to gain a bare majority over the next several months by picking up defectors' (Reed 1997A:124). That is precisely what happened and on 5 September 1997 the LDP achieved a majority in the Lower House. The path is depicted in Figure 3.1. This was a triumph for the YKK camp. In September, Prime Minister Hashimoto was re-elected president of the party without opposition and his new cabinet represented a total defeat for supporters of the 'conservative alliance' option. 


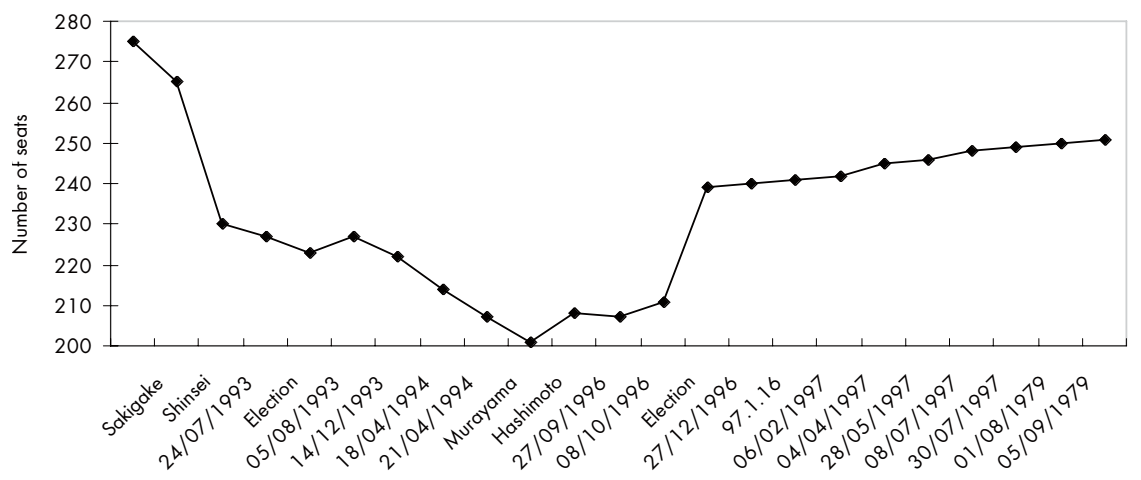

Figure 3.1 The LDP regains its majority

Source: Yomiuri Shinbun, 6 September 1997

The new Hashimoto cabinet, however, included a serious error of judgement: Satou Takayuki (also called Satou Koukou) was given a cabinet post despite the fact that he had been convicted of a felony in connection with the Lockheed scandal of 1976. The uproar that followed his appointment forced Satou to resign and produced a steep drop in support for the Hashimoto administration. Support fell from 56 to 44 per cent and non-support leapt from 31 to 43 per cent (YS 11 October 1997). The Hashimoto cabinet never recovered from this blow. The LDP was fortunate that the opposition parties could agree on little beyond condemning LDP corruption (YS 25 October 1997). The problem was Ozawa's desire for a conservative alliance with the LDP. Ozawa demonstrated his commitment by pursuing a disastrous strategy in the Miyagi gubernatorial election.

\section{The Miyagi gubernatorial election}

The Miyagi story begins in 1989 when the five-term LDP incumbent, an exbureaucrat and ex-vice-governor retired. The LDP nomination would virtually ensure victory, so the key battle was over who would get the nomination. The winner was Aichi Kazuo, a popular second-generation LDP Diet member. His only serious competition was Honma Shuntarou, also son of an LDP Diet member and a town mayor. Honma accepted the support of the JSP when he failed to get the LDP nomination. Conservative candidates supported by the JSP had upset LDP-nominated favourites in the past, but only rarely. Aichi was heading for an easy victory when the Recruit scandal broke. He was forced to withdraw from the gubernatorial election because of his involvement in the scandal. The LDP was unable to agree on another candidate but its members could not bring themselves formally to support Honma. The LDP did not nominate a candidate and Honma defeated a conservative independent. The LDP has never been comfortable in opposition and quickly declared its support for the new governor. 
Honma was re-elected in a typical ainori ('everyone on board') election against a token Communist opponent in 1993 but was soon arrested in the Zenecon (General Construction Company) scandal. He resigned and an election was held to replace him in November. The established parties (LDP, JSP and DSP) supported the vice-governor in a typical ainori pattern. This time, however, three new parties, Shinsei, Sakigake and the JNP, challenged the status quo. They supported Asano Shirou, a bureaucrat from the Ministry of Health and Welfare. Asano won in a close race marked by a record low turnout of only 39 per cent. Now in 1998, Asano was running for a second term. He had established a good record of reform, including one of the strongest 'freedom of information' ordinances in the country. In order to maintain his non-political image, he declared his intention not to accept the formal support of any party. The NFP, the DPJ and the SDP all wisely decided to accept his decision while continuing to support him informally. Asano fitted perfectly the image that the new parties were trying to project, 'a reformer above petty party politics'. An incumbent governor running for his second term is hard to beat under any circumstances and Asano was popular to boot. By supporting Asano, the reformers could simultaneously uphold their principles and back a sure winner.

A hitch developed when Aichi Kazuo, who had defected from the LDP to Shinsei in 1993 and was the head of the prefectural NFP at the time, defected back to the LDP. The NFP needed a new leader in Miyagi. Its members came up with the brilliant idea of asking the national party leader Ozawa, who hailed from the neighbouring prefecture of Iwate, to take on the job temporarily. Ozawa accepted and the NFP seemed to have minimised, perhaps even reversed, the damage caused by Aichi's defection. Ozawa, however, led them in a surprising direction. He decided that, if Asano would not accept party support, his party would not support Asano. Instead, he chose to support Ichikawa Ichirou, the LDP candidate. Ichikawa had been in the NFP in the House of Councillors but had defected back to the LDP in order to run for governor. Ichikawa thus represented Ozawa's policy of rapprochement with the LDP as perfectly as Asano represented a new kind of politics.

Ozawa's decision decimated the prefectural NFP. Several prefectural assemblymen left the party and several others remained but supported Asano in defiance of Ozawa's decision. Ichikawa ran a traditional campaign supported by the LDP, the NFP and Koumei. Asano ran a non-traditional campaign without formal party support. Asano won with more than double Ichikawa's vote total. Turnout went up for the first time in 24 years to 55.9 per cent.

Ozawa's strategy was clearly 'irrational' in the sense that he did not maximise any of the usual goals of a political party. He decided to back a loser instead of a sure winner. His strategy devastated his party in Miyagi prefecture and hurt the party's image nation-wide. He was not maximising the long-run support of his party. Though his actions seemed inexplicable at the time, it turns out that he was not maximising party goals because he did not expect the party to exist for much longer. 


\section{The NFP breaks up}

In December the NFP held its second election for party leader. The opposition to Ozawa was led by Kano Michihiko, who proposed an alliance with the Democrats and the Sun Party as an alternative to Ozawa's policy of a conservative alliance. During the campaign, Koumei formally decided to run separately from the NFP under its own label in the PR tier of the upcoming House of Councillors election (YS 8 December 1997). Koumei was split on which candidate to support and did not want to appear to be supporting either candidate en bloc. Ozawa was also losing his enthusiasm for the NFP. He campaigned on a policy of reforming all aspects of the party, excluding no topic as taboo. Even at the time this was taken to be a public announcement that the NFP might not continue to exist for much longer (YS 14 December 1997). Ozawa won the election but the NFP dissolved by the end of the year. Ozawa formed another new party, the Liberals (the second time since 1993 a Liberal Party had been formed). He was hoping to build a party with a coherent policy position unified under his control but the Liberals were immediately beset by disagreements over whether or not to seek a coalition with the LDP (YS 1 January 1998). Ozawa nurtured his links with the 'conservative alliance' group inside the LDP, aiming either to form a new right wing party or to re-enter the LDP and take control of the party from the inside.

The constituent parties of the NFP re-emerged, more or less intact. Koumei reemerged as an independent party but was split into separate Upper and Lower House groups and several ex-Koumei politicians chose to stay with Ozawa in the Liberal Party. Although Koumei would eventually reunify and play a major role in the subsequent manoeuvring, it remained deeply divided by its experience inside the NFP. Local Koumei party organisations had established working relationships with politicians from a wide range of other parties, making it difficult for central party officials to enforce any kind of coherent political strategy.

Apart from Koumei and Ozawa's Liberals, the rest of the NFP was drawn toward the Democrats as the primary alternative to the LDP after the disintegration of the NFP. The Democrats quickly organised a new parliamentary faction in an attempt to unify the anti-LDP remnants of the NFP. The Minyuuren started with 99 members in the Lower House and 41 in the Upper House. As events moved toward merger into a new Democratic Party, a group led by former Prime Minister, Kaifu Toshiki, declined to participate. This group of conservatives found it difficult to co-operate with socialists, preferring cooperation with Koumei, and hoped to form a centre party between the LDP and the Democrats (YS 17 April 1998). Though the effort failed, a small group of conservatives formed the Reform Club (Kaikaku Kurabu) and entered another parliamentary faction with Koumei.

The 'new' Democratic Party ${ }^{1}$ was founded in April 1998 with 93 members. The balance of forces within the party had changed significantly from the old DPJ. Ex-socialists declined from 49 to 30 per cent of the party though they still 
formed the largest single component. Because many Sakigake members participated in the new but not the old DPJ, their weight stayed constant at around a quarter of the party. The several parties which had started in the LDP, joined and then left the NFP (Hata's Sun Party, Hosokawa's From Five, and Kano's People's Voice) now formed a parliamentary faction called Minsei (Popular Government) and joined the new Democrats as a group, forming about a quarter of the DPJ. Finally, the old DSP now formed around 15 per cent of the DPJ.

\section{The 1998 House of Councillors election}

The LDP entered the House of Councillors election determined to regain a majority in that house as it had in the House of Representatives. Its members were confident of victory. The polls showed a recovery in support for the LDP and predicted victory. The opposition parties were not only weak, they were also in disarray. Rengou made yet another effort to co-ordinate opposition party efforts in order to present voters with a single alternative to the LDP in each electoral district (YS 6 June 1997). The problem was that both the SDP and Sakigake were still supporting the LDP government and therefore not willing to join an anti-LDP alliance. Neither was the SDP willing to co-operate with the Democrats. The SDP ran candidates against the DPJ in 14 of the 47 districts. Koumei also declined to participate in a broad anti-LDP alliance. The central party headquarters recommended 15 NFP candidates but ran their own candidates in two districts, Tokyo and Osaka. As important, they declared a 'free vote' in 22 districts, allowing the local party to decide which candidate to support (YS 6 July 1998).

When the results were announced, the LDP was shocked to find that it had dropped 16 seats. Both the Democrats and the Communists gained nine seats and were declared the winners. Even though the polls showed the DPJ with less than 10 per cent support, it won 21.7 per cent of the PR vote, not that far behind the LDP's own 25.2 per cent. The LDP had done better than in 1989 when it lost to the JSP or in 1995 when it lost to the NFP but the party had lost yet again. Moreover, two straight losses meant that the party could not hope to regain a majority in the House of Councillors without two straight victories, which would take at least six more years.

Another important result was that Koumei had garnered only 7,740,000 votes in the PR tier, 60,000 votes under target and, for the first time, fewer votes than the JCP. The party investigated and found that it had lost PR votes in those districts where it had supported district candidates from other parties instead of fielding candidates of its own. It feared that Gakkai members were dissatisfied with Koumei's policy of co-operating with the LDP (YS 18 January 1999).

A record 19 independents were elected. Many were backed by coalitions of opposition parties. Only three entered the LDP after the election while six joined the Democrats. This was taken to be an indication of which party's fortunes were rising and which were waning (YS 4 August 1998). 
The LDP had placed its bets on a low-turnout election that would be determined by mobilising its organisational support. The party could not expect to attract the floating vote in the midst of a prolonged recession and widespread criticism of the government's economic policy. It assumed that floating voters would stay home and that the LDP's superior organisational support would bring it victory. In the event, turnout rose, the organisational strategy proved ineffective, and dissatisfaction with the economy proved more important than anyone had anticipated (YS 14 July 1998). Kabashima Ikuo (1999) saw in these results the advent of economic voting in Japan. Overconfidence and overnomination had, moreover, cost the party four seats. In Saitama, Tokyo, Kanagawa and Aichi prefectures the LDP nominated two candidates, both of whom lost. If it had nominated one per district, they could probably have won easily.

\section{Hashimoto resigns}

Prime Minister Hashimoto immediately took responsibility for the House of Councillors defeat and resigned as president of the LDP (YS 14 July 1998). The only candidate who was fully prepared to make a run for the leadership position was Obuchi Keizou (YS 14 April 1998). Obuchi headed the largest faction, the direct successor to the Tanaka and Takeshita factions. Obuchi thus stood for the LDP establishment and that establishment began arranging a smooth transition. This plan was upset by protests from the younger members of the party, who charged that this would demonstrate to voters that the LDP had not reformed itself and was still playing by the old rules of factional politics (YS 15 July 1998). They demanded and got a presidential primary election.

Obuchi faced two challengers. Kajiyama Seiroku ran against the current leadership group and Koizumi Junichirou ran as a representative of the younger generation. Kajiyama ran against factional politics, symbolised by the fact that he belonged to the Obuchi faction and was therefore breaking rank to run. Koizumi is one of the Ks in YKK but was supported, not by the YKK group, but by his own Mitsuzuka faction. Polls indicated that Obuchi was the least popular among voters but he was chosen anyway. It was a triumph of 'politics as usual' but Obuchi would grow into the job.

\section{Obuchi looks for coalition partners}

Like the Hashimoto administration before it, Obuchi's government had a bare majority in the Lower House and no majority in the Upper House. The government therefore needed some opposition party support to pass bills. Rather than establishing links with one or another party, Obuchi decided to negotiate each bill separately, establishing particular coalitions to pass particular bills. The LDP had had some experience with this technique, called 'partial coalitions' (bubun rengou) in Japanese, during the period after the 1976 election when the 
New Liberal Club robbed it of its 'working majority' (Krauss 1984). Under the Obuchi administration, the Liberals opposed the LDP bill for revitalising financial markets and so the LDP negotiated amendments with the Democrats, the SDP and Koumei (not yet reunified at the time). The bill for disposing of the debts of the old national railways was opposed by the Democrats and Koumei, so the LDP negotiated with the Liberals and the SDP. The Democrats opposed another bill for reforming finance markets and so the LDP negotiated with Koumei, the Liberals and the SDP. Only the Communists were left completely out of the picture (YS 14 October 1998).

This process worked but proved unwieldy so the LDP began to search for stable coalition partners. The Liberals were the closest in policy terms (though to the right of the LDP) and were quite interested in joining a coalition but the Liberals could not provide a majority in the Upper House. Ozawa had also made many enemies in the LDP and was responsible for splitting the party and deposing it from power for the first time in its history. Opposition to any cooperation with Ozawa was led by, but not limited to, the YKK group.

In November, Koumei was reunited into a single party, making it an attractive coalition partner. A coalition with Koumei would have solved the LDP's problem but Koumei was not interested. The LDP therefore overcame internal opposition and opted for the LDP-Liberal coalition (called JiJi in Japanese, unfortunately also a pun on an unflattering word for 'old man'). An agreement was reached in November and the coalition formally begun on 14 January 1999. In essence, YKK had lost to the 'conservative alliance faction' within the LDP.

Ozawa negotiated an ambitious policy agreement, including several provisions that were controversial within the LDP. Many commentators thought Ozawa had outwitted Obuchi.

The coalition agreement also included a provision for electoral co-operation between the two parties in the next general election. Most of the Liberals had defected from the LDP and had defeated LDP opponents by co-operating with Koumei. Now, without the help of Koumei, their prospects for defeating an LDP challenger had dropped drastically. To honour this agreement, however, the LDP would have to persuade loyal candidates who had battled with defectors in 1996 now to stand down in favour of those same defectors. Any electoral arrangement would involve tough negotiations between sworn political enemies over the politician's most precious asset, his district.

The Liberals also lost organisational support when they entered into coalition with the LDP. Rengou announced that it could no longer honour any agreements for electoral co-operation with the Liberals and Koumei began distancing itself from Ozawa. By joining the LDP, the Liberals seemed to have burned their bridges behind them.

The LDP was doubly divided over potential coalition partners. The 'conservative alliance' group demonstrated its interest in allowing the Liberals to return to the LDP or perhaps even leaving the LDP to join the Liberals (YS 16 April 1999). The second division concerned the wisdom of allying with an 
avowedly religious party in Koumei. The two cleavages tended to overlap, with conservative alliance supporters being opposed to Koumei, but the overlap was far from complete. The Obuchi administration, however, sought the largest possible coalition, including both the Liberals and Koumei and its efforts to attract Koumei were beginning to have an effect.

\section{Koumei joins the LDP-Liberal coalition}

In May, Koumei offered external support in exchange for a return to MMD (YS 8 May 1999) and the JiJiKou (LDP-Liberal-Koumei coalition) was formed later that month. Local party branches complained that they had campaigned against the LDP and were now being told to co-operate with it (YS 12 May 1999). Many local organisations had already made arrangements to co-operate with the Democrats in the next election. These considerations, however, were overridden by the desire to have greater influence in the policy-making process and some hope of getting rid of the new MMM electoral system in favour of a return to MMD. Koumei understood that MMM would make it difficult for third parties to secure election and there was scattered support for a return to MMD both within the LDP and inside the other small parties.

Koumei's desire to return to MMD was in direct conflict with the LDP's previous agreement with the Liberals to reduce the number of PR seats in the MMM system from 200 to 150 . Koumei had supported electoral systems such as MMM that favour large parties when it was part of the NFP but, now that the party had decided to go it alone, it needed a system such as MMD that was more tolerant of small parties. The Liberals were also a small party but Ozawa had long stood for fostering a two-party system. Presumably, he also planned to be part of one of the two large parties in the future, either by re-entering the LDP or by breaking off the right wing of the LDP and starting a new conservative party. When Koumei entered the coalition the LDP put the 50-seat reduction on the back burner, thus upsetting Ozawa and the Liberals (YS 19 May 1999). This issue was to become the major bone of contention among the coalition partners throughout the JiJiKou coalition government. Electoral co-operation between the Liberals and the LDP was also jeopardised by the entry of Koumei. The new coalition caused confusion and consternation in many electoral districts around the country as yesterday's enemies had become today's friends.

The Liberals justifiably felt betrayed by the LDP but their options were limited. If they left the coalition, the coalition would still have a majority in both houses and the Liberals would face the next election as a small party with very few allies and many enemies who felt betrayed by Ozawa at some point in the recent past. Koumei confirmed that it would remain in the coalition even if the Liberals left (YS 24 July 1999). The only thing that could make leaving the coalition attractive would be if the party could take a significant portion of the LDP with it. The LDP was definitely divided, with the YKK group taking a relatively open stance against the JiJiKou coalition (YS 10 July 1999). The 
Democrats were also put in a bad position by the formation of JiJiKou. They went from the largest opposition party and magnet for all LDP opponents to a party whose only allies were the SDP and the Communists. The Democrats also understood the divisions within the LDP and made overtures to Katou of the YKK group (YS 13 June 1999).

One other group reconsidered its position after the formation of JiJiKou: the 'April Society' (Shigatsukai), the alliance of Buddhist organisations formed before the 1996 election to oppose the NFP. The established Buddhist and other religious groups had long supported the LDP. The support was low-key and the groups made few demands upon the political system. They all supported a strict form of separation of church and state, presumably because of their experiences with State Shinto during the pre-war military regime. The avowedly religious party, Koumei, violated their notions of separation of church and state, adding to other grievances against the Gakkai. Several districts had seen 'religious wars' between a Koumei candidate and a candidate supported by the established Buddhist organisations. When Koumei joined the NFP, and especially after the LDP began to attack the NFP as 'the Koumei in disguise', the established groups formed the April Society and redoubled their efforts in support of the LDP. Now that the LDP was allied with their enemy, they were forced to reconsider their position (YS 13 June 1999).

The Liberals chose to assert themselves over two issues: electoral co-operation and the electoral system. Little progress was made on either front. When the Liberal proposal to reduce the PR section of the electoral system by 50 seats was postponed once again, Ozawa threatened to leave the coalition (YS 13 August 1999, evening edition). Once again, he was forced to back down. It was later revealed that, if Ozawa had led the Liberals out of the coalition, Noda Takeshi, the single Liberal in the cabinet, was prepared to split the Liberal Party and form a new party which would then remain in the coalition (YS 23 August 1999). Moreover, at the same time as Ozawa was blustering about leaving the coalition, he was also making overtures to re-enter the LDP. Obuchi seemed to have solved his coalition problems at Ozawa's expense.

When the JiJi coalition was formed, the dominant impression in the mass media was that poor Obuchi had been outsmarted by the slick Ozawa. Suddenly it seemed as if that original impression had been completely mistaken and that Ozawa had actually been outfoxed by Obuchi. Obuchi agreed to all of Ozawa's demands but, once the Liberals were inside the coalition, their demands were subject to normal LDP policy-making procedures that feature endless discussion until a consensus is reached (Campbell 1984). Such discussions sometimes result in compromise but, if consensus is not achieved, the decision is simply postponed. The press began talking about Prime Minister Obuchi's tactic of 'swallowing whole' (marunomi): agree to everything and then allow time to teach one's opponent that his demands cannot possibly be met. 


\section{The LDP and DPJ choose their leaders}

Obuchi faced his second run for the party leadership on 21 September 1999, this time challenged by Katou Kouichi and Yamazaki Taku, two leaders of YKK. Though he was easily re-elected, as expected, the two challengers also walked away reasonably satisfied both with their performances and with the process. The three candidates managed to maintain a public show of unity throughout the contest and intraparty rancour was kept to a minimum, though discrimination against the losing candidates was visible in the formation of the new cabinet after the election. The primary issue of the campaign was the new JiJiKou coalition. Both challengers criticised the decision to include Koumei in the coalition and were publicly supported by the April Society and other anti-Koumei Buddhist groups, the first time religious groups had taken a public stance on the LDP's leadership choices. Obuchi survived the challenge and the returns gave little evidence of any protest against the JiJiKou coalition.

The Democrats also held a leadership contest, voting one week later, on 25 September. The incumbent, Kan Naoto, faced two challengers, Hatoyama Yukio and Yokomichi Setsuo. The Democrats were suffering from miserable standings in the polls and the primary issue was leadership. Hatoyama and Kan were the two founders of the party, sharing leadership during its early days. Although ex-socialists continue to form the bulk of the party, Yokomichi was the only candidate to come from a socialist background. The other two candidates had come from Sakigake. In yet another twist, Yokomichi and Hatoyama come from the same prefecture, Hokkaido. Like the LDP, the Democrats also managed to maintain unity, despite debating the contentious issue of constitutional revision. The party had recently revealed its divisions over Ampou issues with a divided vote on the national flag and national anthem (YS 25 July 1999). Though it took two rounds of voting, Hatoyama was duly elected as the new leader, keeping both of his opponents in leadership roles in the party.

\section{The Liberals search for options}

Though publicly denying it, Ozawa continued to look for a way to re-enter the LDP (YS 10 November 1999). Behind all of the wrangling lay two basic facts. First, having a large coalition helps pass bills smoothly through the Diet but, when an election rolls around, the coalition partners have too many candidates for too few seats. Add to this the complexities of asking candidates to stand down in favour of the candidates who had defeated them in the previous election, local histories of co-operation and rivalry, and internal divisions within each party over the wisdom of forming the coalition in the first place, and the stage was set for rancorous negotiations. Local party branches resisted pressures to co-operate emanating from the centre. If local branches were not handled with care, they might defy the central headquarters and back an independent or they might simply refrain from actively supporting the coalition's chosen candidate. 
The second fact producing conflict between the Liberals and the LDP was that the LDP did not need the Liberals in the same way as they needed Koumei. Koumei provided a sufficient number of seats to guarantee a majority in the House of Councillors without the Liberals. The Liberals have no independent support base. Most Liberal voters were simply LDP voters who were currently voting Liberal because they liked the local Liberal candidate. They could be expected to re-enter the LDP fold if the Liberals disappeared. Moreover, Liberal strength tended to be in the rural areas, where the LDP was strong. At best, the Liberals offered the LDP a few individual candidates backed by their own personal kouenkai in districts that the LDP could expect to win in the long run in any case.

Koumei, on the other hand, boasted an independent and disciplined support base. Moreover, Koumei had supported the LDP's major opponent in 1996 and gaining its support moved a significant bloc of votes from the opposition to the LDP. Finally, Koumei supporters tend to live in urban areas where the LDP is weak. An alliance with Koumei offered the LDP a way to regain a stable, longterm hold on power. There were only two flies in the ointment: coalition with Koumei meant more compromise on issues; and the Koumei alliance might drive away voters from other religious groups. Opponents to JiJiKou thought the price too high to pay and openly called for dissolving the coalition before the election (YS, 9 January 2000).

After prolonged wrangling and repeated postponements, the coalition finally decided to push the bill to reduce PR by 20 seats (down from the original Liberal demand of 50) through the Diet in the new year even before the budget was passed (YS 23 January 2000). The primary goal was clearly to keep the Liberals in the coalition. The opposition parties were outraged both by the decision and by the railroading tactics used to enforce it. They boycotted the proceedings.

The line used to sell the bill, that the private sector was suffering through restructuring and downsizing so the government should also do its bit, made sense to the public. The Democrats could counter with nothing as reasonable. Indeed, the party had previously supported the idea of a 50-seat reduction and had trouble explaining why it now opposed a 20 -seat reduction. The Democrats were reduced to attacking the tactics of the coalition in achieving a goal with which they agreed. Finally, the controversy pitted the three coalition parties against the Democrats, the Socialists, and the Communists. While the Democrats were not averse to co-operation with the Socialists, they were uncomfortable siding with the Communists. The LDP immediately attacked the Democrats for joining with the Communists.

The bill was passed without the participation of the opposition parties (YS 3 February 2000) and the Diet settled down to the business of passing the budget. Though Ozawa could claim a victory, there was still no progress on electoral cooperation and everyone expected an election soon. The Osaka gubernatorial and Kyoto mayoral elections in February seemed to confirm that Koumei co- 
operation with the LDP could win elections (YS, 8 February 2000), reducing pressure on the LDP to deal with the Liberals.

\section{The religious cleavage divides the parties}

Koumei's decision to enter into coalition with the LDP caused problems for all of the other parties and in virtually every district. Koumei had been part of effective anti-LDP alliances in several prefectures, most notably Hyogo (see Chapter 5). Much of Part II will be taken up with discussion of the scramble to obtain Koumei support in particular prefectures and particular districts.

Electoral considerations aside, many politicians in each of the other parties were, for one reason or another, unalterably opposed to Koumei and its role in Japanese politics. Koumei opponents inside the LDP organised the 'Society for Protecting the Separation of Religion and Politics' (Seikyou Bunri wo Tsuranuku Kai, hereafter SBTK) in February (YS 19 February 2000). The group was linked to the April Society and claimed to have 32 members but only 10 were willing to release their names to the public because the group was in clear violation of party discipline. Two of the group's leaders went on a television talk show to make their position clear and one published a book criticising JiJiKou (Shirakawa 2000). The SBTK were potential defectors from the LDP if it continued its policy of alliance with Koumei, but opponents of Koumei did not necessarily agree on many other issues. Katou Kouichi, for example, opposed the alliance with Koumei but his policy positions were closer to Koumei's than many of those who favoured the alliance (YS 5 May 2000).

The Democrats were no more unified in their attitude toward Koumei. On the one hand, JiJiKou was unpopular and the Democrats could win votes by opposing the coalition. The SDP and the JCP were already taking the lead in criticising the coalition. The April Society also offered an extremely attractive and seemingly available support group. On the other hand, the Democrats had to be careful about linking their image to the 'old left'. The Democrats did not want to appear to be the successor party to the JSP or to be particularly friendly with the Communists, while simultaneously gaining as much support as possible from the labour unions and voters who had previously supported the socialists. In addition, many Democrats, particularly those who came from the DSP, had long-standing relationships with Koumei and could not expect to win their SMDs without Koumei support. Both the LDP and the Democrats were forced to play a difficult balancing act, trying to win votes from both sides of this newly activated religious cleavage.

\section{The Liberals finally exit the coalition}

In March 2000, Ozawa approached Obuchi with a plan to dissolve both the LDP and the Liberals in order to form a new conservative party (YS 15 May 2000). Although this was not known at the time, it proved the breaking point for the 
coalition. Ozawa finally gave up his hopes for either re-entry or electoral cooperation. He chose to leave the coalition and run as an opposition party (YS 2 April 2000). Noda Takeshi chose to remain in the coalition and formed the Conservative Party (YS 4 April 2000). Of the Liberal's 50 Diet members, 26 chose to stay with Noda and 24 to leave with Ozawa. A second party led by Ozawa had fallen apart.

Ozawa began to talk to other opposition parties and Rengou, trying to reestablish networks that he had recently abandoned. The Democrats planned to field a candidate in every one of the 300 SMDs and would not sacrifice that goal for the sake of co-operation with the Liberals. Many criticised the Liberals for acting like an opposition party during elections but not between elections. The Conservatives, on the other hand, would have little or no public image for the election campaign. Ougi Chikage, a female member of the House of Councillors, was chosen as party leader. The party was created primarily as a vehicle for reentering the LDP and did not need a viable prime ministerial candidate as leader. The prime mover behind the creation of the Conservatives was Noda Takeshi. Later, during negotiations over electoral co-operation, he publicly stated that he was willing to consider even the most extreme forms of electoral co-operation with the LDP (i.e., formally joining the LDP) and did not care if the Conservative Party lost seats in the election (YS 23 April 2000).

\section{Mori succeeds Obuchi}

Immediately after the coalition broke up, Prime Minister Obuchi entered hospital. At first the public was told that he was suffering from fatigue but they were soon informed that he had suffered a stroke and could no longer serve (YS 4 April 2000). The LDP announced that the secretary-general, Mori Yoshirou, would succeed Obuchi as prime minister. The transition was handled smoothly with hardly a hint either of factional conflict or of the deep disagreement over future party strategy.

The opposition parties criticised the LDP for making the decision informally and in secret and for keeping the public in the dark for 22 hours concerning Prime Minister Obuchi's true condition, and the charge seemed to have an effect on public opinion. The LDP was not above using this tragedy for political purposes. It was easy to blame Ozawa's decision to leave the coalition for causing the stress that toppled the prime minister, especially given the timing of the two events. Secretary-general Nonaka also suggested, with no apparent justification, that Hatoyama Yukio, leader of the Democrats, should shoulder some of the blame.

The choice of the secretary-general to succeed the fallen Obuchi was a choice for maximum continuity. The whole cabinet and leadership structure was maintained. The only vacant slot was that of secretary-general and that slot was filled by Nonaka, Obuchi's previous secretary-general. Perfect continuity was, of course, impossible. Prime Minister Mori did not have the same close connections with Koumei though, as secretary-general, he had been responsible for managing 
the political aspects of the coalition. Koumei expressed approval of the choice but some doubt was thrown upon the relationship. The most important change, however, concerned the timing of the election.

Mori had had little experience in foreign policy. He could not be expected to give a command performance at the Okinawa summit, especially as a leader who had never led his party to victory in an election. He had not even been chosen by a vote of party members. He could be expected to have more influence in Okinawa if he had an election victory under his belt. More generally, Mori needed an election victory to solidify his position within the party. Speculation soon focused on a June election and, although it took a long time for the decision to become official, the rumoured date of 25 June was finally chosen.

In the longer term, the most important result of Obuchi's premature departure from the political stage may prove to be that it threw his faction into disarray (YS 21 April 2000). The largest faction inside the LDP, successor to the Takeshita and Tanaka factions that had dominated the LDP since the 1980s, now found itself without a strong leader and with few potential candidates for prime minister.

Mori soon proved himself less than the ideal choice for prime minister. A series of 'mis-statements' (shitsugen) reduced public support for the Mori cabinet to less than 20 per cent. Before a Shinto group he described Japan as 'a divine nation' or 'the country of the gods' (kami no kuni), a phrase reminiscent of wartime propaganda and efforts to establish Shinto as the state religion. This phrase is particularly upsetting to Buddhists, including the Gakkai. After a series of apologies, but without a formal withdrawal of his statement, he failed to learn his lesson and allowed more mis-statements to mar his image.

\section{Negotiating electoral co-operation}

The most important preparations for the election concerned electoral co-operation among the coalition parties. The coalition had a huge majority in the Diet, which was convenient for passing bills but extremely inconvenient for nomination politics. When the Liberals joined the coalition in 1998, they extracted several promises from the LDP but one of the most important was the promise of electoral co-operation. Co-operation was expected to be difficult because the NFP already had candidates in 35 districts and both parties had incumbents in seven districts (YS 12 November 1998). Progress over electoral co-operation proved even more difficult than reducing the size of the Diet. The two parties decided to give preference to incumbents but argued over the precise definition of an incumbent. When a deal seemed in the offing, the local party and the candidates concerned often refused to budge. When Koumei joined the mix, the number of problem districts rose to 59 (YS 10 May 1999). In one district, Kanagawa $16^{\text {th }}$, all three coalition partners had a candidate.

As the election drew near the LDP got more interested in the Koumei vote. There were 23 districts where both parties had candidates. The LDP withdrew in 15, Koumei withdrew in five and three were left unresolved with both parties 
nominating candidates. That the LDP was willing to abandon 15 districts in order to maintain the coalition with Koumei and to get Koumei votes is testimony to the importance the leadership placed on the coalition. It was also extremely controversial within the party and extremely unpalatable to local LDP party branches. In six of the districts where the LDP stood down in favour of Koumei, an LDP-affiliated incumbent ran against Koumei and the wishes of his own party, leaving effective co-operation in only six districts.

Much of the problem of electoral co-operation with the Liberals was solved when the Liberals left the coalition. Of the 37 districts where the two parties had both had candidates, 18 Liberal candidates left the coalition with Ozawa. Of the 19 who remained in the coalition, two returned to the LDP, ${ }^{2}$ and 16 ran for the Conservative Party. The LDP found it much easier to co-operate with the Conservatives. The local organisations were compatible and most, if not all, of the Conservatives were looking for a way back into the LDP. In 11 districts the LDP stood down in favour of the Conservative and in two the Conservative ran in the PR tier, leaving the SMD to the LDP. In only three districts did a Conservative compete directly with an LDP candidate.

The LDP thus co-operated with the Conservatives and competed with the Liberals. It would be interesting to know which was the cause and which the effect. Did Liberals follow Ozawa out of the coalition because they knew they could not get LDP co-operation or did the LDP punish those who left by running candidates against them? Did the Conservatives who decided to stay in the coalition do so because they knew that they could get LDP co-operation or did the LDP reward those who stayed with electoral co-operation? Unfortunately, there is no reason to think we will ever know the answers to these questions.

\section{The issues}

All the polls indicated that the economy was the main issue on the minds of the voters. A survey of candidates showed that most responded by talking about the economy more than any other issue. Only the Socialists continued to march to the beat of a different drummer, speaking first and foremost about protecting the peace constitution (YS 10 June 2000). Despite all of the attention, no party distinguished itself as having the best economic policy so the issue was not one that moved many votes.

The issue most likely to move votes was the participation of Koumei in the coalition government, the 'separation of religion and politics' issue. This issue was important at both the national and the district levels. At the national level, the LDP was in coalition with Koumei and could therefore expect Koumei votes. It could also expect to lose votes from anti-Koumei voters and to lose support from anti-Gakkai religious groups. On this latter front there were several ominous signs. First, some groups belonging to the April Society froze payments of LDP membership dues from their members (YS 13 June 1999). Next, many religious groups that normally send representatives to the LDP national convention refused 
to do so (YS 20 January 2000). Finally, the number of LDP candidates receiving recommendations from establishment religious groups fell sharply (YS 15 June 2000). The Democrats spotted the opportunity and began courting the antiKoumei groups (YS 30 August 1999) and attacking the fusion of religion and politics represented by the LDP-Koumei coalition (YS 10 May 2000).

The 'religious cleavage' was potentially powerful but divisions within each camp prevented it from being fully mobilised. First, the presence of the SBTK represented the vociferously anti-Gakkai elements within the LDP. Second, YKK (or at least Katou and Yamazaki) argued against the coalition with Koumei more on the grounds of political strategy (YS 14 May 2000). They argued that the goal of the LDP should be a single-party majority government, and that both electoral co-operation with Koumei and coalition government were detrimental to that cause. The LDP was thus seriously divided on the religious issue.

Though the Democrats recognised the potential of the religious cleavage, they were also divided. Many of their candidates had come from the Democratic Socialist Party and had maintained electoral co-operation agreements with Koumei dating from as far back as the 1970s. Other Democratic candidates had developed ties to Koumei during their experiences with the ill-fated NFP. As the election approached, internal divisions forced the Democratic leadership to 'tone down' its criticism of Koumei and the Gakkai (YS 10 June 2000).

At the district level, the religious cleavage took on a wide variety of patterns. Both local history and current realities shaped the cleavage. History, particularly recent history, clearly mattered. A campaign organisation that had long considered Koumei to be either 'the enemy' or 'an ally' had trouble changing its loyalties. Candidates who had run against Koumei candidates in 1996 had particular trouble accepting them as allies in 2000. Nevertheless, current realities sometimes overrode the historical legacy. Most noticeably, candidates who needed Koumei votes to win recanted critical statements made in the past. The media joked about the prevalence of 'religious conversions' based upon electoral necessity. In many prefectures, Koumei ran no SMD candidates so that electoral co-operation consisted of Koumei supporting LDP candidates in the SMDs and LDP candidates directing their supporters to vote Koumei in PR. LDP candidates who felt safe tended to urge their supporters to vote LDP in both the SMD and PR tiers. The candidates who enthusiastically urged a PR vote for Koumei tended to be those candidates whose electoral prospects were uncertain.

Koumei had similar, though lesser, problems in mobilising its voters to support former enemies. The polls documented a dramatic shift in the attitudes of Koumei supporters toward the LDP but much less change in the attitudes of LDP supporters toward Koumei (YS 31 May 2000). Koumei has been plagued by this asymmetry from the beginning of its experimentation with electoral co-operation. After the election, several LDP candidates attributed their defeat to Koumei supporters refusing to support them and casting blank ballots in the SMD.

If the religious issue was the most likely to move votes, the issue most dangerous to the future of the LDP may well have been 'public works'. LDP 
support had been built more on pork barrel than on issue politics. LDP candidates, especially those in rural areas, campaigned on being a 'pipeline to the central government' which would bring home public works projects that would stimulate the local economy. This campaign strategy had been challenged in the 1970s by pollution concerns and the progressive slogan of 'a pipeline to the people'. The LDP successfully weathered that storm but the issue had not faded away. Recent efforts to stimulate the economy through public works had failed to turn the trick and many expensive projects were clearly a waste of the taxpayers' money. Many public works projects aroused as much local opposition as local support. Public works often also involved kickbacks, collusion and bribery. LDP corruption scandals often involved the construction industry. The Democrats took the antidevelopment position in several districts with controversial public works projects, arguing that the public works budget contained a good deal of waste, and attacked the LDP for using public works as a fund-raising technique. The LDP moderated its stance but could not disassociate itself from its long history of supporting public works.

The issue that worked most clearly in favour of the coalition was 'stability'. The coalition had indeed provided stable and effective government. Its members attacked the Democrats for failing to present voters with a clear alternative coalition. The most difficult question for the Democrats was whether they would join the JCP in coalition if that were the only way to gain power. The Communists were expected to gain seats and were anxious to escape their ghetto. They were also, however, unwilling to abandon any of their controversial issue positions. The LDP attacked the Democrats for 'joining hands with the Communists' in the Diet. All of the coalition parties, but especially Koumei, predicted that a Democratic victory would produce only instability and confusion.

The Democratic response to this issue was unappealing but probably also the best available option. The party set itself the totally unrealistic goal of a singleparty majority or at least more seats than the LDP. Though clearly unrealistic, this strategy allowed the Democrats to avoid the issue of coalition partners. Their answer was: 'We do not plan on needing any coalition partners. If we finish first but without a majority, we will talk to all potential partners and choose the one with the most compatible policy positions.' Since it would have taken a miracle for the Democrats to finish first, let alone capture a majority, this strategy neutralised the issue of potential coalition partners as much as was possible. Any admission that they might consider a coalition with the JCP might have been fatal. The idea of coalescing with the Liberals and Ozawa was almost as unpalatable. The Liberals belong on the right of the LDP and the Democrats needed to maintain their centre-left image. The Socialists were somewhat more attractive but still seemed to belong to an earlier era. The Democrats thus chose to run as the alternative to the LDP, pretending that Japan had a two-party system, ignoring both the reality of the multiparty system and the unreality of their own chances of winning a majority. 
The campaign itself was uneventful. The LDP campaign advertisements were forgettable and those of the Democrats were virtually incomprehensible. The Liberals produced the only memorable advertisement. This showed their leader, Ozawa, walking along the street. He was slapped in the face by an invisible hand, first to the left, then to the right. The message was, 'Even so I will keep going.' This advert tried to turn a series of political failures, from the failure of the NFP, to the failure of the coalition with the LDP, to the halving of the party in a split, into an advantage. It drove home the message that Ozawa is a man of principle, undeterred by setbacks. The Liberals were also able to air their commercials as often as the larger parties because they had refused to divide their campaign funds with the Conservatives when the party split.

\section{The results}

The results of the 2000 general election can be interpreted in two contradictory ways. On the one hand, the coalition won a comfortable majority with 271 seats to the combined opposition total of 188. On the other hand, the coalition lost 64 seats while the opposition parties gained 35 . Though either side could thus claim victory, it was clear from the expressions on the faces of the party leaders that the coalition had lost and the opposition had won (Reed 2001a).

Even though the LDP and its coalition partners sit on the front benches of the Diet, all of them interpret the election result as a loss and are reconsidering their future strategies. They were not looking forward to the House of Councillors election due in the summer of 2001. The strategy of using Koumei votes to shore up the LDP's urban base failed. The biggest surprise of the campaign was the number of established LDP incumbents who lost in urban districts. It appears that Koumei supporters did vote for LDP candidates in respectable numbers. Kabashima (2000a) estimates that 35 LDP candidates owe their victories to Koumei votes. Nevertheless, the LDP won in the countryside and lost in the cities, just as the party had done before allying itself with Koumei. Ironically, the failure of electoral co-operation with Koumei has rendered the LDP even more dependent upon Koumei votes in the Diet. The LDP had a majority in the Lower House entering the election, but now needed Koumei votes in both houses.

LDP losses and DPJ gains were even clearer in the PR tier. LDP candidates who ran in both 1996 and 2000 gained, on the average, 3.2 percentage points of the electorate (over 12,000 votes) but in the average single-member district the LDP lost 1.8 percentage points in the PR tier. The LDP has a serious problem in that the support for its candidates adds up to a great deal more than the support for the party. By way of contrast, the average DPJ candidate who had run in 1996 gained 4.7 percentage points in the single-member districts and the party gained 5.8 percentage points per district in the PR tier. Where the DPJ ran a candidate in the SMD it gained over 6 percentage points, but gained only 4 when it failed to nominate a candidate in the district. If the DPJ had been able to find more candidates willing to run, the party would have done even better in the PR race. 
Given the results of the 2000 election, the DPJ expected to have less trouble in finding willing candidates in the next election.

Koumei had most reason to be disappointed with the results. LDP voters did not consistently vote Koumei even when LDP leaders campaigned vigorously for them to do so. Although LDP voters did vote for Koumei candidates to some degree in some districts, the party has every reason to feel that it gave much more than it received. Even when the LDP stood down in its favour and no independent ran to protest the decision, Koumei secured the election of only five of its eight candidates, and only three of those victories were SMD wins. In the other two cases, the Koumei candidate lost the SMD but won a PR seat. In all three of the districts where both parties nominated a candidate both lost. In the seven districts where an LDP-affiliated independent ran against party policy, Koumei won three seats and lost four.

Koumei's fundamental problem is single-member districts. The party had originally demanded a return to MMD as a condition for entering the coalition with the LDP and can be expected to press the issue based on its first experience of running as an independent party under MMM. Whatever the LDP may have secretly promised to get Koumei into the coalition, its own experience with SMDs has been extremely positive. In 1996 the LDP won 39 per cent of the vote and 56 per cent of the seats in the SMDs. In 2000 it won 41 per cent of the vote and 59 per cent of the seats. SMDs favour the largest party and the LDP is enjoying this advantage. Prime Minister Mori has already been heard saying that pure SMD is the ideal electoral system. Koumei desperately needs a return to MMD but is unlikely to get it.

The Conservatives did not do well but neither did they expect to. They lost all three districts where they competed with the LDP, but won seven of the 11 districts where the LDP stood down in their favour. They won no PR seats. Their future clearly lies with the LDP but joining the LDP no longer looks quite as attractive as it did when they decided to continue the coalition at any cost.

The coalition parties failed to co-ordinate across parties and it cost them seats. The LDP also had two internal co-ordination problems: candidates who returned to the LDP after the NFP broke up and candidates involved in 'Costa Rica arrangements' who were supposed to switch SMD and PR nominations in 2000. (A Costa Rica arrangement involves giving one candidate the SMD nomination in the current election, compensating the other candidate with a PR nomination. In the following election they promise to trade places.)

First, of the 21 NFP SMD incumbents (including one independent supported by the NFP) who returned to the LDP, 14 received the LDP nomination in their SMD and seven were forced to run in the PR tier. Two of the seven forced to run in PR had returned to the LDP late, by way of the Conservative Party. For these two, running in PR was thus a condition of their re-entry into the LDP. The LDP has always been more likely to back a winner than to reward loyalty. The seven cases in which the LDP candidate lost the SMD in 1996 but were re-nominated in 2000 were victories of the local party branch over the central headquarters. The 
party headquarters had a point. When the party nominated 1996 NFP winners, they won 12 of 14 contests $(85.7 \%)$. When they nominated 1996 loyal LDP losers, they won only four of seven (57.1\%). The candidates, however, appear to be irrational in their preference for the SMD nomination. Of those who were forced to accept a PR nomination, eight of nine (88.9\%) won seats and the sole PR loser finished in the runner-up position. If anyone retires from his PR bloc before the next election, he will get the open seat. Of those who won the SMD nomination, only 76 per cent won seats.

I have been able to identify 10 districts in which the LDP used a Costa Rica arrangement to solve its nomination problems in 1996. Many wondered if the promises involved in these arrangements would be kept. Not only were the promises kept, switching places caused conflict in only one district, Ehime $1^{\text {st }}$. Part of the problem in Ehime was that the original arrangement was not to switch in the next election but to switch after a specific date. If the election had been held earlier, the switch would have been postponed by one election. As the election approached both candidates prepared for an SMD race and, after the switching date had past, the SMD candidate proved unwilling to back down. In the end, he accepted the nomination in a House of Councillors by-election held on the same day as the general election. Both candidates won their respective seats.

In Gunma $3^{\text {rd }}$ district a Costa Rica arrangement was rendered void when the PR nominee was arrested and convicted on violations of the electoral law. Nakajima Youjirou was afraid that his campaign organisation would rust if unused and that the voters would forget him if he did not demonstrate a personal presence in the district. He thus spent large sums of money in preparation for his next SMD run while accepting a safe PR nomination in 1996. Needless to say, his efforts proved counterproductive.

In the remaining eight districts, the switch was accomplished with no serious problems. Again, however, a PR nomination proved safer than an SMD nomination. All eight PR nominees won their seat while only five SMD nominees (62.5 per cent) were elected.

The DPJ was the big winner, gaining 32 seats. Many of these victories were achieved in urban areas at the expense of established LDP incumbents. The party also finished only three points behind the LDP in the PR tier. The Democratic Party of Japan has been confirmed as the current alternative to the LDP. The party was looking forward to the upcoming House of Councillors election. Many of its losing candidates enthusiastically prepared for their rematches in the next general election.

In 2000 the DPJ was the big winner and is clearly the alternative to the LDP but Japan is not yet a two-party system. The Democrats are still over 100 seats behind the LDP. More importantly, they did not do quite as well as the NFP had done in 1996. In Japan as a whole, the DPJ in 2000 won 27.6 per cent of the vote and 26.7 per cent of the seats. In 1996 the NFP had won 28.0 per cent of the vote and 32.0 per cent of the seats. The DPJ received 25.2 per cent of the PR vote in 2000 but the NFP had received 28.0 per cent in 1996. More importantly, a DPJ 
candidate replaced an NFP candidate as the sole major party challenger to the LDP in 43 districts. The DPJ gained more votes than the NFP had in 1996 in only 16 of these districts and lost an average of 7,919 votes per district. The only sense in which Japan is closer to a two-party system after the 2000 election than it was after the 1996 election is that the DPJ now lays sole claim to being the major opposition party. In 1996 there were two challengers, the NFP and the DPJ. Because the NFP disbanded, there is now only one.

The only opposition party to lose seats was the JCP. It won no SMD seats. Like Koumei, its problem is single-member districts. Though the party refuses to change either its name or its policy platform, it has both gained popularity and reduced the number of voters who say they would not vote for it under any circumstances. Nevertheless, the JCP is clearly on the far left of the political spectrum and cannot expect to win many, if any, SMDs. It will have to depend upon the PR tier. Though that strategy has clear limits, the performance of the Liberals and the SDP may give the JCP some hope.

Unexpectedly, both the Liberals and the Social Democrats gained seats. Each won only four SMDs but the Liberals won 18 PR seats and the SDP won 15. The Liberals have nation-wide support, presumably fans of Ozawa, but fared badly in the SMDs. Liberal candidates lost, on the average, 17,744 votes, the worst performance of any party. An NFP candidate who chose to run for the Liberals lost votes but one who chose to run for the DPJ won 11,301 votes. PR has kept these two minor parties alive for the present but one wonders how long they will be able to last.

Finally, the Diet now contains 15 conservative independents. The LDP has vowed not to follow past practice and allow them back into the party, but it may prove difficult to keep that vow because many of the independents are formal members of LDP factions. Many are members of the Katou faction and Katou was the leading candidate for the next LDP party president and is very probably a future prime minister.

\section{Notes}

1 It is the norm in Japanese politics to allow all parties to save face by changing the party name after any merger. The decision to retain the Democratic label violated this norm but made it much easier for the party to retain its share of public funding. The provision for public funding of political parties has made it more difficult for parties to break up or to merge.

2 Katou Mutsuki of Okayama 4th district did not himself return to the LDP. He retired and his son entered the LDP. 



\section{Part II}

\section{Four prefectural case studies}



Elections are fought primarily over national issues and are properly analyzed as national events. Much of the action, however, happens at the district level. As the American Congressman Tip O'Neill once said, in a quip that Japanese political commentators love to repeat, "all politics is local". In the 1996 general election the district level action was particularly complex and particularly important because the new electoral system had forced the redrawing of district lines. New district lines and the reorganization of the party system forced old enemies to cooperate and pitted former friends against each other. In 1996 there were complex stories for each of the new 300 single-member districts and the 2000 election was not much simpler.

In Part II, we present case studies of the 1996 and 2000 elections in four prefectures that cover a wide range of political experiences. Table II-1 presents the basic data. The first column gives the percentage of the 1993 vote captured by the two main parties of the old 1955 party system. We cover two prefectures, Kagoshima and Ibaraki, where the 1955 system still dominated politics in the 1993 election and one, Hyogo, where the old party system had broken down. As shown in the second column, we include one prefecture, Nagano, where the new parties gained over 40 per cent of the vote in 1993 and one, Ibaraki, where they gained less than 5 per cent. Turning to the 1996 election, we find two prefectures, Nagano and Kagoshima, where the DPJ gained less than 10 per cent of the vote and one, Nagano, where the NFP captured nearly half the vote. Finally, we have one prefecture, Kagoshima, where the LDP continued to dominate and two, Hyogo and Nagano, in which it captured less than 30 per cent of the vote. Perhaps most satisfying is the fact that on all five indicators, our prefectures are spread out quite evenly across the whole spectrum. We can have some confidence that the prefectures included in this section cover a broad range of political experiences. 
Table II. 1 The prefectures included

\begin{tabular}{|c|c|c|c|c|c|c|c|c|c|c|c|}
\hline \multicolumn{5}{|c|}{ The 1993 election } & \multicolumn{7}{|c|}{ The 1996 election } \\
\hline Rank & $\begin{array}{ll}k & L D P \\
& +J S P \\
\end{array}$ & $\%$ & New & $\%$ & Rank & $k D J P$ & $\%$ & $N F P$ & $\%$ & $L D P$ & $\%$ \\
\hline 11 & Ehime & 89.4 & Kumamoto & 45.9 & 1 & Hokkaido & 31.8 & Iwate & 51.2 & Toyama & 68.3 \\
\hline 27 & Toyama & 84.8 & Nagano & 40.3 & 2 & Tokyo & 23.4 & Nagano & 48.1 & Okayama & 63.6 \\
\hline 3 & Akita & 82.3 & Wakayama & 36.6 & 31 & Kanagawa & 22.4 & Kumamoto & 44.9 & Yamanashi & 57.8 \\
\hline 41 & Kagawa & 82.0 & Tochigi & 35.8 & 4 & Chiba & 19.8 & Aomori & 43.7 & Yamaguchi & 57.5 \\
\hline 51 & Kagoshima & 79.3 & Kanagawa & 34.2 & 5 & Yamanashi & 19.6 & Mie & 41.7 & Kagoshima & 57.3 \\
\hline 61 & Ibaraki & 75.4 & Oita & 33.6 & 6 & Tokushima & 19.3 & Wakayama & 40.9 & Ehime & 57.0 \\
\hline 71 & Fukui & 75.0 & Chiba & 33.4 & 7 & Saitama & 18.2 & Aichi & 40.6 & Shimane & 54.9 \\
\hline 8 & Aomori & 74.1 & Shiga & 32.9 & 8 & Miyagi & 17.4 & Nagasaki & 38.7 & Saga & 52.8 \\
\hline 9 & Yamagata & 73.1 & Iwate & 29.6 & 9 & Gunma & 17.2 & Miyazaki & 38.3 & Kagawa & 52.3 \\
\hline 10 & Gunma & 71.7 & Hyogo & 28.9 & 10 & Tochigi & 16.8 & Miyagi & 37.5 & Akita & 51.3 \\
\hline 111 & Miyazaki & 70.4 & Saga & 26.9 & 11 & Fukui & 16.6 & Nara & 37.2 & Gunma & 50.7 \\
\hline 121 & Ishikawa & 69.1 & Saitama & 26.5 & 12 & Aichi & 16.1 & Osaka & 37.0 & Tokushima & 49.8 \\
\hline 13 & Tokushima & 67.5 & Nagasaki & 25.3 & 13 & Shizuoka & 15.6 & Fukui & 33.4 & Miyazaki & 49.8 \\
\hline 14 & Gifu & 64.3 & Ishikawa & 24.9 & 14 & Kyoto & 15.2 & Gifu & 32.6 & Yamagata & 49.7 \\
\hline 15 & Hiroshima & 63.4 & Tokyo & 24.2 & 15 & Yamaguchi & 15.2 & Fukuoka & 31.7 & Gifu & 49.0 \\
\hline 16 & Fukushima & 62.8 & Fukuoka & 23.7 & 16 & Ibaraki & 15.1 & Hyogo & 31.6 & Ibaraki & 48.3 \\
\hline 171 & Nagasaki & 62.6 & Niigata & 23.6 & 17 & Ishikawa & 14.7 & Saga & 31.2 & Hiroshima & 47.7 \\
\hline 18 & Hokkaido & 61.8 & Okinawa & 23.5 & 18 & Hyogo & 14.5 & Kanagawa & 29.4 & Nagasaki & 46.8 \\
\hline 19 & Yamanashi & 61.2 & Miyagi & 21.6 & 19 & Nagasaki & 14.5 & Akita & 28.8 & Fukushima & 43.7 \\
\hline 20 & Okayama & 61.0 & Fukushima & 20.7 & 20 & Nara & 14.3 & Ishikawa & 28.7 & Aomori & 43.6 \\
\hline 211 & Kochi & 60.6 & Nara & 20.0 & 21 & Osaka & 14.2 & Saitama & 27.3 & Tochigi & 43.1 \\
\hline 22 & Saga & 59.2 & Shizuoka & 19.9 & 22 & Fukushima & 14.1 & Ibaraki & 26.0 & Niigata & 43.0 \\
\hline 231 & Miyagi & 56.1 & Aomori & 19.4 & 23 & Kagawa & 14.0 & Kyoto & 25.7 & Chiba & 41.1 \\
\hline 241 & Niigata & 55.8 & Kyoto & 18.4 & 24 & Toyama & 13.9 & Kagawa & 25.6 & Shizuoka & 40.3 \\
\hline 25 & Yamaguchi & 54.8 & Gifu & 17.6 & 25 & Fukuoka & 13.9 & Hiroshim & 25.4 & Kochi & 40.2 \\
\hline 26 & Shimane & 53.9 & Hiroshima & 16.2 & 26 & Gifu & 13.5 & Gunma & 25.1 & Nara & 39.7 \\
\hline 271 & Mie & 53.8 & Hokkaido & 14.5 & 27 & Shimane & 13.4 & Chiba & 24.9 & Mie & 39.3 \\
\hline 28 & Aichi & 52.4 & Gunma & 14.5 & 28 & Niigata & 13.2 & Tokyo & 24.9 & Fukuoka & 38.5 \\
\hline 29 & Tottori & 52.4 & Yamanashi & 14.3 & 29 & Hiroshima & 12.5 & Fukushima & 24.8 & Wakayama & 37.4 \\
\hline 301 & Iwate & 51.7 & Kagawa & 14.1 & 30 & Mie & 11.7 & Oita & 24.4 & Fukui & 36.8 \\
\hline 31 & Oita & 50.7 & $\mathrm{Mie}$ & 13.9 & 31 & Okayama & 11.1 & Ehime & 23.9 & Kyoto & 36.7 \\
\hline 32 & Tochigi & 50.6 & Osaka & 12.6 & 32 & Ehime & 10.6 & Okinawa & 23.5 & Hokkaido & 35.5 \\
\hline 33 & Shizuoka & 50.6 & Toyama & 12.5 & 33 & Tottori & 10.4 & Tokushima & 23.3 & Aichi & 34.9 \\
\hline 341 & Nagano & 48.7 & Tokushima & 12.3 & 34 & Shiga & 10.2 & Tottori & 21.4 & Oita & 34.8 \\
\hline 35 & Okinawa & 48.6 & Shimane & 12.0 & 35 & Yamagata & 10.1 & Yamaguchi & 19.5 & Miyagi & 34.2 \\
\hline 36 & Chiba & 44.7 & Aichi & 11.5 & 36 & Wakayama & 10.1 & Shizuoka & 18.5 & Ishikawa & 33.9 \\
\hline 371 & Kumamoto & 42.7 & Yamaguchi & 11.3 & 37 & Kochi & 9.9 & Tochigi & 18.4 & Kanagawa & 32.6 \\
\hline 38 & Wakayama & 42.6 & Akita & 10.1 & 38 & Kumamoto & 9.5 & Yamagata & 17.7 & Saitama & 31.8 \\
\hline 39 & Shiga & 41.7 & Kagoshima & 10.0 & 39 & Nagano & 9.1 & Okayama & 17.1 & Kumamoto & 30.6 \\
\hline 40 & Fukuoka & 40.8 & Kochi & 8.0 & 40 & Kagoshima & 8.9 & Shiga & 15.3 & Iwate & 30.3 \\
\hline 411 & Kanagawa & 40.7 & Ehime & 7.3 & 41 & Akita & 8.6 & Yamanashi & 14.3 & Osaka & 30.3 \\
\hline 421 & Hyogo & 40.7 & Ibaraki & 4.4 & 42 & Saga & 8.4 & Hokkaido & 14.2 & Tokyo & 30.2 \\
\hline 43 & Tokyo & 38.9 & Yamagata & 0.0 & 43 & Aomori & 7.7 & Niigata & 10.6 & Shiga & 29.9 \\
\hline 441 & Nara & 38.1 & Fukui & 0.0 & 44 & Miyazaki & 7.7 & Toyama & 8.9 & Hyogo & 29.7 \\
\hline 45 & Kyoto & 37.9 & Tottori & 0.0 & 45 & Oita & 7.4 & Kochi & 8.3 & Nagano & 26.1 \\
\hline 46 & Osaka & 37.7 & Okayama & 0.0 & 46 & Okinawa & 6.4 & Shimane & 6.9 & Tottori & 23.1 \\
\hline 47 & Saitama & 36.5 & Miyazaki & 0.0 & 47 & Iwate & 4.6 & Kagoshima & 5.1 & Okinawa & 21.3 \\
\hline
\end{tabular}

Note: This analysis was originally suggested by Rob Weiner. 


\title{
4 Political realignment in Nagano \\ Hata Tsutomu and the new opposition challenge the LDP
}

\author{
Ethan Scheiner \\ with research assistance from \\ Tatsuhiro Yamamoto
}

The most powerful LDP politician in Nagano, Hata Tsutomu, was leader of the faction that left the LDP to become Shinsei, and, as such, he served as prime minister of Japan. Nationally prominent and powerful in Nagano, Hata drew many LDP Nagano politicians into Shinsei and later into the New Frontier Party (NFP). This decimated the LDP in Nagano, but also solved most problems the LDP might have faced in co-ordinating nominations, as it did not have enough candidates for all five single-member districts (SMDs) in 1996. The NFP had exactly five (one per district), and therefore had little to co-ordinate. The most serious co-operation issues in the prefecture were minor, affecting the SDP and Sakigake. Rather than a tale of party co-operation successes and failures, Nagano offers lessons about the importance and limits of personal influence in Japanese politics.

The NFP did tremendously well in Nagano in the 1995 House of Councillors (HC) election. In the 1996 House of Representatives (HR) election, the LDP and NFP competed fiercely. The NFP won three out of the five Nagano SMDs, and came a close second in the other two. In addition, the party dominated the proportional representation (PR) races in all five Nagano SMDs.

After the 1996 election, the NFP unravelled in Nagano just as it did at the national level. Because Hata led the NFP's primary successor, the new Democratic Party of Japan (DPJ), the DPJ picked up some of the slack left by the NFP's decline and did well in the HC races. However, opposition parties hold almost no power in Nagano's prefectural assembly and two out of the three HR SMD candidates who won for the NFP returned to the LDP before the 2000 election. Yet, in the 2000 HR election, the DPJ picked up an additional SMD victory, leaving the party holding two of five SMDs and was again the top PR winner in each Nagano SMD. Indeed, in PR races for all elections between 1995 and 2000, Japan's leading opposition parties found their greatest success in Nagano, while the prefecture delivered some of the LDP's worst defeats.

To some extent, Nagano simply tells a classic story: Japanese politics is personalistic. Hata's influence is so great in Nagano that many came to follow him. In this way, Nagano is far from exceptional. In recent elections, opposition 
success has tended to be greatest in prefectures where the opposition is led by influential defectors from the LDP.

However, Nagano also shows the limits of the simple story: personalism is not a sufficient explanation. Nagano highlights three other important factors. First, ideology does play a role in Japanese politics. As the NFP folded and defectors from the LDP and former Socialists joined together to form the new DPJ, ties to Hata could not overcome conservative candidates' ideological opposition to joining with Socialists. Second, many explain LDP success in terms of Japan's electoral system, and the opposition's success in recent Nagano HC elections gives this argument credibility. The old MMD and current MMM electoral systems in the HR give advantage to candidates who cultivate targeted bases of support. The HC electoral system utilises the entire prefecture as a multimember district and bestows greater advantage on candidates who can develop broader appeals and networks of support. Third, as I shall discuss below, changes in Nagano over the 1990s also indicate the impact of Japan's clientelistic and centralised political system.

\section{The Nagano prefecture}

Nagano is a rural prefecture and the fact that the new system reduced the malapportionment that had favoured the countryside meant that Nagano lost seats. It went from 12 seats in four districts in 1993 to five SMDs and a share of 13 PR seats with four other prefectures in the Hokuriku-Shinetsu bloc in 1996.

Nagano has a long history of successful reformist politicians. In the 1970s, a number of Nagano's leading cities were run by progressive executives. However, the changes in the 1990s came from conservatives, led by Nagano's most powerful politician, Hata Tsutomu. Hata had been a leader within the LDP, and especially within the powerful Takeshita faction. In late 1992, the faction split into two: one led by Obuchi Keizou and the other by Hata and Ozawa Ichirou (Kato 1998; Reed and Scheiner forthcoming). After the LDP failed to pass political reform legislation in 1993, the Hata faction split from the LDP to form the new party Shinsei. The other two Nagano members of the Takeshita faction joined Hata in forming both the new faction in 1992, and Shinsei in 1993, but membership in the Hata faction was not a prerequisite for LDP defection. While Shinsei was forming, Ide Shouichi and Tanaka Shuusei left the LDP to join another new party, Sakigake. Finally, when Kosaka Kenji, an active supporter of political reform from the Watanabe faction, joined Shinsei, Hata's new party which merged with others to become the NFP - new parties had an incumbent candidate from every Nagano MMD. In 1996, Nagano had seven new party candidates running in its five SMDs. Hata had always carried great power in Nagano, but his stature grew further when he became prime minister for a brief period in 1994 .

Partly because of Hata's influence, and that of those who joined him in the new party in Nagano, the NFP did exceptionally well in 1996 PR balloting in the 
prefecture, receiving more PR votes than the LDP in every Nagano SMD. In some districts, such as Nagano $4^{\text {th }}$ and $5^{\text {th }}$ where the LDP won the SMD seats, the difference between the PR ballots cast for the NFP and those cast for the LDP was less than 15,000, but in the others the difference was substantial. In Nagano $3^{\text {rd }}$ (Hata's district), the NFP won nearly 130,000 votes in the PR race, compared to just over 20,000 for the LDP.

Predicting SMD candidacies and victories in 1996 was not difficult. The key to winning a seat was getting the nomination in one's strongest district. In every case, the leading candidates were given nominations in districts containing regions where they had their largest vote bases. Also, parties had few difficult nomination decisions to make. Because of defection to new parties, the LDP had no need to make such decisions. Moreover, merely by examining candidates' vote bases from 1993 it was often easy to predict the 1996 victor. Based on 1993 results, it was crystal clear who was going to win in Nagano $2^{\text {nd }}, 3^{\text {rd }}$ and $4^{\text {th }}$ in 1996. However, with multiple candidates maintaining roughly equal bases from 1993, the $1^{\text {st }}$ and $5^{\text {th }}$ districts appeared to be up for grabs.

In 1996, there was little party co-operation in the prefecture. As Nagano is fairly rural, Souka Gakkai has relatively little influence and Koumei is fairly weak. However, as a part of the NFP, what presence Koumei did have worked on behalf of NFP candidates. Neither the SDP nor Sakigake was able to run a candidate in every district, but before the $1995 \mathrm{HC}$ election an agreement was worked out between the two parties which ensured SDP endorsement and support for Sakigake candidates in Nagano's new $1^{\text {st }}$ and $3^{\text {rd }}$ districts. In exchange Sakigake supported the SDP candidate in the 1995 Upper House election and the one SDP HR candidate in the prefecture (Niigata Nippou, hereafter NN, 20 February 1995).

In 2000, electoral co-operation again played little part in the larger results. Koumei mobilised a number of its supporters behind LDP candidates, but their success appears to be attributable to personal votes cast for them rather than to the support of party-mobilised voters. Nevertheless, it is possible that greater Koumei support in Nagano $4^{\text {th }}$ might have helped the LDP pick up an additional seat that it lost to the DPJ. Electoral co-operation appeared to play no role in the cases of DPJ victory, but the division of union support between the DPJ and SDP candidates in Nagano $2^{\text {nd }}$ may have cost the Democrats a seat.

In both 1996 and 2000, the LDP's SMD candidates all ran as evenly ranked, dual candidates. The NFP, however, in line with its practice throughout the country, ran no dual candidates in Nagano. In 2000 the DPJ made much use of evenly ranked, dual candidacies. As it did throughout the country, the JCP ran a weak candidate in every district. However, of these, the JCP ran only one dual candidate in 1996 and two in 2000, with each JCP dual candidate being given a clear ranking on the PR list. The SDP ran only one candidate (in Nagano $2^{\text {nd }}$ ) in each election, and in both cases ran the nominee as an evenly ranked dual candidate in the PR bloc. 
As a rural area, private-sector business does not dominate the Nagano economy and the strongest unions tend to be public sector. As a result, the Socialists have had only moderate strength in Nagano. With the predominance of the NFP and the emphasis on leftist, public-sector union-supported Socialist candidates, the DPJ had no presence in Nagano in 1996. When the new DPJ was formed in 1998, the party immediately began making efforts to bring together the different parties of which it was composed into unified organisations in each of Japan's 47 prefectures. Because of Hata's influence and the fact that new DPJ members in Nagano came from a limited number of parties, the Nagano DPJ was unified fairly quickly. It was the fourteenth DPJ prefectural organisation to unify and did so within six months of the creation of the new DPJ in April. However, organisational development was slow for the party. In prefectures where the organisation is strong, the party has a complete, differentiated staff. But, as of late 1999, the DPJ organisation in Nagano had only one staff member, a former Democratic Socialist Party member. ${ }^{1}$ While the national parties that came together to form the new DPJ hoped to have a voice in the creation of the new organisation, in reality organisational development was led by DPJ candidates' kouenkai (YS 12 April 1998). In four out of Nagano's five SMDs, the party set up a headquarters with a single staff member devoted to the DPJ candidates in the district. In the fifth, Hata's district, there are a number of branch offices devoted to Hata, other candidates affiliated with him and the DPJ, broken down at the subdistrict level with roughly eight full-time staff.

The DPJ does not co-operate much with other parties in Nagano. The party has typically had the support of the trade union confederation, Rengou. Rengou Nagano established a Prefectural Politics Centre whose purpose is to reflect Rengou policies, unite the various unions behind specific political activities, groups and candidates, and act as a base for DPJ electoral activities (YS 28 November 1999). Rengou's central headquarters has made clear that it intends to respect the political activities of each union, even those particularly bound to Socialist candidates. This policy was in practice in Nagano $2^{\text {nd }}$, where unions were divided between DPJ and SDP candidates in 2000 (Shinano Mainichi Shinbun, hereafter SMS, 10 June 2000). However, despite such divisions, Rengou's leaders point to the necessity of DPJ-Socialist partnership in order to succeed electorally (AS 30 October 1999). As proof of this point, the division of the union vote may even have cost the DPJ victory in Nagano $2^{\text {nd }}$ in 2000.

Yet, while Socialists might be the most obvious choice to co-operate with, Nagano Socialist Party members tend to oppose the DPJ. Although many Socialists switched to the DPJ at the national level, only one from the prefectural assembly, Kurata Tatusuhiko, did so in Nagano. The public-sector unions in Nagano remain staunch supporters of the Socialists and among Socialist prefectural assembly members only Kurata was a private-sector union representative. This has remained a substantial part of the DPJ's problem in Nagano. DPJ party members are primarily union members - in Nagano, primarily private-sector ones - and, with a small private sector, the DPJ has a small 
membership base. This has had an impact on the party's (in)ability to develop support networks.

Now, let us examine the new electoral system's impact in Nagano.

\section{Nagano 1st district}

In the north-east corner of the prefecture, Nagano $1^{\text {st }}$ district is composed of a large part of old Nagano $1^{\text {st }}$. Old Nagano $1^{\text {st }}$ was a partly urban, partly rural three-seat district. The LDP usually won two seats, with a Socialist always taking the third, and by 1990 , voting patterns in Nagano $1^{\text {st }}$ remained largely unchanged and tightly bound to specific candidates. In 1990, long-time Socialist incumbent Shimizu Isamu won a seat, while LDP incumbent Tanaka Shuusei and Kosaka Kenji, son of a long-time-incumbent won as well, with Wakabayashi Masatoshi, who had already twice won a seat for the LDP, finishing just behind. Not long before the 1993 election, Tanaka, a strong supporter of political reform, left the LDP to help form Sakigake. While splintering the LDP, this move gave the conservatives a strong base in Nagano $1^{\text {st }}$, as Tanaka and both LDP candidates, Kosaka and Wakabayashi, easily secured the seats. A victim of the 1993 reform wave that bludgeoned the JSP throughout the country, Shimizu narrowly lost.

\section{The 1996 election}

All three incumbents from 1993 looked competitive in what was to become the new Nagano $1^{\text {st }}$. When totalling their likely support bases that would be carried over to the new district, Tanaka, Wakabayashi, and Kosaka had, respectively, $27.2 \%, 25.6 \%$ and $21.4 \%$ of the total electorate vote (Miyagawa 1994: 222-227). At first, the LDP was left in a difficult position, with its two incumbents from old Nagano $1^{\text {st }}$ coming in with roughly the same level of strength in the new district, but eventually the LDP's decision became easy. Typically, only members of the Takeshita (and, then, Hata) factions defected to Shinsei. A member of the Watanabe faction, Kosaka was the weaker of the two LDP incumbents in Nagano $1^{\text {st }}$. Partly because of concern about whether he would get the LDP nomination in 1996, and, partly because it was unclear whether his nomination would be in the SMD or in PR, he split from the party to join Shinsei in March 1994 (AERA 1994: 32).

With Kosaka's defection, this left three conservative incumbents competing for the SMD in 1996. All of those had been in the LDP, but now, with Tanaka in Sakigake, Wakabayashi in the LDP, and Kosaka in the $\mathrm{NFP}^{2}$ all were in different parties. With three incumbents competing, there was little space for party cooperation and co-ordination of votes. The one exception was the SDP, which faced a difficult choice, whether to run 1993 runner-up Shimizu again in 1996. Ultimately the labour unions that dominated Socialist Party decision-making led the push to run no candidate, and instead endorsed Tanaka of Sakigake, the Socialists' partner in the coalition government (AERA 1994). This was part of a 
larger deal in which the Socialists endorsed Sakigake candidates in the $1^{\text {st }}$ and $3^{\text {rd }}$ districts in exchange for the co-operation they received from Sakigake in the 1995 Upper House election (NN 20 February 1995).

In the end, Kosaka received a massive vote boost in 1996 and won by 40,000 votes. Had the LDP-SDP-Sakigake coalition government managed to unify behind a single candidate and combine the votes cast for Tanaka (Sakigake) and Wakabayashi (LDP), it would have defeated Kosaka by 25,000 votes. But it is difficult to conceive of many candidates who would have simultaneously satisfied leftist Nagano SDP voters and conservative LDP ones.

\section{The 2000 election}

The opposition seemed to have a foothold in the district, but continued realignment turned the situation upside down. When Hata left the NFP to form Taiyoutou in December 1996, Kosaka joined him and when the NFP fell completely apart, Kosaka joined the bulk of the anti-Ozawa, former NFP forces in forming Minseitou in January 1998. However, in April when Minseitou linked up with the 1996-born Democratic Party to form the new DPJ, Kosaka broke with the opposition and ultimately rejoined the LDP. Kosaka's kouenkai made clear its distaste for the former Socialist portion of the DPJ and Kosaka also felt uncomfortable, saying that he did not 'see eye to eye on policy and principles with the former Socialist members' (YS 19 June 1998). The DPJ ran businessman and Rengou-endorsed Kanakubo Yoshikazu as a dual candidate.

Kosaka increased his vote total to win easily. In PR, the DPJ was the top votegetter in the district, with nearly 95,000 votes, while the LDP and Koumei secured around 60,000 and 20,000 votes respectively. In short, if votes had been cast along straight party lines in the SMD ballot (i.e., if voters had supported a candidate of the party they had supported in PR) and if all Koumei supporters had given him their votes, Kosaka would have lost to any DPJ candidate. Given these numbers and the fact that Kosaka has shown no difficulty in winning, no matter what party banner he runs under, it is clear that his strength is primarily attributable to his personal popularity in the district.

\section{Nagano $2^{\text {nd }}$ District}

New Nagano $2^{\text {nd }}$ is also partly urban and partly rural, is centred on Matsumoto City and is made up partly by a portion of the old Nagano $1^{\text {st }}$ and mostly by the northern half of the old Nagano $4^{\text {th }}$. A three-seat district, old Nagano $4^{\text {th }}$ was much less stable and far more competitive than old Nagano $1^{\text {st }}$. The opposition frequently held two seats, but beginning in 1983 the LDP took control of a second and the DSP and JSP fought over the third. Long-time DSP incumbent Ozawa Teiko held a seat in nearly every election beginning in 1972, but lost to Socialist Kitazawa Seiko in 1990. In 1990, the LDP's long-time incumbent Karasawa Shunjiro and second-time winner Murai Jin took the other two seats. Like all 
other Takeshita faction members in Nagano, Murai joined the Hata faction and in 1993 split from the LDP and joined Shinsei. Also like most Shinsei members in 1993, his vote total went up dramatically; in his case, nearly doubling. However, little else changed as Kitazawa and Karasawa were also re-elected.

\section{The 1996 election}

In 1996, Murai was the NFP candidate, with a base - from the 1993 election results - of 26.29 per cent of the eligible electorate, that was far superior to the base of Karasawa (LDP) and Kitazawa (Shamin). One of his party's strongest candidates, Kitazawa - along with a Sakigake endorsement - ran for the SDP. As the only LDP incumbent in Nagano $2^{\text {nd }}$, Karasawa was slated to run for the party in 1996, but retired for health reasons (AS 13 June 1996) and Mochizuki Yuunai (a first-term local politician) ran instead. The fact that the LDP was running only a first-term local politician who had not won his seat by a large margin suggests that the party did not seriously think it could challenge Murai.

Murai's vote was more than double Mochizuki's. Interestingly, Kitazawa was also a winner. As a dual candidate, he shared the top rank on the SDP's Hokuriku-Shinetsu PR list. Despite garnering a vote total equal to only 22.8 per cent of Murai's vote, he defeated his intra-party competitor, who gained only 16.35 per cent of the winner's share in Niigata $5^{\text {th }}$.

\section{The 2000 election}

However, the NFP's December 1997 intra-party battles led Murai to leave the party to become an independent and by the end of January, at the urging of his kouenkai, he returned to the LDP (YS 14 May 2000). The election divided Nagano's unions, as the DPJ and SDP each nominated a dual candidate in Nagano $2^{\text {nd }}$ in the persons of Shimojou Mitsu and Yamaguchi Wakako, respectively. Having determined a policy of supporting DPJ candidates, Rengou endorsed only Shimojou, but a number of its unions supported Yamaguchi and expressed outrage at the Shimojou-only endorsement (SMS 10 June 2000). Shimojou generated great support in Matsumoto City, running roughly even with Murai, largely as a result of the support of independents and even some LDP voters (SMS 26 June 2000). However, even though Murai's vote total declined by nearly 30,000 , the LDP candidate beat Shimojou by 95,046 to 81,710 . As happened with Kosaka and in Nagano $1^{\text {st }}$, Murai's victory was clearly a testament to his personal popularity, as the combined Nagano $2^{\text {nd }}$ LDP-Koumei vote totalled nearly 80,000 , a few thousand short of the DPJ's total. The division of the union vote may also have cost Shimojou victory. Transferring only about one-quarter of Yamaguchi's (SDP) vote to Shimojou would have allowed the latter to defeat Murai. 


\section{Nagano $3^{\text {rd }}$ District}

New Nagano $3^{\text {rd }}$ is nearly identical to the old Nagano $2^{\text {nd }}$, a heavily rural district in the middle of the eastern part of the prefecture. Old Nagano $2^{\text {nd }}$ contained three seats, two dominated for decades by the names Hata and Ide. Hata Tsutomu was first elected in 1969, and his father Hata Bushirou had held the seat since 1952. Ide Ichitarou held a seat in the district from 1947 until 1986 when he retired and was replaced by his son Ide Shouichi. The third seat was held by various Socialists. Hata of course helped to lead the Takeshita faction and Shinsei splits. Already very popular, his vote doubled in 1993. A big supporter of political reform, Ide also split from the LDP before the election and won for Sakigake in 1993. Horigomi Ikuo, the Socialist incumbent from 1990, took the third seat in 1993.

\section{The 1996 election}

Based on his 1993 vote totals, it appeared that Hata had the support of nearly 40 per cent of the likely total electorate in the new Nagano $3^{\mathrm{rd}}$, but there were questions about whether Hata would run in the SMD, or simply head the NFP's list in the regional PR bloc (NN 17 October 1995). The NFP opposed the dual candidacy rule in principle, and, with rare exceptions, avoided running any candidates in both the SMD and PR sections. The question, therefore, was what type of candidate Hata should be: an SMD candidate who was sure to win his district seat, or a candidate at the top of the PR list who could attract voters to the party. Ultimately, the NFP tended to run most of its star candidates in their SMDs, and Hata was no exception.

Hata was deemed so unbeatable that the LDP did not even run a candidate. Instead in January 1996 - nearly nine months before the election - it joined the SDP in endorsing Sakigake candidate Ide. Meanwhile, Horigomi had close ties to Hata, and negotiations had been conducted to bring Horigomi into the NFP. Having been promised a high position on the party's PR list, he joined the NFP in October 1995 (YS 3 January 1996). In the end, only Hata, Ide and the Communist Matsuzawa Mizue ran in Nagano $3^{\text {rd }}$ in 1996. Hata won by 90,000 votes. Horigomi, listed second on the NFP PR list, also took a seat.

\section{The 2000 election}

In December 1996, Hata (with Horigomi following) led a group of politicians unhappy with Ozawa out of the NFP to form the small Taiyoutou. Both Hata and Horigomi linked up with other anti-Ozawa, former NFP members to form Minsei when the NFP split and both played a role in the formation of the new DPJ in April 1998. Hata was at the centre of the new DPJ, as its leading member after Kan Naoto and Hatoyama Yukio.

Unlike 1996, when it ran no candidate, in 2000 the LDP ran former Ministry of Home Affairs bureaucrat, Iwasaki Tadao. While given no chance of beating 
Hata, running a candidate was seen as important in attracting attention to the party and increasing its PR vote. Iwasaki was persuaded to run in Nagano $3^{\text {rd }}$ by being promised the opportunity to run as a dual candidate, with a good position on the LDP PR list. Hata crushed Iwasaki by nearly 100,000 votes; Iwasaki took the final LDP PR seat in Hokuriku-Shinetsu; and Horigomi won from the top position on the DPJ PR list.

\section{Nagano $4^{\text {th }}$ and $5^{\text {th }}$ Districts}

New Nagano $4^{\text {th }}$ spans the whole of the prefecture from east to west across its centre and two-thirds of it is formed from the old $3^{\text {rd }}$ district. New Nagano $5^{\text {th }}$ is wholly made up of the southern portion of the old $3^{\text {rd }}$ district and candidates from the old $3^{\text {rd }}$ district competed in both new Nagano $4^{\text {th }}$ and $5^{\text {th }}$. Old Nagano $3^{\text {rd }}$ had traditionally been the opposition's area of greatest strength in Nagano. A four-seat district until 1993, the opposition typically won two. Despite opposition, the conservatives experienced intense intra-party competition, in some years running as many as five candidates - three officially nominated by the LDP and two conservative independents. During the 1980s, this list included Miyashita Souhei, Nakajima Mamoru and Ogawa Hajime (following his father Heiji), all of whom played a significant role over the next decade, sometimes with all three winning.

Old Nagano $3^{\text {rd }}$ lost a seat before the 1993 election. Nakajima, a Takeshita-Hata faction member, joined Shinsei and won 50 per cent more votes. The district's loss of a seat and the new party boom hurt the opposition and all three conservatives - Miyashita, Nakajima and Ogawa - won. With old Nagano $3^{\text {rd }}$ turning into both new Nagano $4^{\text {th }}$ and $5^{\text {th }}$ districts, the key issue was how to divide the leading candidates from old Nagano $3^{\text {rd }}$, as Shinsei's Nakajima, and the LDP's Ogawa and Miyashita all were incumbents and all had very strong vote bases.

\section{New Nagano $4^{\text {th }}$ District}

\section{The 1996 election}

In the new Nagano $4^{\text {th }}$, Ogawa Hajime was the clear front runner and the LDP SMD candidate. The JCP ran former seat-holder Kijima Hideo as a dual candidate, and placed him at the top of its Hokuriku-Shinetsu list. The NFP ran Gotou Shigeyuki, a 39-year-old former Ministry of Finance bureaucrat. In addition to his strong bureaucratic background, Gotou had a strong presence in the district through his father-in-law's successful company, 'Chinon' (NN 27 March 1995). The SDP neither ran nor endorsed any candidates. Ogawa won, but Gotou finished a mere 7,000 votes and 3 per centage points behind. The JCP's Kijima took the party's only PR seat in the bloc. 


\section{The 2000 election}

Ogawa ran again for the LDP in 2000. It was clear that Gotou intended to run, but with the collapse of the NFP, he had become an independent and, despite the fact that a two-party system was one of his goals, it seemed he might remain outside the party network. However, he grew worried that the DPJ might run someone else, who might cut into his voter base (SMS 21 April 2000). In addition, the possibility of getting into office through PR as a dual candidate gave Gotou greater incentive to join the DPJ. Moreover, the electoral law that came in with MMM places a prohibition on posters advertising individual politicians for a period of six months prior to an election. ${ }^{3}$ Only posters advertising political parties are allowed, but in such posters, parties are permitted to advertise their candidates, as long as the candidate's picture does not take precedence over that of the party (SMS 19 April 2000). With six months remaining until the 2000 election had to be held, unaffiliated candidates in April were forced to remove their posters and, not surprisingly, Gotou joined the DPJ (SMS 17 April 2000).

After his loss in 1996, Gotou regularly attended local events to increase his prominence and strengthen his kouenkai. Largely as a result of his youth, he appealed effectively to younger voters. Ogawa received the support of local LDP politicians and conservative groups, but his ageing organisation appeared sluggish (SMS 26 June 2000). In Nagano's closest race, Gotou defeated Ogawa by just over 5,500 votes.

Greater Koumei support might have lifted Ogawa to victory, but, again, the PR votes won by the LDP and Koumei totalled under 60,000. This figure was less than the DPJ PR vote and also less than the number of votes won by both Gotou and Ogawa. Just as in 1996, Kijima finished well behind, but, at the top of the JCP's PR list, he was again the party's only PR seat winner in the bloc.

\section{New Nagano 5th District}

\section{The 1996 election}

In 1996, Nakajima was the NFP candidate and Miyashita ran for the LDP: they had had roughly equal success in 1993 in the areas that were to become new Nagano $5^{\text {th }}$. The JCP ran non-factor Yamaguchi Norihisa, and Sakigake and the SDP endorsed no one. In the end, Miyashita beat Nakajima by a mere 4 percentage points.

\section{The 2000 election}

The DPJ spent a great deal of energy attempting to recruit Nakajima to run for it in 2000, but he rebuffed the party, explaining that the DPJ remained too underdeveloped to win in the HR (YS 29 October 1999). The party was left with businessman and former LDP Diet member secretary Katou Takashi (SMS 26 May 2000), who campaigned on the issue of whether people's lives had improved 
since the previous election (SMS 13 June 2000). Miyashita swept to victory. However, as elsewhere in the prefecture, the DPJ won the most PR votes in the district, beating the LDP by 10,000 votes. Also, as happened in the case of strong candidates in other districts, Miyashita's 120,000 votes were clearly based on a personal connection with the voters, as he far outstripped the combined 75,000 won by the LDP and Koumei.

\section{Implications}

Party co-operation had little impact in Nagano in the first two elections under the new system. In 1996, electoral co-ordination played little part in the moves made by the primary parties. In 2000, while Koumei and the LDP may have had some success in co-operating, in general candidates had little need to tap into such extra support to succeed. Personal ties were far more important. Hata's leadership played a critical role in causing LDP politicians to split from the ruling party and join new ones. Moreover, voters were willing to continue to support specific politicians, no matter what party they joined. As noted in a poll of Nagano voters conducted shortly before the election, the most common reason for supporting any SMD candidate in 2000 was his character or personality (SMS 20 June 2000).

However, personalism is only part of the story. To begin with, ideology also played a critical role. A past history of antagonism no doubt played a substantial role in the Kosaka kouenkai's refusal to link up with Socialists and enter the new DPJ. Yet, as Kosaka himself explained, a very large part of his unwillingness to join the DPJ was his simple disagreement with the former Socialists over political principles.

In addition, the events in Nagano in recent years highlight the impact of the electoral system and of clientelism and centralisation on politics in Japan. To explain these, I turn to recent events in the HC and Nagano Prefectural Assembly.

\section{The House of Councillors election}

Traditionally, the LDP did very well in HC races. In 1986, the LDP and JSP split the two prefectural seats, but the LDP was clearly the strongest party in PR with nearly 40 per cent of the vote, and the JSP was well behind at 20 per cent; both figures were approximately equal to their national averages. The 1989 'Doi boom' election briefly altered things, as the parties again split the two district seats, but the LDP received only 25 per cent of the Nagano prefectural PR vote, well behind the JSP's 40 per cent. Yet, in 1992 things returned to normal: a split of the district seats, but the LDP won 35 per cent of the PR vote to 24 per cent for the JSP - again close to the national averages for both parties.

In 1995, the LDP was devastated in Nagano, winning neither district seat, as former Vice-Governor Koyama Mineo (NFP) and Socialist incumbent Murasawa Maki took both. Murasawa beat LDP incumbent Shimojou by only half a per centage point, but the LDP was left with no HC seat in Nagano. Nagano was the 
LDP's weakest prefecture, as the party won only 17 per cent of PR ballots, just ahead of the Socialists' 16 per cent. In contrast, Nagano was the NFP's strongest prefecture in PR, as it won over 45 per cent of the vote. Koyama's connection to Hata was unmistakable as he moved with him to Taiyou and later to the new DPJ. Similarly, Kitazawa Toshimi, who had won HC district office for the LDP in 1992, had over time moved with Hata to Shinsei, to the NFP, to Taiyou, and to the DPJ.

In 1998, Kitazawa (DPJ) got the highest number of votes in Nagano. The LDP made sure of getting the second seat by running Wakabayashi Masatoshi, former winner in old HR $1^{\text {st }}$ and the LDP loser in the new Nagano $1^{\text {st }}$ in 1996. In PR in Nagano, the DPJ outpolled the LDP by 28.5 per cent to 18 .

\section{The 1999 by-election}

This left the DPJ with two of the four HC seats in Nagano, with the SDP and the LDP holding one each. However, when Murasawa (SDP) died in September 1999, a by-election was called for 17 October. Not long before the election, the JiJiKou coalition government had been formed, and Hatoyama Yukio had been elected to replace Kan Naoto as leader of the DPJ. As the first major election after these events, it attracted national attention and was seen by many as a way to gauge support for both the coalition and the new DPJ.

Many LDP leaders felt that DPJ success in 1998 had less to do with the new party and more to do with the LDP dropping the ball (AS 14 September 1999). The party also saw the by-election as an opportunity to restructure its prefectural organisation, which collapsed with Hata's departure. It nominated Fukasawa Kenichirou, a former four-term member of the prefectural assembly, the party expended great energy to win back the seat, and during the campaign period the LDP transferred its general affairs office staff to its election bureau (YS 23 September 1999). National party leaders came to the prefecture to campaign on Fukasawa's behalf. In addition, leading LDP HC PR seat holders from Nagano (AS 29 September 1999), the major political operatives for the five LDP Diet incumbents from Nagano, the kouenkai of 38 (out of a total of 62) members of the prefectural assembly and many of the leading industrial organisations in the prefecture all actively campaigned for Fukasawa (SNS 18 October 1999). Perhaps most strikingly, Koumei endorsed Fukasawa, quickly establishing the Nagano race as a battle between JiJiKou and the opposition (AS 29 September 1999).

In contrast, the DPJ had great difficulty in organising. The party put great effort into trying to convince Nakajima Mamoru, who had lost as an NFP candidate in Nagano $5^{\text {th }}$ in 1996, to run as a Democrat, but were rebuffed (e.g., SMS 14 September 1999). There was concern that the DPJ might run no candidate at all, until, just three weeks before the election, Hata Yuichirou, Hata Tsutomu's secretary and eldest son, declared his candidacy. Within two weeks, he received a major endorsement from the agricultural labour unions (SMS 
8 October 1999) and was the only candidate endorsed by Rengou (SMS 18 October 1999).

The SDP and the JCP nominated, respectively, Nunome Yukio and Yamaguchi Norihisa, each of whom put substantial effort into attacking JiJiKou (YS 4 October 1999). However, neither candidate received the type of support that would have been necessary to offer a chance of victory. In particular, while no union was obliged to support any specific candidate, Rengou Nagano did not support Nunome. Indeed, while the DPJ was still deciding whom to nominate, Rengou did not offer Nunome any support, but rather said that it would have to wait for the DPJ nomination (AS 16 September 1999), and ultimately passed over Nunome to support Hata.

A key to the election was the extent to which JiJiKou could succeed in its electoral co-operation. The LDP was very much depending on Koumei to deliver votes for Fukasawa (YS 14 October 1999). However, the DPJ and its candidates had a substantial history of co-operating with Koumei. In his successful HC bid in 1995, Koumei had supported Koyama, who was then an NFP candidate but is today a prominent DPJ leader in Nagano. In 1998, Koumei supported DPJ candidate Kitazawa in his HC victory. And, in 1999, the DPJ endorsed two Koumei candidates in the prefectural assembly race (AS 30 September 1999). In the end, in order to honour the agreement it had with the LDP at the national level, the central Koumei headquarters decided to endorse Fukasawa, but the Gakkai gave its members a 'free vote' in the election (AS 9 October 1999), equivalent to allowing Koumei members to vote as they chose.

Finally, while originally seen as a major part of Fukasawa's support, Kenseikai, the leading Nagano prefectural assembly kaiha (parliamentary caucus or working group within the assembly), ultimately was less helpful than the LDP had hoped. Kenseikai endorsed Fukasawa in the first half of September (AS 13 September 1999), but endorsed Hata Yuichirou as well when he entered the race (AS 30 September 1999).

In the end, Hata easily defeated Fukasawa by 358,949 votes to 244,679 . Nunome and Yamaguchi gained many anti-JiJiKou votes, but could not attract enough independents to win.

Media reports following the election attributed much of Hata's success to frequent Nagano campaign trips by Hatoyama and other DPJ party leaders who sought to begin a national trend through a cry of 'No JiJiKou from Nagano'. Moreover, much was made of the difficulty the 61-year-old Fukasawa had in presenting a fresh image (YS 17 October 1999).

With relatively few voters strongly affiliated with the DPJ, Hata's success was clearly not based on partisan support alone. Much of his support came from independents and even from a substantial portion of LDP voters (SMS 18 October 1999). Geographically, it came from all over the prefecture. Clearly he was able to take advantage of his father's great popularity - and, probably more important, his father's network of support - as he crushed the competition in the area composing the HR's Nagano $3^{\text {rd }}$ district where the senior Hata reigns. 
Fukasawa's loss suggested that LDP-Koumei co-operation would often be difficult to achieve in the future. Voter turnout was low at 49.59 per cent, as compared to the 65.7 per cent rate recorded in Nagano in 1998. Low voter turnout is typically an advantage for parties with highly organised voter bases. Had Koumei delivered more fully for its coalition partner, this would have provided a substantial boost for Fukasawa. Indeed, some calculations suggested that a candidate with the full support of LDP and Koumei ought to defeat a DPJ candidate, but the 100,000 vote loss to Hata left many LDP members feeling unable to rely on Koumei (MS 25 October 1999, Nagano edition). Indeed, even leaders at Koumei central headquarters admitted that the by-election demonstrated a failure to co-operate well with the LDP (YS 19 October 1999).

\section{Implications}

There was much talk in Japan about the meaning of the 1999 by-election, and in particular what it suggested about the general popularity of the JiJiKou coalition and the new Hatoyama DPJ. However, in reality it was a local election, and one held in a prefecture in which Hata Tsutomu is king. Similar to the victories of many of the winners in Nagano's HR elections, the HC success of the NFP and DPJ was in part due to the personal popularity of their candidates: Koyama and Kitasawa had personal popularity that they could bring with them irrespective of party. The junior Hata, of course, had limited electoral experience yet dominated the field because of family name and connections.

Yet, the $\mathrm{HC}$ results also hint at the role of the electoral system in shaping the personal vote and party success. In Japan, opposition parties have been able to ride periodic waves of popularity in the PR and prefecture-wide races, but have found far less success in small district elections. The JSP regularly won half the HC seats in Nagano prefecture-wide balloting, but was less successful in the HR. Successful candidates in small districts - especially rural ones such as Nagano's - derive much of their support from their ability to provide their constituents with targeted, material goods such as pork barrel. Much of the LDP's success under the MMD system was due to voters' impression that LDP candidates were personally responsible for the delivery of such goods to the district. However, given that resources are limited, it is far more difficult to target pork effectively in districts covering larger areas, and therefore it is harder for candidates to attract a large proportion of voters through clientelistic appeals. As a result, PR and prefecture-wide races often witness campaigns with an appeal to broader issues, and parties and candidates with weaker links to Japanese governmental pork can compete more effectively.

To offer a greater sense of the impact of personalism and clientelism on party behavior, I next discuss the recent realignment of forces within Nagano's prefectural assembly. 


\section{The Prefectural Assembly elections}

With only minor exceptions, party defection from the LDP in prefectural assemblies throughout Japan has followed a straightforward pattern. Typically no LDP prefectural assembly members defected from the party to join the new Shinsei in 1993-1994 unless they were closely affiliated with a Diet member at the national level who had also defected to join Shinsei (Scheiner 2001). This left most assemblies with a very large cohort of LDP members and smaller numbers of Shinsei and then later of NFP members.

Nagano's pattern was somewhat different. As noted earlier, leading up to the July 1993 election, three LDP Diet members defected from the party to form Shinsei. On 1 December 1993, after a vote approved by all 39 members of the LDP prefectural assembly group, the group abandoned the LDP title and renamed itself Jiyuu Kenseikai. In May 1994, there were two significant party defections. First, a group dissatisfied with the administration of the Jiyuu Kenseikai formed its own kaiha entitled KenMin Club. Second, with the collapse of the Hosokawa government and the rise of Hata to the national premiership, it became uncomfortable for those closely affiliated with Hata and other Shinsei members to remain in the parliamentary group with those affiliated with the LDP, and eight Jiyun Kenseikai members defected from the group to form the Shinsei affiliate Shin Kenseikai. In September, four veteran members of KenMin Club joined with the existing Shin Kenseikai members to form a group of 12.

Up to this point, prefectural assembly events in Nagano had been similar to those in other prefectures where Diet members had split from the LDP. However, when the Hata government ended its short existence, things changed. After the prefectural assembly elections in April of 1995, Jiyuu Kenseikai and Shin Kenseikai dissolved their respective kaiha and inaugurated Shinseikai. Thus, neither the LDP nor the DPJ (nor the NFP before it) existed as a party or kaiha in the Nagano prefectural assembly. Since 1998, both Hata and Nagano LDP head Miyashita have pushed for the formation of DPJ and LDP prefectural assembly kaiha, but such requests have largely gone unheeded (YS 3 December 1998). ${ }^{4}$ While many of these assembly members have received LDP nominations and endorsements, most failed to acknowledge any sort of relationship with the LDP in their campaign activities and posters, especially in Hata's bastion in the east (AS 19 March 1999).

In the April 1999 prefectural assembly elections - with a turnout of 66.28 per cent, the lowest ever for a Nagano prefectural assembly election - the conservative kaiha (now called Kenseikai) maintained its overwhelming majority. When combined with official LDP and sympathetic independents, Kenseikai's total of 25 seats gives the conservative bloc a dominant 40 out of the total 62 assembly seats. In contrast, the DPJ has only one prefectural assembly seat.

These events suggest that the combined impact of the personalistic politics and the clientelistic and centralised system in Japan has a substantial effect on local 
party movements. I argue elsewhere (Scheiner 2001) that the clientelistic and centralised structure that underpins Japanese politics gives local politicians little incentive to defect from the LDP. However, the presence of Hata Tsutomu and his strong base of power in Nagano gives politicians an incentive to avoid alienating him by remaining too close to the LDP. The result appears to be a prefectural assembly in which nearly all politicians are loath to cut ties either to the LDP or to Hata, but at the same time are careful not to link up too tightly with either group.

The incentives for local politicians to affiliate with the LDP place opposition parties at a tremendous disadvantage in most prefectures by giving them relatively few local politicians and thereby providing a very small number of potentially strong candidates for national office (Scheiner 2001). The case in Nagano is obviously much more complicated. With politicians tending to affiliate with neither party, this leaves open many questions about candidate recruitment for the LDP and DPJ. However, it still appears that the advantage remains with the LDP even in Nagano. As the case of Nakajima indicates, many potentially strong candidates are rather leery about linking up with the DPJ until it develops a clearer show of strength.

\section{Conclusion}

What do we learn from recent elections in Nagano? First, party co-operation has not been at the core of party success there. While insufficient Koumei support may have cost the LDP one seat, and divided union support may have cost the DPJ one, on the whole it is unlikely that greater co-operation would have altered the results substantially. More important, individual candidates played a huge role in shaping politics in the prefecture. This was particularly clear in the ways in which both voters and politicians followed Hata, in the great support maintained by Kosaka and Murai - irrespective of which party's nomination they accepted and in the fact that the outcomes under the new system in 1996 were totally predictable on the basis of the votes a candidate had won in the region in 1993.

As noted earlier, Nagano was very much like other prefectures in this respect. The NFP did particularly well in prefectures where there were conservative leaders who opposed the LDP. This was clearly the case in Iwate (Ozawa), Kumamoto (Prime Minister Hosokawa), Aomori (Governor Kimura) and Wakayama (Nakanishi Keisuke). In this way, NFP success was based less on party image and more on an alliance of conservative kouenkai. To a large degree this continues today, as the DPJ in Nagano is founded far more on the Hata kouenkai than it is on actual party-based organisation.

At the same time, while playing a very important role, personalism does not explain everything. Ideology, for example, was significant in shaping politicians' (lack of) willingness to follow Hata into the DPJ. The Nagano story also indicates the impact of the electoral system on electoral outcomes. Since the LDP's split in 1993, the NFP and DPJ have received markedly more support and success than 
the LDP at the PR and prefecture-wide level. This has been reflected in $\mathrm{HC}$ and HR PR results. However, the LDP continues to be favoured by the small districting system that dominates the Lower House balloting.

Also, as suggested above, most likely much of the LDP's success in SMDs is due to the substantial role played by clientelism in such district elections. Nevertheless, an anti-clientelist backlash may be gaining ground in the prefecture. In a pre-election survey of all party candidates, the DPJ pressed the need to rethink the use of public works. In contrast, candidates of the ruling parties indicated a need to fix the economy before moving on to such changes (SMS 2 June 2000). LDP leaders (whether in the LDP or merely loosely affiliated with it) have pushed Nagano voters to avoid non-LDP votes on the grounds that such moves would lead to a decline in the amount of public works delivered to the prefecture. Leading up to the 1999 HC by-election, LDP leader Kamei Shizuka suggested that not voting the LDP candidate into office would lead to a reduction in the amount of public works going to the prefecture (AS 19 October 1999). Similarly, when a popular Nagano novelist challenged a conservative politician in the 2000 gubernatorial election, Yoshida Hiromi, speaker of the prefectural assembly warned, 'The governor is required to have ... connections with the central government. If we give the job to a [non-politician], we will face severe consequences' (YS 19 September 2000). Despite these not-very-veiled threats, in each case Nagano voters elected the anti-LDP candidate. While such repudiations are most likely simply part and parcel of the prefectural districting system as a whole for each of these two elections, future elections will show the extent to which they reflect a genuine effort on the part of Nagano voters to roll back the clientelist system.

\section{Acknowledgements}

Thanks to Steve Reed for helpful comments on two drafts of this chapter and for sharing his materials on Nagano. Especially great thanks to Ozawa Akira and Kojima Aya for their assistance in the Nagano interviews. Finally, the author gratefully acknowledges the financial support provided by The Japan Foundation, the National Security Education Program, and the Sanwa Bank Research Grantees during portions of this research.

\section{Notes}

1 The information on DPJ organization comes from a telephone interview conducted on behalf of the author with an official from the DPJ's Nagano prefectural office in August 1999.

2 Kosaka naturally moved to the NFP when Shinsei merged with other parties to form the large new party in December 1994.

3 In 1996, nine months remained until another election was required to be held, so this law did not have an effect in that year.

4 This information is based on written correspondence with political reporters from Nagano, various issues of the Shinano Mainichi Shinbun, and various years of the Bun'yabetsu Jinmeiroku published by Yomiuri Shinbun. 


\title{
5 A local five-party alliance challenges the LDP in Hyogo
}

\author{
Karen E. Cox
}

Hyogo Prefecture is the second-most populous of the six prefectures making up the Kinki electoral bloc and includes the two major cities of Kobe and Himeji. Under the old MMM system, Hyogo had five districts ranging from two to five seats for a total of 19. After reform, Hyogo was left with 12 SMDs, in addition to a share of the 33 (reduced to 30 in 2000) PR seats in the Kinki bloc. Of the 12 new districts, nine are fragments and three are the more unwieldy combinations of parts of two or more old districts. By 1993 the LDP was weak in the prefecture, winning only four of nineteen seats in that year's general election (Tani 1998: 103-104).

What particularly distinguished Hyogo in the 1996 and 2000 elections was the variance between local and national electoral co-operation agreements. A fiveparty alliance (Rengou-Gotou, hereafter the Alliance) united both government and opposition parties against the LDP and the Communists. It nominated joint candidates who did very well in 1993 and 1996, but in 2000 the coalition faced a greater challenge in the form of discord between local and national alliance preferences that sabotaged much of their co-ordination. The varying success of this coalition highlights the high degree of opposition unity that is necessary to defeat the LDP. Furthermore, the stories of the two elections in Hyogo illustrate the disconnection between party system movements at the national and local levels. Hyogo was ahead of the times in terms of party system realignment and chose a direction of adjustment that was not matched by the eventual nationallevel movements. As a result, the realignment in Hyogo stalled and was reversed to some degree in 2000 .

\section{Overview}

\section{The 1996 election}

Events leading up to the 1993 election resulted in the LDP losing a number of its candidates and seats to the new parties, while a long-standing divide in the socialist camp had split the SDP by 1994. These events combined with local 
resistance to national-level coalition choices to produce a line-up of parties for the 1996 election rather different from that seen elsewhere in Japan.

First, while the LDP had never been particularly strong in Hyogo, it was nearly swept away after the new party boom of 1993. In the old $1^{\text {st }}$ district Ishii Hajime, an LDP representative since 1967, was part of the disgruntled group that left the party in June 1993 to form Shinsei. This left the party with no experienced candidate in the old $1^{\text {st }}$ district, the areas that were to become the new $1^{\text {st }}$ through $3^{\text {rd }}$ districts. In the old $2^{\text {nd }}$ district, the LDP lost affiliated independent candidate Miyamoto Ichizou, who also moved to the Shinsei. Former LDP nominee Konoike Yoshitaka had been elected to the Upper House in 1995 and was not available for the 1996 election. The party had only one other potential representative in the old $2^{\text {nd }}$ district, Hara Kenzaburou, its oldest and longest serving member. The loss of Miyamoto was an especially serious blow as he would have been the strongest of the three candidates after the redistricting. Yet, the most serious loss for the LDP came in the old $3^{\text {rd }}$ where it had previously won two of three seats. Here it lost both of its representatives in 1993 after Inoue Kiichi joined Shinsei and Tokai Kisaburou moved to Sakigake. The 1993 victories of two new conservative candidates running for the Japan New Party, Takami Yuuichi and Koike Yuriko, only further undercut the LDP's base in the region, leaving it poorly positioned for the first race under the new system in 1996.

On the other side of the political spectrum, the SDP was plagued by serious infighting between its left and right wings. In April 1994 nearly 1,000 leftists were removed from the party's register, reducing its membership base by about 20 per cent (YS 30 April 1994). The leader of the banished group, Okazaki Hiromi, had run (and won) as an independent in the $1^{\text {st }}$ district in 1990 after her left-wing views prevented the party from nominating her. In August Okazaki and her supporters proposed the formation of a new party to be tentatively named Gouken or 'Uphold the Constitution' (YS 8 August 1994). This group later changed its name to the New Socialist Party (NSP) and ran several candidates against SDP-supported Alliance nominees in the 1996 elections.

The departure of the extreme leftists did not end the discord within the socialist camp; the decision of the national party to join the LDP and Sakigake in a new coalition at the end of June created new difficulties for the prefectural party. The prefectural party leadership resisted the national decision and officially informed party headquarters of its opposition to the coalition with the LDP, but these protests had little influence. As a result, another group of disaffected socialists followed the left-wingers and announced their plans to leave the party on 10 December, the day on which the New Frontier Party was also due to be inaugurated. This group included Doi Ryuuichi of the $1^{\text {st }}$ district, Nagai Takanobu of the $3^{\text {rd }}$, Gotou Shigeru of the $4^{\text {th }}$, and Yoshioka Kenji of the $5^{\text {th }}$ (YS, 12 December 1994). Initially this group promoted the idea of a new 'democratic liberal' party, 'Liberal Kinki' but, by the time of the 1996 election, the members had gone their separate ways. Doi and Yoshioka joined the new 
Democratic Reform Alliance (Minkairen), Gotou moved to the Democratic Party, and Nagai retired in the midst of the general disarray.

A final force exerting a strong influence on the likely line-up for the 1996 election in Hyogo was Rengou, the Japan Trade Union Confederation. Nationally, Rengou was struggling with internal splits between its pro-SDP and pro-DSP wings that left it unable to provide unified support to a national party. In Hyogo, however, the organisation had been galvanised by the installation of the 1993 non-LDP Hosokawa cabinet and the events that followed into taking the lead in promoting anti-LDP, anti-Communist co-operation (Tani 1998: 107-108). The Five-Party Alliance was formed in this context in September 1994, during the lead-up to the November Amagasaki mayoral election. The initiative behind the movement was a unified desire to defeat the strong LDP-backed incumbent mayor. The group's somewhat surprising success in 1994 and the forceful leadership of Ishii Ryouichi, head of the Hyogo teachers' union, laid the base for future co-operation. ${ }^{1}$ (Interview, ${ }^{2} 28$ March 2001; Sankei Shinbun, 4 May 2000). By 1996 the Alliance consisted of Rengou, the SDP, the DSP, the DRA, the NFP, and Koumei $^{3}$ - all of the major non-communist opposition parties except the fledging DPJ, which, while receiving some support from the group, chose to make its own way in 1996. The participation of the Socialists in the group, it should be noted, was inconsistent with the national party's coalition with the LDP. The prefectural SDP thus acted as a party separate from the national organisation in many ways.

The DPJ's position in the prefecture in 1996 was also complex. The party had hoped to have unified SDP support within the Kinki bloc, but Doi Takako's unwillingness to abandon the SDP even in the PR tier and the decision of the Kyoto SDP to remain independent from the DPJ gave the party a rough start. In Hyogo, initial plans were for the SDP to ally with the DPJ, but the prefectural SDP gave its support to Alliance NFP candidates in all districts but Doi's $7^{\text {th }}$, and the $11^{\text {th }}$, where the Alliance group nominated a Democrat. ${ }^{4}$

The Alliance was able to nominate an official candidate in each of Hyogo's 12 districts in 1996, although with some difficulty. The major complaint was that the NFP railroaded the process by relentlessly promoting its own candidates. Its decision to run candidates of its own against official Alliance nominees in the $7^{\text {th }}$, $9^{\text {th }}$, and $11^{\text {th }}$ districts highlighted the party's determination to become the sole alternative to the LDP. In fact, the NFP only stepped aside for Alliance candidates in those districts where the party lacked an experienced candidate. To the more cynical, the Alliance seemed to be a good way for the local NFP to guarantee for itself both the Gakkai vote and the labour vote without having to compromise on candidate selection. Koumei and the Gakkai also fell short of complete compliance with Alliance decisions. Koumei endorsed the two DRA candidates and all ten NFP candidates in the prefecture, including the two NFP candidates who ran against official Alliance candidates. The Gakkai followed the Koumei lead with two exceptions: it declared free votes in the two districts represented by the labour-oriented DRA candidates. 
In terms of issues, the 1996 election was dominated by promises of increased assistance for victims of the January 1995 Hanshin earthquake and recriminations against the government for its plans to raise the consumption tax and use public funds to bail out the failed juusen housing loan corporations. Issues, however, were less important than the themes of generational change and seat inheritance. All of the LDP's established candidates were aged 70 or older. Two of the LDP's four elders, Koumoto and Matsumoto, felt the pressures for generational change and opted to retire in favour of their sons. These inheritors played up phrases such as 'the new wind of youth' against opposition calls to 'stop hereditary succession'.

In the end, the 1996 contests were largely decided by the size of each candidate's base in his or her new district and the ability of parties to co-ordinate the trading of supporters across district and/or party lines. The NFP was the most effective in this regard, although other Alliance candidates also had reasonable success. The LDP, on the other hand, was much less effective. Its conservative elders won in their established regions in the $11^{\text {th }}$ and $12^{\text {th }}$ districts but proved of little help to the party's other candidates. Many of the other LDP candidates were newcomers and in one district (the $10^{\text {th }}$ ) the party was not even able to field a candidate of its own. Three of its losing candidates were 'resurrected' in the PR tier, but overall the LDP showing was poor. In the SMDs, the NFP took seven seats, and the SDP and DRA one each, leaving the LDP with only three. In the PR tier, the NFP and LDP each won 10 seats, the JCP six, the DPJ five, and the SDPJ two.

\section{The 2000 election}

The break-up of the NFP in Hyogo resembled national-level movements, with the former NFP members returning to the Koumei, moving to the Democrats, or joining Ozawa in forming the new Liberal Party. Miyamoto Ichizou was the only former-LDP NFP member who returned to the LDP. When the Liberal Party split, with the anti-Ozawa camp remaining in coalition with the LDP as the New Conservative Party, Hyogo's NFP rump also split as two Diet members moved to the new party and one followed Ozawa out of the coalition.

Despite this ongoing fragmentation, the Alliance persisted until less than two weeks before the June 25 election. In fact, by the beginning of the year, the Alliance had expanded to include two solid opposition parties (the DPJ and the SDP) and two government parties (Koumei and the Conservatives), in addition to the Liberals, who had recently moved from government into opposition. As in 1996, when the governing Socialists participated in the opposition coalition in Hyogo, this was seen as a local 'warping' of national alliances.

Despite the maintenance of the Alliance framework, nomination difficulties in Hyogo were more common in 2000 than in 1996. First, 'PR resurrection' produced multiple incumbents in several SMDs and made it more difficult for the Alliance parties to agree on candidates across all districts. Second, a more serious 
problem was created by the discord between the local and national positions of Koumei. The local Koumei initially ignored the party's entry into the JiJiKou coalition in late 1999, continuing to participate in the Alliance. The Hyogo Conservative Party also broke with the national coalition through its decision to join the Alliance, which arose from concerns that the new party did not have enough name recognition to compete effectively, having been formed so close to the election. Participation was also an attempt to capture labour and Koumei votes.

As plans for LDP-Koumei-Conservative electoral co-operation solidified around the country, the prefectural Koumei began to waver in its support for the Alliance. The LDP went to great lengths to support its two allied parties. In districts 2 and 6 the LDP with great difficulty moved its candidates (one a resurrected PR incumbent) to PR in favour of coalition candidates. In districts 4, 7 and 8 it denied nominations to its candidates from 1996 in order to endorse Koumei and Conservative Party candidates. In the $8^{\text {th }}$, as detailed below, the situation became quite heated and the ousted LDP candidate defied the party and ran as an independent.

In stepping aside for its coalition partners in five of Hyogo's 12 districts, the LDP had some success in foiling co-operation by the opposition. However, examination of vote totals indicates that LDP voters did not docilely follow the party's instructions to support Koumei candidates. LDP candidates in Hyogo had been actively opposing Koumei for close to 20 years and many were members of anti-Gakkai groups. The row over the district 8 nomination revolved around this very issue as the original LDP candidate there was a long-time member of the anti-Gakkai April Society. On the Koumei side, years of being attacked by LDP candidates left the Gakkai less than enthusiastic about suddenly embracing its old enemy (KS 21 May 2000). Several of the candidates involved also confirm that the Koumei vote was not easy to redirect (interview with LDP staff member, 26 March 2001; interview, 27 March 2001; interview, 4 April 2001).

Furthermore, the Alliance did not collapse completely. It was able to maintain its support of Koumei and Conservative candidates even though they were also endorsed by the LDP. Furthermore, many Koumei members argued that cooperation with the Alliance was more valuable than co-operation with the LDP because of the opportunity to barter labour voters for Gakkai support. Nonetheless, the Alliance was much more strained than in the past, not only by the LDP-Koumei alliance, but also by criticism of Koumei by DPJ leaders (KS 6 June 2000). Finally, on 12 June, less than two weeks before the election, prefectural LDP and Koumei officials made a joint appearance at which Koumei leaders announced that they would not support DPJ candidates backed by the Alliance after all (KS 13 June 2000). The immediate reason for this switch was the LDP's success in convincing its PR incumbent in the $2^{\text {nd }}$ district to abandon his district campaign in favour of the Koumei incumbent.

The overall effect of these machinations was great voter displeasure and confusion concerning the identities of all of the parties. A Kobe Shinbun survey 
made during the period of Koumei-LDP negotiations indicated a dissatisfaction rate of 80 per cent with current politics. When asked to name the source of their dissatisfaction, large majorities cited the dizzy pace of changes in party names and coalition frameworks (KS 17 May 2000).

The outcomes for the former NFP incumbents were fairly straightforward they all won re-election from their new parties except for Shiota Susumu of the $10^{\text {th }}$ district, who was resurrected in PR after losing to a returned LDP member. The LDP ended up with the same number of seats as in 1996, three, but it retained only one of the districts it previously held. It lost its two seats in the "conservative kingdom' $11^{\text {th }}$ and $12^{\text {th }}$ districts to a former NFP independent and a disgruntled ex-LDP member who had moved to the DPJ. On the PR side, the LDP and the DPJ each won seven seats, while Koumei and the JCP received five each, and the Liberals and SDP three each.

\section{The new SMDS}

\section{Hyogo $1^{\text {st }}$ district}

The new $1^{\text {st }}$ district consists of three wards of the city of Kobe. Based on vote breakdowns from the 1993 election, Ishii Hajime of the Shinsei was the strongest candidate, but Akaba Kazuyoshi of Koumei was nearly as well positioned. Since Akaba and Ishii were also the top two 1993 vote-getters in the new $2^{\text {nd }}$ district, the NFP did not face a particularly difficult nomination battle; Akaba moved to the $2^{\text {nd }}$ district because he was somewhat stronger than Ishii there. Nomination issues were also uncomplicated for the LDP, as it had only one candidate with any significant base in the district, Sunada Keisuke. Sunada was the cousin and former secretary of Sunada Shigetami, LDP representative for the old $1^{\text {st }}$ district, who died shortly after winning re-election in 1990. Keisuke took over Shigetami's kouenkai and ran in the 1993 election, but was placed sixth in the five-seat district (AERA 1994).

Ishii had been competing for the LDP in the first district since 1967 and was a strong rival of Sunada. He was also part of the group that left the party to form the Shinsei in 1993. By 1996 he was a prefectural leader of the NFP and active in the Alliance, participating in the most efficient cross-district electoral cooperation arrangement in Hyogo with Akaba of the $2^{\text {nd }}$ district. Despite having been rivals in 1993, Ishii gave Akaba the names of over 25,000 of his supporters in the new $2^{\text {nd }}$ district, and in return local Koumei representatives introduced Ishii to thousands of its members at a special conference (Tani 1998: 107). The exchange also earned Ishii official recommendation from the Gakkai. The cooperation between the candidates was played up in the media, with many accounts quoting Ishii's comment that 'Akaba and I have a father-son relationship' (KS 4 October 1996).

As expected, Ishii did take the seat, but the contest was close, with the margin between him and Sunada a mere 1.2 per cent of the votes cast. Sunada, who was 
also one of 42 Kinki LDP candidates jointly ranked first on the party PR list, secured a PR seat by gaining 96.3 per cent of Ishii's total, making him the third 'best loser' on the list.

The $1^{\text {st }}$ district thus faced the June 2000 election with two incumbents and no experienced challengers. Ishii's victory in 1996 was seen as largely dependent on Koumei support, so the break-up of the NFP, his move to the DPJ, and the entry of Koumei into coalition with the LDP created serious problems for him. However, despite opposition from the centre, local Koumei representatives continued to support Ishii. Sunada, meanwhile, was determined to take the district seat from Ishii and campaigned to win the support of LDP city and prefectural assemblymen who had been Ishii supporters before his defection (AS 18 May 2000, Hyogo edition, hereafter AS-H). Sunada's hopes were pinned largely on the ability of the centre to override local history and to enforce LDP-Koumei co-operation.

By late May the Alliance framework was being increasingly questioned, largely due to activities in the new $2^{\text {nd }}$ district detailed below. When Koumei finally abandoned its support of DPJ candidates, Ishii's chances were clearly damaged, but he managed to hold on to his seat. The margin between Ishii and Sunada this time was reduced to a mere 265 out of 178,706 votes $(0.15$ per cent), the heated race having helped raise turnout by nearly four percentage points. Ishii was saved in part by the fact that the Koumei vote did not move cleanly to Sunada (interview, 27 March 2001). Sunada, having lost with 99.6 per cent of the winner's vote, topped the LDP's list of best losers in the Kinki bloc, and was again awarded a PR seat. Ironically, despite his improved performance, Sunada's PR election was much more precarious in 2000 than in 1996. Whereas in 1996 the joint candidates had all been given a rank of one, in 2000 the LDP gave all of its double-listed candidates in Kinki a joint rank of seven behind six pure PR candidates. Since, the LDP secured just seven seats in Kinki, Sunada was the only losing SMD candidate to win a PR seat.

\section{Hyogo $2^{\text {nd }}$ District}

The new $2^{\text {nd }}$ district also consists of three wards of the city of Kobe. As described above, the 1996 NFP nomination in the $2^{\text {nd }}$ district was settled fairly simply in favour of Akaba Kazuyoshi. With the other major candidates from the old $1^{\text {st }}$ district running elsewhere, the only other experienced candidate was Takami Yuuichi of Sakigake. Takami had won in 1993 running for the JNP as part of the 'new party boom.' In 1996, despite Sakigake's coalition with the LDP, Takami was endorsed by the DPJ, which had no candidate available to run in the district. Since the LDP also had no experienced candidates in the $2^{\text {nd }}$, its nomination went to prefectural assemblyman Okutani Tooru. Okutani was a vocal supporter of the separation of religion and politics, and thus aimed his attacks at Koumei member Akaba. 
The Ishii-Akaba collaboration was remarkably friendly and efficient, as described above. This, combined with Akaba's pre-existing strength in the district and further bartering for labour votes with Doi of the $3^{\text {rd }}$ district, gave him a victory with a wider margin than that of Ishii. Takami came in a distant fourth, behind even the JCP candidate, while Okutani's showing relative to Akaba placed him just one spot away from gaining a seat on the LDP PR list. The Alliance was once again successful.

Akaba would have looked forward to easy re-election in 2000 had not several events intervened. First, the dissolution of the NFP sent Akaba back to Koumei. Then, in late 1999 an LDP PR seat vacancy made first runner-up and Koumei opponent Okutani an incumbent with a strong claim to the LDP nomination. Thus the 2000 race appeared likely to become a battle between two incumbents, further complicated by the issue of LDP-Koumei electoral co-operation.

At the local level in Hyogo, Koumei continued to maintain its support for the Alliance and leaders of the group made appearances in support of Akaba. However, the safety of Akaba's seat was of great concern to Koumei. Thus, national Koumei leader Fuyushiba Tetsuzou (of Hyogo 8) began to increase his efforts to bring the local party into line with the national coalition between Koumei and the LDP. Okutani provided the major barrier, as he continued to run a campaign centred on opposition to the JiJiKou coalition and to the mixing of religion and politics. Fuyushiba attempted to force the LDP's hand by announcing that the party would maintain its support of the Alliance unless Okutani withdrew from the race. The LDP attempted to persuade Okutani with promises of a better rank on the PR list but he did not agree to drop out of the district race until late May. Even afterwards Okutani only muted his opposition to Koumei, commenting that 'even if [co-operation] is wrong, I will support efforts to defeat the JCP' (AS 27 May 2000; KS 13 June 2000).

The last-minute departure of Okutani turned the election into a two-way contest between Akaba and a new Communist candidate. The DPJ was the only party that could have potentially provided effective opposition to Akaba, but the Alliance framework backfired on the Democrats. Because the Alliance had initially supported Akaba, the DPJ had not put up its own candidate in the district. Further, the DPJ and its Rengou partners found it difficult to argue that a candidate they had supported for over four years should be abandoned.

Despite these factors, Akaba's victory in 2000 was not overwhelming. The Communist candidate received about 84 per cent as many votes and a last-minute LA candidate received nearly 50 per cent of Akaba's total. Despite the absence of candidates from the two major national parties, voter turnout was nearly equal to that in the hotly contested 1996 election. Many voters turned out just to express their displeasure with LDP-Koumei co-ordination. If Koumei can do no better than this against the JCP and the LA, the party has little future in the SMDs. The next election in the district will likely find Akaba in an even more precarious position, as Okutani, whose fifth-place ranking won him a PR seat, will be running in the district once again (interview, 18 April 2001). 


\section{Hyogo $3^{\text {rd }}$ District}

The new $3^{\text {rd }}$ district is made up of two Kobe wards and is largely metropolitan with a strong socialist base. Based on vote totals from 1993, Ishii and Akaba were also the strongest candidates in the new $3^{\text {rd }}$. Doi Ryuuichi, a socialist defector and member of the DRA, was a close third and thus the strongest remaining candidate in the district. The LDP was left without an experienced candidate in this district and nominated former Ministry of Transport bureaucrat Katou Eiichi. The remaining candidate was Okazaki Hiromi, leader of the NSP.

Because the NFP did not have a candidate of its own, negotiations within the Alliance were easily settled in favour of Doi, who also participated in vote barters with Akaba of the $2^{\text {nd }}$ district. Involvement in the Alliance brought Doi a recommendation from Koumei, but the local Gakkai was not comfortable with his status as a Christian clergyman and thus declared a free vote in the district.

Okazaki was an old rival of Doi's, having lost the SDP's nomination to him in 1990 and 1993, but going on to win a seat as an independent. In 1996, Okazaki based her party's campaign on criticism of SDP collusion with the LDP. This was not a serious challenge to Doi because he was also a known critic of the LDP-Socialist coalition and had left the party shortly after the initiation of the LDP-SDP coalition. Okazaki's other campaign theme centred on her claim that the Five-Party Alliance brought together an incoherent mix of parties that did not belong together. The LDP attempted to counter Doi's strength in the district by appealing to the potential value of Katou's 22 years in the Ministry of Transport for assisting with the rebuilding of the city. In the end, Doi took the seat by a fairly wide margin.

The 2000 election was a rematch between Doi - now a member of the 'new' DPJ - and Okazaki. The LDP nominated Ikawa Hiromitsu, a five-term Kobe city assemblyman. Ikawa campaigned as a 'pipe to the centre', hoping to convince voters that if elected he would be the best positioned to bring funds and support to the region (KS 19 May 2000).

Okazaki won a marginally higher percentage of the vote than she did in 1996 but she was, by this point, the only NSP candidate in the entire country. After losing every one of its 37 SMD races, failing to meet the threshold for PR seats in 1996, losing all three of its Upper House seats in 1998, and failing to raise enough money to put up even one PR list, the party had all but folded (KS 28 May 2000). Doi, like Ishii in the $1^{\text {st }}$ district, was affected by the late defection of Akaba in the $2^{\text {nd }}$ to electoral co-operation with the LDP. However, his loss of some of the Koumei vote did not seem to have a significant impact on the election, in part because the Koumei had also failed to recommend Ikawa. The result was that Doi again won the seat by a margin of about 5 per cent of the electorate. 


\section{Hyogo $4^{\text {th }}$ District}

The new $4^{\text {th }}$ district is a combination of parts of the old $1^{\text {st }}$ and $3^{\text {rd }}$ districts. The district is urban but also includes a number of smaller farming cities. The juxtaposition of the western-most section of Kobe and the farm-based sections of the old $3^{\text {rd }}$ created the challenge of simultaneously appealing to two distinct types of voters.

The strongest 1993 candidate in the new district was the NFP's Inoue Kiichi, who had run in the old $3^{\text {rd }}$ for Shinsei in 1993 and was supported by the Alliance in 1996. The LDP nominated a local college professor, Konishi Toshiaki, hoping that he might be able to cut into Inoue's farm base from the old $3^{\text {rd }}$ district. The Democrats selected Yoshimura Seishi, a city assemblyman who had been active in the post-earthquake volunteer recovery movement. Yoshimura had originally hoped to run for the DPJ in Tokyo but party leader Kan Naoto asked him to represent the party in Hyogo instead.

Yoshimura failed to penetrate the areas from the old $3^{\text {rd }}$ district and finished poorly. The race between the incumbent Inoue and Konishi was much closer, but Inoue's Alliance support and his success in maintaining the support of the local farming co-operatives allowed him to defeat Konishi fairly easily. Nonetheless, Alliance cross-district co-operation in the new $4^{\text {th }}$ district was not as harmonious as it was in the $1^{\text {st }}$ and $2^{\text {nd }}$ districts. A substantial part of Inoue's former kouenkai was based in the city of Kakogawa, which became part of the $10^{\text {th }}$ district in the redistricting. Inoue publicly asked his supporters in Kakogawa to back fellow NFP candidate Shiota Susumu in the $10^{\text {th }}$, but the leaders of his support group were unenthusiastic about the exchange because Shiota and Inoue had been rivals from different parties (the DSP and LDP) since the mid-1980s. Even though they now shared NFP affiliation, Inoue's conservative supporters found it difficult to support a socialist.

After the break-up of the NFP, Inoue remained with Ozawa in the new Liberal Party. However, when Ozawa decided to take the Liberal Party out of the JiJiKou coalition, Inoue chose to join the Conservatives and stay in the LDP coalition. Because the Conservatives were still part of the Five-Party Alliance, he received the official nomination of the 'opposition' coalition without challenge and vocally supported fellow Alliance candidate Democrat Tsuiji in his former base in the $10^{\text {th }}$ district.

The LDP initially planned to run Konishi again in hopes of gaining ground on Inoue. However, when electoral co-operation finally began to solidify, Konishi became a prime candidate to step down in favour of an LDP ally. He resisted and threatened to run as an independent for some time, but eventually agreed to drop out at the urging of his faction leaders (AS-H 19 May 2000). Supported both by the opposition Alliance and by the LDP, Inoue thus faced challenges only from the Communists and an LA newcomer and was re-elected by a wide margin. 


\section{Hyogo $5^{\text {th }}$ District}

The new $5^{\text {th }}$ district consists mainly of the entire old $5^{\text {th }}$ district, Hyogo's most rural. To the old $5^{\text {th }}$ was added part of the old $2^{\text {nd }}$ district, including the city of Sanda. Sanda now accounts for about 20 per cent of the new district's voters, a fact that greatly changed the face of competition. Even so, candidates from the old $5^{\text {th }}$ were far better positioned to run in the new $5^{\text {th }}$ than those from the old $2^{\text {nd }}$. Penetration of Sanda thus became the key to winning the $5^{\text {th }}$ district.

The two incumbents, Tani Youichi of the LDP and Yoshioka Kenji, a socialist independent, were closely matched according to 1993 vote totals. Yoshioka had begun running as an independent in 1990 and was part of the group of disgruntled socialists that attempted to start the 'Liberal Kinki' party in 1994, before moving to the DRA (YS 6 December 1994). Yoshioka was given the endorsement of the Alliance and received the NFP and Koumei recommendations that went along with it. His campaign focused on building labour and Gakkai support in Sanda. Nevertheless, Tani's slightly stronger base in the old $5^{\text {th }}$ district and a good showing in Sanda overwhelmed Yoshioka.

The 2000 election was a rematch of the Tani-Yoshioka contest, although several new candidates entered the race and coalition and party shifts complicated the picture. The DRA had folded and Yoshioka had joined the DPJ. The LA nominated Saitou Yoshiake, grandson of a pre- and early post-war Hyogo Diet member, and the Liberal Party nominated a new candidate of its own. Yoshioka was endorsed by the Alliance early in the race and was backed by Koumei prefectural assemblymen, despite the national party's alliance with the LDP. The presence of a Liberal candidate in the same district, however, indicated that not all members of the Alliance took co-operation as seriously as did some. After the $2^{\text {nd }}$ district deal with the LDP was finalised, Koumei switched its endorsement from Yoshioka to Tani. Without the estimated 30,000 votes that the Gakkai could provide, Yoshioka was expected to have no chance to overtake Tani.

Tani did win the seat again, but a comparison of the vote totals from the two contests indicates that the Koumei vote may not have played the role many commentators had predicted. That the gap between Tani and Yoshioka did not change indicates either (a) that Yoshioka did not receive much of a lift from Koumei in 1996 or (b) that the Koumei vote did not shift efficiently to Tani in the last days of the 2000 campaign. In either case, it is important to note that the Koumei switch did not gain the LDP many votes in this district.

\section{Hyogo $6^{\text {th }}$ District}

The new $6^{\text {th }}$ is a fragment of the old $2^{\text {nd }}$ and is metropolitan. Leading up to the 1996 election, the old $2^{\text {nd }}$ had five incumbents and two close losers. Doi Takako was at the front of the pack, with a vote total far higher than any competitor. These six potential candidates had three fragment districts $\left(6^{\text {th }}, 7^{\text {th }}\right.$ and $\left.8^{\text {th }}\right)$ and one combination $\left(9^{\text {th }}\right)$ from which to choose. Doi was the leader in each of the three fragment districts and chose to run in her strongest base in the $7^{\text {th }}$ district. 
In the new $6^{\text {th }}$, this left three candidates. The strongest was Koike Yuriko, who was first elected to the Lower House from the JNP in 1993. Following her were Miyamoto Ichizou, a former LDP-affiliated independent who moved to Shinsei in 1993, and Koumei leader Fuyushiba Tetsuzou. All three were members of the NFP by 1996, but fortunately for the party, each candidate's jiban was located in a different district, so nominations were not difficult. Fuyushiba was strongest in the $8^{\text {th }}$, and Miyamoto was the party's best hope for the more conservative $9^{\text {th }}$ district, so the $6^{\text {th }}$ was left to Koike alone. The LDP, with no experienced candidate, nominated prefectural assemblyman Sakaue Yoshihide. The DPJ, JCP and LA also fielded candidates, but only Sakaue had any chance at defeating Koike.

Koike was endorsed by the Alliance and co-operated with Miyamoto of the $9^{\text {th }}$ district. She also campaigned with fellow NFP candidates Imanishi of the $7^{\text {th }}$ and Yamaguchi of the $12^{\text {th }}$, lending them some of her superior name recognition. As members of the same party, it should come as no surprise that Koike and Imanishi co-operated. However, while the Alliance supported Koike in the $6^{\text {th }}$, it supported Doi, Imanishi's opponent, in the $7^{\text {th }}$ district.

Sakaue managed a decent showing, but Koike won by more than 8,000 votes. Sakaue's 90.7 per cent ratio of the winner's vote total gave him the seventh of the LDP's 10 PR seats in Kinki. The $6^{\text {th }}$ district thus had two incumbents prepared to run for the seat again in 2000 .

Koike moved to the Liberals after the NFP break-up and then joined the Conservative Party when it split from the Liberals. The LDP quickly moved to co-ordinate with the Conservatives by offering to move Sakaue to PR. Sakaue protested the LDP's endorsement of Koike bitterly, referring to the co-ordination as 'rigged bidding (dangou) under the name of electoral co-operation' (KS 23, 27 May 2000). One city assemblyman commented, 'I can understand electoral cooperation, but there are local considerations too. I can't just suddenly support someone because I am told to' (KS 1 June 2000). Sakaue threatened to run as an independent, but his slim chances of winning, the offer of a safe PR rank of third, and the promise that he would only once have to run as PR candidate convinced him to accept the party's decision a full month before the election (AS-H 25 May 2000).

New challenges for Koike came from a new Democratic candidate, Ichimura Kouichirou, and SDP PR incumbent Nakagawa Tomoko. Both of these candidates targeted the labour vote that Koike had received from Rengou in 1996. Nakagawa had been elected as a pure PR candidate in 1996; she was one of two female activists placed at the head of the SDP's PR list by Doi Takako in that year in order to boost the party's image. In 2000 she emphasised her position as a 'regular woman' and got the support of local civic activist groups and a number of private unions (Nakagawa 1998; interview, 21 March 2001). The DPJ candidate, on the other hand, was a former JNP and NFP party employee with connections to Rengou unions (AS-H 20 May 2000). These two candidates complicated the Alliance position in the district and in the end the group was 
unable to endorse any candidate. Nakagawa's position was particularly confused. The local and national SPD organisations endorsed her candidacy - indeed, it was at the request of the national party that she ran in the district in 2000. However, the prefectural SDP followed the Alliance formula and refused to nominate Nakagawa so that it could continue to support the new DPJ candidate (interviews, 19 March and 21 March 2001).

Koike held her seat but the combined total vote of the DPJ and SDP candidates was 50 per cent larger than Koike's. Nakagawa's showing earned her a PR seat. Despite a much stronger performance than Nakagawa's, Ichimura was the runnerup on the DPJ PR list. The success of the first- and third-place candidates, but not the second, in securing a seat highlights another of the unusual results of the double-candidacy provision. Furthermore, with Ichimura in place to fill any PR vacancy that opens up for the DPJ, there is the potential that the $6^{\text {th }}$ district could face the next election with four incumbents - Koike, Sakaue, Nakagawa, and Ichimura. At the very least it will have three incumbents, as LDP faction leader Kamei Shizuka publicly promised that he would guarantee Sakaue's political future (AS-H 25 May 2000). And regardless of whether or not he is 'revived' before the next election, Ichimura appears determined to be prepared and is already campaigning actively (interview, 21 March 2001).

\section{Hyogo $7^{\text {th }}$ District}

Hyogo's $7^{\text {th }}$ district is another metropolitan fragment district. Doi Takako's candidacy for the $7^{\text {th }}$ district seat was decided early, so the $7^{\text {th }}$ district held no appeal for the other candidates from the former $2^{\text {nd }}$ district. Doi's challengers were a prefectural assemblyman running for the NFP and an LDP newcomer.

Doi's SDP was in a precarious position as the 1996 election approached. In Hyogo most of the party had defected to the DPJ and Doi was the party's only SMD candidate. Furthermore, the SDP was supporting the DPJ in the Kinki region, but the Hyogo party also joined the Alliance and thus threw its support behind NFP candidates in most districts, even those running against Democrats. The prefectural party claimed that there was no contradiction between these positions, but the situation was surely not clear to most voters.

Nonetheless, Doi's personal popularity in her district made her own seat safe. The NFP's Imanishi Eiji managed to get only about 70 per cent as many votes as Doi, because the Alliance supported Doi in the $7^{\text {th }}$ and because he had been active in anti-Koumei groups during his days in the LDP. This meant that Koumei was less than enthusiastic about supporting Imanishi, even as a member of the NFP.

Imanishi hoped to challenge Doi again in 2000 as a member of the DPJ. However, in 2000 the DPJ was a full participant in the Alliance and again endorsed Doi. Imanishi considered running as an independent for some time, but eventually abandoned his candidacy. Doi's opponents this time were to be a 26-year-old Conservative, a private school teacher representing the LA, and a 
Communist. The Conservative received an endorsement from the LDP but not from Koumei. In the end, Doi won by an even wider margin than in 1996.

\section{Hyogo $8^{\text {th }}$ District}

The city of Amagasaki makes up the entire new $8^{\text {th }}$ district. With Doi running in the $7^{\text {th }}$, Koumei's Fuyushiba, now running for the NFP, dominated the district. His strength made this district unattractive to the other candidates from the old $2^{\text {nd }}$. The one exception was JCP candidate Fujiki Youko who offered more of a challenge than the usual token Communist.

Despite the strong bases of Fuyushiba and Fujiki, five other candidates also campaigned for the Amagasaki seat. The LDP continued its strategy of filling holes with prefectural assemblymen and nominated Muroi Kunihiko. The DPJ ran JSP-defector Hatanaka Itsuo. The NSP and LA also fielded candidates. The contest developed into a race between the NFP, the LDP, and the JCP, with even the DPJ candidate running well behind the pack.

As a former Socialist, Hatanaka had hoped for the endorsement of the SDP, but the SDP endorsed Fuyushiba as part of the Alliance. Hatanaka argued that the actions of the prefectural party were heavy-handed, and commented that 'Amagasaki's candidate shouldn't be selected in Kobe' (KS 1 October 1996). One dissenting prefectural party official even gave up his post in frustration over the SDP's failure to endorse Hatanaka (YS 7 October 1996).

The LDP's Muroi mounted his own attack on the incumbent by focusing on Fuyushiba's Koumei background. Muroi's often-repeated line was that 'a religious group should not be allowed to have the area's representative under its thumb' (KS 17 October 1996). Despite these complications, Fuyushiba defeated Muroi by a healthy margin. Fujiki was even further behind, but her ranking of sixth on the JCP PR list won her the last JCP seat in Kinki.

After his defeat, Muroi remained vocal in his opposition to the Koumei's mixing of politics and religion. He became active in the anti-Koumei April Society and prepared to mount a new campaign in the next election. The breakup of the NFP and Koumei's entry into coalition with the LDP upset his plans, however, because the LDP could not run a candidate against Fuyushiba. In response to the LDP's decision not to nominate him, Muroi announced, 'Party headquarters has thrown Amagasaki away, but I will not. I will run as an independent' (AS-H 27 May 2000).

At the beginning of the campaign, the Alliance supported Fuyushiba. His DPJ opponent from 1996 even made campaign appearances with him. As Koumei discussions with the LDP continued, however, Alliance support for Fuyushiba wavered. The Amagasaki SDP decided to run Kitagawa Renko despite the prefectural party's support for the Alliance (KS 14-19 May 2000; interviews, 19 March and 21 March 2001). Once the deal with the LDP was sealed it appears that some opposition support shifted to Kitagawa, but no official announcement 
of a change of policy was made and the prefectural SDP did not officially endorse her.

Fuyushiba managed to hold on to his seat once again, but it is interesting to note that in both 1996 and 2000 all three major opponents received significant proportions of the vote and that any two of the three could have combined to defeat him. The combination of losing parties in each case made this unlikely, but it highlights the weakness of Koumei candidates in the SMDs. The fact that Fuyushiba was more successful in securing the backing of local LDP politicians than were most Koumei candidates only further drives this point home. ${ }^{5}$

Both Fujiki and Kitakawa won PR seats, the former for her assigned (high) rank on the list, and the latter for her competitiveness against Fuyushiba. This gives the $8^{\text {th }}$ district three representatives, all of whom are nearly certain to run again in the future. Muroi also plans to run again, having failed to gain a seat in the Upper House in July 2001 as a member of Ozawa's Liberal Party.

\section{Hyogo 9th District}

The new $9^{\text {th }}$ district is another combination district, consisting of the city of Akashi (former $3^{\text {rd }}$ ) and the much more rural island of Awaji (former $2^{\text {nd }}$ ). Akashi, with about 60 per cent of the votes, dominates the new district. Nevertheless, the district held more attraction for candidates from the former $2^{\text {nd }}$ than those from the former $3^{\text {rd }}$ for several reasons. First, turnout is higher in rural Awaji. Second, most of the candidates from the old $3^{\text {rd }}$ were better situated to run elsewhere. The final reason was the candidacy of Hara Kenzaburou. An LDP elder, Hara's roots were rural and based on Awaji; this made him by far the strongest candidate in the new district. Hara's primary challenge also came from the old $2^{\text {nd }}$ district, from former LDP-affiliated conservative independent Miyamoto Ichizou, running for the NFP in 1996. The DPJ nominated Wakamiya Kiyoshi, a college professor who had been a losing JNP candidate in the old $4^{\text {th }}$ district in 1993.

Hara was an old-style LDP politician - at the age of 89 he was hoping for his twentieth straight win - and focused his appeals to the voters on what he had brought to the area. Yet, penetrating Akashi was a challenge and the predominance of elderly LDP candidates in Hyogo lent resonance to the calls of other parties and candidates for generational change.

Miyamoto had run several times as an independent. After his third loss, he moved to Shinsei in 1993 and finally won a seat, riding the wave of the new party boom. He was placed third in that election, in which Hara came fifth. Nonetheless, Miyamoto was given the only NFP PR double candidacy in the Kinki bloc as insurance against defeat. Miyamoto also received support from Koumei and from fellow NFP candidate Inoue of the $4^{\text {th }}$ district.

The DPJ's Wakamiya was starting from scratch, having previously run in the old $4^{\text {th }}$. His campaign slogan was, 'No money, no jiban, just youth and power'. 
He eventually received the Alliance endorsement, but, without the participation of the NFP, this was of only marginal benefit.

Miyamoto's support from Inoue and Koumei proved to be enough to overcome Hara by a comfortable margin, but Hara's performance (winning 89.4 per cent of Miyamoto's total) won him the eighth of the LDP's 10 PR seats in the Kinki bloc. This gave the district two incumbents for the 2000 election.

Hara had intended to remain in the Diet until the end of his life, but Miyamoto chose to return to the LDP after the NFP dissolved. Hara publicly proclaimed that he wanted his district seat back and would fight until his death. However, the LDP decision to make retirement by age 73 a general principle finally convinced 93-year-old Hara to announce his decision to retire on 8 May (KS 8 May 2000). Yet, Hara did not leave quietly. He threw his support behind his former secretary and former MITI bureaucrat Nishimura Yasutoshi. The national party followed its policy of giving priority to incumbents and nominated Miyamoto, even though many within the party felt that he should have been forced to move to the PR as punishment for his severe criticism of the LDP in his previous campaign. As a result, Nishimura mounted an independent campaign and received the endorsement of five local party branches on Awaji (KS 26 May 2000). The prefectural LDP also supported Nishimura initially, although with time it came into line with the national position (interview, 28 March 2001).

On the opposition side, co-ordination among the members of the Alliance was not as difficult as in other districts because Miyamoto had never been an Alliance candidate. Co-ordination efforts centred on a new DPJ candidate, Fujimoto Kinzou, who was hoping that Miyamoto and Nishimura would split the conservative vote (KS 19 May 2000). Fujimoto's main support came from Rengou-affiliated unions. He also received some support from Koumei, but Koumei had supported Miyamoto in 1996 as part of the NFP and, once the coalition government's electoral co-ordination solidified, Miyamoto received the endorsement both of Koumei and of the Conservatives.

In the end, Koumei endorsement solidified Miyamoto's victory, although his margin was only moderate. Fujimoto actually won Akashi but his inability to penetrate Awaji gave him little chance of defeating either of the LDP-affiliated candidates.

\section{Hyogo 10th District}

Hyogo's new $10^{\text {th }}$ district is urban and a fragment of the old $3^{\text {rd }}$ district. The clear leader in the district was Tokai Kisaburou of Sakigake. Tokai was the son of another LDP party elder who had represented the $3^{\text {rd }}$ district from 1955 until 1983. He took over his father's jiban and reclaimed his seat in 1986 before joining Sakigake in 1993.

Tokai's election in 1986 was the start of a rivalry with two union-backed politicians, Nagai Takanobu of the JSP and Shiota Susumu of the DSP. Nagai and Shiota were also the only other candidates with reasonably strong bases in the 
district. Shiota had represented the old district between 1979 and 1986 and was determined to regain his old seat as a member of the new NFP. Nagai found himself in the unenviable position of having his support base spread fairly evenly across the three districts into which the old $3^{\text {rd }}$ was divided. Nagai had also been a member of the Liberal Kinki group that defected from the JSP in 1994 and the failure of that group only aggravated the difficulty of his position. Although he explored the idea of running in the $10^{\text {th }}$ and the SDP tried to recruit him for its PR list, he finally decided that retirement was his best option.

This decision left Nagai's former socialist base open for mobilisation by Shiota and set the stage for a heated competition with Tokai. Shiota received Alliance endorsement and won by a narrow margin. Although Tokai's performance put him at the top of Sakigake's PR list in Kinki, the party won no PR seats.

Party fluidity between elections produced a very different contest in 2000 . Tokai returned to the LDP with the demise of the Sakigake. Shiota remained in the Liberal Party with Ozawa. When the Liberals left the government and became affiliated with the Alliance again, Shiota should have been in position to receive Alliance support, but another candidate had appeared on the scene. Tsuji Yasuhiro had been a prefectural leader of Rengou and, upon joining the DPJ, had received that party's nomination for the $10^{\text {th }}$ district. With an established labour base in the district, he was able to undercut Shiota. Despite ongoing co-operation talks with the Liberals, the Alliance endorsed Tsuji rather than Shiota. The chair of the Alliance explained this by noting that a significant portion of Shiota's 1996 supporters were now allied with Tsuji (KS 24 April 2000). The Alliance hoped to convince Shiota to drop out of the race but he refused, arguing that the Alliance should not have the right to override nomination choices made by individual parties (KS 23 May 2000). On the LDP side, Tokai hoped to receive support from the LDP's coalition partners. The Conservatives eventually endorsed him but Koumei was not able to unify behind him, even after Fuyushiba finalised the $2^{\text {nd }}$ district deal.

The incumbency advantage did nothing for Shiota after he lost Alliance support. He was placed third behind Tsuji and Tokai. Tsuji made a good showing, but Tokai increased his vote significantly over 1996 and won more votes than Tsuji and Shiota combined.

\section{Hyogo $11^{\text {th }}$ District}

The new $11^{\text {th }}$ district consists of the city of Himeji. This district is taken from the old $4^{\text {th }}$ district, Hyogo's 'conservative kingdom'. It was thus one of the few districts in which the LDP had experienced candidates and therefore serious nomination difficulties. Toida Saburou had the strongest conservative base in the new district, but Matsumoto Jurou was a close second. Both were somewhat behind the overall leader in the new district, Akamatsu Masao of Koumei. The other candidates with $11^{\text {th }}$ district bases were Gotou Shigeru of the JSP and 
Gotou Takeshi of Shinsei. The JSP's Gotou had won a seat in every election since 1976 with the exception of 1986, while Shinsei's Gotou was a former prefectural assemblyman who had run unsuccessfully in 1993. With multiple strong candidates for the nomination on both the LDP and Alliance sides, the stage was set not only for a competitive election, but also for a bitter nomination process.

On the LDP side, the dispute centred on the two party elders, Toida and Matsumoto. Matsumoto had been the runner-up in the 1993 election, so the LDP followed its policy of giving priority to incumbents and moved Matsumoto to the PR tier. Incumbency priority extended to the PR rankings and Matsumoto was giving a ranking that was unlikely to win him a seat. He called party headquarters on 20 September to bargain for a better rank, implying that he would run as an independent if not accommodated. Five days later, party headquarters announced that Matsumoto had decided to resign from the PR list. Matsumoto was apparently taken by surprise and commented that he had 'only wanted to negotiate' (KS 2 October 1996). Nonetheless, he was forced to retire, although his son did mount an independent campaign built on Matsumoto's jiban.

On the opposition side, there were three likely candidates, Akamatsu, Gotou Shigeru, and Gotou Takeshi. Akamatsu was the obvious co-ordination point and he was initially given the endorsement of both the NFP and the Alliance. However, because of the strong LDP challenge, it was later decided that it would be better to run Akamatsu on the PR list and let Gotou Takeshi run in the SMD. Following party policy, Akamatsu was given the safe rank of fourth and did indeed win one of the NFP's 10 PR seats.

At this point divisions in the former socialist camp began to assert themselves and caused a new split in the Alliance. In 1996 DSP-affiliated labour groups supported the NFP rather than the DPJ. They thus supported Gotou Takeshi, who was also a former secretary of Matsumoto. However, former socialist Gotou Shigeru had joined the DPJ and was also planning to run. This created a complicated problem for the Alliance. As the DPJ was not officially part of the Alliance, in one sense it would have been more legitimate for the group's endorsement to go to the NFP's Gotou. However, the DPJ's Gotou had a longstanding relationship with Rengou. Furthermore, the NFP's Gotou had opposed the Rengou-backed candidate in the 1995 Himeji mayoral election. The fact that the NFP's Gotou was a resident of the new $12^{\text {th }}$ district, rather than the $11^{\text {th }}$, only added to the confusion. Eventually the Rengou ties of the DPJ's Gotou prevailed and he received the Alliance's support. The NFP, however, did not withdraw.

Thus, in the 1996 election the $11^{\text {th }}$ district had four serious candidates. LDP candidate Toida campaigned with Koumoto of the $12^{\text {th }}$ and attempted to trade kouenkai members. The NFP's Gotou campaigned against 'seat inheritance', targeting the younger Matsumoto. Matsumoto, for his part, played up his youth - he was only 37, while Toida was 75, Gotou Shigeru 68, and Gotou Takeshi 51 - and aimed for the votes of those looking for a change. The JSP's Gotou, despite his Alliance endorsement, focused mainly on the labour vote, expecting most of the Koumei vote to go to the NFP rather than the Alliance. 
The final element of the confused campaign was the sudden death of Toida Saburou six days before the election. His son Tooru stepped in and took over the campaign, giving the district another second-generation candidate who could also expect sympathy votes. The final tally put Toida in first place, just over 3,000 votes ahead of the NFP's Gotou. The DPJ's Gotou and Matsumoto were far behind.

In the nearly four years between elections, affiliations and alliances continued to change. Gotou Shigeru retired and Gotou Takeshi returned to the prefectural assembly. Matsumoto, determined to avenge his defeat and revive his father's jiban, moved to the DPJ. As elsewhere, the Alliance initially endorsed the DPJ candidate, but split when Koumei shifted its endorsement to Toida. Toida also received the endorsement of the Conservatives but it was not enough to save him. Matsumoto avenged his previous loss by making a strong showing among women, youth, and labour in particular. A corner of the conservative kingdom had crumbled (KS 26 June 2000).

\section{Hyogo $12^{\text {th }}$ District}

Hyogo's $12^{\text {th }}$ district consists of the remainder of the old $4^{\text {th }}$ district conservative kingdom and is largely urban. Koumoto Toshio, LDP faction leader and Diet member since 1949, had by far the strongest base in the new $12^{\text {th }}$ district and was looking forward to an easy race in 1996. He thus saw the dissolution of the Lower House in 1996 as the perfect opportunity to retire and pass his kouenkai on to his son Saburou, then a member of the Upper House. The NFP nominated a former Ministry of Foreign Affairs bureaucrat, Yamaguchi Tsuyoshi, to oppose him.

Koumoto Saburou initially hesitated to take over for his father, because the doctors' group that had always endorsed his father had decided to support Yamaguchi instead. This group was an important source of funding - in 1994 its contributions amounted to 154 million yen. In 1996, it split its support between the LDP and the NFP, endorsing NFP candidates in the $9^{\text {th }}$ and $12^{\text {th }}$ districts and LDP candidates elsewhere. Yet, the prospect of co-ordinating with Toida of the $11^{\text {th }}$ district convinced Koumoto that it was worth resigning his Upper House seat to run in the $12^{\text {th }}$ district. The Koumoto kouenkai had also encouraged Saburo to run because the age issue was expected to hurt the prospects of the elder Koumoto. For his part, Yamaguchi was supported by the Alliance and Koumei and was thus able to mount a solid challenge. Nevertheless, Koumoto's longstanding jiban was too much for Yamaguchi and he lost by well over 10,000 votes.

The 2000 election was a rematch. This time, however, Yamaguchi Tsuyoshi was running as an independent, having rejected Ozawa's request to join the Liberals. Yamaguchi decided to stay independent at the behest of Alliance chair and teachers' union leader Ishii Ryouichi. Given the lack of other labour representation in his district, Ishii's support was vital (interview, 14 April 2001). Yamaguchi had used the time between the two elections to completely rebuild his 
support base around what he called his 'Yamaguchi Party'. He spent three years and eight months cycling around the district and holding town meetings (KS 27 May 2000). In particular he aimed to penetrate the conservative vote by criticising the LDP for promising to protect farmers but failing to stand up to foreign pressures. He promised that his background would give him the skills to stand up to and negotiate with other countries.

The Alliance endorsement first went to Yamaguchi, but the LDP's manoeuvrings eventually brought endorsements by Koumei and the Conservatives to Koumoto. However, Koumoto's main strength in 1996, his father's kouenkai, was ageing rapidly. He failed to re-invigorate the organisation and did not capture the independent vote. Yamaguchi picked up the protest vote and soundly defeated Koumoto (KS 26 June 2000). The second corner of the conservative kingdom had thus been lost.

\section{Conclusion}

The main lessons from Hyogo concern the position of the Koumei and the ability of opposition parties to co-ordinate against the LDP.

First, the fragility of the current position of Koumei has been driven home by the stories of the two elections in Hyogo. Even under ideal conditions with no competition from LDP and Conservative candidates, Koumei's candidates were elected by unexpectedly small margins. Koumei's movement between government and opposition has also weakened its ability to compete effectively in the SMDs; the confusion and frustration among the voters caused by the party's manoeuvring have made it difficult for the party to direct votes as skilfully as it has in the past. Even insiders acknowledge that Koumei may well be on the way to becoming the next JCP - able to win seats only by means of PR (interview, 28 March 2001).

The 1996 and 2000 elections also showed the potential for success of local opposition co-ordination, in addition to highlighting the difficulties of this. In Hyogo much of the successful co-ordination was driven by locally based efforts. However, Alliance efforts created 'twisted' alliances at variance with the centre that were difficult to maintain and often incomprehensible to voters. Thus, the Hyogo group found itself too far ahead of the rest of the nation in terms of realignment and suffered for having taken a different direction of realignment. The example of Hyogo also underlines the continued weakness of national leaders in imposing their coalition preferences on party members. The introduction of SMDs mitigated this to some degree, but the weakness remains nonetheless.

Finally, with regard to the competitiveness of elections and the number of candidates, the case of Hyogo presents no clear lessons, other than perhaps the lesson that the new system is not as simple as it seems. Most of the 2000 contests saw a concentration of competition around three or four serious candidates, due largely to the election of more than one candidate from single districts through 


\section{Four prefectural case studies}

the PR list system. The fact that for the next election Hyogo will have two districts with two incumbents and two with three incumbents - one of which may well end up with a fourth - indicates that the new electoral system is not completely successful in reducing the number of candidates to two in each district. Thus, the clearest lesson of all is that the next election can also be expected to have much to tell us about the changing Japanese party system.

\section{Notes}

1 Ishii's role in the Alliance shaped not only multi-party co-operation but also the movements of a number of local politicians.

2 Unless otherwise noted, interviews were conducted with sitting Diet members.

3 Although the national Koumei had joined the NFP, the prefectural-level party maintained a separate identity. Thus, former Koumei candidates for the national elections in Hyogo ran under the NFP label, but were still widely thought of as being Koumei. In this discussion, the Koumei identity of these candidates is salient and therefore highlighted. However, it should be kept in mind that in 1996 these individuals were members of the NFP.

4 The September-October 1996 and May-June 2000 editions of the Kobe Shinbun serve as the central resources for this text and are thus cited only in cases where the text draws from a single article (rather than multiple articles over a given period of time).

5 Fuyushiba achieved this by mobilising his own supporters in favour of the campaigns of the local LDP politicians who had backed Muroi in the 1996 election. This earned him some good will and obligation on the part of the local LDP (interview, 28 March 2001). 


\title{
6 Inheriting the 'Conservative Kingdom' in Ibaraki
}

\author{
Hulda Thóra Sveinsdóttir
}

Ibaraki is a conservative stronghold at all levels of government and has been so throughout the post-war period. The Liberal Democratic Party dominates politics in the prefecture to the extent that Ibaraki has been dubbed a 'Conservative Kingdom' (Hoshu Ookoku). The conservative Diet members have strong roots in the prefecture and many seats are passed down from father to son, or grandfather to grandson. Of the six LDP Diet members elected from Ibaraki in 2000, five had fathers or grandfathers who had been members of the Diet. Nakamura Kishirou, former LDP member but now an independent Diet member in the $7^{\text {th }}$ district is also second-generation. With the latest succession taking place just before the 2000 elections, Ibaraki has also become known as the 'Hereditary Kingdom' (Seshuu Ookoku).

Although multipartisation was visible under the MMD, with both the DSP and Koumei winning one seat each in the 1990s, the LDP always held around 60-75 per cent of the seats. The primary opposition was the JSP. Along with Kagoshima, Ibaraki was a primary example of the 1955 system. From the late 1950s and until the electoral changes in 1994 the LDP (including conservative independents who planned to join the LDP if they won) held from seven to nine seats of the 12 seats in the district. The main opponent to the LDP, the JSP, held between two and four seats, usually managing to hold on to at least one seat in each of the three districts, sometimes winning two in the $2^{\text {nd }}$ district. What gradually ate into the support of these two main parties was co-operation between the smaller parties. The DSP and Koumei co-operated in most elections from the early 1970s, jointly supporting candidates in the old $1^{\text {st }}$ and $3^{\text {rd }}$ districts. This co-operation sometimes included other small parties, such as the New Liberal Club and the Social Democratic League. The co-operation eventually bore fruit. In addition to the seat Koumei had held for most of the time from the late 1960s in the $3^{\text {rd }}$ district, the DSP managed to win a seat in most elections in the $1^{\text {st }}$ district from the early 1980s. The JSP, on the other hand, had little experience in co-operating with other parties. 


\section{Overview}

\section{The 1996 election in Ibaraki}

With the advent of MMM, Ibaraki prefecture went from 12 seats in three districts to seven seats in seven single-member districts, sharing 21 PR seats with three other prefectures - Saitama, Gunma and Tochigi - on the North Kanto list. ${ }^{1}$ At the time of the 1996 election the LDP had eight incumbents, the JSP had two, the DSP one and Koumei one. As in Niigata, it was clear long before the election that the main rival to the LDP would be the NFP, which put candidates forward in six districts. It was, however, also clear that it was going to be a difficult fight for the NFP as it was fighting LDP incumbents in all districts while five of its own six candidates were new. The LDP, on the other hand, was facing incumbents in only two districts.

The LDP had to fit eight incumbents into seven districts. The matter was solved without too many problems, seven incumbents were nominated in singlemember districts and one candidate proved willing to go on the PR list. ${ }^{2}$ The main problem was in the new $3^{\text {rd }}$ district where two LDP incumbents wanted to run. Through LDP mediation, a 'Costa Rica agreement' was set up whereby the two candidates would take turns in running in the single-member district while the other ran on the PR list.

It was to be expected that co-operation between the NFP and the newly formed DPJ might be difficult. The DSP (now part of the NFP) and the JSP had competed with each other in the old $1^{\text {st }}$ and $3^{\text {rd }}$ districts throughout the 1980s. In 1996 these old animosities were reflected in the nomination problems that surfaced in the $1^{\text {st }}$ and the $5^{\text {th }}$ districts between the NFP and the DPJ.

The NFP declared its intention to put candidates forward in all seven districts even if it meant competition with the DPJ. This caused problems in the $1^{\text {st }}$ district where two strong anti-LDP candidates were willing to run. An incumbent for the DSP from the old $1^{\text {st }}$ district decided to run for the NFP, while the DPJ fielded a former JSP candidate who had won a seat in the old $1^{\text {st }}$ district in the 1990 'Doi boom' but was unable to keep it in 1993. Both were intent on running, putting the labour unions in an awkward position as union support was divided between them. Rengou decided to support both candidates (Ibaraki Shinbun, hereafter IS, 25 and 29 September 1996).

The $5^{\text {th }}$ district also posed problems for the anti-LDP forces. The DPJ fielded a JSP incumbent who was able to secure Rengou support. The NFP found a candidate to run but when it became clear that the Yuuaikai, the union which supported the NFP in Ibaraki, was not willing to support him in the district, the party aborted its plan and moved the candidate to another district. The DPJ thus became the main challenger to the LDP in the $5^{\text {th }}$ district. In all other districts the main challenger was the NFP.

After these difficulties in ensuring union support, the NFP ran in six districts. Its candidates came from various directions. In addition to the DSP incumbent in the $1^{\text {st }}$ district, a candidate who had run for the JNP in 1993 ran in the $4^{\text {th }}$ district, 
and a Koumei incumbent ran for the NFP on the PR list. The NFP candidates in the other four single-member districts were all new.

The DPJ ran in two districts only, the $1^{\text {st }}$ and the $5^{\text {th }}$ district. Both candidates had run for the JSP in 1993. The JSP therefore had no candidates to put forward and thus decided to support the DPJ candidates in the two districts but to run as the JSP on the PR list (IS 15 May 2000). The JCP ran candidates in all districts as usual.

Ibaraki went into the 1996 election with the main competition being between the LDP and the NFP. The media made much of the polarisation between the LDP and the NFP, replacing the old LDP-JSP cleavage. However, the only district which featured clear policy differences, with the two parties directly attacking each other, was the $2^{\text {nd }}$ district (Yamada 1997: 132). In other districts the polarisation seemed less evident although the NFP candidates would at times attack the LDP over the suggested rise in consumption tax (IS 15 and 27 October 1996). The LDP also denounced the NFP as a party with no policy, clearly indicating its distaste for the inclusion of Koumei (IS 28 September 1996). But the pre-electoral strength of the LDP in the prefecture indicated that the NFP would be unlikely to pose a real threat. As it turned out the LDP won six SMD seats and an independent with a LDP background won the seventh. As in Niigata, the LDP accomplished a clean sweep in the 1996 general election.

\section{The House of Councillors election of 1998}

The HC election in 1998 seemed to indicate some changes to the political balance in Ibaraki. The LDP decided to put two candidates forward for the two seats in Ibaraki, in a bid to recover its majority in the Upper House. The anti-LDP forces all shared the perception that without co-operation both seats might go to the LDP (IS 6 August 1997). In 1997 four political parties - the NFP, DPJ, JSP and Koumei - and three labour unions - Rengou Ibaraki, Kenrou Senta and Kenyuuaikai started discussions about electoral co-operation, termed the ' 4 parties, 3 groups co-operation' (yontou sandantai). Co-operation was not easy to establish. The NFP and Rengou disagreed on candidacy and in November 1997 the NFP threatened to go it alone if the co-operation partners did not support its candidate (IS 1 November 1997). ${ }^{3}$ However, the NFP dissolved at the end of that year and the remaining parties decided to support Gunji Akira from the DPJ. Koumei left this co-operative arrangement before the $\mathrm{HC}$ elections in 1998 and declared a 'free vote' because it was unable to reach an agreement on support in spite of its clear anti-LDP stance (IS 20 May 1998 and 24 June 2000). What complicated matters was that a former Koumei-NFP member of the House of Representatives, Futami Nobuaki, gave his support to the Liberal candidate in this election. Futami had taken part in the anti-LDP alliance as an NFP member, but after the break-up of the NFP in December he had joined the Liberal Party. Some in Koumei may therefore have followed his lead, while others supported the DPJ candidate (IS 24 June 2000). 
The two LDP candidates, Nomura Itsuo and Kuno Kouichi, divided the prefecture between them in the campaign on the basis of the HR single-member districts, one working in the northern part, the other in the south and west (IS 24 June 1998). They also divided the prefectural assembly groups (kengidan) evenly between them as well as various professional organisations (IS 14 October 1997). The result of the election was that the LDP incumbent, Nomura, lost, but the newcomer, Kuno, won. The DPJ's Gunji, who had the support of the remaining members of the anti-LDP alliance, also captured a seat. The fact that the DPJ managed to win a seat of the LDP in the HC elections was said to be an important step in overthrowing the long-time LDP 'kingdom'. The local newspapers attributed the victory mainly to the anti-LDP co-operation along with sluggish economic conditions, although the LDP electoral strategy and the division of the prefecture between the two LDP candidates was also said to have played a part (IS 13 July 1998).

\section{The 2000 election in Ibaraki}

The DPJ victory in the 1998 Upper House election gave the anti-LDP parties some hope that they might make significant progress in the 2000 election to the Lower House. The LDP ran incumbents in all districts apart from one. In the $4^{\text {th }}$ district the incumbent, Kajiyama Seiroku, retired and his son ran in his place. The DPJ replaced the NFP as the main opponent to the LDP in 2000. Only three of the six NFP candidates in 1996 chose to run again, one for the DPJ, one for the LDP (although forced to run as an independent in the end), and one as an independent. In addition, Futami, who had run for the NFP on the PR list in 1996 and won, ran this time in the $6^{\text {th }}$ district for the Liberals. As had happened in the case of the NFP in 1996, all the DPJ candidates were new except one.

The DPJ planned to run in all districts but had problems with nominations. The party recruited three candidates from the local level in addition to its incumbent in the $5^{\text {th }}$ district, but was unable to find a local person to run in the $1^{\text {st }}$ district. It opted to put forward a young woman from Hokkaido who had joined the DPJ during its recruiting campaign for women. The party was also unable to find a candidate for the $4^{\text {th }}$ district to face the LDP candidate. There were therefore only two candidates running in that district, one each from the LDP and the JCP. In the $7^{\text {th }}$ district, the party considered supporting an independent who had run for the NFP in 1996. In the end it abandoned the idea, mainly because of the candidate's conservative leanings. He had been a member of the prefectural assembly for the LDP before running in 1996. The DPJ thus ran candidates in five of the seven districts.

The JSP ran only one candidate in Ibaraki, in the $1^{\text {st }}$ district, in spite of the fact that the DPJ was also putting a candidate forward there. The JCP ran candidates in all districts in accordance with its national policy.

The LDP also faced serious problems with nomination in the $7^{\text {th }}$ district, where the prefectural office clashed with the party headquarters. The safest bet 
for the party would appear to be to support the incumbent, Nakamura Kishirou, a former LDP member who had run as an independent in 1996. The problem was that Nakamura had been convicted of accepting bribes in 1997 and so the party could not officially nominate him this time. The prefectural LDP office decided therefore to nominate a new LDP member, Nagaoka Youji, a bureaucrat who had run for the NFP in the $3^{\text {rd }}$ district in 1996. Party headquarters refused to nominate Nagaoka, however, because of pressure from the Obuchi faction, which strongly favoured Nakamura. In spite of repeated applications from the prefectural office, Nagaoka was unable to secure the nomination and both candidates ran as independents. This was generally taken as tacit support for Nakamura.

Koumei did not field candidates in the single-member districts but fielded a candidate from Ibaraki on the PR list. The strategy was to support the LDP candidates in support of the government coalition and get the organised vote on the PR list. It was estimated that Koumei had around 100,000 votes in Ibaraki. In the 1998 HC election, however, Koumei support went up to 150,000 votes (IS 9 June 2000). Getting Koumei support could therefore affect the outcome considerably. Koumei gave support to LDP candidates in five districts (the $2^{\text {nd }}$ to $6^{\text {th }}$ ) but, according to newspaper accounts, support was not given to the LDP candidate in the $1^{\text {st }}$ district as he had not requested it (IS 9 June 2000). Koumei also put off support in the $7^{\text {th }}$ district as it could not decide between the two independents who had sought it (IS 9 June 2000). The fact that Koumei was a government party and directed its supporters to vote for the LDP created resistance from other religious groups which did not want to lend support to Koumei, either directly or indirectly. And so religious groups such as Risshou Kouseikai and Reiyuukai, which had supported the LDP in past elections, changed their policy in 2000 , the former supporting the DPJ in the $5^{\text {th }}$ district while the latter declared a free vote (IS 17 June 2000; AS 15 June 2000).

As in 1996, the media emphasised the political polarisation between the LDP and the second largest party, though the DPJ had replaced the NFP as the main challenger to the LDP. The DPJ ran in only five of the seven districts and only two of its candidates had any experience of running in Ibaraki. Again it seemed unlikely that the party would pose a serious threat to the LDP, except perhaps in the $5^{\text {th }}$ district. There were no clear policy differences between the two parties. The DPJ criticised the 'conservative way of politics', inherited Diet seats and corruption (IS 15 June 2000), while the LDP refrained from aggressively attacking any particular party in the prefecture. The DPJ managed to gain one seat in 2000 .

\section{The new SMDs}

\section{Ibaraki $1^{\text {st }}$ district}

This district as formed from parts of the old $1^{\text {st }}$ and $3^{\text {rd }}$ districts and has Mito City, the prefectural capital, at its centre. The LDP candidate in 1996, Akagi 
Norihiko, had been an incumbent in the old $3^{\text {rd }}$ district and had inherited his seat from his grandfather, Akagi Munenori, who was a Diet member for the same district from 1952 until 1990. Akagi was not very happy with being moved to the new $1^{\text {st }}$ district in 1996. He had a strong jiban in the western part of the district, which his grandfather had built up, but Mito City was new to him. Vote gathering in Mito was going to be essential for victory as around 40 per cent of the total votes in the district were in Mito.

This was the only district in 1996 where both the NFP and the DPJ ran, splitting the opposition vote. The JSP had held one seat in the district for most of the post-war period but in the 1980s the DSP grew stronger and won a seat from the JSP in two elections. The NFP and DPJ candidates in 1996 had fought each other in the previous two elections, taking turns in winning a seat. The NFP ran Tsukada Enjuu, who had run for the DSP in 1993 in the old $1^{\text {st }}$ district and was a top vote-winner. The DPJ fielded Tokizaki Yuuji, who had come out first in the old $1^{\text {st }}$ district for the JSP in the 'Doi boom' of 1990 but lost in 1993. He left the JSP with Oohata Akihiro ( $5^{\text {th }}$ district) to establish the DPJ. Both Tokizaki and Tsukada had a jiban in the new district.

The JSP had no candidates to put forward in Ibaraki and recommended Tokizaki in the $1^{\text {st }}$ district and Oohata in the $5^{\text {th }}$. The federation of labour unions was torn between the NFP and the DPJ in this election and in the end decided to support both candidates in the $1^{\text {st }}$ district. The JCP fielded a woman, Sekido Hideko, the only woman running in Ibaraki. As expected with the opposition so divided, Akagi won handsomely, getting more than 50 per cent of the votes and nearly twice as many as Tsukada, who came second.

Akagi ran again in 2000 and was the only LDP candidate in Ibaraki who directly voiced his concerns that Prime Minister Mori's statements about the emperor ('kami no kuni hatsugen') might have serious consequences for the LDP in the prefecture. Akagi's criticism of the Prime Minister may have helped in attracting votes from the large group of unaffiliated voters in Mito City (IS 28 May 2000).

The progressive vote was badly split in the $1^{\text {st }}$ district. In 1996 the JSP supported the DPJ candidate. In the 2000 election the JSP decided to field its own candidate in an effort to build up a presence locally. This caused a split between the labour unions which otherwise were showing unity behind the DPJ. The DPJ and Rengou Ibaraki wanted a candidate who could appeal to voters as a clear alternative to the LDP and decided to run a young woman, Satou Yumi. It worked to her disadvantage that she was born in Sapporo and had only recently joined the DPJ. Satou was thus considered something of an outsider in the district (IS 14 May 2000). She targeted urban voters in Mito and especially women and young people. The JSP ran Takasawa Katsuichi, with the support of the Jichirou Kenhonbu, the biggest force in Rengou, and the Teachers' Union. The LA also ran a candidate, Gunji Takao, who had also run for the party in the HC election in 1998. He was the only candidate for the party in the prefecture. 
Akagi strengthened his position further in the district in this election, securing support from unaffiliated voters and thereby increasing his votes by 18,000 since 1996. He received more than twice as many as the DPJ candidate who got 53,000 votes. The $1^{\text {st }}$ district could have been quite competitive in 1996 if the opposition had managed to co-operate. By 2000, Akagi had made his seat safe against any challenger.

\section{Ibaraki $2^{\text {nd }}$ district}

The $2^{\text {nd }}$ district is a very rural district with no major cities, and was created out of a fragment of the old $1^{\text {st }}$ district. Three candidates ran in 1996 but it was clear from the start that the conservative candidate, Nukaga Fukushirou, was a likely winner. Nukaga, a high level LDP politician, had a strong jiban in the district and had come second in the old $1^{\text {st }}$ district. He had first been voted in as a Diet member from the $1^{\text {st }}$ district in 1983 as a direct successor to the retiring LDP Diet member, Hashimoto Tomisaburou. With the help of Hashimoto he had been able to build a very strong kouenkai over the years. The electoral change was good for Nukaga as he was able to hold on to all of his strongest areas while those where he had done badly now formed part of other districts. It was, however, important for him to widen his support further and this led to extensive co-operation between him and the LDP candidate in the $3^{\text {rd }}$ district, Nakayama Toshio, whom he had fought in the old $1^{\text {st }}$ district. The co-operation consisted of introducing supporters to each other; exchanging name lists for their kouenkai; attending each other's social gatherings; and visiting supporters on each other's behalf. They decided therefore not to dissolve their old kouenkai but to use them in an innovative way to increase their support in the new districts (Yamada 1997: 126). Nukaga also co-operated with Hanashi Nobuyuki, another LDP incumbent from the old $1^{\text {st }}$ district (IS 1 January 1999).

The opposition parties had great difficulties in finding a suitable rival to Nukaga. The two strongest candidates, those who had fought him in the old $1^{\text {st }}$ district, Tokizaki of the JSP and Tsukada of the DSP, were both running in the new $1^{\text {st }}$ district. The NFP was therefore trying to find a candidate until late in the campaign and finally decided to nominate Tokoi Yoshiharu, a company president. Tokoi was persuaded to run, even though he had no chance of winning, because the campaign would be preparation for the prefectural assembly election in 1998 (Yamada 1997: 127). Nukaga's campaign was clearly directed against the NFP, and as it turned out, Nukaga won in all the towns and villages, even in Tomobe, Tokoi's home town (Yamada 1997: 130). He was elected with more than 60 per cent of the votes, twice as many votes as Tokoi.

All the same candidates ran in the district in 2000. Tokoi ran this time for the DPJ. He got support from the local labour union and therefore had a stronger organisational base this time (AS 1 June 2000). Although Nukaga was not able to spend much time in his own district because of his efforts to help other LDP candidates around the country, there was no real threat to his dominance, 


\section{Four prefectural case studies}

considering his victory in the previous election and his high profile in the LDP. Nukaga had been very successful in 1996 in using the kouenkai left over by other LDP candidates in the district to gather votes. In the 2000 election he took this co-operation a step further when he merged the kouenkai which the other conservative incumbents of the old $1^{\text {st }}$ district, Nakayama and Hanashi, had left behind within the borders of the new $2^{\text {nd }}$ district. The extent of the co-operation is best shown in the fact that the head of Nukaga's kouenkai in Ibaraki Town is the former head of Nakayama's kouenkai (IS 27 May 200). In spite of greater organisational support Tokoi got almost the same amount of votes as in 1996, while Nukaga received nearly three times as many as Tokoi, increasing his share by around 30,000 votes. The $2^{\text {nd }}$ district had not been competitive in 1996 and became less so in 2000 as Nukaga expanded and solidified his organisation.

\section{Ibaraki $3^{\text {rd }}$ district}

The $3^{\text {rd }}$ district is a fragment of the old 1st district, a fast growing region with many residents commuting to Tokyo and the highest number of floating votes in the prefecture. There were four candidates running in 1996, the major contest being between the LDP's incumbent Nakayama Toshio, former head of the Defence Agency, and a former bureaucrat, Nagaoka Youji, for the NFP. This was the only district in Ibaraki that posed nomination problems for the LDP in 1996. The old 1st district had had three LDP incumbents: Nukaga Fukushirou, Nakayama Toshio and Hanashi Nobuyuki. Nukaga was running in the new $2^{\text {nd }}$ district but both Nakayama and Hanashi wanted nomination in the new $3^{\text {rd }}$ district. It was decided to set up a Costa Rica arrangement whereby Nakayama, being the elder of the two, would get the seat and Hanashi would go on the PR list. The plan was then for them to switch seats in four years' time.

Both Nakayama and Hanashi were second-generation politicians and had fought each other bitterly in the old $1^{\text {st }}$ district, as had their fathers, Nakayama Eiichi and Hanashi Shingoro, before them. However, they co-operated closely in this campaign, ensuring the support of each other's kouenkai. As mentioned earlier, Nakayama was also involved in extensive co-operation with Nukaga of the 2 nd district. The co-operation was successful and Nakayama won with more than 45 per cent of votes cast, while Hanashi got a seat through the PR list. Nagaoka of the NFP came in second with around 37 per cent of the vote.

In accordance with the Costa Rica arrangement Nakayama moved to the PR list in the 2000 election and Hanashi came back to fight in the single-member district. The main challenge to the LDP in 2000 was the DPJ, replacing the NFP candidate, Nagaoka, from 1996 who moved to the $7^{\text {th }}$ district and ran for the LDP. The DPJ ran a new candidate in the $3^{\text {rd }}$ district, Koizumi Toshiaki, who had been a member of Toride City Council. Koizumi had been a member of the 'Hanashi faction' while in the City Council but ran for the DPJ in the prefectural elections in 1998. He became a harsh critic of Hanashi after he decided to run for the DPJ in 2000 (IS 30 May 2000) and sought to appeal to young voters by calling 
for 'generational change' in the district (IS 6 June 2000). As with other DPJ candidates in Ibaraki, he had the support of the labour unions. In addition, the JCP ran a candidate, Ueno Takashi, who had run before.

In spite of the deep animosities between Hanashi and Nakayama, their supporters continued the trade in votes, resulting in yet another success for the Costa Rica arrangement. Hanashi won with nearly the same percentage of votes as Nakayama before him in the single-member district, while Nakayama got a seat through the PR list. Support for the DPJ, however, also increased greatly, ensuring Koizumi a seat through the PR list. The DPJ also captured more PR votes than the LDP in the $3^{\text {rd }}$ district, which perhaps augurs well for the party's future in the district.

\section{Ibaraki $4^{\text {th }}$ district}

The new $4^{\text {th }}$ district is a fragment of the old $2^{\text {nd }}$ district. Three candidates ran in 1996. The strongest was Kajiyama Seiroku, LDP incumbent from the old $2^{\text {nd }}$ district and former secretary-general of the party, who had a very strong jiban that he had built up over the years. The main challenger, the NFP candidate Saitou Zenichirou, had also run in the old $2^{\text {nd }}$ district in 1993 under a Japan New Party banner.

The new district lines caused some problems for Kajiyama. He had to leave his strongest kouenkai outside the new district lines. He therefore decided to cooperate with one of his former opponents in the old $2^{\text {nd }}$ district who faced a similar problem, Tsukahara Shunpei, who was now running in the $5^{\text {th }}$ district for the LDP. Much emphasis was laid on ensuring the support of prefectural assembly and City Council members who had previously supported the other candidate. It was most important, however, to ensure the support of the kouenkai of the candidate now running in another district. Tsukahara and Kajiyama gave speeches in support of each other in order to integrate the support base they had left behind outside the new district lines (kouenkai no yuugou), and appealed to their old kouenkai to support the other candidate (IS 21 October 1996; Niwa 1997: 201).

The DPJ, faced with a very strong LDP candidate, was unable to find a suitable candidate. This did not, however, work to the NFP's advantage. The Souka Gakkai declared a free vote, and, in spite of Koumei and Kenyuuaikai support, Saitou lost half of the votes he had garnered in the 1993 election. Kajiyama, however, was able to attract a large portion of the left-of-centre support base and got close to 70 per cent of the vote (IS 26 April 2000).

Sudden illness forced Kajiyama to retire in February 2000, less than two months before the election. His eldest son, Hiroshi, decided to run in his place. Kajiyama Seiroku then died unexpectedly in early June. The DPJ contemplated running in the district but decided against it because of the overwhelming strength of the Kajiyama empire (AS 31 May 2000; personal communication with DPJ members). And so the choice was now between an LDP candidate and a JCP 


\section{Four prefectural case studies}

candidate, Oowada Kiichi. Kajiyama's supporters feared criticism of the hereditary succession but it soon died out. Kajiyama won with nearly 140,000 votes against nearly 28,000 for Oowada, a better result than his father got in 1996. As was demonstrated in several other districts around the country, replacing a recently deceased incumbent is a sure way of winning an overwhelming victory.

\section{Ibaraki $5^{\text {th }}$ district}

This district is a fragment of the old $2^{\text {nd }}$ district. It is the smallest district in the prefecture, and at its centre is Hitachi City where 70 per cent of the voters live. Hitachi is the site of an old coal mine and has therefore, like Hokkaido, a strong history of unionism and relative JSP strength. This is the only district in Ibaraki that saw real competition between the LDP and the DPJ in 1996. The battle was between the LDP incumbent, Tsukahara Shunpei, a former cabinet minister, who came third in the old $2^{\text {nd }}$ district in 1993, and Oohata Akihiro, who had also won a seat in the old $2^{\text {nd }}$ district in 1993 for the JSP. Tsukahara inherited the seat in 1976 from his father, Tsukahara Toshio, who had been a Diet member for the LP and the LDP from 1949 until 1976. Oohata was first elected in 1990 but left the JSP to participate in the establishment of the DPJ just before the elections in 1996. The DPJ had no local organisation but many of the local unions, which traditionally supported the JSP, rallied behind Oohata. Oohata also received support from the JSP and relied on the party's local organisation units (Niwa 1997: 200).

Within the old $2^{\text {nd }}$ district the LDP had usually held two seats and the JSP at least one. The new electoral system created a clear division between the labour and management sides within the factories in Hitachi. The local labour union supported Oohata, while the management side supported Tsukahara. However, both sides had to invent new ways of attracting votes, as it was not going to be enough to depend on the usual mobilisation through their respective organisations as had been done before.

Oohata came in first in the old three-member $2^{\text {nd }}$ district in 1990 when he first ran with JSP and DSP support, and second in 1993, after Kajiyama. Kajiyama moved to the $4^{\text {th }}$ district in the 1996 election and Oohata faced Tsukahara. His chances of winning were adversely affected by two factors: divisions among the anti-LDP parties, and the co-operation between Tsukahara and Kajiyama. The anti-LDP forces did not co-operate in this district and the NFP decided to put its own candidate forward. It then became clear that Rengou Ibaraki was supporting Oohata and that the Yuuaikai, which otherwise supported the NFP, was not going to support the NFP in the district. The NFP then backed down and moved its candidate to the $6^{\text {th }}$ district. To do this the incumbent in the $6^{\text {th }}$ district, Futami Nobuaki (who had run for Koumei in 1993) had to be moved to the PR list.

Tsukahara, through his co-operation with Kajiyama, his former opponent in the old $2^{\text {nd }}$ district, was able successfully to incorporate Kajiyama's old support base which was now inside Tsukahara's district lines. He appealed to Kajiyama's 
supporters for 'party unity' (ipponka) and was able to ensure their support. There were some factional divisions within the local government but on the whole the transfer was successful (Niwa 1997: 201). Tsukahara won with a little over 50 per cent of the vote. The nomination problems caused by the clash between the NFP and the DPJ and the ultimate withdrawal of the NFP left many floating votes which Oohata proved unable to catch. Oohata was, however, able to secure nearly 40 per cent and won a seat in the PR tier.

Tsukahara died unexpectedly in January 1998 of heart failure when he was only 51 years old, and a by-election had to be held in the district in February 1998. The LDP tried to persuade Tsukahara's widow to run in an effort to keep the jiban intact. She declined. The party then decided to field the secretarygeneral of the prefectural LDP office, Okabe Hideo. The DPJ was unable to find a candidate in time. Okabe fought a JCP candidate and an independent and won the election with the support of Tsukahara's kouenkai.

In 2000 Oohata and Okabe, though both incumbents, fought each other for the first time. Both camps said the ability to garner votes was decreasing because of the economic recession, restructuring and the decrease in union membership which was affecting the factories in Hitachi (IS 10 May and 9 June 2000). The JCP and the Liberals also fielded candidates.

Okabe started his campaign early and relied on support from Hitachi City as well as from Kita Ibaraki where Tsukahara's jiban had been strongest (AS 1 June 2000). He also concentrated on getting support from women. The LDP and the DPJ vied for the Koumei support that was believed to be vital for victory, a total of around 20,000 votes (IS 9 June 2000). As in most other districts in Ibaraki Koumei gave its support to the LDP candidate. Oohata relied on the labour union for support but was also active in trying to attract unaffiliated voters.

The fight was very even. Oohata won with a majority of only 3,000 votes, increasing his share by 12,000 votes since 1996 . The DPJ also did better in the PR vote than in 1996, leading the LDP by 36 to 24 per cent (IS 27 June 2000). Oohata had been successful in drawing in the protest vote over the recession, strongly felt in Hitachi, while Okabe lost conservative votes to the Liberal candidate. Okabe had been unable to get a seat high enough on the PR list and therefore lost his Diet seat. The LDP blamed the disorganised nature of the cooperation with Koumei in the district for the defeat, saying that the arrangement between the LDP and Koumei had not been explained well enough to Souka Gakkai members (IS 26 June 2000).

\section{Ibaraki $6^{\text {th }}$ district}

This district consists of most of the old $3^{\text {rd }}$ district and part of the old $1^{\text {st }}$ district. It has Tsuchiura City at its centre. In 1996 six candidates ran, compared to only three or four in the other six districts. The LDP candidate, Niwa Yuuya, was an incumbent from the old $3^{\text {rd }}$ district, having inherited the seat in 1979 from his father, Niwa Kyoushirou, who had first run in 1952. He sought to win over some 


\section{Four prefectural case studies}

of the support from other LDP candidates in the old $3^{\text {rd }}$ district but there was no formal co-operation. The competition was between the LDP candidate and a new NFP candidate, Kobayashi Kunio, who had originally planned to run in the $5^{\text {th }}$ district but gave up because of lack of union support. To enable Kobayashi to run in the $6^{\text {th }}$ district, an incumbent of the NFP, Futami Nobuaki, a former cabinet minister who had won for the Koumei in 1993, had to be moved to the PR list less than a month before the election. The JCP, Sakigake, the New Socialist Party and the LA all fielded candidates. Niwa won an overwhelming victory, securing nearly 57 per cent of the vote, almost three times as much as Kobayashi, who came in second. Futami was elected from the PR list.

In 2000 four candidates ran. The biggest challenge to Niwa was a new DPJ candidate, Igarashi Hiroko, a former City Council member in Tsukuba, who concentrated on appealing to women and young people. She also focused on the cities where the LDP had done badly in the HC election in 1998 (IS 10 June 2000).

The $6^{\text {th }}$ district was the only district in Ibaraki affected by the LDP-KoumeiConservative Party coalition. The casualty was Futami Nobuaki, who decided to move back to the single-member district after being elected from the PR list for the NFP in 1996. Futami was first elected in 1969 for the Koumei and had received DSP support in most elections. After the demise of the NFP he was one of the few who decided to join the Liberals rather than return to Koumei. He had been hoping to ensure continuing Koumei support in this election but Koumei announced in the middle of the campaign that it would support the LDP candidate in districts two to six in a bid to maintain the present government coalition. Having lost Koumei support, Futami was forced to move his election campaign to the streets. Before the election it was estimated that Liberal support was around 17,000 votes (IS 10 June 2000), and although Futami managed to push the vote up to 26,000 he lost the election.

Niwa's strong standing in the district was well known. He was a prominent politician, having served as welfare minister in the Obuchi cabinet. Like Nukaga, he was touring the country in support of various LDP candidates and spent only one-third of his time in his district during the campaign. He was active in creating new kouenkai, especially for women. He won the election handsomely, securing more than 50 per cent of the vote, more than twice as much as the DPJ's Igarashi, who came in second. Futami came in third.

\section{Ibaraki $7^{\text {th }}$ district}

The $7^{\text {th }}$ district is made out of a fragment of the old $3^{\text {rd }}$ district. The incumbent, Nakamura Kishirou, a prominent second-generation LDP member and former cabinet minister, had been regarded by many as future leadership material for the party. His father had been a member of the HC but his mother had taken over the seat following her husband's death. Nakamura's kouenkai, the Kiyuukai, was said to be the strongest in the prefecture, and he normally finished first in his district. 
He was, however, arrested in the Zenecon scandal on suspicion of having accepted bribes in 1991-1992 from a construction company to stop a probe by the Fair Trade Commission into a bid-rigging case. He left the LDP in 1994 and ran as an independent in the 1996 election with LDP support. He was offered a recommendation but declined, saying he did not want to be a 'nuisance' (meiwaku) to the party (IS 22 September 1996). The local media guessed that he wanted to appeal to a wider electorate as an independent, realising that he could win without party support (IS 5 and 6 October 1996).

His main opponent was Tanaka Katsuya, a former prefectural assemblyman for the LDP, now running for the NFP. He ran openly as an 'anti-Nakamura' candidate and sought the support of Rengou. Rengou was unable to reach an internal agreement to support Tanaka because of his conservative background and so he ran with the support of individual labour organisations (IS 27 October 1996). Nakamura successfully secured the support of local politicians who had supported Akagi and Niwa, his rivals in the old $3^{\text {rd }}$ district (IS 5 October 1996) and won the election with 53 per cent of the vote while Tanaka came second with 38 per cent.

In 2000 five candidates ran, four of whom had conservative backgrounds. This was the only district in Ibaraki where the LDP had serious nomination problems. Nakamura had received the support of the LDP prefectural office in 1996 because of the prevailing view that he should be presumed innocent until proven guilty (IS 5 June 2000). He was, however, found guilty in October 1997 of accepting bribes and sentenced to one and a half years in prison. He maintained that the money he had received was merely a political donation and appealed (IS 2 October 1997).

Nakamura's case was under appeal during the 2000 election campaign but because of his conviction in 1997 the local LDP decided not to support him in the 2000 election. He decided to run again as an independent. The LDP prefectural office decided to field its own candidate and put forward Nagaoka Youji. Nagaoka had run in the $3^{\text {rd }}$ district under the NFP banner in 1996 but lost and then joined the LDP in 1999. The prefectural office put forward a request for party nomination that was supported by the Etou-Kamei faction.

The party, however, refused to nominate Nagaoka because of Nakamura's strong connections with the Obuchi faction (IS 27 May 2000). The prefectural LDP branch interpreted this as unofficial support for Nakamura in spite of his sentence (IS 5 June 2000) and it criticised the central headquarters, accusing it of 'factional bullying' (IS 3 June 2000). The nomination issue reached down to the prefectural level where many LDP members continued to support Nakamura and would not bend to the prefectural office's pressure to endorse Nagaoka (IS 5 June 2000).

The Ibaraki Shimbun referred to the campaign in the district as a 'twisted election' (nejire senkyo) as there was no official LDP candidate, but four conservative candidates, three of whom ran as independents (IS 26 June 2000). Nakamura and Tanaka Katsuya, who had faced each other in 1996, and Nagaoka Youji, supported by the prefectural LDP office, all ran as independents. Tanaka 


\section{Four prefectural case studies}

requested support from the DPJ, which posed a bit of a dilemma for the party. Tanaka had shown a considerably strong standing in the district in the 1996 election so the DPJ might have stood a chance against Nakamura by supporting him. The party decided, however, against this because of Tanaka's prior conservative affiliation (IS 26 April 2000). The Liberals fielded Nomura Itsuo, a former HC Diet member for the LDP who left the party after losing in the HC elections in $1998 .^{4}$

Nakamura won the election with 43 per cent of the vote, 12,000 votes less than in 1996 but at least 37,000 votes more than Tanaka who came second. Nagaoka, supported by the prefectural LDP, came in third with just over 36,000 votes. Nakamura's calculation was correct: he did not need official nomination from the LDP nor prefectural support to win in his district. He had a very strong and effective kouenkai that was able to gather the vote, with or without the party's support. It is, however, difficult to say whether the outcome would have been the same had Nagaoka got the party's endorsement.

Nagaoka's defeat was seen as a defeat for the LDP. However, Nakamura was still very close to the LDP, had the unofficial support of some LDP politicians, followed the party line in the Diet, and repeatedly indicated that he would join the LDP again in the future if found innocent of the bribery charges. The prefectural office was nevertheless still ready to fight Nakamura and declared that it would support Nagaoka in the next general election if he chooses to run (IS 26 June 2000).

\section{Conclusion}

Ibaraki prefecture has always been a Conservative stronghold with up to threequarters of the seats going to the LDP. In the first elections under the new system in 1996, the Conservative grip on the prefecture became almost total. The LDP (including Nakamura of the $7^{\text {th }}$ district who ran as an independent) got all seven seats in the single-member districts. LDP candidates won by large margins over their strongest challengers. Five of those LDP candidates got over 50 per cent of the vote and the sixth (Nakayama in the $3^{\text {rd }}$ district) came very close to that figure.

It was of great benefit to the LDP candidates that they were all incumbents and most were second-generation politicians who had built their support on their fathers' or grandfathers' jiban. But they were facing new district boundaries and had to fight in areas where they had no stable support, while losing some of their support to other districts and other candidates. In spite of the fact that these LDP politicians had fought each other bitterly under the old electoral system, they successfully co-operated with each other, borrowing kouenkai support from their former foes, even taking over their kouenkai and campaigning for each other. At the prefectural level, the 1996 election also saw unprecedented involvement of Conservatives who assisted in co-ordinating the election campaign, and a very active role of the LDP prefectural office (Yamada 1997:128). Many LDP 
prefectural assemblymen were active in the campaign, attending meetings, speaking for LDP candidates and asking their own supporters for support.

The anti-LDP forces were, however, scattered. The main opposition was in the NFP but the DPJ also fielded two candidates. They proved unable and unwilling to co-operate. Labour union support was therefore not unified behind one party but varied between districts. Anti-LDP co-operation in the 1998 House of Councillors election was successful but further co-operation did not materialise. In the prefectural assembly elections that followed in December 1998, distrust between the JSP and the DPJ was evident and there was no co-operation between them (IS 26 May 2000). The LDP won a big victory in that election, although dropping from 55 to 47 seats out of a total of 66 (IS 15 December 1998).

The distrust remained in the general election of 2000. The media referred to the past anti-LDP co-operation as an illusion and argued that due to the changing political situation anti-LDP co-operation was not viable (IS 26 March 2000). Koumei had changed sides and now supported the LDP in five districts. It appeared to be the common understanding on all sides that with Koumei out of the alliance there was no basis for co-operation between the JSP and the DPJ (IS 26 March 2000; private communication with a DPJ activist in Ibaraki, June 2000).

The DPJ replaced the NFP as the main challenger to the LDP in the 2000 election but ran in only five of the seven districts. This time labour support was more complete and the unions rallied behind all the DPJ candidates. The LDP opposition was better organised and somewhat more solidified than in 1996 although the progressive vote was still badly split in the $1^{\text {st }}$ district. The LDP candidates continued in their effort to incorporate the remaining kouenkai from other Diet members into their own. Many were also active in establishing new kouenkai within their districts, appealing to young people and women (IS 1 January 1999).

The result of the election was that the LDP got five single-member seats, an independent (of LDP descent) got one, and the DPJ got one. On the PR list the LDP, DPJ and Koumei secured one seat each. The 2000 election was generally interpreted as a defeat for the LDP. Overall, the LDP lost one seat to the anti-LDP forces, which got three seats. The biggest defeat was considered to be that Okabe, the secretary-general of the local LDP office, who lost a single-member district seat to a DPJ candidate. The loss in the $5^{\text {th }}$ district was a major blow for the LDP and the local media referred to the defeat as a 'collapse of one of the foundations of the conservative kingdom' (Jimin Ookoku ikkaku kuzureru) (IS 26 June 2000).

The PR system, by allowing double candidacy in SMDs and on the PR list, helped to counter the overwhelming influence of the LDP in Ibaraki and secured an additional seat for the DPJ in 2000. Furthermore, the LDP vote on the PR list went down in every district and the LDP finished second to the DPJ in the $3^{\text {rd }}$ and $5^{\text {th }}$ districts. In 1996 the LDP received 40 per cent of the PR vote in four districts. In 2000 its vote had fallen significantly with its best result being in the $2^{\text {nd }}$ district where it got 38 per cent. Overall, the DPJ held 24.6 per cent of the vote 
in the PR system in Ibaraki while the LDP held 32.5 per cent. This 'cross phenomenon' (kurosu genshou) whereby voters voted for the LDP in the singlemember district but voted for other parties in the PR tier (IS 27 June 2000) increased bipolarity which may continue to grow.

There were also visible trends toward bipolarity at the district level, in the sense that the main challenge to the LDP was the NFP in 1996, running in six out of seven districts, and the DPJ in 2000, running in five districts. However, as under the MMD, the challenge to the LDP was very limited. The incumbency advantage is strong in Ibaraki and the LDP dominates most districts. The DPJ victory in 2000 in the only competitive district, the $5^{\text {th }}$ district, was narrow, as was the LDP victory in 1996, but in 2000 the LDP incumbent was relatively new, having first won his seat in 1998. With the exceptions of the $5^{\text {th }}$ and $7^{\text {th }}$ districts, LDP incumbents all gained votes. In an election where the LDP was losing nation-wide, four of the LDP candidates in Ibaraki got more than 50 per cent of the vote. Elections which had not been particularly competitive in 1996 became even less so in 2000 .

In spite of the DPJ victory in the HC election in 1998 and signs of growing bipolar competition in the PR tier in 2000, the SMDs are likely to remain dominated by the LDP as long as the anti-LDP forces have no local organisations capable of challenging the LDP kouenkai (see IS 23 October 1996). Anti-LDP cooperation, such as that which secured a victory for the DPJ candidate in the HC election in 1998, cannot substitute for local organisation. Such co-operation is very fragile and changes with the political winds. Furthermore, although the DPJ was more successful in ensuring union support in the 2000 election than the NFP had been, such support alone is not sufficient to win. In response to this problem the DPJ has made some efforts to establish its presence in Ibaraki and opened a party office in Ibaraki in March 1997, vowing to strengthen it further after the HC elections in 1998. Local organisation is, however, still practically non-existent. Without local organisation the DPJ is unlikely to defeat the "Conservative Kingdom' in the near future.

\section{Acknowledgement}

I would like thank Kurita Hiroko, Satou Rieko, Seki Akiko and Tateno Yasuko for taking the time to discuss politics in Ibaraki with me. I am very grateful to Oohata Akihiro and his staff who welcomed me at the DPJ office in Hitachi City and gave me valuable insight into the electoral campaign. Many thanks also go to Steven Reed and John Metson for their help.

\section{Notes}

1 The PR seats were reduced to 20 in early 2000.

2 I am including here Nakamura Kishirou, although he ran as an independent in the $7^{\text {th }}$ district in 1996. He had been a member of the LDP but was forced to run as an 
independent because of his involvement in the Zenecon scandal. He received LDP support.

3 The candidate the NFP wanted to nominate, Nagaoka Yoji, had run for the NFP in the HC elections in 1996, and was to run in the $7^{\text {th }}$ district for the LDP in the general election in 2000.

4 Nomura had been supported by Nakamura in the HC election (IS 1 January 1999). 


\title{
7 Kagoshima: the prefecture that realignment forgot
}

\author{
Robert Weiner
}

Before 1993, Kagoshima maintained an extreme version of Japan's 'one-and-ahalf party system'. A dominant Liberal Democratic Party (LDP) was checked by a smaller Japan Socialist Party (JSP), which itself dominated the opposition. Since 1993, the Socialists have faded, but no new opposition party has fully dislodged them. What remains is the LDP, and the prefecture is rapidly becoming a one-party system. Electoral system change has re-shaped Kagoshima politics, but party realignment has largely passed the prefecture by - as it has since 1955 .

The introduction of single-member districts in the Lower House, as expected, made the translation of votes into seats less proportional. The Socialists were promptly shut out. The LDP's native strength and new-found skill in managing candidacies, combined with opposition fragmentation and well-timed good fortune, has won it nine of 10 SMD races over two elections. Meanwhile, neither the Socialists nor the LDP offered up major defectors, leaving new-party development stunted and idiosyncratic. New-party candidates, all conservatives, have laboured to set themselves apart from conservative LDP incumbents; the Socialists are still well-entrenched; former centrist parties are tiny and their own organisations are slight. The prefecture's one new success story has been a de facto local party, the Liberal Alliance (LA), whose presence adds to alreadyincreased opposition fragmentation. The non-LDP, non-Communist electorate remains divided, and has been kept from spreading its votes among multiple candidates only because no more than one party in any SMD has had the energy to mount serious challenges.

The effects of national-level party realignment were felt mostly in Kagoshima's one urban and one semi-urban district, which receive the most attention below. In the prefecture's three rural districts, outcomes hinged more exclusively on LDP internal co-ordination, which proceeded smoothly in all cases. 


\section{The foundations of realignment}

\section{Kagoshima's one-and-a-half party system}

The term 'one-and-a-half party system' hardly needs quotation marks in Kagoshima. Perhaps more than in any other prefecture, the LDP and the JSP have dominated political life.

Kagoshima might be called the Virginia of Japan: a once-dominant political force whose historical pride remains intact, even as its influence has waned. The prefecture was formerly the Satsuma domain, one of the leading forces in the creation of the modern Japanese state. But Kagoshima's post-war LDP, though extraordinarily strong, has produced no outstanding leaders, with the possible exception of Tanaka faction general Nikaidou Susumu. Nor was the Kagoshima LDP particularly well disciplined before realignment, and maverick conservative candidacies often hurt the party in the urban old $1^{\text {st }}$ district.

The absolute strength of Kagoshima's LDP sometimes obscures the relative strength of its Socialists. Kagoshima Socialist support was rooted in cities and public-sector unions, in contrast to the rural base of strong Socialist branches in Niigata, Nagano, Akita, and Tottori, or the coal-miner base found in Hokkaido, Fukuoka, and Ibaraki $5^{\text {th }}$ district. Teachers' unions were particularly powerful and supplied most Diet candidates. These unions and the party as a whole maintained a rough balance between leftist and rightist tendencies. The right wing was led, at least symbolically, by Councillor Kubo Wataru, a major figure in the national JSP and its coalition governments in the early 1990s (see Chapters 3 and 4).

Other parties had little presence. The Democratic Socialist Party (DSP) was held back by the scarcity of private industry, and gained only a slight boost from nuclear energy interests in Sendai City. Koumei and its Souka Gakkai base were fairly small everywhere but the Amami islands - and in Amami Koumei was outmobilised by warring conservatives. Kagoshima's Japan Communist Party (JCP) was weaker than that of any other prefecture (and will mostly be ignored below). Thus, the Kagoshima JSP nearly monopolised the non-LDP electorate, and that relatively small share was large enough to make it one of the strongest Socialist branches in the country.

Most elections before realignment were LDP-JSP contests, alongside token efforts from the JCP. Other parties generally ran no candidates. Such strategic non-entry by weak parties is by no means rare across Japan (Kohno 1997; Scheiner 1999; Weiner 2000). Between 1980 and 1990, 39 of 130 old-system MMDs never saw candidates from parties other than the LDP, JSP and JCP. Kagoshima, however, was one of only six prefectures whose districts all fell into this category. 


\section{Four prefectural case studies}

Given the Kagoshima LDP's rough 2:1 vote support advantage over the JSP in national elections, and the lack of other viable candidates, MMD provided a proportional translation of votes into seats. In the four-seat old 1st district, conservatives won three or two seats to the Socialists' one or two in all but one HR election between 1952 and 1990. In the three-seat old $2^{\text {nd }}$ district, over the same span, conservatives always took two seats, and the Socialists one. Only in the thoroughly rural three-seat (and later two-seat) old $3^{\text {rd }}$ district did the LDP regularly shut out the JSP. In the two-seat House of Councillors district, the two parties split the prefecture's seats just as often as the LDP won both. In SMDs, though, the Socialists would have little chance against a unified conservative camp, as suggested by their failure ever to win either a governor's election or the old Amami SMD.

\section{Amami, early redistricting and the 1990 Socialist boom}

Realignment in Kagoshima has since strengthened the LDP at the Socialists' expense, with little intrusion from new parties or shifting Diet coalitions. The process was jump-started by developments before 1993 that left the once strong Socialists vulnerable in the lead-up to the 1993 Lower House election and subsequent electoral reform. The party was hobbled by the effects of redistricting in Amami, by poorly timed short-term cycles in its electoral fortunes, and by longer-term generational cycles (alongside more general causes of Socialist decline nation-wide). The same factors eased LDP co-ordination after 1993, and help to explain why the otherwise obscure LA has posed the strongest new-party challenge to Kagoshima's LDP.

Prior to the 1993 election, the Amami SMD was eliminated and appended to the old $1^{\text {st }}$ district, and the introduction of its two leading candidates to the mainland ultimately proved to shape outcomes in Kagoshima's most closely contested post-1993 districts. Amami's unusual experience as the old electoral system's only territory represented by an SMD foreshadowed the effects of the new electoral system. Reformers argued that SMDs would encourage party- and policy-centred campaigns. But this two-party ideal requires more than electoral rule changes. If one party or faction dominates, SMD elections may lapse into either non-competition or factional warfare, as the American South once showed. Of course, many Japanese MMDs produced their own faction-backed rivalries, colourfully known as 'wars'. But the Amami SMD's 'Yasu-Toku War' - in which one side was sure to lose - was fought on islands whose local elections sometimes involved angry mobs protesting dubious recounts, relegation of enemy-faction civil servants to janitorial duty, and spending so vast that some think it a drain on the local economy (Katou 1985).

Yasuoka Okiharu, a former central bureaucrat and lawyer who had helped to defend Tanaka Kakuei during the Lockheed scandal, won the Amami seat in 1972 and enjoyed only token opposition in the next three elections. In 1983, though, he was challenged by Tokuda Torao, chief director of the private Tokushuukai 
hospital group. Tokuda has one of the more messianic-charismatic personalities in Japanese politics. He has entered campaign rallies to 'Thus Spake Zarathustra', and is given to pronouncements like 'One day I'll be President of the World Federation' and 'I'm going to do things the Buddha couldn't do' (Katou 1985: 28 and 50). Tokuda's powerful 1983 campaign combined populism, relentless zeal, an organisational base in his hospitals, and criticism of Yasuoka for having neglected Amami and supported the Tanaka regime. The ensuing Yasu-Toku War pitted Yasuoka against Tokuda, the Tanaka faction against the Fukuda faction, and the Japan Medical Association (JMA) against the Tokushuukai. Yasuoka held his seat in 1983 by a $50-49$ percentage point margin, and again in 1986 by $51-48$. In 1990, Tokuda finally defeated Yasuoka, 50-48, though a retroactive endorsement from the LDP, a standard gift for conservative incumbents, was scuttled by JMA pressure (Minami Nihon Shinbun, hereafter MNS, 3 October 1996). The three Yasu-Toku elections mobilised the islands totally: each prompted turnout above 92 per cent, a level unmatched by any other district since at least 1958 . Shoehorning Amami into the four-seat old $1^{\text {st }}$ for 1993, then, stood to give both Yasuoka and Tokuda room to win seats, and to squeeze out Socialists and other mainland candidates with less fervent followings.

The Socialists were also left in a weak position in 1993, curiously enough, by their strength in 1990. In the old $1^{\text {st }}$ district, the JSP's two candidates surged to first and second place in 1990, capturing two of the district's four seats. But such unusually good performances can prove counterproductive once conditions return to normal. If none of the last election's lucky incumbents stands down, the windfall of seats may be promptly transformed into excess candidacies, a split party vote, and self-defeating losses (Weiner 1998).

In the old $3^{\text {rd }}$ district, Socialist success in 1990 left the party prey to a different type of electoral cycle: the runner-up rebound (jiten bane) phenomenon (Reed 1994b). In 1990, the Socialist Arikawa Seiji squeaked past LDP heavyweight Yamanaka Sadanori to win the second of two seats by 62,488 votes to $62,460-$ the smallest victory margin that year. Unfortunately for Arikawa and the Socialists, nothing motivates a candidate like the sting of a razor-thin loss. Candidates consistently respond to close defeats with crushing victories in the next election, fuelled both by regret and by the freedom to campaign full-time.

\section{The 1993 election and its aftermath}

The 1993 LDP split had relatively little effect on that year's election in Kagoshima. None of the three Kagoshima LDP candidates associated with the Takeshita faction defected alongside Hata, and no LDP incumbent suffered much damage from new-party challengers. The only defector of any sort was former LDP incumbent Nagano Sukenari, who had lost in the old $1^{\text {st }}$ in 1990 and then retired in (self-preserving) protest against the Amami merger, but reversed his position and became a Shinsei candidate once that party formed. 


\section{Four prefectural case studies}

The 1993 results installed LDP candidates as incumbents and drove their strongest progressive challengers into retirement. The old $1^{\text {st }}$ district witnessed its first LDP sweep since 1960. Amami's Yasuoka and Tokuda dominated the island vote and exploited groups including Amami Natives' Associations to outdraw other candidates even on the mainland. LDP incumbents Miyaji Kazuaki and Miyazaki Moichi hung on as well. The total Socialist vote would have been enough for a second-place finish, despite the entry of new parties, but the two incumbents split them nearly evenly and both lost. Shinsei's former incumbent Nagano and JNP newcomer Kawauchi Hiroshi split a smaller new-party vote.

The old $2^{\text {nd }}$ district, untouched by redistricting or new-party candidates, once again gave two seats to the LDP and one to the Socialists.

In the old $3^{\text {rd }}$ district, the LDP re-established its customary monopoly. Yamanaka avenged his previous slim loss, easily defeating both the Socialist incumbent Arikawa and a weak JNP newcomer. The LDP's Nikaidou also retained his seat.

Even if not by design, the LDP had displayed unusual efficiency and strength: the party's nine candidates won eight seats (including Tokuda's) out of nine in the prefecture. Then, after the election, LDP $1^{\text {st }}$-district winner Miyazaki helpfully pruned the LDP's complement of incumbents by announcing his intent to retire before the next election. Similar retirements by the two Socialist losers in the $1^{\text {st }}$ robbed the party of its two strongest candidates, in its most promising area of the prefecture.

By the 1994 electoral reform, then, the Kagoshima LDP found itself in a comfortable position. Some of the pain of reapportionment and seat reduction had already been endured in earlier elections. Now, the party would need only to fit seven incumbents (including Tokuda) and one former incumbent into five new SMDs with relatively familiar boundaries. The other parties faced a harder task: parlaying a single first-term incumbent, two former incumbents, and two soundly beaten newcomers into at least five viable candidacies.

\section{The new $1^{\text {st }}$ district}

\section{The 1996 election}

The new $1^{\text {st }}$ district is a fragment of the old $1^{\text {st }}$, encompassing one tiny county and about 75 per cent of Kagoshima City. Wholly urban, and with an LDP incumbent whose ties to the district are weak, the $1^{\text {st }}$ has witnessed the most activity by national new parties. Non-LDP forces have come close to unseating the LDP, but fragmentation has held them back.

The new district's candidate field was wide open. New parties hadn't run strongly in 1993, and losses and retirements had left the Socialists without an obvious candidate. The LDP, meanwhile, had no returning old $1^{\text {st }}$ incumbents whose support bases fell inside the new $1^{\text {st }}$. Yasuoka was the LDP's leading contender: though his stronghold was Amami, in the new $2^{\text {nd }}$ district, he had 
finished first within Kagoshima City in 1993, and showed interest in remaining and letting Tokuda take control of the islands.

Things became even more unsettled when Yasuoka, like Imazu in the Hokkaido $6^{\text {th }}$, followed Kaifu Toshiki out of the LDP and into Kaifu's 'Koushikai' group as an independent, and then into the newly formed New Frontier Party (NFP) in December 1994 (MNS 30 August 1994). Suddenly, all three non-Communist candidates remaining from the 1993 election were members of the NFP: the Koushikai's Yasuoka, Shinsei's Nagano, and the JNP's Kawauchi (who joined the NFP despite the JNP's decision to opt out). Yasuoka became head of the Kagoshima branch and confirmed his intention to run in the $1^{\text {st }}$, while Nagano stood down and became a party adviser, but Kawauchi intimated he might run as an independent if denied the NFP endorsement (MNS 29 January 1995). Meanwhile, the LDP and the JSP - the twin pillars of Kagoshima politics and now strange bedfellows as coalition partners - were left without a candidate between them in the district.

But just as suddenly, six months after defecting and two months after receiving the NFP's district endorsement, Yasuoka ended his short stay in the opposition and announced his desire to return to the LDP. Though the reasoning behind Yasuoka's quick return to the LDP remains unclear, we may speculate. Affiliation with the fledgling NFP offered no great added value, a fact brought home by the recently concluded local elections - the party was essentially a front for its respective politicians' personal support organisations. Koumei was neither large nor a particularly vigorous NFP supporter, and Yasuoka had personal ties to Koumei that could survive his return to the LDP. His own 'young' kouenkai, on the other hand, might not have survived the switch to the NFP. His first campaign in Kagoshima City had taken place only two years before, and he had likely relied on LDP ties to round up his supporters then. One report claimed that in his short time as chair of the prefectural NFP, Yasuoka had opposed the idea of running an NFP candidate in every SMD, and one NFP official attributed this to Yasuoka's desire to avoid conflict with the LDP (MNS 25 June 1995).

Many local LDP legislators reacted strongly against accepting Yasuoka's boomerang homecoming, having fought against him and the NFP two months before in local elections, but no other viable claimants for the LDP nomination had come forth, and Yasuoka was soon named the $1^{\text {st }}$-district candidate (MNS 6 August 1995). The $1^{\text {st }}$-district NFP, meanwhile - and by extension, the prefectural branch - was devastated. Now-adviser Nagano ran a weak campaign in the 1995 Upper House election and soon retired, and the party's struggle to find a $1^{\text {st }}$-district candidate finally petered out by the filing deadline (MNS 22 September 1996). Kawauchi, meanwhile, had earlier abandoned the NFP and announced his plan to run with Sakigake's endorsement.

By mid-1996, then, the major contenders for the $1^{\text {st }}$-district seat were the LDP incumbent Yasuoka; Kawauchi, backed by Sakigake; and the Socialists, still unable to decide whether to field a candidate. Just weeks before the election, the Socialists' HR delegation split and the DPJ formed. But before the Kagoshima 


\section{Four prefectural case studies}

Socialists could decide whether or not to pursue a joint candidacy with the DPJ, the DPJ decided to endorse Kawauchi. The next day, the outflanked Socialists abandoned their attempt to run a candidate, and Kawauchi asked for their support. Socialist officials noted that unions were free to make up their own minds, but that Kawauchi, a conservative (albeit of the 'soft/liberal' JNP-Sakigake variety), was unlikely to enjoy a large flow of Socialist votes (MNS 3 October 1996). 'On policy', one union official said, 'of course, we have nothing in common' (MNS 8 October 1996). Kagoshima's unions proved more reluctant than their national counterparts to make the switch to the DPJ (Kato 1998). The civil service workers' union and the Peace Movement Centre decided to stick with the Socialists and to instruct their members to vote Socialist in PR (MNS 29 September 1996).

Just before the election, Kawauchi and the DPJ gained the official support of the NFP, the NFP-affiliated and former-DSP private-sector union federation Yuuaikai, and the LA, but none of these enjoyed much strength in the district. Koumei kept its distance, leaving its members free to choose between Kawauchi and Yasuoka, in part because Koumei officials claimed Kawauchi never requested their support (MNS 8 October 1996).

For a seven-term incumbent, Yasuoka was vulnerable. He was running in a large city, and only for the second time. His switch to the NFP had alienated some within the LDP. Anti-LDP, anti-Communist voters could unite behind Kawauchi, who also enjoyed a certain personal reputation built on countless speeches in Kagoshima City's main shopping district. But with Kawauchi's 'organisational support' coming only from rootless new parties, and with the Socialists and Koumei on the sidelines, the LDP's basic strengths prevailed. Yasuoka won the seat, gaining 48 per cent of the vote to Kawauchi's 39 per cent and the Communist candidate's relatively high 12 per cent. Kawauchi did run strongly enough to earn a DPJ PR seat in the Kyushu district.

\section{The 2000 election}

The 2000 election was a rematch between district incumbent Yasuoka and PR incumbent Kawauchi. By 2000, the Socialists had grown more willing to cooperate with the DPJ: they had returned to opposition alongside the DPJ, and perhaps realised that their own decline and the DPJ's growth might make accommodation necessary for survival. Still, non-LDP co-operation fell short.

After the 1996 HR election, the $1^{\text {st }}$ district's non-LDP parties had grown even more fragmented. In early 1997, Councillor Kubo, Kagoshima's most prominent Socialist and long a proponent of the 'centre-left dream' (see Chapters 3 and 4), left the Socialists and joined the small Democratic Reform Alliance (DRA, Minshu Kaikaku Rengou), the successor to a group originally formed by Rengousponsored Councillors after the 1989 election. But this opposition disarray prompted the LDP to nominate two candidates for the 1998 House of Councillors election, in a risky attempt to win both the prefecture's seats. This, however, 
prompted some non-LDP parties to co-operate in an attempt to exploit a now-split LDP field. Socialist incumbent Kamiyama Kazuto eventually agreed to campaign as an independent, which allowed the DPJ, Sakigake and Kubo's DRA (which eventually joined the new DPJ) to support him. Kamiyama barely missed winning a seat, but only because the LDP engineered an unusually deft bailiwick system for its two candidates (MNS 12 May 1998). The two LDP candidates received 27.9 per cent and 27.0 per cent, respectively, Kamiyama 26.1 per cent, an LA candidate 12.2 per cent, and the Communist 6.8 per cent. Votes from the LA or from Koumei, which declined to take sides, would have been enough to give Kamiyama a seat (MNS 2 March 1998). Still, the results were promising for future co-operation.

Anti-LDP co-operation in 2000 was furthered by the Socialists' changed fortunes. The Socialists had lost Rengou backing to Kawauchi, now an incumbent, and Rengou even threatened to abandon the Socialists' $4^{\text {th }}$-district candidate if the party insisted on splitting the $1^{\text {st }}$-district labour vote. By February 2000, the Socialists had again decided not to run (MNS 26 January 2000). Rengou Kagoshima mediated a DPJ-Socialist co-operation agreement: the Socialists would support Kawauchi, and the DPJ would support the Socialist candidate in the $4^{\text {th }}$ district (MNS 26 May 2000). But traditional intra-labour rifts between the Socialists and the former-DSP wing of the DPJ were still sharp, and Kawauchi's conservative background remained an obstacle to smooth cooperation (MNS 16 July 1995 and 4 June 2000).

Meanwhile, Koumei, now the LDP's coalition partner, granted Yasuoka its recommendation, even though Yasuoka claimed to be making no attempt to divert his supporters' PR vote to Koumei in return (MNS 9 June 2000). Yasuoka also received a recommendation from the locally inconsequential Conservative Party.

The 2000 election results were similar to those of 1996: Yasuoka and the LDP received 47 per cent, Kawauchi and the DPJ 43 per cent, and the Communist 9 per cent. Yasuoka's vote share was almost unchanged from 1996, while Kawauchi pulled closer. Kawauchi, now an incumbent, may have gained support from some strategic anti-LDP voters who had voted Communist before; he may have received a boost from Socialist co-operation; his party's stance against pork barrel may have resonated in a city where an anti-harbour development campaign dominated local politics. His support was again enough to win him one of the DPJ's Kyushu PR seats. Yasuoka, for his part, may have been saved from LDP unpopularity by Koumei support (Kabashima 2000a, MNS 3 August 2000).

\section{The new $2^{\text {nd }}$ district}

\section{The 1996 election}

The LDP's decision to spurn Tokuda Torao, and Tokuda's independent appeal to voters, helped to recharge the Amami War in the new $2^{\text {nd }}$ district and turn it into 
a nominally partisan race. Personalistic ties and interest groups governed the contest, though, and rendered inter-party co-operation largely irrelevant.

The new $2^{\text {nd }}$ district, another fragment of the old $1^{\text {st }}$, is a mainland-islands hybrid. It includes one quarter of Kagoshima City (with 41 per cent of the district's eligible voters in 2000), one additional mainland city and county (22 per cent), and Amami (37 per cent). With Yasuoka left behind in the new $1^{\text {st }}$, the incumbent conservative independent Tokuda was the only experienced candidate with a support base in the district. If the LDP had tacitly supported Tokuda - and plans to do so were occasionally floated - he would have been assured of a comfortable victory. But Tokuda's two perennial opponents, Yasuoka supporters and the JMA, remained willing and able to fight him and his Tokushuukai hospitals in the LDP's name. By the end of 1994, the prefectural LDP had moved to support Sonoda Shuukou, a young prefectural legislator from Kagoshima City (MNS 3 September 1994).

For a short time, though, national-level politics intruded. In December 1994, Tokuda joined six other conservatives of disparate partisan backgrounds to form the LA. Some of the six had previously left the LDP, but all were also reluctant to join the newly formed NFP, and the LA moved almost immediately to collaborate with the LDP in a joint parliamentary group, or kaiha (YS 12 March 1995). Tokuda was now a valuable ally of the LDP, and the national party dragged its feet on ratifying prefectural support for Sonoda.

In Kagoshima, though, animosity between the LA and the LDP grew, as the expansionist Tokuda attempted to build support relationships with LDP prefectural politicians. The national LDP finally endorsed Sonoda in September 1995. Tokuda protested, claiming that LDP leaders had promised not to back any opponents in his district (MNS 8 February and 30 September 1995). But by this point, the LA was expendable: four of its seven members were about to leave and join the LDP, and another to join Sakigake. The LA's HR delegation was soon reduced to Tokuda and one first-term former JNP member.

This seems to be the point at which Tokuda took over the LA. The chance to mastermind a party may be enough to explain why Tokuda chose not to defect to the NFP and secure Amami's Koumei votes. The power of the party label certainly had little to do with it: only 12 of 88 LA candidates in 1996 even drew enough votes to recover their deposit money.

Even without a helpful party label, though, Tokuda was in a position to fight the LDP's usual organisational advantages. The LDP did receive unusually zealous backing from the prefecture's doctors', dentists' and pharmacists' associations, but some questioned how effective their money, endorsements and mobilisation efforts were in producing votes (MNS 6 July 1998; see also, for example, Curtis 1999: 50-51). Tokuda's Tokushuukai hospital 'family' made for a smaller but tighter campaign organisation. Nouseiren, the political arm of the agricultural co-operatives' association and an LDP backer in Kagoshima's other SMDs, remained neutral in the $2^{\text {nd }}$. The co-operatives likely included a large number of Tokuda supporters, and political organisations in Japan, be they 
political parties, unions or religious groups, often shy away from official endorsements when rank-and-file members harbour strong but divergent prior loyalties. Tokuda also had just as good a chance of winning as Sonoda, and anger remained over LDP support for liberalisation of agricultural goods (MNS 25 October 1996). The prefectural construction association did recommend Sonoda, but suffered some 'leakage' to Tokuda (MNS 12 and 16 June 1998). Recession had undercut the LDP's ability to provide government contracts, and Tokushuukai hospital expansion was an alternative and promising source of construction work (MNS 8 October 1996).

This relative parity in organisational backing, coupled with the rough balance between Tokuda's and Sonoda's (and Yasuoka's) personal support, produced a race nearly as intense as the old Amami Wars, and just as tight. Still, Sonoda won with 48 per cent, Tokuda finished with 46 per cent, and the Communist candidate gained 6 per cent.

\section{The 2000 election}

The 2000 election campaign was largely a repeat of 1996. National-level realignments did little to alter the balance of power or produce new challengers.

Nation-wide, the LA continued as a nominal political party. In the 2000 election, it ran PR slates and 123 SMD candidates, fourth most after the Communists, the LDP and the DPJ. But the LA remained Tokuda's plaything or, in his own words, 'like a party out of a comic book' (YS 15 June 2000). About one-third of its candidates were doctors and other medical staff with Tokushuukai connections, and another quarter were found through a nation-wide public search. Again, only 12 received enough votes even to recover their deposit money (and five of these ran in districts vacated by the LDP).

In the Kagoshima $2^{\text {nd }}$, though, Tokuda remained a strong challenger. Though the JMA again backed Sonoda, and this time Nouseiren climbed aboard the incumbent bandwagon (MNS 5 June 2000), Sonoda received no official support from Koumei, now the LDP's coalition partner and a major presence in Amami. Prior to realignment, Koumei members had been mobilised on both sides of the Yasu-Toku War, and, as one observer noted, Koumei stood to gain more PR votes from remaining neutral than from supporting one side and alienating the other (MNS 5 June 2000).

Other cross-party support deals were inconsequential. The Conservative Party, another LDP coalition partner, endorsed Sonoda. The DPJ backed Tokuda in exchange for LA support in the $3^{\text {rd }}$ district, but the agreement was announced less than two weeks before the election, the two parties were competing against each other in the $5^{\text {th }}$ district, and neither party had much clout in the other's district in the first place (MNS 14 June 2000). Tokuda likely gained more assistance from a visit by his friend and Tokyo governor Ishihara Shintarou campaigning on his behalf (YS 21 June 2000). 


\section{Four prefectural case studies}

The 2000 race was close again, but this time Tokuda's 50 per cent of the vote outdid Sonoda's 45 per cent and the Communist candidate's 5 per cent. Tokuda became the LA's only Lower House member, joining the party's single Councillor, Ishii Ichiji of Hyogo. Sonoda, despite his close finish, narrowly missed a consolation PR seat. The LDP won only seven PR seats, and inter- and intra-party agreements in other Kyushu districts had reserved the top of the LDP's PR slate for PR-only candidates and pushed most SMD candidates, including Sonoda, down to the eighth position.

\section{The new $3^{\text {rd }}$ district}

\section{The 1996 election}

The story of the new $3^{\text {rd }}$ district reduces to two main elements: successful coordination among two LDP incumbents and a lack of serious competition otherwise.

The new $3^{\text {rd }}$, a heavily rural district, combines another fragment of the old $1^{\text {st }}$ with a fragment of the old $2^{\text {nd }}$. The old $-1^{\text {st }}$ fragment accounts for about 60 per cent of the new- $3^{\text {rd's }}$ voters, and the old $2^{\text {nd }}$ district fragment, split evenly between Sendai City and one county, accounts for about 40 per cent.

Three 1993 candidates, all from the LDP, had support bases within the $3^{\text {rd }}$ district. Two were frontrunners for the LDP's nomination: incumbent Miyaji Kazuaki of the old- $1^{\text {st }}$ district fragment and incumbent Matsushita Tadahiro of the old-2 ${ }^{\text {nd }}$ district fragment. The two were evenly matched. In 1993, each had gained about half the votes in his respective old-district fragment (MNS 29 August 1994). Miyaji had won two previous elections and Miyashita one, and both were in their late fifties. Miyaji was a product of the Agriculture Ministry, Matsushita a product of the Construction Ministry. Miyaji belonged to the Mitsuzuka faction and was backed by Mori Yoshirou, then the LDP secretarygeneral; Matsushita belonged to the Obuchi faction, and was backed by then-LDP vice president Obuchi Keizou. Each incumbent suggested that he would run as an independent if denied the LDP's endorsement (MNS 29 August 1994). By July 1995, the prefectural LDP decided to use a Costa Rica strategy, even though it had already spent one slot on its Kyushu PR list to accommodate a $5^{\text {th }}$-district incumbent (MNS 28 May 1995). The party used a lottery - or so it was reported (MNS 7 July 1995) - to choose Matsushita as the district nominee. PR nominee Miyaji was promised the SMD candidacy in the next election, and was named chair of the party's $3^{\text {rd }}$ district branch.

Campaigning under a Costa Rica settlement is prone to co-ordination failure, but the two rivals moved quickly to advertise their new-found solidarity and link their support organisations. The overwhelming strength of the LDP made the bargain easy to execute: Matsushita didn't need Miyaji's support, as long as Miyaji stayed out of the race himself. Matsushita also had no need to co-operate with candidates other than Miyaji, since between the two of them they controlled 
all of the district's territory. And because the two had never directly sparred (or even run many campaigns at all) under the old electoral system, antagonism and candidate loyalties were fairly weak. The strongest conservative challenger on the horizon was Hirata Shinichirou, who had won an old $2^{\text {nd }}$-district seat for the LDP in 1990, but whom Matsushita had already muscled out in 1993.

Hirata, whose bureaucratic background in energy and technology was trumped by Miyaji's and Matsushita's in agriculture and construction, respectively, had abandoned any hope of the LDP's endorsement. He joined the NFP immediately upon its formation in December 1994 (MNS 13 December 1994). The LDP's successful Costa Rica accommodation let Hirata become the district's major challenger, but a distant one. The NFP as such barely existed in the prefecture, let alone in the $3^{\text {rd }}$ district. Koumei did support Hirata, but the Gakkai declared a free vote, allowing members who were not also Koumei members to vote for Matsushita (MNS 5 October 1996). Rengou gave Hirata support (shiji), but not a full recommendation (suisen). And neither Koumei nor Rengou boasted many members in the district in the first place.

The LDP's smooth management of its two rival candidates thus paved the way for a rout. Matsushita gained 66 per cent of the vote to Hirata's 26 per cent and a Communist candidate's 9 per cent. The LDP delivered for Miyaji as well. The party had ranked him sixth on its list, and won nine Kyushu PR seats.

\section{The 2000 election}

The LDP's two incumbents carried out the second round of their Costa Rica arrangement as smoothly as the first. Miyaji reclaimed the district endorsement and Matsushita shifted to PR with only traces of resentment (MNS 6 June 2000). Though two seats had been shaved from the Kyushu PR bloc, retirements cleared the way for the LDP to rank Matsushita second on its list, tantamount to a guaranteed seat.

Non-LDP efforts were anaemic. After the NFP disbanded in December 1997, the nomadic Hirata joined the conservative splinter Kokumin no Koe (Citizens' Voice) (MNS 31 December 1997), and later abandoned Kagoshima to run as an LDP candidate in the Tokyo $9^{\text {th }}$ district (MNS 22 May 1998), though the candidacy never materialised. The Socialists made only nominal efforts to find a candidate. By February 2000, the DPJ had recruited Oozono Katsushi through a public search (MNS 6 June 2000), but Oozono had no real personal support organisation, and the DPJ offered little organisation of its own. The Socialists also offered no official support, unwilling to go beyond their tit-for-tat arrangement with the DPJ in the $1^{\text {st }}$ and $4^{\text {th }}$ districts. Rengou did campaign for Oozono, but its resources were limited. At one prefectural rally, Rengou's chief was reduced to explicitly pleading for members to pay attention to the $3^{\text {rd }}$ district (MNS 6 June 2000). The LA also supported Oozono, in exchange for DPJ support in the $2^{\text {nd }}$ district, but with little apparent effect (MNS 14 June 2000). 


\section{Four prefectural case studies}

The minor Conservative Party, but not Koumei, supported Miyaji. Koumei would have required appeals on behalf of its own PR list in exchange for recommendations, and the Costa Rica agreement compelled Miyaji to ask supporters to vote for the LDP in PR.

The race thus reduced to a lopsided head-to-head contest between an LDP incumbent and a weak DPJ candidate in a rural district. Miyaji won 72 per cent of the vote to Oozono's 19 per cent and a Communist candidate's 9 per cent. Matsushita, as expected, won an LDP PR seat.

\section{The new $4^{\text {th }}$ district}

\section{The 1996 election}

Results in the new $4^{\text {th }}$ district were a simple matter of redistricting and reapportionment, not realignment. The LDP and Socialists made uncomplicated nominations, and the single-seat contest ensured that the Socialists' long-held seat would vanish.

The new $4^{\text {th }}$ district is another mostly rural fragment of the old $2^{\text {nd }}$, though overflow from Kagoshima City, a 'technopolis' development project, and the presence of Socialist Councillor Kubo's hometown have created pockets of Socialist support. LDP incumbent Ozato Sadatoshi and first-term Socialist incumbent Hamada Ken'ichi were the only 1993 candidates from $4^{\text {th }}$-district territory, and each became his party's endorsee without controversy. The LA quickly aborted an attempt to muster a challenger, and no other non-communist party even tried.

Though the LDP and the Socialists were coalition partners, neither Ozato nor Hamada considered standing down (MNS 31 August 1994). Ozato expected to win. Hamada was an incumbent and his party's only sure candidate in the prefecture, and the LDP was unlikely to reciprocate any Socialist deference by asking LDP supporters to vote Socialist in PR - or, before Yasuoka became an LDP candidate in the $1^{\text {st }}$ district, by backing a Socialist there.

The formation of the DPJ just prior to the 1996 election further damaged the Socialists' position. Hamada, though the product of a teachers' union, gave serious and prolonged thought to joining the DPJ, and took until the candidate registration deadline to re-declare himself a Socialist. By that time, his hesitation had compromised vote-mobilisation efforts (MNS 6 October 1996). No support from other parties, including Koumei, was forthcoming. Hamada's camp soon decided that its only hope was to salvage victory through the Socialist PR slate, on which Hamada had been cross-listed, by running as strong a losing race as possible. The campaign went as far as to change its slogan to 'We Can Elect Two Hometown Representatives' - that is, Ozato in the district and Hamada through PR (MNS 23 October 1996).

Ozato won handily, with 63 per cent of the vote to Hamada's 31 per cent and a Communist candidate's 6 per cent. With slightly less than half of Ozato's vote, 
Hamada squeaked past three other dual candidates to earn the second of the Socialists' two PR seats. Hamada had been saved by overall Socialist strength in Kyushu. Only there and in the larger Kinki PR bloc did the Socialists gain as many as two PR seats.

\section{The 2000 election}

District incumbent Ozato and PR incumbent Hamada again became the LDP's and Socialists' respective nominees - and again, no other party saw enough reason to run.

By 2000, Ozato had become head of the Kagoshima LDP and secretarygeneral of the Katou faction. Ozato also gained recommendations from Koumei and the Conservative Party, weak as these parties might have been in the district. Like Yasuoka in the $1^{\text {st }}$ district, Ozato made no particular appeal to his supporters to give Koumei their PR votes (MNS 9 June 2000).

Hamada did gain DPJ electoral co-operation, which amounted to securing continued support from Rengou Kagoshima, but Rengou's priority was the DPJ, not the Socialists. Rengou had been prepared to withdraw its support for Hamada if the Socialists had decided to challenge the DPJ in the $1^{\text {st }}$ (MNS 26 January 2000).

Ozato won by roughly the same margin as in 1996, gaining 63 per cent of the vote. Hamada gained 33 per cent, and a Communist candidate 4 per cent. Hamada had inched slightly closer to Ozato - but not close enough, this time, to retain his PR seat. Though the Socialists won three PR seats in Kyushu - once again, a total only matched in the larger Kinki bloc - Hamada was outperformed by a strong Socialist in Oita and two other dual candidates whose 'loser ratios' (sekihairitsu) were boosted by split conservative fields.

\section{The new $5^{\text {th }}$ district}

\section{The 1996 election}

The new $5^{\text {th }}$ district offered a paler version of two patterns found in the $2^{\text {nd: }}$ a contest between the LDP and the LA, and a new candidate's attempts to exploit old MMD rivalries. Here, though, a weak LA candidate hoped to profit from intra-LDP conflict. Ruling-party and incumbency advantages and moderate LDP solidarity held off the LA's challenge.

The old $3^{\text {rd }}$ district was re-named the new $5^{\text {th }}$ with no boundary changes. As an MMD before reform and now as an SMD, it has been the most rural and LDPdominated of Kagoshima's districts. LDP veterans Yamanaka and Nikaidou had won decisively in 1993. Other candidates knew that only a grave LDP split would allow them any chance of victory in an SMD, and the district's losers in 1993, former Socialist incumbent Arikawa and JNP newcomer Katou, both retired by 1995. 


\section{Four prefectural case studies}

The only nomination issue at first, then, was how the LDP would adjudicate between Yamanaka and Nikaidou, who both applied for the LDP endorsement in December 1994. The prefectural federation referred the matter to party headquarters, which by March 1995 named Yamanaka as its district candidate and moved Nikaidou to PR.

In December 1995, Hashiguchi Ryouichi, the head of a Tokushuukai hospital, joined the race as an LA candidate. The election thus paralleled the $2^{\text {nd }}$ district's Sonoda-Tokuda LDP-LA battle, but with a much stronger LDP advantage: Yamanaka was a 14-term LDP incumbent in a wholly rural district. Still, Hashiguchi and the LA served as a conservative alternative to the LDP, an alternative to Yamanaka for diehard Nikaidou and Tokuda supporters, an authoritative voice on health care issues and a potential source of contracts for construction firms.

Both sides coveted the Nikaidou vote. Nikaidou made a show of LDP unity by appearing at Yamanaka's campaign-opening ceremony and publicly declaring his support for Yamanaka (MNS 11 October 1996). But only a few weeks before, Nikaidou had announced his immediate retirement and withdrawal from the PR list (MNS 18 September 1996). Now, with Nikaidou nowhere on the ballot and rarely on the hustings, abstention and crossing of party-lines among his supporters grew more likely. As one Nikaidou-camp LDP official observed, 'A good number of [us] are flowing into Hashiguchi's camp, saying 'We can support anyone but Yamanaka' (MNS, 27 September 1996). Other parties, meanwhile, declined to back either candidate officially.

Yamanaka and the LDP prevailed, with 61 per cent of the vote to Hashiguchi's 34 per cent and a Communist candidate's 5 per cent. One LA official estimated that one-third of Nikaidou's voters had supported Yamanaka, one-sixth had gone to Hashiguchi, and half had abstained (MNS 8 June 2000).

\section{The 2000 election}

The $5^{\text {th }}$ district was the only one whose candidate field changed noticeably between 1996 and 2000, and the only one in either year contested by more than one non-LDP, non-Communist party. But the $5^{\text {th }}$ 's new new-party candidates were even weaker than the LA's Hashiguchi, and simply split the non-LDP vote.

In late 1998, Kajiwara Hirotoku, a two-term prefectural legislator from Tanega Island, announced that he planned to run in the $5^{\text {th }}$ district. Kajiwara had been a member of the LDP and one of Yamanaka's aides. But both the LDP label and Yamanaka's were still owned by Yamanaka himself. Kajiwara turned to the DPJ, which made him chief of the party's $5^{\text {th }}$-district branch by June 1999 and the party's nominee by January 2000.

The Liberal Party established its Kagoshima branch in early 1999. In June the party chose Hirano Shigenobu as its $5^{\text {th }}$-district nominee, and in December as head of its entire prefectural federation. Hirano, who was in the rental car and 
gasoline businesses, had made three unsuccessful runs for a prefectural assembly seat beginning in 1971 (MNS 9 June 1999).

The DPJ and the Liberals were weak partisan presences in the district, though, and their candidates' personal followings were anaemic beyond their hometowns. The Socialists also declined to expend precious energy backing DPJ candidate Kajiwara, a former LDP legislator, for no return. The race was essentially a rematch between the LDP's Yamanaka and the LA's Hashiguchi.

Nikaidou died several months before the election, leaving no authoritative voice to urge his supporters to vote for Yamanaka and the LDP. Yamanaka did gain the support of his party's coalition partner Koumei, though, and the three other conservative candidates stood to split the anti-Yamanaka vote.

Yamanaka again drew 61 per cent of the vote. Hashiguchi seemed to suffer most from the crowded field, dropping to 21 per cent. The DPJ's Kajiwara finished with 10 per cent, the LP's Hirano with 5 per cent, and a Communist candidate with 4 per cent. Hashiguchi, Kajiwara, and Hirano were all dual-listed on their parties' PR lists, but none came close to winning a PR seat. Hirano was arrested on vote-buying charges three weeks after the election, and the Liberal Party's Kagoshima branch immediately closed down.

\section{Conclusions}

As of 2003, the LDP seems poised to remain predominant in Kagoshima in the near future. Incumbency advantage and strategic non-entry should make the LDP's three 'safe' districts - the $3^{\text {rd }}, 4^{\text {th }}$ and $5^{\text {th }}-$ even safer. Upper House elections have become safer for the LDP as well: reapportionment turned the twoseat prefectural district into an SMD during the 2001 election, and transformed the LDP's rough two-to-one advantage over the combined opposition into a secure victory. Unlike those in Ibaraki, the Democrats in Kagoshima cannot even take hope from PR returns.

The DPJ and the Socialists remain in a state of weak parity. Neither has a Diet member in the prefecture. The DPJ's national presence is unquestionably larger, and its PR incumbent Kawauchi could win in the $1^{\text {st }}$ district, while the Socialists' decisive defeats in the $4^{\text {th }}$ may persuade them to abandon the district and complete their withdrawal from contesting SMDs. Still, it was a Socialist prefectural legislator who succeeded Kubo as an Upper House candidate in 2001, with the DPJ's support. The continued existence of the LA, now with Tokuda as an incumbent, only adds to opposition fragmentation.

Only in the $1^{\text {st }}$ district might shifts in national-level party alliances be enough to change outcomes in the near future. The LDP's slim margins of victory there suggest that Koumei's national coalition decisions could prove crucial. Still, the speed of Socialist organisational atrophy - and whether lapsed Socialists drift toward the DPJ, abstention, or even the LDP - may prove just as important. Socialist voters are by no means as organised as Koumei's, but there are more of them (as is the case in about 15 per cent of SMDs nation-wide). 


\section{Four prefectural case studies}

In the prefecture's other four districts, only more dramatic developments could produce significant change. In the $2^{\text {nd }}$, Tokuda-LDP battles should remain closely fought unless the LDP replaces Sonoda with a new challenger of very different quality. In the $4^{\text {th }}$, if Ozato - who as head of the LDP's General Affairs Council supported Katou's attempted 'coup' against the party leadership in 2000 - were to follow Katou out of the LDP, he might invite an LDP challenge. That the LDP Councillor elected in 2001 was also affiliated with Katou suggests that such a move would have repercussions for Upper House races as well. In the $5^{\text {th }}$, if LDP incumbent Yamanaka's eventual retirement were to spark a succession battle between his and Nikaidou's supporters, the DPJ or the LA might profit from an opportunistic endorsement of any sore-loser candidacy.

But Kagoshima's experience so far has belied the claims of proponents of electoral reform and party realignment. Kagoshima illustrates rather starkly that non-competition is at least as likely to emerge in SMDs as two-party and twocandidate competition (Weiner 2000). Of course, some SMDs will indeed draw strong challengers, such as the DPJ's Kawauchi in the $1^{\text {st }}$ district or self-made Tokuda in the $2^{\text {nd }}$ - and support two-candidate races. Other SMDs, including the $3^{\text {rd }}, 4^{\text {th }}$ and $5^{\text {th }}$ districts, will have sure winners, and discourage other parties and candidates from wasting resources on a serious challenge. Whether one pattern or the other will hold in a particular district - or predominate across all districts depends on whether the political environment encourages challengers, and we have no reason to expect that it will.

Under MMM, parties do have relatively more incentive to sponsor SMD challengers, since these generate publicity for parties' PR lists (Cox and Schoppa 2002). But the absolute incentive may not be enough. Koumei and the DSP, for example, rarely used this strategy in Upper House MMM elections before realignment. A more potent instigator of SMD candidacies is the joint-candidacy provision, which encourages weak SMD candidates - including PR incumbents, such as the Socialist Hamada in the $4^{\text {th }}$ - by granting them a PR safe haven. But dual candidates might continue to be squeezed out by intra- and inter-party coordination agreements that save PR spots for displaced district candidates. Over time, then, parties may increasingly abandon hopeless SMD candidacies, increasing the number of districts contested only by an incumbent, a Communist and perhaps a representative of quixotic candidacy binges by party leaders such as the LA's Tokuda or the LP's Ozawa Ichirou in 2000.

Kagoshima's experience also points to the difficulty of nurturing 'indigenous' new-party candidates - that is, ones other than defectors from established parties - especially in SMDs and in more rural districts. The LDP dominates Kagoshima largely because all its incumbents have stayed put. New-party candidates have suffered not only from their own challenger status, but also from the lack of fellow-incumbents in the prefecture. Support from an incumbent co-partisan might have pushed the DPJ's Kawauchi over the top in the $1^{\text {st }}$ district, for example. 
Finally, Kagoshima helps to show that transforming a multi-party system into a two-party system in the aggregate, nation-wide, also takes time. The process requires a particular balance of party mergers and failures. SMDs do not simply produce this balance naturally, especially amid interference from PR districts, coalition agreements and electoral co-operation. In nine of 10 Kagoshima SMD races over two elections, the LDP candidate did face only one major opponent. But in each election year, these opponents represented three different parties, and the PR vote reveals fragmented loyalties within each district. At the same time, one party dominates the prefecture.

Local parties have helped to sustain aggregate-level multipartism. Kagoshima's LA and other conservative new parties including Sakigake, the Conservatives and the Liberals have thrived mainly in party leaders' respective prefectures and districts, and played comparatively minor roles in the Diet. These are de facto rather than genuine local parties, built around particular candidates, not local issues. Of course, the LDP is similar - which is why its defectors and their parties can survive outside the LDP in the first place.

But the Socialists are also an important source of friction in party realignment. The party's persistence is sometimes obscured by its diminished Diet presence and 'has-been' image. But in strongholds where the DPJ hasn't swallowed the party whole, the Socialists retain as much electoral support, and at least as much organisational strength, as most other parties. And the Socialists' comparatively progressive and organised voters, particularly those who have already resisted the DPJ, may prove more difficult for other parties to absorb. The Socialists may be in decline, but prefectures like Kagoshima are not through with the 1955 system just yet. 



\section{Part III}

\section{Statistical analysis}



In Part I we reviewed political events leading up to the 1996 and 2000 elections in historical detail. Part II introduced us to the kinds of fascinating local stories and bewildering variation that characterised the two elections. These case studies illustrate a complex and confusing geographical variation in both elections. A standard analysis of polls and election results risks missing much of the action and many of the variables that influenced the outcomes. Yet we cannot be satisfied with simply saying the results were complex. We need to control for as much of the complexity as possible to reveal the fundamentals of Japanese voting behaviour in 1996. The case studies suggest several hypotheses that should supplement standard analyses and help render understandable both the complexity and the underlying patterns. It will be the task of Part III to control for as much of the complexity as possible in order to interpret the national election results. 



\title{
8 Who won the 1996 election?
}

\author{
Steven R. Reed
}

In this chapter I will begin by reviewing the results of public opinion polls between the 1993 and 1996 elections. The goal will be first to analyse the dynamics of public opinion: what events led to increased support for one party and decreased support for another? The second goal is to put the election in context. Elections occur at specific times and under specific circumstances. Though we are interested in generalisations that apply broadly to all elections, we ignore the context of particular elections at our peril. One cannot apply broad generalisations to particular elections without understanding the specific contexts of that election. And there is simply no need to choose between the search for universal generalisations and historical specificity (Reed 1999). Broad 'scientific' generalisations help us understand the particulars of specific elections, not least by helping us distinguish between the general and the particular. Moreover, immersion in detail in no way precludes generalisation.

The core of this chapter will consist of statistical analysis of two sets of data. First, I will analyse candidate votes, asking what candidate characteristics systematically attracted or repelled voters. Next I will analyse electoral returns by district, asking what types of districts were favourable to particular parties and what kinds of elections produced higher or lower turnout. Finally, I will summarise the statistical findings and offer an interpretation of 1996 election.

\section{An overview of public opinion between the 1993 and 1996 elections}

Once the Hosokawa administration was finally formed, it was greeted with record levels of public support. Support for it started high and continued to climb during its first two months, peaking at a record 73 per cent. The Japanese public do not appear to have expected much from the 1993 election, as indicated by the low turnout, but they seem to have been quite pleased with the result. Support dropped in December with the liberalisation of rice imports but rebounded in January 1994. Once political reform had been passed and the tax increase had been proposed, support dropped drastically but remained above 50 per cent. The 
majority of the public still supported the Hosokawa administration when the Prime Minister resigned.

Support for the Japan New Party, the biggest winner in the 1993 election, never exceeded 15 per cent. Support for Hosokawa's party tended to parallel support for his administration. The party gained a boost when Hosokawa became prime minister and fell in March when support for the cabinet dropped. The JNP lost some support when the scandal hit and then again when Hosokawa resigned. It never recovered. The JNP was a personal vehicle for Hosokawa and never established an image of its own independent from its leader. This was the fate that Hosokawa and the founders of the JNP had expected from the beginning, based upon their reading of the experience of the New Liberal Club in 1976. A new party could hope for a one-time boost based upon attracting floating voters but, because they had no base of loyal supporters, most JNP candidates could expect to lose their second election and the party could not expect to survive on its own for long. The JNP needed to run under a different label in 1996 and that was one of the driving forces of party reorganisation after 1993.

The Hosokawa administration was followed by the 'strange bedfellows' coalition between the LDP and the JSP, enemies since 1955. New administrations are normally given the benefit of the doubt and receive a boost in the polls. The Murayama administration proved one of the rare exceptions to this rule. Support for the Murayama administration never reached 50 per cent but non-support did. The government lost support in January of 1995, primarily over its handling of the Hanshin earthquake and never recovered thereafter.

The Hashimoto administration continued the same coalition but brought the prime ministership back to the LDP. Hashimoto was greeted with the normal honeymoon boost in the polls but lost it within a couple of months. Nevertheless, support hovered around 50 per cent, with non-support around 35 per cent, right up to election time.

Turning now from government support to support for political parties, I begin with the LDP. Support for the LDP dropped precipitously from 32 to 25 per cent when it lost power in 1993. Many observers had long suspected that support for the LDP was mainly support for the party in power, the party capable of distributing pork-barrel projects and influencing public policy. The party regained some support when it regained power under the Murayama administration but did not really rebound until it regained the prime ministership under the Hashimoto administration. Note, however, that the Hashimoto administration enjoyed 50 per cent support while Hashimoto's party, the LDP, enjoyed less than 35 per cent support.

Support for Shinsei jumped when it gained the prime ministership under the Hata administration and the party lost support as soon as it lost power with the founding of the Murayama administration. The founding of the NFP produced a temporary boost in popularity and the party's high profile opposition to the Murayama government seemed to produce results. The party's support peaked with the House of Councillors election in July but declined thereafter. As the 
general election approached, however, the NFP faced dwindling support, entering the election at below 10 per cent of voters.

Finally, the JSP had dropped below 10 per cent support after the 1993 election. Gaining the prime ministership in the Murayama administration produced a temporary boost but the party soon fell back to the 10 per cent level, which then eroded even further over the course of the coalition government. Support dropped to less than 5 per cent when the LDP took over the prime ministership and the party entered the election with this low level of support.

Perhaps the most important figures are those for voters who supported no party. This jumped from 28 to 35 per cent with the Hosokawa administration and climbed steadily through the Murayama administration. It levelled off at between 45 and 50 per cent during the Hashimoto administration and stayed at that level as the election approached. The confusion caused by the founding of the new parties and the departure of the LDP from power produced a great potential for change. Almost half of the electorate entered the 1996 election without supporting any party.

Japan entered the 1996 election with the leading party being supported by only 33 per cent of voters. The NFP, the second largest party and primary challenger, enjoyed less than 7 per cent support. Over 48 per cent of voters supported no party. By way of comparison, in the 1994 Italian election, held under similar circumstances and the first under the new MMM electoral system there, the leading party had 17 per cent support, the second party 12 per cent, and 39 per cent supported no party (Sniderman et al. 2000: 106). The LDP had not suffered the disintegration experienced by Italy's predominant party, the Christian Democrats. With the exception of the LDP, however, the Japanese party system in 1996 was in worse shape even than the Italian party system in 1994. The 1996 election thus took place amid a profound state of dealignment.

\section{Lessons from the case studies}

The beginning of wisdom in analysing the 1996 election is to realise that elections held during periods of party realignment differ in several important respects from those held in more settled circumstances. Elections held under stable party systems are primarily matters first of mobilising a party's base of support and then of expanding support by appealing to uncommitted individuals and groups. In any given election, most voters choose the same party and the same candidate that they voted for in the previous election. Switchers are few but decide the close races and often determine who wins the election nation-wide. In multiparty systems, it is often also important to get the support of parties who are not fielding a candidate in the current election or the particular electoral district. We can thus identify three basic campaign strategies: base mobilisation, popular appeals, and electoral co-operation. In stable party systems, this is the order of importance. 


\section{Statistical analysis}

A party cannot win elections without a stable base of support. This was one lesson learned from the experience of the New Liberal Club: a party based primarily upon popular appeals to floating voters cannot expect to compete effectively over the long haul. Moreover, a party with a stable support base cannot expect to win an election if it cannot mobilise that base. The clearest case of the failure to mobilise one's base may be the British Labour Party in 1970. After two successive Labour administrations, neither of which had enacted much to make a socialist proud and both of which had overseen rising rates of unemployment, Labour Party activists did not campaign with any enthusiasm resulting not only in a Labour loss but also in a lower turnout (Bromhead 1971: 107).

Most of the drama of elections comes from attempts to win over the uncommitted voter. Drama requires movement and uncertainty, neither of which are available from stories about the attempt to mobilise a party's base of support. Media analysis thus tends to focus on the less important (in terms of the number of voters involved) but more interesting campaign strategies that aim at changing voters' minds. Political science has also displayed a tendency to focus upon the campaign to attract uncommitted voters, not only because it is dramatic, but also because it is the stuff of normative democratic theory. The idea of an uncommitted voter weighing the policy implications of voting for this or that party presents an attractive picture of democracy in action. The idea of a committed party activist deciding how much effort she should put into getting out the vote in this particular campaign plays little role in democratic theory but is an indispensable aspect of democratic practice.

In multiparty systems, interparty co-operation often plays a significant role in determining election outcomes. If two parties, A and B, are in coalition - actual, potential or even partial - party leaders may instruct their supporters to vote for the other party. The simplest case is when party A directs its supporters in those districts where A has no candidate to vote instead for party B. Supporters of party $\mathrm{B}$ then have the choice of following the instructions of their leaders, ignoring their leaders by abstaining, or rebelling against their leadership by voting for some other party. This was the predominant form of electoral co-operation in Japan during the period of the 1955 party system (Christensen 2000). More complex forms of interparty co-operation are made possible when voters have two or more votes to cast.

The dynamics of interparty co-operation and competition has been most thoroughly analysed in France. France uses single-member districts but holds a run-off election if no candidate receives a majority of the vote. The key to winning French elections is often, therefore, a matter of maximising co-operation on the second run-off ballot (Rochon and Pierce 1985; Tsebelis 1988). Electoral co-operation is also a prominent feature of Irish elections. Ireland uses the single transferable vote in which voters rank candidates. If the voter's first preference candidate is eliminated, her vote goes to her second or lower preference. Cooperation can thus be achieved by asking voters to cast lower preferences for one's coalition partner. The evidence indicates that voters tend to follow 
instructions and that co-operation produces more seats from the same number of first-preference votes (Sinnott 1978: 63; Farrell and Farrell 1987: 240).

When the party system is undergoing realignment, the effectiveness of base mobilisation can drop drastically, its primary role being taken over by electoral co-operation. New parties, almost by definition, have no stable base of support. The most striking finding in this regard was that Sakigake had no single supporter across a seven-wave panel survey conducted between 1993 and 1996 (Kabashima and Ishio 1998). The new parties simply had no stable base of support to mobilise.

When new parties are formed from the merger of several old parties, the problem of mobilising the old parties' support bases on behalf of the new party is analogous to the problem French parties face in mobilising their supporters on behalf of their allies in the run-off election. In Japan in 1996, the key question for both the NFP and the Democrats was the degree to which they could mobilise the constituent parts of their new party for specific candidates in specific districts. Would ex-Koumei voters turn out to support ex-LDP candidates currently running on the NFP label? Conversely, would ex-LDP voters turn out to vote for exKoumei candidates currently running on the NFP label? Would ex-JSP voters turn out to support ex-LDP candidates currently running on the Democratic label? And would ex-LDP voters turn out to support ex-JSP candidates currently running on the Democratic label? Would those who had voted for the same LDP candidate all of their adult lives follow the candidate to a new party or stick with the LDP? Voting behaviour was affected by the voters' attitudes toward the individual candidate, the candidate's past affiliation, and the candidate's current party label.

The new electoral system and new district lines used for the first time in 1996 added yet another complication. Redistricting meant that many voters could not find their favourite candidate's name on the ballot because he was running in another district. In Niigata, for example, would an LDP voter who had voted for Tanaka all of his adult life vote for Tanaka's sworn enemy Sakurai simply because Sakurai was now the LDP candidate in the district?

There was a national election in 1996 but local situations varied so widely that the national election was often invisible to the naked eye. Journalists and political commentators were often blinded by the fascinating local stories and missed the bigger picture. Other commentators ignored the local variation and interpreted the outcome of the election as the result intended by the median voter. Voters around the country faced so many different sets of choices that the idea of the average voter's choice simply makes no sense. The proper strategy for analysing the 1996 election is to understand and control for the variation in choices and competitive situations in order to reveal the underlying national election result.

The trick to winning an SMD seat in the 1996 election was, first and foremost, to get a major party nomination in the district where your personal support was strongest. A candidate's most reliable voters are those who have voted for her in the past or who can be reached through her existing organisation. Very few candidates could, however, win with only their own personal support base. After 
getting a nomination, or deciding where to run as an independent, the next step was to create as many co-operative relationships as possible. Making cooperative deals within and across districts proved the deciding factor in many districts. The degree to which effective co-operation could be established among traditional rivals was the key to most close races. Some deals operated smoothly and efficiently. Others were half-hearted and ineffective. Some actors were more capable of delivering promised votes than were others. Koumei stands out in this regard as the actor most capable of co-operating with candidates from anywhere across the political spectrum and delivering the promised vote effectively.

Thus far it appears as if the voters played no role in determining the outcome of the 1996 election. Getting the optimal nomination and making bargains among organisations did indeed determine most electoral outcomes, but voters were far from being inert pawns moved about by elite players. First, co-operative relationships were never perfect. We are fortunate to have good data on Niigata $6^{\text {th }}$ district and we know that about 60 per cent of voters followed the advice of their leaders (NN 23 October 1996). Moreover, the deals struck in Niigata $6^{\text {th }}$ were probably among the most effective possible, so 60 per cent may be thought of as the upper boundary of effectiveness for any party or group except Koumei. The average co-operative agreement was probably much less effective. Advice from leaders was one important cue for voters but voters were not simple automatons mindlessly following that advice.

Second, excessive manoeuvring often proved costly. A candidate must send voters clear cues. It takes time to establish a clear image. Excessive manoeuvring leaves voters confused at best, disgusted at worst.

Finally, party nominations meant more than one would have guessed from past studies of Japanese elections. Traditional studies emphasise the personal vote and the virtual absence of party discipline. At least some of these findings derive from the nature of MMD. Under SMD, party nominations should mean more in the long run. It appears that the nomination actually meant more in the first MMM election than most observers noticed.

\section{Analysing the returns}

We now turn to the statistical analysis of the electoral returns. I will first deal with the determinants of the candidate's vote and then analyse the vote for political parties. Finally, I will analyse turnout at the district level.

\section{The candidate's vote}

In analysing the candidate's vote, I use the per centage of the electorate received by the candidate in the 1996 election as the dependent variable. That is, I divide each candidate's vote by the total number of eligible voters, not the total number who voted. This calculation, known as the 'absolute per centage' (zettai tokuhyouritsu) in Japanese, includes abstention as one option for voters and 
controls for changes in turnout. All other per centages are calculated using the same denominator.

The first independent variable is the per centage of the vote received in 1993. Under normal circumstances, this variable is easy to calculate, but the electoral districts were very different in 1993. Fortunately Miyagawa (1994) has aggregated the 1993 vote by the 1996 electoral districts so we have a good measure of the candidate's strength in the new district. I have coded votes for a candidate's relative as his support base in those districts where there was a family succession. In 1996, family succession could happen in two ways. Either the father (typically) retires and is replaced (typically) by the son or the father runs in one district and the son runs in a neighbouring district. Several strong incumbents might have won in more than one new SMD and they solved the problem by giving their son one of their winnable districts. Kouno Youhei and his son Kouno Tarou formed a typical father-son combo winning seats in Kanagawa $15^{\text {th }}$ and $17^{\text {th }}$ districts. This variable ranges from zero to 39 per cent. No one entered the 1996 election with majority support. Every candidate needed to increase his support in order to guarantee himself a seat.

The second independent variable is the per centage of the electorate received in 1993 by the candidate's 1996 allies. The case studies were full of stories of candidates trading support and seeking support from former enemies. Based on newspaper reports from the various districts, I calculated the votes that should have gone to each candidate based on the promises made by other candidates and parties. This variable is important but limited because it can be calculated only for those candidates who had run in the 1993 election. Thus, for example, we can estimate the number of votes provided by Koumei to the candidates they supported only in those districts where Koumei ran a candidate in 1996.

Our third independent variable is the amount of money spent by the candidate. Money matters in politics and may matter more in Japan than elsewhere (Cox and Thies 1998, 2000; Kawato 2000). The indicator is simply the total amount of expenditure reported to the Ministry of Home Affairs. ${ }^{1}$ Finally, I use a dichotomous variable to distinguish incumbents from non-incumbents. Incumbents have been found to have an advantage in any electoral system where voters choose from among candidates rather than parties. The results are presented in Table 8.1.

We find first that the candidate's strength in 1993 was indeed the strongest predictor of her vote in 1996. As we learned from the case studies, the first trick to winning a seat in 1996 was to get a nomination in your strongest district. Also as expected, the second strongest predictor is the vote of allied candidates and parties. While alliances were one secret to success, one clearly could not expect to get all of the votes from one's former enemies only recently turned into allies. The coefficient for the allied vote is much weaker than for the candidate's own support in 1993. And money does indeed matter. Candidates who spent more money on the campaign received more votes. The only surprise is that incumbency proves insignificant. In 1996 the districts had all been redrawn so 
Table 8.1 Determinants of a candidate's vote in 1996

\begin{tabular}{|c|c|c|c|c|c|c|}
\hline Previous vote & 0.736 & $(.029)^{* *}$ & .711 & $(.027)^{* *}$ & .693 & $(.027)^{* *}$ \\
\hline Allied vote & .439 & $(.016)^{* *}$ & .367 & $(.017)^{* *}$ & .373 & $(.017)^{* *}$ \\
\hline Expenditures & \multicolumn{2}{|c|}{$3.19 \mathrm{E}-07(.000)^{* *}$} & $1.941 \mathrm{E}-07$ & $(.000)^{* *}$ & \multicolumn{2}{|c|}{$1.86 \mathrm{E}-07(.000)^{* *}$} \\
\hline Incumbency & .248 & $(.491)$ & -.255 & $(.457)$ & .524 & $(.434)$ \\
\hline LDP & & - & 6.82 & $(.545)^{* *}$ & 6.33 & $(.557)^{* *}$ \\
\hline NFP & & - & 4.06 & $(.546)^{* *}$ & 4.01 & $(.703)^{* *}$ \\
\hline DPJ & & - & 1.89 & $(.521)^{* *}$ & 2.40 & $(.634)^{* *}$ \\
\hline Sakigake & & - & -0.71 & $(1.29)$ & -1.11 & $(1.42)$ \\
\hline SDP & & - & -0.99 & $(.790)$ & -0.00 & $(.900)$ \\
\hline JCP & & - & 2.62 & $(.398)^{* *}$ & 2.29 & $(.413)^{* *}$ \\
\hline From Koumei & & - & & - & -3.30 & $(1.017)^{*}$ \\
\hline From Shinsei & & - & & - & 0.89 & $(.638)$ \\
\hline From Sakigake & & - & & - & 0.51 & $(.937)$ \\
\hline From JNP & & - & & - & -2.91 & $(.761)^{* *}$ \\
\hline From JSP & & - & & - & -1.49 & $(.594) *$ \\
\hline Constant & & 3.194 & & 2.094 & & \\
\hline $\mathrm{n}$ & & 1,257 & & 1,257 & & \\
\hline R-squared & & 0.778 & & 0.814 & & \\
\hline Adjusted & & 0.778 & & 0.812 & & \\
\hline
\end{tabular}

* = significant at the .05 level.

$* *$ significant at the .001 level.

Note: The dependent variable is the candidate's percentage of the electorate in 1996. All other voting percentages are calculated with the total electorate (not the total vote) as the denominator. Entries are the coefficients with the associated standard errors in parentheses.

incumbency did not have its usual effect. It often happened that more than one incumbent ran in the same district, which may also reduce the statistical effect of incumbency.

Just by knowing the candidate's strength in 1993, her allies' strength, and the amount of money she spent, we can explain over three-quarters of the variance in her 1996 vote. These are the fundamentals of the 1996 election. Next we want to know which party labels attracted voters and which labels repelled them. We therefore add dichotomous variables for the party nominations of each major party. The results are presented in the second column of Table 8.1. The story told by analysing candidates' votes varies somewhat from that told by the national returns. The districts in 1996 did not contain all of the candidate's vote from 1993. Some of her vote was now in some other district. Thus, most of the coefficients are positive; all candidates tended to gain votes over the per centage they had captured in the new district in 1993.

The LDP gained only two per centage points in the vote nation-wide but each LDP candidate gained almost seven per centage points on the average after controlling for other factors. This finding explains why many LDP candidates 
were pleased with the result, even though the party did not gain a majority of the seats. Similarly, the NFP lost 1.7 per centage points nation-wide but its candidates picked up over four per centage points. The national returns show the SDP and Sakigake as the major losers, but candidates from these parties tended to hold their own. The difference between the national-level and candidate-level results is accounted for by the changing party affiliations of the candidates between elections. Most clearly, the national-level losses of the SDP and Sakigake were caused primarily by candidates defecting to other parties, not by voters abandoning their candidates. Only the JCP statistics tell the same story nationwide and district by district because the Communists ran a candidate in every district. There was no way of calculating a baseline for the DPJ nation-wide, but it appears the Democratic label was worth some votes, though not as many as the LDP, NFP or JCP labels.

We can control for candidate movement between parties by adding dichotomous variables for the candidate's party affiliation in 1993. We find, first, that the pundits were indeed correct: the NFP won fewer votes when it nominated a candidate from Koumei than when it nominated a candidate from some other party. Shifting Koumei candidates to PR seems to have been a good idea. Although few argued that the NFP should not nominate JNP candidates in the SMD, candidates from the JNP also lost votes. Hosokawa, their party leader, had been telling JNP candidates from the beginning that the 1993 election was likely to be their first and last victory. The new party boom that brought victory in 1993 would no longer be available in 1996. He was proved correct as many candidates proved unable to sustain their 1993 vote. Finally, it is interesting to note that candidates who came from the JSP fared badly, even though those running for the successor SDP did not. Once we control for coming from the JSP, we find that the Democrats did somewhat better than originally estimated. The most plausible explanation is that JSP candidates who joined the Democrats lost some support from labour unions, and that pulled the DPJ average down.

Finally, we should note that campaign expenditures favoured the LDP. The average LDP candidate spent over 14 million yen in reported campaign expenditures while the average NFP candidate spent 12 million and the average DPJ candidate less than 10 million. The DPJ was clearly disadvantaged but it would have taken a very large redistribution of campaign funds to alter the basic election result. Minor candidates and independents were prevented from winning seats because they lacked sufficient funds to put up a serious campaign but most major party candidates spent enough to give themselves a chance to win.

\section{Analysing the district-level returns}

What type of districts favoured each of the different parties? In this section, I will analyse variations in the party vote across the 300 single-member districts for the LDP, the NFP, the DPJ and the JCP. The urban-rural dimension has long been the most important in Japanese politics but we must first control for the three 


\section{Statistical analysis}

variables that proved so powerful in explaining the candidate vote: the party's vote in 1993, the allied vote in 1993, and campaign expenditures.

Looking across the first row of Table 8.2, we find that the JCP was the most efficient at holding on to its 1993 vote. On two counts this finding is not surprising. First, the Communists are a well-organised party with solid support among a small proportion of the public but little prospect for attracting votes from other parties. Second, the JCP was the only party to suffer no defections and to run under the same label in 1993 and 1996. Each of the three larger parties held on to comparable proportions of its 1993 vote. The Democrats fared somewhat better on average but with greater variance among districts. Though the Communists were very efficient in retaining their 1993 vote, they also started from the weakest base. The LDP had the strongest candidates, followed by the NFP and the DPJ.

Turning to the second row of the table, we find that the Democrats benefited most from their ally's vote and the NFP the least. The Communists, of course, had no allies. The difference can be explained by differences in who was being asked to support whom. For the DPJ, allies were most often retiring socialists who were being asked to support either other socialists or candidates from Sakigake. Most of the allied vote for LDP candidates came from other LDP candidates, either retiring candidates or those who moved to the PR tier. Whereas the LDP and, to

Table 8.2 Determinants of the vote by party, 1996

\begin{tabular}{|c|c|c|c|c|c|c|c|c|}
\hline \multirow{4}{*}{$\begin{array}{l}\text { Previous vote } \\
\text { Allied vote } \\
\text { Expenditures }\end{array}$} & \multicolumn{2}{|c|}{$L D P$} & \multicolumn{2}{|c|}{$N F P$} & \multicolumn{2}{|c|}{$D P J$} & \multicolumn{2}{|c|}{$J C P$} \\
\hline & .542 & $(.039)^{* *}$ & $* .534$ & $(.040)^{* *}$ & .619 & $(.074)^{* *}$ & $* .820$ & $(.065)^{* *}$ \\
\hline & .269 & $(.038)^{* *}$ & $* .190$ & $(.032)^{* *}$ & .349 & $(.057)^{* *}$ & & \\
\hline & $0.36 \mathrm{E}-$ & $-7(.000)$ & $0.13 \mathrm{E}-7$ & $7(.000)$ & $3.04 \mathrm{E}--7$ & $7(.000)^{*}$ & $2.48 \mathrm{E}-$ & $7(.000)^{*}$ \\
\hline percent DID & -9.98 & $(1.30)^{* *}$ & -8.16 & $(1.02)^{* *}$ & .949 & $(1.56)$ & 2.69 & $(.418)^{* *}$ \\
\hline Versus NFP & 1.26 & $(.862)$ & & - & & - & & - \\
\hline Versus DPJ & .860 & $(1.08)$ & & - & & - & & - \\
\hline Versus JCP & 5.96 & $(1.68)^{* *}$ & & - & & - & & - \\
\hline From Koumei & - & & -1.52 & $(.903)$ & & - & & - \\
\hline From JNP & - & & -2.42 & $(.835)^{*}$ & & - & & - \\
\hline From JSP & - & & - & & -1.81 & $(.810)^{*}$ & - & \\
\hline JCP only & - & & - & & - & & 5.33 & $(.602)^{* *}$ \\
\hline Constant & 18.8 & & 18.3 & & 3.8 & & 1.5 & \\
\hline $\mathrm{n}$ & 287 & & 235 & & 143 & & 29 & \\
\hline R-squared & 0.745 & & 0.586 & & 0.531 & & 0.6 & \\
\hline
\end{tabular}


a lesser extent, the DPJ were asking traditional intraparty rivals to co-operate, the NFP was asking rivals from different parties to co-operate. Though we have ample evidence testifying to the intensity of LDP intraparty rivalries, when push came to shove, it proved easier to co-operate with intraparty than with interparty rivals.

The DPJ proved the most efficient at attracting votes from allies but also had fewer allied votes than either of the other two large parties. The average value of the allied vote was 16.7 per cent for the NFP, 14.4 per cent for the LDP, but only 8.8 per cent for the DPJ. The Democrats started out behind and could depend upon fewer allies. The LDP started out ahead and had more help. The NFP started out only a bit behind, had the most allies, but failed to convert its allied vote efficiently.

The third row of Table 8.2 contains a surprise: campaign expenditures did not affect either the LDP or the NFP vote. Given that the LDP has been so often implicated in scandals involving money and its candidates so often arrested for election law violations, this finding may seem incredible but the explanation is relatively clear. The primary purpose of campaign expenditures is to give the candidate visibility in the district. Once a candidate spends enough money, he is visible and increasing expenditures any further produces diminishing returns. In Japan in 1996, the magic number appears to have been somewhere around 11 million yen. If one analyses only those candidates who spent more than 10 million yen - the top 515 candidates - controlling for previous and allied vote, expenditures is still significant at the .05 level. However, if one analyses only those candidates who spent more than 11 million yen - the top 454 candidates expenditures no longer have a significant effect on the vote. Over 76 per cent of LDP candidates spent more than 11 million yen. The threshold of 11 million yen is a nation-wide average effect. Many of the LDP candidates who spent less were running in rural areas or did not face a serious challenger and thus did not need to spend that much. Variation in expenditures among LDP candidates did not explain any of the variation in their vote.

The NFP result is more difficult to explain because only 54 per cent of its candidates spent more than the magic 11 million yen. The most likely explanation is that the candidate's party of origin and the effectiveness of intraparty cooperation explain much more of the variance in the NFP vote than do expenditures.

The DPJ spent more than 11 million yen in only 40 per cent of the districts and there was much greater variance among districts than for either of the other two large parties. The DPJ featured several well-known and well-funded incumbents but also nominated many unknown and under-funded new faces. Varying levels of expenditure thus explained a significant proportion of the variation in the DPJ vote.

The explanation for the significant effect of expenditures on the Communist vote is different than for the other parties because the JCP central headquarters has the power to allocate funds among districts. There is substantial variation in 


\section{Statistical analysis}

JCP expenditures by prefecture, suggesting that some of the variance can be explained by the relative affluence of local party branches. The more important variance, however, is explained by the concentration of expenditures in several 'focus districts' (juuten) where the party has a chance of winning a seat or wants to make a good showing for some other reason.

Now turning to the urban-rural dimension we find, as expected, that the LDP did better in rural districts and that the JCP did better in urban districts. The indicator of urbanisation is the per centage of the population living in DIDs ('densely inhabited districts') as defined by the Japanese census. The coefficient for the LDP vote is strongly negative indicating that the LDP did much better in rural than in urban districts. The coefficient for the JCP vote is smaller but significant in the other direction. The Communists are an urban party. The DPJ and NFP offered two different types of challenge to the LDP. The Democrats were neither an urban nor a rural party but the NFP coefficient is almost as strongly negative as that for the LDP. The NFP challenged the LDP on its home turf in rural Japan.

There have been three major 'booms' in recent Japanese electoral history: the New Liberal Club boom of 1976, the Doi boom of 1989-1990, and the new party boom of 1993. Most of these booms have occurred primarily in urban areas, but the new party boom of 1993 was actually stronger in rural than in urban areas (Reed 1997b), and that was primarily due to the strength of Shinsei in rural areas (Scheiner 1999). In 1996 the NFP represented a double-barrelled challenge to the LDP. First, Shinsei and other rural-based candidates challenged the LDP in rural areas. Second, Koumei candidates challenged the LDP in urban areas. The former challenge proved more effective than the latter.

Finally, Table 8.2 contains some variables that are relevant for one party only. Thus, I checked out whether the LDP did better when challenged by the NFP or by the DPJ. The result indicates that the LDP did as well against one of its major opponents as against the other. The only districts in which the LDP did particularly well were those in which its primary opponent was the JCP. These 11 districts were non-competitive rural districts in which neither of the LDP's larger opponents could find a candidate to run against an established LDP incumbent. Offered a choice between the LDP and the Communists, many voters who would otherwise have voted against the LDP chose it as the lesser of two evils. As we can see for the final column of Table 8.2, however, many other voters faced with the same set of limited choices opted for the JCP. Both the LDP and the JCP gained votes when they were the only two parties running in the district. As we shall see below in the analysis of turnout, many voters faced with the option of LDP or JCP chose to stay home and not vote at all.

For the DPJ and NFP the extra factor that must be taken into account is party of origin. As we have seen above, DPJ candidates who came from the JSP and NFP candidates who came from either Koumei or the JNP lost votes relative to other candidates. These findings are confirmed in Table 8.2 with one exception. The negative coefficient for ex-Koumei candidates is not significant in this 
analysis. The statistical reason is clear enough: ex-Koumei candidates ran mainly in urban districts so controlling for the urban-rural dimension reduces the effect of Koumei origins. It is less clear how to interpret the result. One could argue that the negative effect for Koumei origins in Table 8.2 above is spurious: the NFP was weak in urban areas no matter who was nominated and ex-Koumei candidates fared poorly only because they happened to be nominated in urban districts. However, the only plausible reason to explain the weakness of the NFP in urban areas is that the NFP was more closely linked to Koumei in urban areas. Both NFP candidates and supporters were more likely to come from Koumei in urban than in rural areas. Though the micro explanations remain uncertain, the macro result is clear: despite incorporating the urban-based Koumei, the NFP was a rural party in 1996. The NFP experiment failed in part because Koumei failed to deliver urban seats. The failure of the LDP-Koumei coalition to win urban seats was widely noted after the 2000 election but there had been a less-noticed precedent in 1996.

\section{Turnout}

One of the most surprising things about the 1996 election was the drop in turnout. Despite the drama of the 1993 election, the presence of three new parties and the real possibility of throwing the LDP out of government, turnout dropped from 73.3 per cent in 1990 to 67.3 per cent in 1993. Turnout dropped again in 1996 to 59.6 per cent. Political scientists around the world were fascinated with these two elections but the Japanese public did not seem to share our interest. What happened?

Since Downs (1957), the dominant approach to understanding turnout has been the 'closeness hypothesis' (Matsusaka and Palda 1993), that the instrumental benefit of voting increases with the probability that one vote might change the electoral outcome, so turnout should be higher in close elections. Though the closeness hypothesis suffers from many logical problems, it has been confirmed empirically in many different studies. I use the standard 'margin', the difference between the first and second candidates' vote divided by the total number of eligible voters, to indicate the degree of closeness.

The major alternative to the closeness hypothesis is the 'mobilisation hypothesis' (Cox and Munger 1989; Rosenstone and Hansen 1993). Whereas the closeness hypothesis locates agency with the voter, the mobilisation hypothesis focuses on the efforts of parties, candidates and groups to get out the vote. Voters are neither well enough informed nor sufficiently concerned with election outcomes to fulfil the role assigned to them by the closeness hypothesis, but political elites, political parties and candidates should be both well informed and highly motivated. When elections are close, elites exert greater efforts to mobilise voters, producing higher turnout. The standard indicator is total campaign expenditures. 


\section{Statistical analysis}

In Japan turnout is higher in rural than in urban areas. The standard interpretation is a variation of the mobilisation hypothesis, that rural areas are more densely organised and rural voters are thus more easily mobilised than urban voters (Flanagan 1968 and 1991; Cox, Rosenbluth and Thies 1998). I thus include the per centage of people living in densely inhabited districts. The results, presented in Table 8.3, support all of the standard hypotheses. Only total expenditures proves to be weaker than expected.

The 1996 Japanese general election featured a new electoral system and we must also control for the effects of redrawing district boundaries. I therefore calculated the per centage of the electorate in the new SMD that had the option of voting for the candidate they supported for in 1993. Many voters found that the candidate they voted for in the previous election was now running in the district next door. We know from the survey conducted by the Niigata Nippou that voters support a specific candidate and are less likely to vote if they do not find their favourite candidate on the ballot (NN 23 October 1996). Kouenkai were also divided by the redrawn district lines so that mobilisation efforts were more effective in districts where more of the candidates' organisations remained in the new SMD. I thus call this variable, 'remaining'. The second column of Table 8.3 demonstrates the power of this variable. When it is added to the equation, the level of expenditures is rendered insignificant.

Another important indicator of mobilisation efforts in Japan concerns Koumei. Koumei is well organised and particularly capable of mobilising its supporters. When Koumei has a large stake in a particular district, either in order to elect a friend or to defeat an enemy, its supporters turn out in larger numbers. When Koumei has little stake in a particular district, it declares a 'free vote' (jishu

Table 8.3 The determinants of turnout in 1996

\begin{tabular}{|c|c|c|c|c|c|}
\hline Turnout in 1993 & .773 & $(.044) * * *$ & $(.043)^{* *}$ & ** .710 & $(.041)^{* * *}$ \\
\hline Margin & -14.98 & $(2.77) * * *$ & $(2.62) * * *$ & -9.25 & $(2.65)^{* *}$ \\
\hline Total expenditures & $3.40 \mathrm{E}-8$ & $(.000)^{*}$ & $1.78 \mathrm{E}-8(.000)$ & $-0.03 \mathrm{E}-$ & $-8(.000)$ \\
\hline percent DID & -2.34 & $(1.11)^{* *}$ & $(.168)^{*}$ & -1.93 & $(1.00)^{*}$ \\
\hline Remaining & - & & $(1.68)^{* * *}$ & * 9.67 & $(1.62)^{* * *}$ \\
\hline Koumei effort & - & & - & 1.18 & $(.449)^{* *}$ \\
\hline JCP only & - & & - & -5.65 & $(1.07)^{* * *}$ \\
\hline Constant & & 9.105 & 12.700 & & 12.076 \\
\hline $\mathrm{n}$ & & 298 & 298 & & 298 \\
\hline $\mathrm{R}$-squared & & 0.748 & 0.776 & & 0.799 \\
\hline
\end{tabular}

* $\quad=$ significant at the .10 level.

** = significant at the .05 level.

$* * *=$ significant at the .001 level.

Turnout is calculated using the valid vote, not the total vote, as the numerator. Invalid votes are counted as abstentions. 
touhyou), allowing its supporters to vote as they wish. When this happens, many of the supporters stay home and do not vote. I thus coded a variable, 'Koumei effort' which takes the value of 1 when Koumei had a large stake in the election, -1 when Koumei declared a free vote, and zero otherwise. The results shown in the third column of Table 8.3 confirm the importance of Koumei's mobilisation efforts.

Finally, the analysis presented in Table 8.2 indicated that those districts where the opposition to the LDP was represented only by the Communists were significantly different from other districts. Both the LDP and the JCP gained votes when these two parties represented the options available to voters. However, many voters also decided to stay home if they were not offered some other option. Turnout was significantly lower in those districts where the JCP represented the opposition. Adding the 'JCP only' variable reduces explanatory power of margin because LDP versus JCP races were all one-sided victories for the LDP. Nevertheless, margin retains its power and significance even after controlling for these lopsided races. Both non-competitive races and races featuring a choice between the LDP and the JCP reduced turnout.

\section{Conclusions}

Who won the 1996 election? The most important answer to this question is those candidates who got the nomination in the district where they were strongest, who were best able to construct co-operative relationships with candidates who had just retired from their district, and who had plenty of money to spend. Most of the action in 1996 was at the level of candidates.

Which party won the 1996 election? This is a much harder question to answer. One must control for candidate-level factors before one can see the contest among political parties. The fundamental answer is that the LDP won the 1996 election. The LDP label attracted more votes than any other party label. The NFP, its major challenger, attracted the next largest number of votes. Voters were thus attracted by the two major parties. The DPJ and JCP also attracted votes, but at lower levels.

Which parties lost the election? The losers were those candidates who had previously run for Koumei, the JNP, and the JSP. Previous party labels proved almost as important as current party labels. Again, the key lies at the candidate level. Candidates with the same party label but from different party backgrounds projected different images of their party. An NFP candidate from Shinsei projected a different image of the NFP than did a NFP candidate from Koumei. Similarly, a DPJ candidate from Sakigake projected a different image of the DPJ than did a DPJ candidate from the JSP. The NFP and DPJ were new parties running in their first elections. Party images had yet to be established and the candidate in the district remained the most important cue to the party's identity.

The 1996 election was a confusing election. Between the 1993 and 1996 elections, the Japan Communist Party was the only major party which had not 


\section{Statistical analysis}

participated in one of the four coalition governments that had formed and fallen. It was difficult to tell which parties were the 'ins' and which were the 'outs.' Similarly, at the district level, there were few candidates who could clearly be identified as 'the incumbent'. Many districts had either no incumbents or more than one, and all but eight districts had been redrawn. The only two parties running under their traditional labels were the LDP and the JCP. Many individual candidates were running under new labels and some candidates had changed parties two or three times since the previous election. Finally, the Japanese voter faced a new electoral system. Under these circumstances, district-level factors proved more important than national-level factors and inter-elite bargaining proved more important than issues and campaigns. Nevertheless, though obscured by local variation, a national contest among parties did occur and the LDP won. The NFP challenge had been met and defeated.

\section{Note}

1 Candidates are required to report some of their expenditures to the Ministry of Home Affairs and other expenditures to the prefectural government. The former data is readily available but the latter data is almost impossible to obtain. Sasaski (1999a) have collected complete data from both sources but have published data only for 1996 winners. 


\title{
9 Who won the 2000 election?
}

\author{
Steven R. Reed
}

The 2000 election was not quite as complex as the 1996 election had been. Most notably, the opposition camp had been simplified. Instead of both the NFP and DPJ competing to unseat the LDP, this time there was only one, admittedly weak, challenger in the DPJ. The Communists were pleased with their performance in the 1996 election and had high expectations for the 2000 elections but they had no hope of beating the LDP. The other two opposition parties, the SDP and the Liberals, were fighting for survival.

Complexities arose primarily on the government side of the aisle. The LDP still led the government but had acquired two new coalition partners, Koumei and the Conservatives. The most complex districts were those in which the coalition was represented by a candidate from one of the coalition partners. Would LDP supporters turn out to vote for a Conservative? Would they vote Koumei? These complexities were further compounded when the local LDP failed to go along with the national decision and supported an independent running against the official coalition candidate. Complexities were also contained inside the LDP. There were candidates who had just returned from the defunct NFP, having defeated LDP nominees in 1996 but running for the LDP in 2000. There were also LDP candidates who openly opposed the party's coalition with Koumei as well as candidates who welcomed, indeed depended upon, Koumei support.

We know that the coalition won in the sense that it maintained its collective majority but lost in the sense that it lost both seats and votes. We now turn to an analysis of why that mixed result occurred and how it should be interpreted.

\section{An overview of public opinion between the 1996 and 2000 elections}

Let us begin with cabinet support. Prime Minister Hashimoto had reason to be pleased right after the 1996 election. His support was above 50 per cent and nonsupport was below 30 per cent. The honeymoon did not last long, but the administration staged a rebound near the end of 1997. Then came the error: the appointment of convicted (and pardoned) felon Satou Takayuki to the cabinet. Cabinet support and non-support merged at the 45 per cent level and the 


\section{Statistical analysis}

administration lost its momentum in the polls. By the time of the House of Councillors election, non-support had passed the 55 per cent mark and support had fallen below 35 per cent.

My interpretation of the Satou affair is that it confirmed widespread public suspicions that the LDP was corrupt and, perhaps even more importantly, that the party did not punish corruption within its ranks. Whatever the cause, however, the LDP administration entered the House of Councillors election with dismal support and Prime Minister Hashimoto was forced to take responsibility when the party was defeated.

It is worth looking at this pattern in some detail, for two reasons. First, the pattern was later to be reproduced by the Koizumi cabinet. Like Hashimoto, Koizumi started his prime ministership as a reformer, though Hashimoto could hardly have been called an outsider like Koizumi. All recent reformers, from Kaifu through Koizumi, have been greeted by high levels of support. Second, the reasons for the sharp drops experienced by both Hashimoto and Koizumi concerned personnel decisions, Hashimoto's decision to include a convicted felon in his cabinet and Koizumi's decision to expel a popular reformer, Tanaka Makiko, from his. Most notably, none of the sharp moves in popular support were caused by changes in the economy. The economy may affect cabinet support but, if it does, it does so in a subtle and hardly noticeable way.

The newly installed Obuchi administration received a minuscule boost in the polls. Support rose to 33 per cent from 29 per cent and non-support fell from 57 to 52 per cent. The administration was not even able to maintain that microscopic boost as support soon dropped below 25 per cent and non-support rose to above 60 per cent. The formation of the JiJi (LDP-Liberal) coalition turned things around and Prime Minister Obuchi began to appear as a gentle but effective leader. Support continued to rise, and non-support to fall, until support passed the

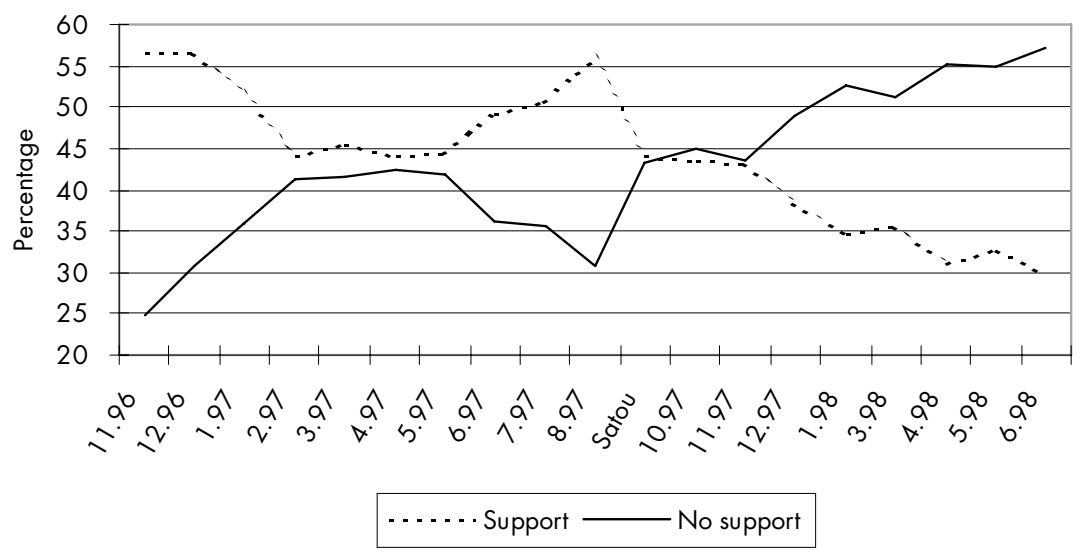

Figure 9.1 Support for the Hashimoto administration 


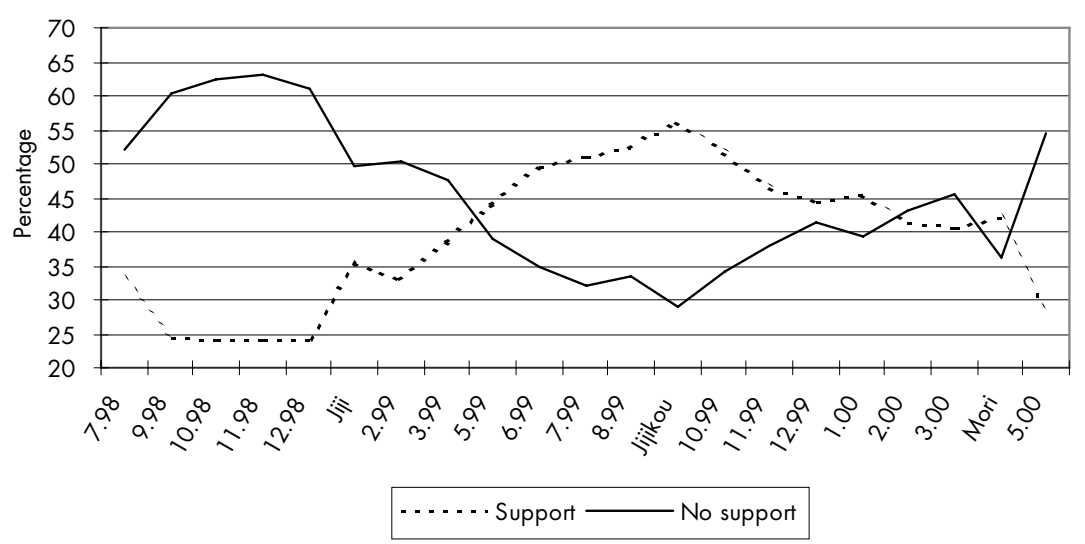

Figure 9.2 Support for the Obuchi administration

55 per cent mark (with non-support below 30 per cent). At this point, however, Obuchi decided to include Koumei in the coalition and his fortunes were again reversed. When asked whether they approved of the JiJiKou (LDP-LiberalKoumei) coalition, only 35 per cent of voters expressed approval while just over half disapproved.

The timing of each reversal in Obuchi's fortunes closely matches the changes in the composition of the coalition. I believe the relationship to be causal. I think that $J i J i$ was considered an accomplishment and the public generally approved of the way in which that coalition worked, and that JiJiKou was considered a problem and the public disapproved of the way in which the new three-party coalition operated. Coincidence of timing is importance evidence supporting the idea of a causal connection, but further evidence would be required before reaching a definitive conclusion. Similarly, I would not argue that the changing coalitions were the only reasons for increasing and decreasing support for the Obuchi cabinet. Academics must be careful in claiming causal connections. Participants, however, are not similarly constrained. I imagine that many inside the LDP noticed these two coincidences and used them as ammunition in internal party debates. I would wager that supporters of $J i J i$ used rising support as an argument against their opponents. Similarly, I would be surprised if opponents of JiJiKou failed to mention that support for the Obuchi cabinet started falling right after that coalition was formed.

I cannot confirm these speculations about the debate within the LDP but can confirm the amazing absence of any such debate in the mass media. I was reading the newspapers and watching the Sunday morning talk shows throughout this period and never heard anyone mention the striking coincidence between changing coalitions and changing levels of support. The most common reason given for rising cabinet support was Obuchi's personality. Commentators noted 


\section{Statistical analysis}

the decline in support for the Obuchi cabinet but considered it a mystery. It would be interesting to know whether this was a case of agenda control. Was the LDP able to keep this issue off the agenda of political debate? If so, how did it manage to do so?

The Mori administration was greeted with a substantial boost that Prime Minister Mori quickly squandered. The LDP entered the 2000 election led by an unpopular prime minister. Analysis of survey data also suggests that Mori's unpopularity drove independent voters away from the LDP (Kabashima and Imai 2002).

As we observed in the previous chapter, support for an LDP cabinet is not necessarily reflected in support for the LDP as a party. It would also appear that support for an LDP-led coalition is even less related to support for the party. Some events affected both. For example, the Satou affair appears to have hurt the party as much as it hurt the administration. However, support for the party dropped precipitously during the House of Councillors campaign, while support for the LDP cabinet showed a steady decline.

Though support for the Obuchi cabinet closely paralleled coalition decisions, support for the LDP was not affected as much or as clearly. Despite Prime Minister Mori's unpopularity, the LDP entered the election on something of a high note, with increasing support in the polls. Of course, that increase was from a low base and did not reach 35 per cent of the public.

Support for the NFP never breached the 10 per cent level after the 1996 election. Neither did it rise or fall very much from that very low baseline. Support for the Democrats provides a more interesting story. The Democrats were not the major challengers to the LDP as long as the NFP was in existence. They were supported by less than 5 per cent of voters. When, however, the NFP broke up and the 'new Democratic Party' was founded, incorporating many NFP incumbents, the party suddenly became the leader of the opposition forces. The 'new' Democrats received a slight boost in the polls, but as the House of Councillors election approached the party's fortunes soared to above 20 per cent. Even with such a dramatic increase, however, the party was still a long way from becoming a major player in a two-party system. Even more worrisome, however, was the fact that support dropped back below 10 per cent soon after the election.

Falling support was the main reason why Kan was replaced as party leader, but the installation of Hatoyama did not produce any change in the party's fortunes. Support revived and again reached the 20 per cent level only as the June, 2000 election approached. Support for the DPJ fell again right after the 2000 election. The pattern is striking. When we look back at support for the NFP, we find a similar pattern: a rise right before the House of Councillors election followed by a decline once the election was over. The exception to this rule is the 1996 general election. Otherwise, it would seem that the LDP's primary opponent gains support right before an election but loses that support right afterward. A clue to resolving this puzzle lies in the changing percentage of voters who support no party. 


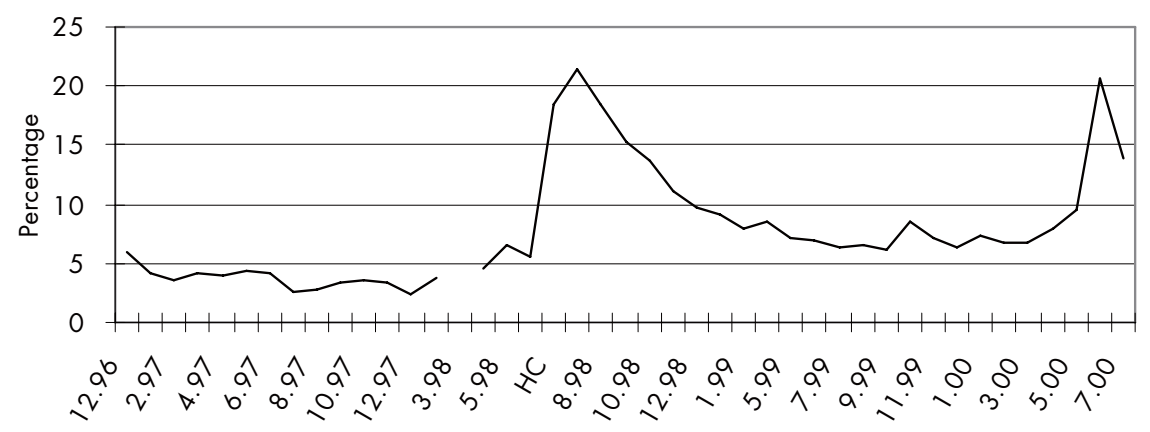

Figure 9.3 Support for the DPJ

The percentage of voters who support no party at all drops sharply before each election, at least since the 1996 election. While many other factors influence the number of independent voters, the effect of an election is clear. Miyake, Nishizawa and Kohno (2001: 42) provide a similar graph which indicates that this pattern dates back at least to the 1960s, though some elections appear to be exceptions to the rule. A similar, though less dramatic, pattern in the number of voters who support no party is also visible in Canada (Clarke, Kornberg and Wearing 2000: 130). Canada has long been a country with unstable party identification and has recently witnessed an increase in the number of nonidentifiers. The similarities with Japan are indeed suggestive.

While one would need a detailed analysis of individual level survey data as confirmation, these aggregate results suggest a simple hypothesis: elections invite uncommitted voters to choose sides. Though not supporters of either the NFP or the Democrats, when forced to choose, independent voters tend to opt for the party most likely to defeat the LDP. This pattern may extend back to the 1989 House of Councillors election, when the Doi Socialists appeared to offer some hope of unseating the LDP. This analysis also supports the standard wisdom in Japanese politics today: the key to winning elections is to attract the independent voter.

If my hypothesis were to prove correct, it would be a mirror image of the classic 'party identification' hypothesis in American politics (Campbell et al. 1964). The authors of The American Voter hypothesised that American voters have a stable identification with one party or the other. They may occasionally vote for the party in special circumstances, but will tend to return to their original party thereafter. I am hypothesising that many Japanese voters have no party identification, though they may adopt one temporarily during an election campaign. Once the campaign is over they return to their stable state, an absence of party identification. Again, it would require an analysis of survey data, ideally panel data, to confirm this hypothesis, but my interpretation is consistent with Tanaka's (1997) analysis of Japanese independent voters. 


\section{Statistical analysis}

The picture that emerges from the national-level analysis is that support for the LDP depended upon its choice of coalition partners. Allying with the Liberals proved to be a popular choice but allying with Koumei proved to be a vote loser. Note that this analysis of polling results conflicts with an analysis based on managing the Diet. Allying with the Liberals did not give the LDP a majority in the House of Councillors and proved remarkably difficult to manage. Ozawa is not an easy person to deal with. Allying with Koumei, however, provided a stable basis for expeditiously passing legislation. Negotiations with Koumei caused fewer problems.

JiJiKou made more sense as a strategy for managing the Diet than it did for winning elections, but there was also an electoral logic behind this coalition. Koumei is strong in urban areas and can deliver a substantial number of votes to any candidate it supports. The LDP is weak in urban areas. If a coalition with Koumei could deliver urban districts to the LDP, it might solve the LDP's primary electoral problem and lead to another long period of LDP dominance. Everyone knew there would be a cost to pay. Koumei is still disliked by a large number of voters, many of whom are conservative. I doubt that LDP strategists expected support for the party to decline after JiJiKou and they may not even have attributed the decline to the decision to ally with Koumei. They certainly did know that attacking the NFP as 'Koumei in disguise' had proven to be an effective weapon in 1996, and they must have expected some backlash from their decision to ally themselves with Koumei. JiJiKou was a risky electoral strategy, no matter how much sense it made as a Diet management strategy.

If the LDP had embarked upon a risky strategy, the opposition remained extremely weak and extremely soft. Without an election to stimulate interest, DPJ support remained under 10 per cent. Though support increased dramatically as an election approached, it still reached only 20 per cent. The DPJ has yet to develop a stable base of support. The main attraction of the Democrats is that it is the party most likely to defeat the LDP.

Finally, a party system in which the strongest party hovers at between 30 and 40 per cent support while the second party has trouble breaking 10 per cent is not a two-party system. About half of the voters support no party. This is a de-aligned party system in which a major event could produce a large shift in voting behaviour.

\section{Analysing the returns ${ }^{1}$}

We now turn from a macro-analysis of cabinet and party support to a mesoanalysis of candidate and district vote returns. Candidate-level analysis is particularly important because it tells us what candidate characteristics attracted voters and what characteristics repelled them. 


\section{The candidate's vote}

Let us begin with a simple analysis of the average change in a candidate's vote. (See Table 9.1.) National vote totals are affected by changing the number of candidates running from each party. The fortunes of individual candidates may tell us more about whether a party label attracted or repelled votes. To begin with, the average candidate who ran both in 1996 and in 2000 gained 2 points, calculated as a percentage of the electorate. These gains were due to the reduction in the total number of candidates running and to increased turnout.

Though the LDP lost both seats and votes nation-wide, the average LDP candidate gained votes. Even after controls are added below, the LDP label attracted voters. The Koumei label also proved a plus. On the government side, only the Conservative label reduced a candidate's votes. As expected, the DPJ gained the most votes. Surprisingly, the party to fare worst was the Liberals. Nation-wide, the Liberals were seen as having performed quite well but the average Liberal candidate lost over 5 percentage points. This finding also holds up after controls are added.

Turning now to a multivariate analysis, we find first that the basic factors determining a candidate's vote in 1996 were still the basics in 2000, as shown in Table 9.2. As in 1996, the dominant factor is the candidate's vote in the previous election followed by the allied vote. The difference between 1996 and 2000 is that the importance of the candidate's previous support grew stronger and the importance of the allied vote grew weaker. The ranges of both variables have also changed, with higher average values for the previous vote and lower average values for the allied vote. Both phenomena are exactly what should have been expected in the second election under the new electoral system. The problems caused by redistricting in 1996 had been basically resolved by 2000 . Candidates had reorganised their kouenkai to fit the boundaries of the new electoral districts and fewer candidates retired or moved to the PR tier, producing fewer opportunities for retiring candidates to support one of the remaining candidates. Most of the allied vote involved retiring candidates from the defunct NFP. Either

Table 9.1 Mean change in vote percentage by party

Coalition parties

Vote change (n)

$\begin{array}{lrr}\text { LDP } & 3.21 & (213) \\ \text { Koumei } & 2.13 & (14) \\ \text { Con } & -3.13 & (15)\end{array}$

Opposition parties

Vote change (n)

$\begin{array}{lrl}\text { DPJ } & 4.69 & (98) \\ \text { Liberal } & -5.65 & (25) \\ \text { JCP } & -0.45 & (79) \\ \text { SDP } & 1.59 & (16)\end{array}$

Note: The table includes only candidates who ran in both 1996 and 2000. The overall average for candidates running in both elections is a gain of 2.05 percentage points. 


\section{Statistical analysis}

the NFP candidate retired and supported one of the remaining candidates or the NFP candidate ran for another party with the support of the retiring candidate of that party. Differences among the parties had also narrowed by 2000. LDP candidates managed to hold on to a higher percentage of their 1996 vote but the coefficients for the allied vote vary little across parties.

Money mattered to about the same degree in 1996 and in 2000. One surprising continuity between the 1996 and 2000 findings is the failure of incumbency to have any effect on a candidate's vote. In 1996 incumbency was confused by redistricting, with 106 of the 300 districts featuring more than one incumbent. In a strict sense, there could be only one incumbent per district in 2000, the winner of that district in 1996. However, there were three other types of candidates who were also incumbents in the sense that they held a Diet seat when the 2000 election began even though they had not won the SMD in 1996.

First, there were candidates elected in PR in 1996 without running in an SMD. Most of these 'pure PR incumbents' had no more claim to the SMD seat than any other challenger. A few, however, had run in an MMD in 1993 and were forced to run in PR due to difficulties in the nomination process. Several Koumei candidates, for example, were returning to areas where they had won MMD elections in the past. For others, however, the only advantage they might have

Table 9.2 Determinants of a candidate's vote in 2000

\begin{tabular}{llll}
\hline & & & \\
Previous vote & $.847(.028)^{* * *}$ & $.806(.025)^{* * *}$ & $.823(.025)^{* * *}$ \\
Allied vote & $.235(.037)^{* * *}$ & $.223(.033)^{* * *}$ & $.265(.034)^{* * *}$ \\
Expenditures & $3.22 \mathrm{E}-7(.000)^{* * *}$ & $1.08 \mathrm{E}-7(.000)^{* * *}$ & $1.17 \mathrm{E}-7(.000)^{* * *}$ \\
SMD incumbent & $-.229(.590)$ & $-.521(.534)$ & $-.144(.533)$ \\
PR incumbent & $.790(.733)$ & $-.328(.658)$ & $-.510(.636)$ \\
Costa Rica incumbent & $3.238(1.92)^{*}$ & $2.325(1.68)$ & $2.52(1.67)$ \\
& & & \\
LDP & - & $4.42(.658)^{* * *}$ & $3.52(.681)^{* * *}$ \\
Koumei & - & $.610(1.02)$ & $2.24(1.36)$ \\
Conservative & - & $-3.28(1.33)^{* *}$ & $-1.75(1.36)$ \\
& & & \\
DPJ & - & $5.77(.627)^{* * *}$ & $5.67(.620)^{* * *}$ \\
SDP & - & $1.52(.960)$ & $1.06(.954)$ \\
Liberal & - & $-4.72(1.02)^{* * *}$ & $-2.96(1.09)^{* *}$ \\
JCP & - & $-1.20(.593)^{* *}$ & $-1.59(.591)^{* * *}$ \\
& & & \\
From NFP & - & - & $-2.93(.661)^{* * *}$ \\
Koumei support & - & - & $2.35(1.13)^{* *}$ \\
& & & \\
Constant & 1.303 & 2.264 & 883 \\
$\mathrm{n}$ & 883 & 883 & 0.860 \\
R-squared & 0.858 & 0.858 & \\
\hline
\end{tabular}

* = significant at the .10 level.

** = significant at the .05 level

*** = significant at the .001 level. 
obtained from their technical incumbency was the name recognition that might be associated with it. Pure PR incumbents were thus similar to 'talent' candidates, those who had made a name for themselves in some field of endeavour other than politics.

Second, there were the 'Costa Rica incumbents'. These candidates did not run in the SMD in 1996 and won a pure PR seat but actually campaigned in tandem with an SMD candidate in expectation of running in the SMD in the 2000 election. Technically, these candidates were pure PR incumbents but in fact they had a clear connection to the district, had worked hard performing constituency service between elections, and were part of a team that had won the SMD in 1996. The difference between a Costa Rica incumbent and an SMD incumbent is that no voter wrote the Costa Rica incumbent's name on her ballot in 1996. The team had changed leaders.

Finally, there were candidates who ran in the SMD in 1996 and lost but were elected to a PR seat. These 'PR incumbents' (fukkatsu or 'resurrected' in Japanese) are a new phenomenon in electoral studies and deserve our attention. Like Costa Rica incumbents, PR incumbents tended to act as representatives of their SMD between elections because they planned to win the SMD at their next opportunity. However, whereas a Costa Rica incumbent expected to co-operate with the current SMD incumbent, a PR incumbent expected to challenge him in a rematch of the 1996 election. In fact, 34 districts featured just such rematches between two 'incumbents', both of whom had run in the district in 1996. In these cases, it is by no means clear which candidate should enjoy the normal 'incumbency advantage'. Under MMM, incumbency has suddenly become a complex concept.

I coded the three variables of greatest theoretical interest, SMD incumbency, PR incumbency, and Costa Rica incumbency. Preliminary findings in the first column of Table 9.2 indicate that PR incumbents actually did better than SMD incumbents and Costa Rica incumbents fared best of all. The standard error for Costa Rica incumbents, however, is very high and, as soon as controls are added, it also falls into insignificance. There are two possible explanations for this surprising finding. First, it may be that we are still in a transition period and that, once political realignment is accomplished, the normal incumbency advantage will become apparent. The second possibility is more interesting. The confusing nature of incumbency under MMM, most notably in the case of rematches between SMD and PR incumbents, may weaken or destroy the advantages normally enjoyed by incumbents under pure SMD. An electoral system in which voters choose candidates but incumbents have no advantage would be a new and interesting phenomenon indeed.

In the second column of Table 9.2 we find that candidates for the two major parties, the LDP and DPJ, both gained votes, with the Democrats gaining more than the LDP. Koumei and the SDP each held its own while the other minor parties, especially the Liberals and Conservatives, lost votes. Though it was not 
immediately apparent in the aggregate returns, there was some significant movement toward a two-party system.

Two other factors influenced a candidate's fortunes in 2000: whether he had come from the NFP and whether he was supported or opposed by Koumei. That Koumei support or opposition should make a difference should come as no surprise. It was a topic of heated discussion throughout the campaign. This finding confirms Kabashima's (2000) contention that Koumei votes were decisive in electing many LDP candidates. I would add that Koumei votes were probably also decisive in defeating several LDP candidates who opposed the coalition. Koumei can deliver votes, though apparently not enough to secure the election of many of their own candidates nor enough to provide the winning margin in urban areas.

Candidates who had run for the NFP in 1996 lost votes in 2000. In fact, the losses of Conservative Party candidates are explained simply by the fact that they had run for the NFP in 1996. This fact also explains a fair portion of the Liberal losses. Those voters who were attracted by the promise of the NFP in 1996 were repelled in 2000 by the candidates who broke that promise. Joining the NFP in 1996 turned out to be a bad strategic move. Not only did the NFP fail to become the primary opposition to the LDP, it cost its candidates votes after the party fell apart.

It is worth analysing the results for ex-NFP candidates alone. (See Table 9.3.) When the NFP broke up, NFP candidates were faced with a variety of choices. Strategically, the worst possible decision was to follow Ozawa into the Liberal Party. It made little difference whether you continued to follow him after the Liberals left the coalition or whether you stopped following him at that point, joined the Conservatives and remained in the coalition with the LDP. Following Ozawa into the Liberal Party cost you about 7 percentage points in the vote.

Table 9.3 The fate of the 1996 NFP candidates

\begin{tabular}{ll}
\hline Previous vote & $.964(.068)^{* * *}$ \\
Allied vote & $.435(.066)^{* * *}$ \\
Expenditures & $-8.9 \mathrm{E}-8(.000)$ \\
& \\
LDP & $-4.35(1.88)^{* *}$ \\
DPJ & $-0.74(1.43)$ \\
Koumei & $-2.07(1.76)$ \\
Liberal & $-7.06(1.43)^{* * *}$ \\
Conservative & $-7.57(1.76)^{* * *}$ \\
& \\
Constant & 2.970 \\
$\mathrm{n}$ & 118 \\
R-squared & 0.728 \\
\hline
\end{tabular}

* = significant at the .10 level.

** = significant at the .05 level

$* * *=$ significant at the .001 level. 
Returning to the LDP also cost a candidate about 4 percentage points. Of course, returning to the LDP may well have been a wise strategic move, costing votes in the short run but getting the candidate back into the ruling party which would, hopefully, pay off in the long run. Joining the Democrats was the wisest short-run move though the long-run returns remain in doubt.

Looking at the aggregate returns, the Liberals did much better than expected, giving hope to those who want small parties to survive under MMM by utilising the PR tier. This analysis of the SMD returns, however, paints a different picture. The Liberal Party label lost votes. Many Liberal candidates were devastated. They had run in 1996 with the support of Koumei and some labour unions. They lost that support in 2000 and may have even incurred the wrath of Koumei. The trick to surviving by relying upon the PR tier will depend upon the ability of the party to find willing candidates to run in the single-member districts. I doubt whether the Liberals will be able to pull this trick off again, given the experience of Liberal SMD candidates in the 2000 election.

Candidates running for one of the two major parties attracted votes but minor party candidates did not attract votes no matter what party they ran for. The SDP label did not repel voters but neither did it attract them. Communist candidates also lost votes, despite their high hopes for continued growth. The JCP serves primarily as a receptacle for protest voting and there was less to protest about in 2000 than there had been in 1996. Both candidates from the Liberals and those from the Conservatives repelled voters. More fundamentally, candidates who had run for the NFP in 1996 repelled voters in 2000. The NFP disappointed voters who had hoped that the party would change Japanese politics. The only way in which NFP candidates could maintain their vote after the break-up of their party was to join the DPJ.

\section{The district-level returns}

We now turn from candidates to parties. In 1996 we were able to calculate a baseline for the SMD vote from 1993 returns re-aggregated into the new SMDs but were unable to create a similar baseline for the PR vote. The 1996 election provides accurate baselines for both the SMD and PR tiers so we can analyse both sets of returns for the 2000 elections. I shall analyse the returns for each party in turn, beginning with the LDP. (See Table 9.4.)

We find first, and not surprisingly, that the LDP was strong in 2000 where they had been strong in 1996. The LDP remains a rural party, as indicated by the negative relationship between urbanisation and the LDP vote in both tiers. The third variable in Table 9.4 identifies those districts in which the NFP candidate from 1996 returned to the LDP before the 2000 election. The coding includes cases in which the NFP was the candidate for the LDP in 2000 but also includes many other circumstances, from candidates returning and retiring to candidates returning but moving to the PR tier. When the NFP candidate returned to the LDP, the LDP gained a substantial number of votes in the SMD tier but not in the PR tier. The NFP candidate was able to direct his supporters to support the LDP 
Table 9.4 Determinants of the LDP vote, 2000

\begin{tabular}{|c|c|c|c|}
\hline \multirow{4}{*}{$\begin{array}{l}\text { Previous vote } \\
\text { Per cent DID } \\
\text { NFP candidate to LDP }\end{array}$} & SMD tier & \multicolumn{2}{|l|}{ PR tier } \\
\hline & $.678 \quad(.048)^{* * *}$ & .653 & $(.031)^{* * *}$ \\
\hline & $-.058(.015)^{* * *}$ & -.047 & $(.007)^{* * *}$ \\
\hline & $3.71 \quad(.930)^{* * *}$ & .760 & $(.412)^{*}$ \\
\hline LDP candidate & -- & 1.605 & $(.395)^{* * *}$ \\
\hline LDI candidate & $-6.42(1.160)^{* * *}$ & -.083 & $(.452)$ \\
\hline Liberal candidate & $-1.94(.740)^{* *}$ & -.454 & $(.338)$ \\
\hline SDP candidate & $-2.05(.729)^{* *}$ & -.809 & $(.336)^{* *}$ \\
\hline versus DPJ & $-1.42 \quad(.904)$ & -.879 & $(.397)^{* *}$ \\
\hline versus JCP & $4.25(1.615)^{* *}$ & -1.004 & $(.648)$ \\
\hline Constant & 16.946 & 8.678 & \\
\hline $\mathrm{n}$ & 262 & 300 & \\
\hline R-squared & 0.771 & 0.863 & \\
\hline
\end{tabular}

* = significant at the .10 level.

** = significant at the .05 level.

$* * *=$ significant at the .001 level.

Note: LDI is Liberal Democratic Independent

candidate in the district, but was not able to convince them to write 'LDP' on their PR ballots.

The LDP vote was affected by the other choices available to voters in each district. First, and most clearly, the LDP gained votes in the PR tier when the party had a candidate running in the SMD. The variable 'LDP candidate' is coded as +1 if the LDP did not run an officially nominated candidate in the SMD in 1996 but did in 2000, -1 if the LDP ran a candidate in 1996 but not in 2000, and 0 otherwise. The variable thus measures the effect of change, either entering or exiting the SMD race. Several previous studies have estimated the effect on the PR vote of having a candidate in the SMD (Mizusaki and Mori 1998; Cox and Schoppa 2002; Herron and Nishikawa 2001). The results of this analysis confirm previous findings. We can be quite confident that running a candidate in the SMD raises a party's PR vote.

In several districts, disgruntled potential LDP candidates ran as independents against the officially nominated candidate. The option of voting for an LDPaffiliated independent (LDI = Liberal Democratic Independent) cost the official LDP candidate over 6 percentage points in the vote. Two LDP candidates in a district split the LDP SMD vote, hurting the official nominee, but, as one would expect, having no effect on the PR vote.

The presence of minor party candidates also hurt the LDP but in a somewhat surprising way. Both Liberal and SDP candidates hurt the LDP in the SMD but the effect of a Socialist competitor is greater than the effect of a Liberal competitor. In a Downsean world of spatial modelling, one would expect just the 
opposite. The Liberal Party originated in the LDP and, in many respects, takes policy positions to the right of the LDP. One would thus expect Liberal voters to come from the ranks of the LDP and for a Liberal candidate to draw off support from the right wing of the LDP. Instead, we find that the LDP's traditional leftwing rival from the previous 1955 party system, the SDP, draws off more support in both the SMD and the PR tiers. This suggests that the old left-right cleavage has faded, to be replaced to some degree by a new cleavage between traditional and new parties.

The LDP vote is also affected by the identity of the LDP's primary opponent. The LDP did not suffer from Democratic competition in the SMD but did lose a significant number of votes in PR when the Democrats ran a candidate in the SMD. This is probably a reflection of the fact that a DPJ candidate in the SMD increased the DPJ vote in PR. When the LDP's primary challenger was the JCP it gained a substantial number of votes in the SMD. This confirms our finding for 1996 (see Table 8.2 above).

Turning to the Democrats, we find that they were also strong in 2000 where they had been strong in 1996, though to a lesser degree than the LDP. (See Table 9.5.) Surprisingly, given all of the talk about the Democrats' success in urban areas, the party did not do any better or any worse in urban SMDs. The Democrats' relative success in urban areas was due more to LDP weakness than to Democratic strength.

In those districts where the NFP candidate joined the Democrats, the Democrats gained votes in both the SMD and the PR tiers. The decision of the NFP candidate helped whichever party they joined, whether the LDP or the DPJ,

Table 9.5 Determinants of the DPJ vote, 2000

\begin{tabular}{lll}
\hline & \multicolumn{1}{l}{ SMD tier } & PR tier \\
\hline & & \\
Previous vote & $.527(.061)^{* * *}$ & $.735(.055)^{* * *}$ \\
Per cent DID & $-.020(.018)$ & $-.057(.007)$ \\
NFP candidate to DPJ & $4.18(1.060)^{* * *}$ & $2.66(.451)^{* * *}$ \\
& & \\
DPJ candidate & - & $1.938(.326)^{* * *}$ \\
Liberal candidate & $-2.68(1.060)^{* *}$ & $-.949(.420)^{* *}$ \\
SDP candidate & $-4.00(1.113)^{* * *}$ & $-1.54(.386)^{* * *}$ \\
& & \\
versus LDP & $-0.61(1.865)$ & $-.174(.728)$ \\
versus Koumei & $-2.78(3.038)$ & $-.713(1.056)$ \\
& & \\
Constant & 17.363 & 8.186 \\
$\mathrm{n}$ & 142 & 300 \\
R-squared & 0.493 & 0.522 \\
\hline
\end{tabular}

* = significant at the .10 level.

** = significant at the .05 level.

$* * *=$ significant at the .001 level. 


\section{Statistical analysis}

in the SMD race but helped only the DPJ in the PR race. An NFP candidate returning to the LDP did not affect voter perceptions of the LDP. However, when the NFP candidate joined the Democrats, this move confirmed the latter party's role as the primary challenger to the LDP and identified the DPJ as taking over the NFP's quest to create a new kind of politics.

The Democrats gained PR votes when they entered an SMD which they had not been able to challenge in 1996. The effect of an SMD candidate on the PR vote is somewhat higher for the DPJ than for the LDP, probably because of the availability of 1996 NFP voters. On the other hand, minor party candidates drew off more votes from the DPJ than from the LDP. The presence of other ways of voting against the LDP and the coalition government drew off some of the primary opposition party's votes. That a Liberal candidate drew more votes from the Democrats than from the LDP does not make sense in traditional left-right terms but does make sense in terms of cleavage between a new politics and old politics. Conversely, that an SDP candidate drew off more votes from the Democrats makes good sense in left-right terms but not in terms of the new-old cleavage. I was surprised to find that the Democratic vote was not affected by the identity of the party's opponents. The DPJ did as well against LDP candidates as against Koumei candidates.

Finally, turning to the JCP, we find that the party's previous vote is a much more powerful determinant of the party's vote in the PR tier than in the SMD tier. (See Table 9.6.) The vote for the Communist SMD candidate is affected to a

Table 9.6 Determinants of the JCP vote, 2000

\begin{tabular}{|c|c|c|}
\hline & SMD tier & PR tier \\
\hline Previous vote & $.557 \quad(.041)^{* * *}$ & $.796(.025)^{* * *}$ \\
\hline Per cent DID & $.028 \quad(.004)^{* * *}$ & $.005(.002)^{* *}$ \\
\hline JCP only & $4.746(.459)^{* * *}$ & $.116 \quad(.191)$ \\
\hline Liberal candidate & $-.428(.272)$ & $-.003(.113)$ \\
\hline SDP candidate & $-.728(.249)^{* *}$ & $-.228(.103)^{* *}$ \\
\hline versus LDP & $.495 \quad(.354)$ & $.003 \quad(.196)$ \\
\hline versus Koumei & $2.110(.680)^{* *}$ & $.518(.283)^{*}$ \\
\hline NFP to LDP & $.495 \quad(.354)$ & $.318 \quad(.145)^{* *}$ \\
\hline NFP to DPJ & $.052 \quad(.295)$ & $-.003(.123)$ \\
\hline Constant & 0.651 & 0.457 \\
\hline $\mathrm{n}$ & 299 & 300 \\
\hline $\mathrm{R}$-squared & 0.701 & 0.870 \\
\hline
\end{tabular}

$* \quad=$ significant at the .10 level.

** = significant at the .05 level.

$* * *=$ significant at the .001 level. 
greater degree by the competitive configuration in the district and by idiosyncratic factors than is the party's PR vote. As we have come to expect, the Communists are definitely an urban party, though the gradient is much higher in the SMD tier than in the PR tier. The Communists run or support a candidate in every electoral district so the question of whether a Communist candidate in the SMD increases the party's PR vote is moot. However, when the JCP is the only representative of the opposition to run a candidate in the district, the party's nominee gains a substantial number of votes in the SMD. As in 1996, given a choice between the LDP and the JCP, many voters who would not otherwise have done so choose the Communists.

The JCP vote is also affected by the identity of its opponents. The party loses votes when voters have the option of voting for the SDP. This finding makes perfect sense in the left-right scheme. It would seem that many socialist voters prefer to vote for the left and do not consider the Democrats to be a party of the left. Even more interesting is the finding that the JCP gained votes in those districts where the coalition government was represented by a candidate from Koumei. Recall that the Democrats did not gain when faced by a Koumei opponent. Voters who were upset at the coalition for running a Koumei candidate tended to vote Communist both in the SMD and the PR tiers. I interpret this more as a protest vote than as support for the JCP because that interpretation is consistent with the findings from 1996 and earlier. Moreover, I find it difficult to interpret the final finding in Table 9.6 as anything other than a protest vote. The JCP PR vote rose in those districts where the NFP candidate chose to return to the LDP, but not in those districts where he chose to join the Democrats. Turnout also dropped in those districts where the NFP candidate returned to the LDP (analysis not shown). I interpret this finding to mean that some voters were upset when the NFP candidate returned to the LDP. Some of those who were upset protested by voting Communist. Others protested by staying home.

This analysis suggests three hypotheses about the emerging cleavage structure of the next Japanese party system. First, there is some evidence that the previous left-right cleavage, the Ampou cleavage, has not disappeared completely. In particular, the fact that competition from the SDP hurts the Democrats indicates that there is competition between the two leftist parties. The most probable mechanism producing this finding, however, is the shifting support of specific labour unions. Some unions support the SDP when that party nominates a candidate but the DPJ when there is no socialist alternative.

Second, the old-new cleavage appears to have largely replaced the previous left-right cleavage. The Liberals are on the right of the political spectrum but are also a new party. A Liberal candidate draws more votes from the DPJ (a new party) than from the LDP (a party of the right). An SDP candidate also draws votes from the LDP indicating that these two old parties are competing for votes. The old-new cleavage is currently policy-free. Neither do any notable demographic characteristics predict who will support a new party and who will support an old party. Realignment is not being driven by social change or by 


\section{Statistical analysis}

specific policy preferences. It is a political process in which the old had been rejected first by a large segment of the political elite, most notably by younger politicians. These reformers have been able to tap into a large reservoir of public dissatisfaction but have not been able to lead in any consistent direction. Neither have voters provided much direction to the process. Reformers have proposed a large number of mutually inconsistent visions for Japan's future, and voters have ignored the inconsistencies and responded positively to all of them, only asking that they be new and different. Sooner or later some event will presumably add policy and demographic content to the old-new cleavage, but that event has yet to occur.

Our third hypothesis relates to the most likely content for the new cleavage: the urban versus rural cleavage. Current political commentary has focused on LDP losses in urban areas. My analysis confirms the idea that the LDP is a rural party and becoming more so. The Democrats, however, are not an urban party, though they may become one. No party yet knows how to attract the urban voter.

\section{Conclusions}

The most important event between the 1996 and 2000 elections was the break-up of the NFP. The first major attempt to create a party capable of defeating the LDP failed. The story of why the NFP broke up has yet to be told in any detail but one point seems clear: the party was unable to overcome the disunity caused by the diverse political backgrounds of its members. Koumei was certainly one of the problems and may have been the major problem. The party held together so long as it was winning elections but fell apart once the momentum was lost in the 1996 election.

The break-up of the NFP promoted the DPJ to the position of primary challenger to the LDP. The change from NFP to DPJ slowed the transition to a two-party system and changed the nature of the challenge to the LDP. Organising the NFP required a huge expenditure of effort. Negotiations were extremely difficult at both the national and local levels. Building trust took time and failure created both distrust and frustration. It would prove harder to organise a new challenge to the LDP after the previous challenge had just failed. The DPJ in 2000 was unable to match the NFP's performance in 1996. It was both harder to get attractive candidates to run and harder to get co-operation among the various groups that opposed the LDP. The transition proved particularly costly in rural areas. In 1996 the NFP had mounted a strong challenge to the LDP in its rural base. In 2000 the DPJ was unable to do so. In 2000 the LDP dominated most of the rural districts, often facing only token competition from the JCP.

The break-up of the NFP also had a significant impact on the fortunes of individual candidates and parties in particular districts. Candidates who had run for the NFP in 1996 lost votes in 2000. Koumei candidates and those who joined the DPJ were not hurt badly, but those who returned to the LDP or followed Ozawa suffered significant losses. On the other hand, the decision of the NFP 
candidates helped the party they decided to join. If the 1996 NFP candidate returned to the LDP, the LDP vote went up, especially in the SMD. If the 1996 NFP candidate joined the DPJ, the DPJ vote went up both in the SMD and in the PR tier. Finally, districts in which the NFP candidate returned to the LDP saw a significant increase in protest voting, as indicated by the increase in the JCP's PR vote, and a significant decrease in turnout. The break-up of the NFP not only delayed progress toward a two-party system and hurt the political careers of those who had participated, it also alienated a significant number of voters.

The second most important event was the entry of Koumei into the government in coalition with the LDP. Between the 1996 and 2000 elections, Koumei went from being part of the NFP, the LDP's major opponent, to being the LDP's primary coalition partner. Of course, the break-up of the NFP was a precondition for Koumei's decision to ally itself with the LDP. On the one hand, Koumei brought the LDP a majority in the House of Councillors and an overwhelming majority in the House of Representatives. JiJiKou was clearly a success in terms of Diet management. The coalition with Koumei also brought electoral advantages. The coalition provided a huge cushion of seats so that even the substantial losses suffered in 2000 could not deprive the coalition of its majority. Koumei support also brought a significant number of votes to the LDP. Many LDP incumbents now owe their seats to Koumei voters. The costs of the coalition, however, were also substantial.

Support for the Obuchi cabinet began to fall right after Koumei joined the coalition. Party unity was severely tested as significant numbers of the LDP's Diet delegation organised to oppose the coalition. Strains increased, often to breaking point, in those districts where the LDP withdrew to support Koumei candidates. Though Koumei support helped the LDP win votes and seats, there are several indications that voters were not pleased with the inclusion of Koumei in the coalition. Conservative candidates who ran as independents against Koumei candidates not only gained votes and won seats, but also increased turnout and reduced the number of invalid votes. Moreover, the JCP gained votes in those districts where the coalition was represented by a Koumei candidate. Finally, however one evaluates the pluses and minuses of the JiJiKou coalition, one basic fact remains: despite getting Koumei support, the LDP lost in urban districts. As an electoral strategy, JiJiKou failed both the LDP and Koumei.

\section{Note}

1 I wish to thank Asano Masahiko for his help in getting the expenditure data as soon as this material became available. 


\title{
10 Conclusions
}

\author{
Steven R. Reed
}

In April of 1994, two years before the first election under the new MMM electoral system I made three confident predictions:

First, it will take voters, candidates, and parties two or three elections to figure the system out. The first election will not be a particularly reliable guide to how the system will work out in the long run.

Second, almost everyone will be disappointed in the system at first ... right after the first election held under the new system, we can expect cynics to tell us that nothing has really changed.

Fortunately, the third and final thing we know with confidence is that the cynics are always wrong ... change will happen. Unfortunately, we cannot be certain that the changes will be for the better.

(Reed 1994d: 31)

Despite the common claim that the social sciences cannot produce accurate predictions, these three were easy to make and quickly confirmed. Major reforms always disappoint reformers because they always produce some unanticipated outcomes and they always take longer than expected to have any effect. The mode of prediction that currently dominates the social sciences is to make predictions about equilibrium outcomes that should occur 'in the long run' and then to assume that 'the long run' takes less than a year. We would be better served by developing theories that predict what will happen next than what will happen in some mythological long run.

Another reason why political reform always disappoints is the fact that political reform is enacted through a haphazard process of compromise and confusion. Inconsistent goals and contradictory intentions characterise both the process and the result. Reform cannot, therefore, satisfy all the reformers because they do not have consistent intentions. We can, nevertheless, identify what Katz (2001: 103) calls a 'rhetorical consensus', a set of vaguely defined phrases made repeatedly during the reform process. Three topics have been part of the discourse on political reform throughout the post-war period and provide a convenient way to organise this concluding discussion. Reformers have repeatedly argued for: 
(1) reducing the costs of elections, which would presumably also reduce corruption; (2) replacing candidate-centred with party-centred campaigns; and, (3) moving toward a two-party system which would produce alternation in power between the party of government and the party of opposition.

\section{Low-cost, low-corruption elections}

Much of the energy needed to break the LDP's long hold on power and to enact political reform was provided by public disgust with political corruption. On the one hand, the electoral system chosen was the one that had been on the agenda longest, not the one best designed to reduce political corruption. On the other hand, some strong anti-corruption provisions accompanied the new electoral system. It is hard to predict how the new electoral system will change the relationship between money and politics but we can make a few generalisations with confidence.

First, we can be absolutely certain that Japan will not become the first state in human history to eliminate corruption from politics. I feel the need to state the obvious because many political commentators interpret any evidence of continuing political corruption as evidence that nothing has changed. If zero corruption is the standard for judging political reform, political reform will fail so long as politicians are human beings.

The second thing we can say with confidence is that the 1996 election was different from previous Japanese elections. One comment heard often was that you could hardly get a free cup of sake at most campaign headquarters. All the evidence indicates that candidates were much more careful with money in 1996 than they had been in the past.

Upon reflection, however, there is very little reason to expect any significant decrease in corruption. The new electoral system does eliminate one factor blamed for high election costs: candidates from the same party running against each other in the same district. Cox and Thies (1998) have shown that having multiple candidates from the same party does indeed raise campaign expenditures but the effect is small. The new system still produces powerful incentives to build up a personal vote and thus to pursue clientelistic politics. Voters must still write down the name of an individual candidate and candidates can still build support based on their individual merits instead of or in addition to their party affiliation. The system of having one candidate per party per district will tighten the link between party and candidate but hope for reducing corruption must come primarily from law enforcement, not from the electoral system.

\section{Prosecuting political corruption}

Since the passage of electoral reform, the courts have overturned the election victories of three sitting Diet members and 20 sitting local assemblymen for having violated electoral laws (Iwai 1999). All have been banned for five years 
from running in their respective districts. Seven losing Diet candidates have also received five-year bans. These penalties provide clear evidence that corruption continues, but they also show that it has become easier to secure convictions on electoral law violations since the reform. From 1947 through 1993, only one member of the Diet and three local assemblymen had their elections overturned.

The key reform was the expansion of the 'renza-sei', the Japanese version of the 'agency principle' in British election law. The renza-sei means that an election result can be declared void if a relative, campaign manager, or 'political secretary' is found guilty of violating electoral laws. The definition of 'political secretary' has been interpreted broadly by the courts. The five-year ban is designed to prevent a corrupt candidate from cleansing himself of his sins (misogi in Japanese) through winning re-election, a practice perfected by former Prime Minister Tanaka Kakuei. Diet and local elections must be held at least once every four years so that a five-year ban means that the convicted candidate must miss at least one election. In order to continue his political career, the convicted politicians must run for a different office, something that has already occurred. Two prefectural assemblymen banned for five years from running in the same district have been elected to other offices, one to a city assembly (YS 25 May 1998 ) and the other to the office of mayor (YS 21 December 1998). Nevertheless, convictions normally end, and always harm, political careers. Political reform has made the enforcement of electoral laws more effective.

\section{Public funding}

Public funding has made two potentially important changes in the flow of political money: a substitution of public for private funding, and a funnelling of a higher proportion of funds through the political parties. According to the official reports of campaign expenditures, contributions from private firms have dropped drastically, but total spending has gone down much more slowly, the difference being made up by public subsidies (Iwai 1998b). One of the clearest and most reliable trends produced by the reforms is the channelling of more funds through party leadership. LDP Diet Members have been heard complaining that the new system gives the party secretary-general too much power because he controls the flow of the party subsidies (YS 23 April 1998).

Public funding does not go to the candidate directly, but to the district party branch. This simple fact has several ramifications. First, it gives official party nominees an advantage over independents. Public funding is thus working, to some degree, to promote party-centred campaigns. The introduction of public funding also makes it easier to enforce regulations on political finances. The government can audit public funds delivered to official party branches more effectively than it can audit private contributions to the array of private organisations that constitute a kouenkai.

One celebrated case made this point in a way that will be difficult for other politicians to ignore. Nakajima Youjirou took his public funding and simply 
transferred it to his private and kouenkai accounts, forging receipts after the fact to balance the books (YS 20 October 1997). Such accounting practices would have been hard to detect in the past but this time Nakajima was arrested. Once the investigations began, police found a lot of very black corruption. Nakajima soon stopped denying his crimes and began seeking mercy from the courts (YS 23 January 1999) becoming the third incumbent Diet member to be banned for five years from running in his district.

More recently, several politicians, including both socialist Tsujimoto Kiyomi and conservative Suzuki Muneo, have claimed that some suspect income was a political contribution, only to be embarrassed by the fact that they had failed to report it as such. Stricter reporting is proving useful to anyone investigating corruption but the legal restrictions on income and expenditures are not. Politicians have found a large loophole in the current law.

\section{The loophole}

The campaign expenditure law was designed to restrict the fundraising capacity of kouenkai and other candidate-centred organisations, but to enhance the fundraising capacity of party branches (Yoshida and Yamamoto 1999). First, every candidate is required to designate one organisation as the 'fund management organisation' (shikin kanri dantai). This organisation can receive contributions up to a maximum of 50,000 yen per company or 1.5 million yen per individual. The candidate may have as many other organisations as he wishes but no other organisation can accept donations from companies or groups. Kouenkai are thus restricted to collecting donations from individuals. Political parties and branches of political parties are left free to collect money from any type of donor in any amount. The law seems a perfectly reasonable way to direct funds away from kouenkai and toward party branches. Unfortunately, there are two problems with the law.

First, funds can be freely transferred among these organisations. The party can, quite reasonably, transfer funds to its candidates and their organisations. The problem is that political parties do not yet have institutionalised party branches. Most party branches continue to be no more than one of the candidate's kouenkai under a different label. Most candidates, therefore, had one organisation (the party branch) which was free to collect donations from anyone in any amount and then free to transfer those funds to any of the candidate's other organisations. If party branches actually were to represent the party instead of the candidate, this problem would not be as serious and the law might actually work as intended. Thus this problem might fade over time with the evolution of party branches.

The second problem, however, is potentially devastating, even in the long run: the law does not define the term 'party branch' and does not limit the number of party branches that can be established. One normally thinks of having a party branch in each SMD and perhaps in each municipality but the law contains no provision restricting party branches to those representing administrative 


\section{Conclusions}

boundaries. Thus, for example, one can create a party branch to represent the local construction industry. And, in fact, candidates began rapidly establishing new party branches as the 2000 election drew near (YS 18 January 2000) and the number continued to expand after the election (YS 22 January 2001). A candidate can therefore have several kouenkai designated as party branches making them free to collect as much money as they can. If this loophole is not closed, reform may fail to achieve one of its most important goals, reducing the level of political corruption.

In sum, we can conclude that there is every reason to believe that political reform has changed and will continue to change the relationship between money and politics in Japan. Perhaps the clearest trend is toward centralisation of party finances due to the advent of public funding. On the other hand, there is little reason to think that reform will accomplish its objective of reducing political corruption. Students of Italian politics seem to have come to very similar, if somewhat more optimistic, conclusions about the effects of political reform on corruption in Italy (Newell 2000: 78-79).

\section{Party-centred campaigns}

Miyake finds that voting behaviour in 1996 under the new MMM electoral system continued to be strongly influenced by voter evaluations of the candidate, even more so than under the old MMD system (Miyake 2001: 55). In 1996 only the LDP and the JCP were running under the same labels as they had in 1993. With few familiar party labels, voters presumably depended upon the cue of familiar faces. We should expect evolution toward party-centred elections to occur first among the political parties. Once voters are offered relatively stable choices among parties, they should begin to vote more on the basis of their evaluations of the party.

Japanese political parties (with the exception of the JCP) have never had significant local party branches (Foster and Edelman 1982). Under MMD, large parties were forced to run more than one candidate per district, forcing candidates to compete against other candidates from the same party. Such systems produce incentives for intra-party factionalisation, reduce the relevance of a party-based policy-oriented campaign for the re-election of individual candidates, and reward a strategy of cultivating a personal vote (Reed 1994c; Carey and Shugart 1995). Candidates then organise their personal vote into kouenkai (Ishikawa and Hirose 1989, chapter 3).

The new electoral system had two major effects on kouenkai, first, forcing existing kouenkai to reorganise and, second, changing the environment in which further evolution will take place.

By redrawing district lines, the new system split most kouenkai into two or three SMDs (only eight districts retaining the same geographical areas) and forced all kouenkai to merge (or at least co-operate and promise eventually to merge) with some of their historic enemies. Kouenkai were also disrupted by the 
disintegration of the party system, some candidates changing parties several times between the 1993 and 1996 elections.

The clearest aspect of the new political environment of kouenkai is the rapidly emerging norm that there can be but one candidate per party per district. MMM has eliminated the need for large parties to run more than one candidate per district. As the largest party, the LDP has had the most trouble making the transition to one candidate per district but has developed such innovative strategies as the 'Costa Rica arrangement' described above. Nevertheless, the key to enforcing the one candidate per district rule will be the ability to punish candidates who violate the rule, run as independents and defeat the party nominee. The LDP has always rewarded winning and has never been able to punish disloyalty. The party continues to struggle with this problem under MMM.

In the 2000 election, the Katou faction had followed traditional practice and actively supported independents during the election, hoping thereby to increase the size of the faction. Right after that election, LDP secretary-general Nonaka took a strong stand against allowing conservative independents into the party (YS 30 June 2000). Ten conservative independents formed the '21st Century Club' inside the Diet and discussed forming a new party but its members were also actively seeking entry into the LDP. The party announced tough guidelines for reentry. Re-entry would require the acquiescence of the prefectural party and of the defeated candidate (including defeated candidates from the other parties in the coalition). Yet most of the conservatives independents have found their way back into the LDP and candidates from other parties who defeated LDP nominees continue to be allowed to join the party. Incumbents are both proven winners and current votes in the Diet. The LDP has never been able to resist this combination.

Evolution toward one candidate per party per district will, nevertheless, continue even if the LDP never learns how to punish rebels. First, independents will find it more difficult to defeat official party nominees because the new system favours party nominees. Second, because the LDP cannot nominate more than one candidate, it is forced to choose. Choosing involves saying no to a candidate with an organisation in the district and some influence in the central party headquarters. Under MMD the LDP could nominate several candidates or none and simply declare the winners members of the LDP. That is no longer possible under MMM, though it has been proposed more than once. A conservative independent who wins a seat and wants to return to the LDP can rest assured that he will, sooner or later, be readmitted, but the hurdles that he must clear are now much higher. Within three or four elections MMM should solve the LDP's problem with conservative independents.

\section{Evolution toward stronger party branches?}

Whenever a party in a particular district settles on a candidate, that candidate loses much of her incentive to form an independent personal support organisation, a kouenkai. Instead she will face new incentives to merge all of the 
organisations affiliated with her party into a single organisation based on the SMD branch offices in order to stabilise her support among local office holders who run under the same party label. With the elimination of multiple candidates per district, central party headquarters should also have greater leverage to produce a more unified party. We do not yet know how strong these incentives will be and there is no reason to expect kouenkai to disappear in the foreseeable future. Nevertheless, we should expect the one candidate per district rule to produce an evolution toward stronger party branches.

One indication of how MMM will affect party organisation came in the July 1998 House of Councillors election. In most prefectures parties, particularly the LDP, organised their campaign efforts around the newly established SMD branch offices (YS 19 June 1998). Most importantly, linkage between Upper and Lower House elections was enhanced by the new SMDs. Under MMD, a party with multiple candidates running in the same Lower House district could hold its Lower House Diet members accountable for their efforts in Upper House elections. If the LDP vote was low in the first district, This could have been caused by a failure of any one of the several LDP Diet members from that district. With the introduction of SMDs, there is only one branch chief (normally the SMD candidate) and he can be held directly responsible for delivering the vote to LDP candidates in elections other than his own. In Hokkaido, each branch chief was given a target of 50,000 votes in the 1998 House of Councillors election. Anyone who failed to reach the target was warned that they would lose influence within the local party (YS 19 June 1998). Even where such strict guidelines were not announced, the LDP's Upper House vote from the Lower House SMD became part of the debate over responsibility of the LDP's defeat in the 1998 upper house election (YNS 19 July 1998).

In the Upper House SMDs, the clarity of responsibility introduced by MMM also produces stronger and more enforceable incentives to support the party nominee in other elections. For example, in Yamaguchi prefecture, LDP Diet member Satou Shinji was put in an interesting position vis-à-vis the party's nominee in the 1998 House of Councillors election. The LDP nominee was relatively weak and his opponent was Muraoka Masuo, Satou's 1996 opponent in his Lower House SMD. If Muraoka lost the Upper House election, he would be free to run against Satou again in the next Lower House election. Satou preferred to run against a weaker opponent and thus had an incentive to minimise his efforts on behalf of the LDP Upper House candidate. There were indeed rumours that Satou was not putting all of his efforts behind the LDP candidate but, unlike in the past, any failure to produce LDP votes in the Upper House election would now be visible to all. Moreover, many of Satou's supporters argued that the most important result of the House of Councillors election would be the percentage of votes delivered by Satou to the LDP, and the larger the vote share, the more potential challengers would be deterred (YS 21 June 1998). In the event, the LDP lost the House of Councillors seat and Satou faced a new challenger in 2000. 
Despite this favourable outcome, however, Satou lost to the presumably weaker newcomer.

A similar situation faced the then Prime Minister Hashimoto. The LDP candidate in the House of Councillors election was the nephew of his long-time rival and SMD opponent in the 1996 general election, Katou Mutsuki. Under the new system, Hashimoto could not get by with passive support and his kouenkai was treated to the spectacle of a member of the rival Katou family attending one of its meetings (YS 21 June 1998). In the past, personal rivalries like the Hashimoto-Katou feud regularly overrode party loyalty but party discipline is proving easier to enforce under MMM.

Many aspects of MMM are making it easier to enforce party loyalty and develop stronger party branches. There is, however, a large fly in the ointment: the loophole analysed above. If a single party branch served each SMD candidate, we could expect an evolution toward stronger party branches. Once the loophole was discovered and candidates began establishing multiple party branches, however, much of the incentive to form a single unified organisation in order to contest elections was countered by incentives to form many diverse organisations in order to raise money. We cannot yet see how these two incentives will interact and which will prove the stronger.

\section{LDP factions: toward a more coherent party structure?}

One of the factors causing the factionalisation of large parties in Japan, most notably in the LDP, was the MMD electoral system. MMM removes one incentive for organising factions. If parties run one candidate per district, a major function of factions will have disappeared: no longer will a candidate need help competing against other candidates from his own party (Cox, Rosenbluth and Thies 1999). In addition, the factional system has been in turmoil at least since Prime Minister Takeshita's retirement in 1990, turmoil which reached its peak in the split of the Takeshita faction in 1993. The introduction of MMM thus occurred when factions were in a relatively malleable state, increasing the probability that the new electoral system would affect factional organisation. One of the forces producing factions has weakened and, given the currently disorganised state, there will be less reason for factions to become as institutionalised as they were under the previous system. We may also expect some changes in the form and functions of factions. Nevertheless, there is no reason to expect factions to disappear.

First, the electoral system was never more than one of several reasons for institutionalised factions within the LDP. Second, having been part of political life since 1957, and having evolved out of pre-LDP organisations, factions have become part of the cultural repertoire of politics in Japan. People know how to organise and run a faction and they will utilise this knowledge when facing analogous problems under new circumstances. 
In April of 1998 seven unaffiliated conservatives who had returned to the LDP from sojourns in the New Frontier Party joined the Miyazawa faction (YS 11 April 1998). The reasons given represent a list of the factors that still sustain factionalisation. First, a cabinet re-shuffle was expected after the Upper House election in July, and factions represent their members in the competition for places in the cabinet. Second, Katou Kouichi, the presumed successor to the leadership of the Miyazawa faction, appeared to have a good chance of being prime minister some day and the new members wished to hitch their wagon to his rising star. Similarly, in the midst of the succession struggle in which the factions appeared to be in disarray, four unaffiliated Diet members entered the Obuchi faction, i.e., the faction of the leading candidate for party president and prime minister (YS 23 July 1998). Finally, one member of the group has close personal relations with Katou. Personal ties still count in politics.

Factions have also formed inside the new Democratic Party. The Democrats, like the LDP in 1955, was formed from a merger of several pre-existing parties, and faction formation is a natural way of maintaining one's original political identity and making sure the new party is not dominated by any single group. However, faction formation was specifically stimulated by the prospect of the 1998 Upper House election and the expected debates over the rankings on the PR list (YS 15 May 1998).

Under MMM factions should play a smaller role in nominations and in elections than under MMD, but they still play a major role in the competition for cabinet posts and in party presidential elections. Factions may also develop new, currently unforeseen, functions under the new system.

Electoral reform achieved one of its primary objectives: no longer will members of a party compete directly for the same seat in the Diet. The rule will be one candidate per party per district. This simple achievement has many ramifications, most of which point to an evolution toward more coherent political parties. Though we may feel confident about the direction this evolution will take, we cannot be as confident about the pace of that evolution. The most appropriate framework for evaluating the results of political reform is decades, not years.

\section{Toward two-party alternation in power}

The third and final part of the 'rhetorical consensus' on reform was concerned with the desirability of a two-party system. Though reformers had long repeated the arguments in favour of a two-party system, 'consensus' was much less evident for this goal than for either reducing the cost of elections or moving toward partycentred campaigns. In fact, the debate over the merits of a two-party system was heated and, among academics and political commentators at least, opponents of a two-party system outnumbered proponents. One characteristic of two-party systems, however, commanded a near consensus: the desirability of alternation in power. If the main problem with the old system were one-party dominance, a twoparty system would appear to be the obvious solution. In fact, one of the most 
common arguments heard in Japan 'proving' that political reform has failed is the simple fact that the LDP is still in power.

The goal of a system that would allow alternation in power has an obvious attraction for opposition parties. More importantly, reformers within the LDP tended to blame the ills of their own party on its long tenure in power and the lack of a credible alternative. They supported the idea of a two-party system in order to force the socialist parties to abandon their irresponsible opposition and/or to destroy the left wing in order to make the remainder available for merger into a centre-left party. For some reformers within the LDP, a two-party system might also provide them with an exit option. They would no longer be locked inside the corrupt old LDP with its unbending seniority rules, but might join (perhaps even lead!) a centre-left party shorn of its left wing. The rhetoric of a two-party system was thus an integral part of both the centre-right and the centre-left dreams. While theoretical support for a two-party system had waned over the post-war period, support for these two dreams had not. Thus, the two-party system remained, if somewhat ambiguously, part of the rhetorical reform consensus.

The most appropriate questions for evaluating the effects of political reform upon the party system are, first, 'Has alternation in power become more likely?' and, second, 'Have two main political parties emerged both of which can be trusted to run to government?' These questions both deal with the evolution of the party system as aspects of Japanese politics. However, the question of whether the next Japanese party system will be a two-party system also has significant ramifications for political science theory.

One of the most reliable generalisations in political science is 'Duverger's Law' (Duverger 1954; Riker 1986). Duverger's Law states that single-member districts tend to produce a two-party system. Duverger's Law operates through two distinct though related processes. The primary effects of an electoral system occur at the level of the electoral district and so the strongest effect of SMDs is to produce two-candidate competition in each SMD. This effect has been confirmed for the United States and India (Chhibber and Kollman 1998) and, most relevantly for the Japanese case, for Italy after its adoption of MMM (Reed 2001B). On the other hand, it has been strongly disputed in Canada (Gaines 1999). In this chapter, we shall ask, first, 'Has Japan experienced an evolution toward bipolar competition at the district level?' I am on record as having predicted that this would be the case (Reed 1997a).

The second process involved in creating a two-party system is what Cox calls 'cross-district linkage' (1997: 182), the tendency for the two candidates competing in each SMD to represent one of only two national alternatives. This process is not as well understood as the mechanisms producing two-candidate competition at the district level, but we know that it involves the structure and operation of the legislature in addition to the electoral system (Cox 1987). 


\section{Toward bipolar competition at the district level}

Has Japan moved toward two-candidate competition at the district level? I will use three measures of two-candidate competition. The most common measure of the effective number of parties is Laakso and Taagepera's index (1979). I have used this index to create a measure of the effective number of candidates, which, if Duverger's Law holds, should equal two. My personal preference, however, is what I call the effective number of challengers, calculated using the Molinar index (Molinar 1991). It is the Laakso-Taagepera index standardised around the vote for the winning candidate. Duverger's Law predicts that the effective number of challengers should equal one. Finally, I have developed a measure of bipolarity that equals zero when two candidates each get 50 per cent of the vote but increases with any deviation from this norm (Reed 2001a). Bipolarity rises when more than two candidates divide the vote and when one candidate takes more than half the vote. (See the statistical appendix at the end of this chapter.)

The results for both Japan and Italy are presented in Table 10.1. On the one hand, between the 1996 and 2000 elections well over half of all Japanese SMDs moved in the correct direction based on all three measures (68 per cent for the effective number of candidates, 65 per cent for the effective number of challengers, and 57 per cent for bipolarity). On the other hand, the movement in Japan was much weaker than what occurred between the first and second elections in Italy. Whereas over 80 per cent of Italian districts moved in the direction predicted by Duverger's Law, less than 70 per cent of Japanese districts did the same.

Table 10.1 also contains a clue to explaining this puzzle. In those districts where the number of candidates or challengers was too high in the first election, over 70 per cent of Japanese SMDs moved down toward equilibrium. This is about 10 percentage points lower than in Italy in its second election under MMM, though still impressive support for Duverger's Law. However, in those districts where the number of candidates and challengers was too low in 1996, less than half of Japanese SMDs moved up toward equilibrium, a figure almost twenty percentage points lower than in Italy. The reduction of excessive competition was achieved in Japan at a rate somewhat lower than in Italy but non-competitive districts in Japan did not move toward equilibrium at all. In fact, these districts

Table 10.1 Movement toward equilibrium between the first and second elections

\begin{tabular}{lccccc}
\hline Measure & \multicolumn{2}{c}{ Japan } & & \multicolumn{2}{c}{ Italy } \\
\cline { 2 - 3 } & $\begin{array}{c}\text { Too low } \\
\%\end{array}$ & $\begin{array}{c}\text { Too high } \\
\%\end{array}$ & & $\begin{array}{c}\text { Too low } \\
\%\end{array}$ & $\begin{array}{c}\text { Too high } \\
\%\end{array}$ \\
\hline Candidates & 31.6 & 70.8 & & \\
Challengers & 48.2 & 75.5 & & & \\
Bipolarity & $\mathrm{n} / \mathrm{a}$ & 57.0 & & 67.5 & 80.7 \\
\hline
\end{tabular}


were more likely to become less rather than more competitive in the second election. Our prefectural case studies suggest that the key to understanding decreasing competition may be found along the urban-rural dimension. Table 10.2 confirms this hypothesis for the nation as a whole.

I define a non-competitive district as one in which the effective number of challengers fell below 0.6. This is figure is currently based on experience, not theory. It is around this figure at which turnout begins to drop rapidly indicating that voters perceive the district to be non-competitive. Next, I divided the districts into three levels of about 100 districts each based upon the percentage of the population living in densely inhabited districts as defined by the census bureau. I classify all districts with less than 40 per cent of the population living in DIDs as rural, those with between 40 and 80 per cent as urban, and those with over 80 per cent as metropolitan. A simple cross-tabulation demonstrates that the number of non-competitive districts increased from 50 in 1996 to 71 in 2000. The number of non-competitive districts is higher in rural districts in both years and falls monotonically with the level of urbanisation. Transitions to non-competition outnumbered transitions to competition at each level of urbanisation, but the phenomenon of non-competition is primarily a rural one.

District-level competition in Japan is becoming bipolar. This generalisation must, however, be qualified by adding that the movement was much slower than that witnessed in Italy's second election. Why was the movement toward bipolarity so slow? The answer is that the NFP, the primary challenger to the LDP in 1996, fell apart. The break-up of the NFP slowed the evolution toward bipolar competition because the DPJ was unable to mount as effective a challenge in 2000 as the NFP had done in 1996. The difference was greatest in rural areas.

The NFP was able to challenge the LDP in its rural strongholds but was able to do so only by drawing LDP defectors into the NFP. When those defectors returned to the LDP, there was little organisational basis left for challenging the LDP. As Sveinsdóttir points out in Chapter 6, without the kouenkai of LDP defectors, rural society offers the opposition little in the way of organisations

Table 10.2 Competitiveness in urban and rural districts

\begin{tabular}{lccc}
\hline & \multicolumn{3}{c}{ The number of non-competitive districts } \\
\cline { 2 - 4 } & $\begin{array}{c}\text { Became } \\
\text { non-competitive }\end{array}$ & $\begin{array}{c}\text { Stayed } \\
\text { the same }\end{array}$ & $\begin{array}{c}\text { Became } \\
\text { competitive }\end{array}$ \\
\hline & 24 & & \\
Rural & 10 & 64 & 11 \\
Urban & 2 & 89 & 4 \\
Metro & 96 & 0 \\
All & 36 & 249 & 15 \\
\hline
\end{tabular}

Note: I would like to thank the Kabashima seminar for providing data on DIDs broken down by electoral district. 
capable of challenging the LDP. In urban districts the DPJ has other resources, most notably labour unions, but in rural areas it must build new political organisations from scratch. The DPJ did very well in urban districts in the 2000 election, primarily with the help of floating voters but also supported by labour unions and citizens' movements, but rural areas offered fewer floating voters, weaker unions and fewer alternative organisations.

Shinsei and the NFP were the first parties ever to challenge the LDP on its home turf in rural areas (Reed 1997b). Of course this feat was accomplished almost exclusively by the defection of LDP incumbents, as illustrated neatly in Scheiner's analysis of Nagano in Chapter 4. If these defectors returned to the LDP, the NFP challenge evaporated. Depending on what the defectors decided to do after the break-up of the NFP, the challenge could survive, as in Nagano, or could disappear, as in Aomori. In Aomori, Kimura Morio followed Ozawa and Hata out of the LDP and then won the governor's mansion for the NFP. His son succeeded him in the rural $4^{\text {th }}$ district. Governor Kimura used the powers of his office to strengthen the NFP organisation in Aomori but, after the break-up of the NFP, his son wished to return to the LDP and the two conservative forces merged. NFP defectors returned to the LDP and the result was the re-establishment of an LDP-dominant 'Conservative Kingdom' (Touo Nippou 25 May 2000).

Let us therefore turn to those districts that went from being non-competitive in 1996 to being competitive in 2000. Several of these districts tell fascinating but unique stories. For example, in Tochigi $1^{\text {st }}$ district, an entrenched conservative incumbent divorced, remarried, and was defeated by a female challenger. In Iwate $3^{\text {rd }}$ district, part of Ozawa Ichirou's fiefdom, one NFP candidate had the gall to stay in the coalition with the LDP after Ozawa had left. Ozawa punished this disloyalty by nominating a candidate to run against and defeat him. Thus, in Iwate $3^{\text {rd }}$, a Conservative incumbent was defeated by a Liberal challenger in a race that also included two other conservative candidates, one nominated by the LDP and one running as an independent. The DPJ candidate finished fifth. Of more general interest is the case of Mie $3^{\text {rd }}$ district where an entrenched NFP incumbent moved to the DPJ, and the LDP was able to mount a significant but unsuccessful challenge in 2000. Though we have only one case so far, it would appear that the LDP can challenge entrenched incumbents in rural areas even if the DPJ cannot yet do so. Most importantly, however, in eight rural districts the opposition was able to mount significant challenges to conservative incumbents who had not been challenged in 1996. Six of the relatively successful challengers came from the DPJ, one from the SDP and one was an independent.

How did the opposition find candidates willing to run against entrenched conservative incumbents in hopeless rural districts? For the DPJ and the SDP the answer is the PR tier. On the island of Shikoku the DPJ nominated all of the SMD candidates ranked first on its PR list, allowing the final order to be determined by the SMD results. The DPJ was thus able to challenge the LDP in 2000 in three extremely rural districts where no effective challenge had been possible in 1996. None of these candidates gained a seat because the DPJ won only one PR seat in 
Shikoku, but the potential of the PR district to attract competitive candidates was clear even in rural Shikoku. In four other districts, opposition party candidates won PR seats by challenging entrenched SMD incumbents. In all of these districts, the opposition persuaded candidates to run not by promising them a guaranteed PR seat but by offering the chance to win a PR seat based on their relative performance in their respective SMD races. Voters in several districts enjoyed a competitive campaign because MMM has a PR tier.

Movement toward bipolarity was stronger in urban areas and we can expect bipolar competition to become the norm by the next election. In rural areas, we should also expect the trend toward non-competition to be reversed and replaced by a trend toward bipolar competition. The break-up of the NFP was a low probability event (see Chapter 3) and is unlikely to be repeated. In the absence of any further exogenous shocks, the normal evolution toward bipolar competition at the district level should become manifest. Several of the mechanisms by which this evolution can be accomplished have already become visible.

First and foremost, the experience of the 2000 election demonstrates that the DPJ (and the SDP) can use PR nominations to entice candidates to run against entrenched conservative incumbents even in rural districts. The DPJ worked very hard to get candidates to run in every SMD in 2000 but failed because potential candidates were unwilling to run for a party with less than 10 per cent support in the polls. We should expect potential candidates to learn from the experience of the 2000 election and be more willing to run for the DPJ in the next election.

The opposition has a long way to go before it will be able systematically to challenge the LDP in rural areas. Building organisations takes time. Nevertheless, there are two mechanisms working to produce more competitive elections even in rural districts. First, PR incumbents are using the resources provided by their incumbency to build support. Second, the LDP has never been a coherent political party. Fortunately for the opposition, where the LDP is strongest it is also at its most fissiparous. Several incumbents denied the LDP nomination ran as independents and accepted support from opposition parties and groups. The clearest example occurred in the by-election held in Wakayama $2^{\text {nd }}$ district in April of 2001. In a familiar scenario, two candidates sought the LDP nomination. The son of the deceased Diet member was not nominated but ran as an independent. In order to defeat his conservative rival, he accepted opposition support. Though he lost, the opposition gained a candidate with organisational support in a rural district. We can expect to see more splits in the conservative ranks producing more competitive elections in rural SMDs over the next several elections. What cannot yet be predicted with confidence is whether conservative challengers who defeat conservative incumbents will be allowed to join the LDP or be forced to join an opposition party.

I would wager that non-competitive districts will become rarer under MMM than under pure SMD. The PR tier allows parties to field competitive candidates where they are weak and even allows them to win PR seats without winning the SMD. Rematches between two incumbents both of whom may win seats again 


\section{Conclusions}

may not meet the ideal of democratic competition. Nevertheless, competition between two incumbents should be preferred to the lack of competition implied by an incumbent who faces no serious challenge. MMM should ameliorate one of the most difficult problems of pure SMD systems, the large number of noncompetitive districts.

\section{Towards a two-party system?}

The data indicate that there is indeed movement, albeit halting, toward bipolar competition at the district level as predicted by Duverger's Law. Is there also movement toward a two-party system at the national level? Again the answer must be yes but not much yet. The data is presented in Figure 10.1.

After the 1993 election the effective number of parliamentary parties rose to over four. The figure dropped to three after the founding of the NFP. The breakup of the NFP produced a small, temporary increase but the founding of the new Democratic Party resulted in a return to three effective parties. There have been no significant deviations from this value since that time. Movement toward a twoparty system in the Diet has stalled.

At the time of this writing (October 2002), the LDP is the clear leader of a 'centre-right' coalition government. The Conservative Party is a member of the coalition but shows little potential for surviving as a viable force in the long run. If no further party splits occur before the next election we should again find Conservative candidates attempting to re-enter the LDP. Koumei is the other member of the coalition and can clearly survive in the PR tier but can win no SMDs without the support of other parties as Cox's analysis of Hyogo Prefecture in Chapter 5 makes abundantly clear. Koumei is the primary obstacle preventing further progress toward a two-party system. The party is also facing some tough choices about its future. Currently, its members seem to be placing their bets on changing the electoral system back to MMD and resuming the role of a niche

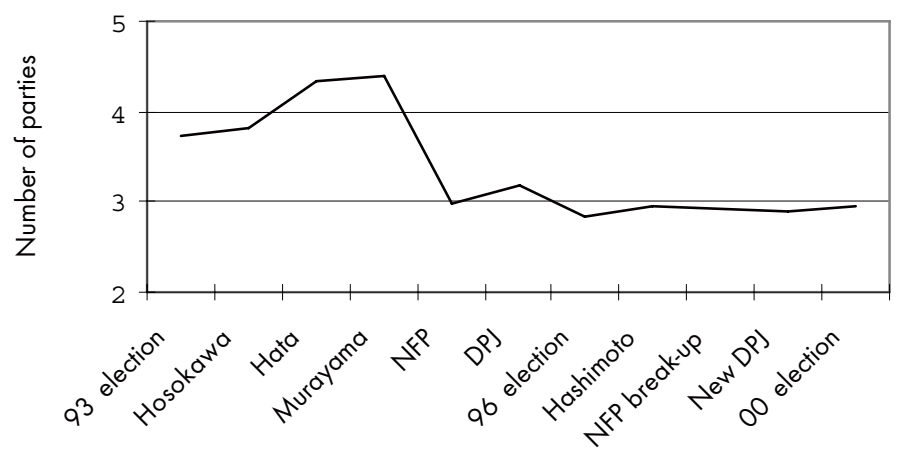

Figure 10.1 Changes in the effective number of parliamentary parties since political reform 
party in elections and a centre party in the Diet. The future of Koumei under MMM does not look bright.

The Democrats have clearly established themselves as the leading party of the opposition but have not yet been able to establish a clear public image. They refused to co-operate with the other opposition parties in the 2000 election and that strategy paid off in the sense that it established the DPJ as the primary rival to the LDP. Now that the primacy of the Democrats has been established, they are seeking co-operation with the other opposition parties, most notably the SDP and the Liberals but also including the Communists. The SDP and the Liberals may be able to retain a few seats, primarily in the PR tier but have few prospects under MMM. The Communists, however, have the organisational strength to survive on a few PR seats and to run candidates in every SMD even with no prospects of winning any at all. The JCP is the primary obstacle to further evolution toward a two-party system within the opposition camp. At this point, Japan has a two-camp system if not yet a two-party system.

The leading parties of both camps are internally divided and either or both could well split again. Nevertheless, there are several reasons to believe that competition between the LDP and the DPJ will form the backbone of the Japanese party system for many years to come. First, as the break-up of the NFP demonstrated to all concerned, public funding gives parties an incentive to stick together and, at a minimum, to keep the same party label. Though many of the detailed interpretations of the law have yet to be worked out, public funds are provided to parties on basis of the the number of votes won in the last election. By definition, a new party won no votes in the past election. When parts of the NFP joined the DPJ to form the 'new' Democratic Party, they decided to retain the name in order to assert the party's claim to its share of public funding. When the Liberal Party split into the Liberals and Conservatives, the Liberals took most of the funds because they retained the original party label. The system of public funding gives parties an incentive to stick together or merge but not to break apart. Of course, knowing one set of incentives does not produce a prediction but the system of public funding provides one set of incentives that should help deter further splits.

There are groups inside the LDP that are extremely dissatisfied with the current party line. In November 2000 the Katou and Yamazaki factions (two of the three YKK factions) threatened to support a motion of no confidence against their own government. Though the attempt failed, the threat was quite serious and demonstrated the level of frustration among some LDP factions and especially among younger members of the LDP (18 November 2000). Throughout the drama, Katou repeatedly asserted that he had no intention of leaving the LDP. Many interpretations of his motives are possible but my interpretation is that he had learned from past mistakes. There have been three defections from the LDP: Kouno in 1976, Takemura and Hata/Ozawa both in 1993. One might include Hosokawa and the JNP as a fourth case, though it did not involve defections of sitting Diet members. None has succeeded. Any leader wanting to try again 
would have to demonstrate to potential followers how he planned to succeed where all previous attempts had failed. Though the LDP may well split again, I would bet against it.

A DPJ split appears more likely. The party encompasses a wide range of organisational cultures and the various groups within the party have had a very short history of working together. Any setback could put the party on a path toward disintegration. The only things holding the party together are antipathy toward the LDP and the hope of eventually gaining power. No matter how small that hope becomes, however, sticking together in a party called the Democrats will continue to be the best hope the opposition has of gaining power. If the Democrats do well in upcoming elections, they will learn to work together and they will rapidly evolve into an alternative government party. If they do badly, that evolution will be slowed and perhaps ended.

Would a small chance of unseating the LDP prove sufficient to hold the party together simply because that small chance is also the best chance? If politics were only about elections, I would confidently predict the emergence of a two-party system, though I would be less confident about predicting how soon that system would emerge. Politics, however, is also about legislation and policy making. The question thus becomes: when the DPJ suffers electoral reverses, will the LDP be able to exploit the ideological divisions within the party? The answer to this question lies more with legislative than with electoral politics, and legislative politics is harder to predict.

\section{Prospects for a two-party system}

At the beginning of this chapter I suggested that the most appropriate questions for evaluating the effects of political reform upon the party system were: 'Has alternation in power become more likely?' and 'Have two main political parties emerged, both of which can be trusted to run the government?' My answer to both questions is yes. Japan does not yet have a two-party or even a stable two-camp system, but alternation in power is more likely since political reform than it was before.

First, elections under MMM should produce more decisive electoral results than did elections under MMD. Under MMD, normal vote shifts tended to produce a change of no more than one seat per district (Reed 1994b). One seat per district under MMD meant that only about a quarter of the seats could change hands at any one election. Not only were actual results far short of this theoretical maximum, but the LDP often lost seats not only to opposition parties but to independents who later joined the LDP. Whereas MMD tends to 'muffle the swing' (Mair 1982), SMD tends to magnify the swing. Under SMD, small vote shifts often produce large seat shifts (Taagepera and Shugart 1989). The Japanese case in point is the 1989 House of Councillors election in which the Socialists defeated the LDP in the single-member districts but not in the multimember districts. 
The SMD tier of MMM should both magnify the swing and guarantee that LDP losses are more often translated directly into opposition gains. Twocandidate races featuring one candidate from the government and one from the opposition have already become the norm in Japanese SMDs. The PR tier may allow small third parties to survive and may muffle the swing to some degree, but my guess is that the primary function of the PR tier will be to reduce the number of non-competitive districts. If my guess proves correct MMM may well produce greater responsiveness than pure SMD. SMD does not magnify the swing when there are many non-competitive districts. In Britain between 1982 and 1989, for example, Conservative incumbents in the south of England felt safe against any possible swing against the government (Adonis 1994: 155-156). If the PR tier of MMM reduces the number of non-competitive districts, it will produce the conditions under which the SMD tier most effectively magnifies the swing.

Even if elections prove more decisive, the question remains whether voters trust the opposition to take over the government. Though the Democrats are far from becoming an attractive alternative to the LDP, they are a much more acceptable alternative than the JSP was under the old party system. The ideological gap has narrowed, so much so that there appears to be little that divides the parties. A competence gap remains in the public consciousness, but the Democrats have one member with experience as prime minister (Hata Tsutomu) and several more with ministerial experience. Putting the Democrats in power would be much less of a leap into the dark than putting the JSP in power would have been under the previous party system. Political reform has succeeded in making it easier for voters to effect an alternation in power. Finally, the clear tendency for DPJ support to rise as elections approach indicates that it is considered the alternative to the LDP. All the DPJ need do to win elections is to hold together and be this alternative.

\section{What will divide the parties?}

If we see continuing evolution toward two-camp competition, either in a twoparty system or in a two-camp system, what will be the cleavages that divide the two sides? Political cleavages emerge through an interaction between voters and political parties. They are not mere reflections of public opinion, and political parties are not free to mobilise any cleavage they might find convenient. Rather, public opinion is the raw material from which parties must select and create cleavages. The process is one in which various parties propose policies and emphasise various differences between themselves and their rivals. Voters then respond to these policies and the parties learn lessons from their response.

Each party tries to identify itself with issues that attract voters and to identify its rivals with issues that repel voters. Once identified with an issue, however, a party finds it difficult to disassociate itself from that image. Parties have some control over the issues with which they are identified, but the most powerful 
factors identifying a particular party with a particular issue are beyond their control. For example, the LDP did not choose to become identified with political corruption but repeated scandals have etched that image in the public mind. Anything that reminds the public of the connection between the LDP and corruption, no matter how minor it might be, moves public opinion. Thus the Hashimoto administration experienced a sudden drop in support when convicted felon Satou Takayuki was appointed to the cabinet. Similarly, the LDP has long been associated with public works. That policy was chosen by the party because it won votes for the party in the past but it may now have become a burden. Instead of attracting voters, it now tends to repel them.

The LDP has a relatively clear set of images that it cannot escape but the Democrats do not. The image of the DPJ is not so much a bad image as a vague image. In Chapter 9 we found some evidence for a new versus old cleavage. The DPJ's successes have been based primarily upon being the 'new' alternative to the LDP but somewhere along the line some event will crystallise the party's image. While there is no way to predict what that event will be, when it will occur and what issue will become the primary cleavage dividing the Democrats from the LDP, we can speculate on several of the more likely possibilities. Given the above, my speculation will be based on what issues seem to move votes. I will not analyse public opinion directly nor will I pay much attention to how the parties currently characterise either themselves or their rivals.

What are the issues that have moved votes in 1996 and 2000? The most powerful issue in both the 1996 and 2000 elections was religion, or, more specifically, attitudes toward Koumei. This issue has never been part of official campaign platforms but played a prominent part of the informal 'whispering campaign', to use the British phrase. In 1996 the LDP attacked the NFP as 'Koumei in disguise' and the issue moved votes from the NFP to the LDP. In 2000 Koumei was allied to the LDP, and LDP popularity declined as soon as Koumei entered the coalition. In both elections, one of the most important factors at the district level was the candidates' relationship with Koumei. The issue moved candidates as well as votes. In 1996 several members of the Democratic Socialist Party who had long run against Koumei in their districts refused to follow their party into the NFP because it included Koumei. In 2000 several LDP candidates refused to withdraw in favour of Koumei and ran as independents against their own coalition government. Neither the LDP in 1996 nor the DPJ in 2000 was able to mobilise the issue to its full capacity because each party included candidates close to (or dependent upon) Koumei. Similarly, both parties include groups dedicated to excluding Koumei from government.

The religious issue does move votes but does not currently clearly divide the parties. Koumei has been allied with both the anti-LDP camp and the LDP, and has strong links to particular politicians in both camps. Both camps also include vehement enemies of Koumei. Koumei would thus seem to have the potential to play the role of a centre, swing party, analogous to the role played by the Federal Democratic Party in early post-war Germany. The FDP went into coalition first 
with the right, then with the left, then returned again to the right. There are several reasons, however, to think that it would prove quite difficult for Koumei to play this role or even to change camps one more time.

First, a controversial party like Koumei should find it difficult to move back and forth from one camp to the other. With each of its moves, the German FDP lost voters and incumbents (Hoffman-Lange 1986). We can expect Koumei to suffer similar losses and it did cost the party a good deal of effort to sell the idea of a coalition with the LDP to its supporters. Not only would another switch be at least as difficult as the first, it might also sow seeds of cynicism about the party's leadership. More importantly, one may also doubt whether the party would be welcomed back into the anti-LDP camp again. Although candidates still covet Koumei votes, parties may be becoming more wary of manifest links to the controversial party. In two consecutive elections, the party associated with Koumei - the NFP in 1996 and the LDP in 2000 - has not done as well as expected. If the DPJ learns from recent experience, it will not wish to repeat an experiment that has thus failed twice in succession. The LDP and Koumei may be more inextricably linked than either side intended or expected when the coalition was formed. Koumei now has few options except to continue co-operating with the LDP. Similarly, the only way the LDP can free itself of its dependence upon Koumei is to win a majority without Koumei.

The religious cleavage could be mobilised if Koumei were to take some dramatic action that forced LDP candidates to take sides either for or against the coalition. The most likely scenario is that Koumei gives the LDP an ultimatum which divides the LDP, or that Koumei makes a serious public gaffe that hurts the party's image and drags down the image of the LDP with it. Another possibility is the organisation of another new party based on a rival religious organisation. If, for example, Shirakawa Katsuhiko of Niigata $6^{\text {th }}$ district or Ishihara Shintarou, governor of Tokyo Prefecture, forms a new party, that party's electoral base will certainly contain Koumei's primary rival, the Risshou Kousei Kai. In the absence of an event to trigger the religious cleavage, the most likely scenario for Koumei would be a decline at the national level and a return to its roots in local politics. The party could either exit the national arena or hold on to a small base via the PR tier. In either case, the Koumei vote could continue to play a major role in determining which candidates of the two major parties win particular SMDs.

The most intriguing possibility for a new cleavage is the issue of public works. The LDP has built its economic policy (Sakakibara 1991) and electoral strategy around the building of public works (Woodall 1996). Not only are public works inextricably linked to the LDP in the public mind, the LDP has depended on the promises of public works to win votes. If public works were to become a vote loser, the LDP would find it extremely difficult to extricate itself from its identification with pouring concrete.

The issue of public works came up in several specific electoral districts in the 2000 election with ambiguous results. The DPJ was clearly less enthusiastic about public works than the LDP but neither party took a clear stand on the issue. 
Recently, however, several gubernatorial elections have brought in independents who took clear stands against further public works and these individuals have enacted much clearer policies of reducing public works after assuming power in their respective prefectures. This phenomenon is not limited to urban areas, as indicated by the surprising results in Nagano and Tochigi prefectures, where outsiders with no party support defeated incumbents supported by all the major parties. The DPJ has not yet been able to take advantage of these elections to build an anti-public works image because the candidates in question refused the endorsement of all political parties. Nevertheless, the success of these governors enhances the attractiveness of the public works issue for the opposition camp.

If one simply looks at the returns from the 2000 general election, as we did in Chapter 9, it would appear that an urban-rural cleavage is evolving. The Democrats did well in urban areas and the LDP did well in rural areas. The issue of public works divides urban and rural areas to some degree, so the urban-rural cleavage overlaps with the public works cleavage. More generally, LDP style clientelistic politics works best in rural Japan. On the other hand, it is in rural areas that voters have experienced the clearest examples of expensive but useless public works. LDP-style public works may be more effective in attracting contributions from construction companies than votes from rural voters. Though the party has made great efforts to overcome its disadvantages in urban areas, the LDP still does not know how to attract the urban voter. In fact, no party has mastered the art of urban campaigning.

The old Ampou cleavage appears to be dead. The peace issue has not moved a significant number of votes for several years now. The Democrats are now led by a proponent of constitutional reform who also supports a rethinking of the peace clause. The LDP now talks openly of constitutional reform but few voters think of them as warmongers who pose a danger to world peace. Nevertheless, there are still quite a few members of the DPJ who continue to take the issue very seriously and both the SDP and the JCP are ready to fight over the issue. Barring some major international event, it is hard to imagine the peace issue dividing voters into two camps. It is, however, still easy to imagine the LDP using the peace issue to divide the opposition.

The most important thing to remember in thinking about the future Japanese political system is that Japan is currently in a state of profound dealignment. Between 40 and 50 per cent of voters support no party. In this situation, a triggering event can shift the balance of support rapidly and drastically. Not only are we not in equilibrium, we are not even moving toward some predictable equilibrium. The jump in cabinet support from under 10 per cent for the Mori cabinet to around 80 per cent for the Koizumi cabinet is only the most recent case in point. We can expect similar fluctuations in the future.

\section{Postscript: the Koizumi phenomenon}

After the 2000 election, the DPJ was looking forward to the next election, trying to make it happen as soon as possible, while the LDP and its coalition partners 
hoped to put it off as long as possible. The mood reversed, however, after Koizumi Junichirou was chosen to lead the LDP. Koizumi defeated former Prime Minister Hashimoto in a party presidential primary that allowed party members to vote for their leader. Hashimoto and the Conservatives managed to avoid a national primary but LDP prefectural federations, with a few exceptions, decided to hold primaries to determine how their votes would be cast. Koizumi ran as a reformer supported by party outsider Tanaka Makiko, though he also tacked down some conservative support by promising to participate in the ceremonies for the war dead at Yasukuni Shrine if elected. Despite the fact that most LDP party members join as members of some organisation supporting the LDP indeed are often signed up without their knowledge or consent - and the fact that those organisations overwhelmingly supported Hashimoto, primary voters flocked to Koizumi.

As prime minister, Koizumi promised to change Japan by changing the LDP. He appropriated the role as the leader of the opposition to the LDP (or at least traditional LDP politics) and stole the DPJ's major policy positions. He was rewarded with 80 per cent support ratings and the LDP 'won' the 2001 House of Councillors elections.

Koizumi's reforms were not designed to curry popularity or to win votes. They were designed to wean the LDP from its dependence on clientelism and the organizational vote. 'Privatize the Post Office' and 'Change Road Construction Funding' are not the kind of slogans to put on placards to rally public support. They do, however, strike at the heart of the traditional power bases of the LDP and particularly of the Tanaka-Hashimoto faction. Reform generates popularity not because the public supports the particular reforms but because it demonstrates that Koizumi is serious in his commitment to change.

Koizumi faces massive resistance within the party. He has made a little progress in changing the LDP and even less progress in enacting economic reform. Much of his popularity faded when he fired Foreign Minister Tanaka Makiko, the symbol of uncompromising reform. He is making some progress but the pace is glacial. Nevertheless, it is still too early to give up on the Koizumi project. The LDP has twice before accomplished the 'impossible'. In 1960 the LDP abandoned what many at the time saw as the essence of the party platform: constitutional revision and rearmament. In 1970, in the face of growing concern over pollution, the LDP abandoned the 'essence' that had replaced rearmament, economic growth at any cost. In both cases the logic was simple: if we continue down this path, we will lose elections. The LDP faces the same choice today. The current 'essence' of LDP politics is clientelism. Clientelism and the organisational vote no longer brings election victories while the leading proponent of reform, whether inside or outside of the LDP, bring both popularity and votes. Whichever party and leader best symbolises reform will do well in the next election. Will it be the LDP, the DPJ or a new party? 


\section{Appendix: calculating bipolarity}

The most commonly used measure of the effective number of parties in political science is the Laakso-Taagepera index (Laakso and Taagepera 1979). With v being the proportion of the vote of candidate $\mathrm{i}$, the LT index is calculated as:

$$
L T=\frac{1}{\sum V_{i}^{2}}
$$

The LT index is elegant mathematics and has deservedly become the standard in political science but it does have some problems. For current purposes the LT index tends to give excess weight to smaller parties producing estimates of the effective number of candidates which seem too high. The LT index seems well designed for bargaining situations in which smaller parties actually do exercise greater power than their proportion of the seats would merit.

The Molinar index (Molinar 1991) corrects for some of the problems with the LT index, though it also creates other problems of its own. The Molinar index standardises the LT index around the top vote-getter:

$$
\text { Molinar }=1+L T \frac{\left(\sum v_{i}^{2}\right)-v_{1}^{2}}{\sum v_{i}^{2}}
$$

The Molinar index would seem to be particularly appropriate when the top vote-getter carries particular significance and, in this case, the top vote-getter is the winner and her vote represents the 'post' in the phrase 'first past the post'. I calculate the Molinar index as the effective number of challengers by omitting the 1 in the formula above. Duverger's Law thus predicts that there should be but one effective challenger.

I have derived a third measure of bipolarity from an analysis of SMDs in prewar Japanese elections by Nagayama (1997). He plotted the percentage of the vote received by the first-place candidate against the percentage received by the second-place candidate. He noticed that the plots all took the form of a triangle. No point can be found beyond the line defined by ' 1 st $+2^{\text {nd }}=100$ ' because percentages cannot exceed 100. Neither can any point be found beyond the line defined by ' 1 st $=2^{\text {nd' }}$ because the percentage of the vote garnered by the $2^{\text {nd }}$ place finisher cannot exceed that of the $1^{\text {st }}$ place finisher. All points must fall within the triangle defined by these equations. I thus calculate the geometrical distance between any given point and the peak of the triangle where the 1st and 2nd candidates both receive 50 per cent of the vote. The Pythagorean theorem yields the following definition of bipolarity:

$$
\text { Bipolar }=\sqrt{(1 s t-50)^{2}+(2 n d-50)^{2}}
$$

This index measures not bipolarity but the distance from bipolarity, but I will continue to call it 'bipolarity' for the sake of simplicity. This formula implies that elections can deviate from bipolarity in two different ways, either by becoming 
non-competitive and moving toward unipolarity or by reducing the total vote received by the top two candidates and moving toward multipolarity. This bipolarity measure treats both types of deviations as equivalent. For example, a 67-33 distribution and a 33-33-33 distribution of the vote yield identical values for bipolarity. 


\section{References}

Adonis, Andrew (1994) 'The Transformation of the Conservative Party in the 1980s' in Andrew Adonis and Tim Mames (eds) A Conservative Revolution? (Manchester University Press).

AERA (1994) Special Issue, Shin Senkyo he Resshima Douran, 20 May 1994.

Barker, Fiona et al. (2001) 'An Initial Assessment of the Consequences of MMP in New Zealand' in Matthew Soberg Shugart and Martin P. Wattenberg (eds) Mixed-Member Electoral Systems: The Best of Both Worlds? (Oxford: Oxford University Press) 297-322.

Berton, Peter (1992) 'The Japanese Communist Party' in Ronald J. Hrebenar (ed.) The Japanese Party System (Boulder, CO: Westview Press).

Bromhead, Peter (1971) 'The British Constitution in 1970' Parliamentary Affairs 22: 104-122.

Butler, David and Anthony King (1999) The British General Election of 1964 (London: Macmillan).

Cain, Bruce, John Ferejohn and Morris Fiorina (1987) The Personal Vote (Cambridge, MA: Harvard University Press).

Calder, Kent E. (1988) Crisis and Compensation: Public Policy and Political Stability in Japan, 1949-1986 (Princeton NJ: Princeton University Press).

Campbell, Angus et al. (1964) The American Voter (New York: John Wiley and Sons).

Campbell, John Creighton (1984) 'Policy Conflict and Its Resolution within the Governmental System' in Ellis S. Krauss, Thomas P. Rohlen and Patricia G. Steinhoff (eds) Conflict in Japan (Honolulu: University of Hawaii Press).

Carey, John M. and Matthew Soberg Shugart (1995) 'Incentives to Cultivate a Personal Vote' Electoral Studies 14: 417-40.

Chhibber, Pradeep and Ken Kollman (1998) 'Party Aggregation and the Number of Parties in India and the United States' American Political Science Review 92: 329-342.

Christensen, Ray (1994) 'Electoral Reform in Japan' Asian Survey 34 (July) 589-605.

Christensen, Ray (2000) Ending the LDP Hegemony (Honolulu: University of Hawaii Press).

Clarke, Harold D. Allen Kornberg and Peter Wearing (2002) A Polity on the Edge: Canada and the Politics of Fragmentation (Peterborough, Ontario: Broadview Press).

Cox, Gary W. (1987) The Efficient Secret: The Cabinet and the Development of Political Parties in Victorian England (Cambridge: Cambridge University Press).

Cox, Gary W. (1997) Making Votes Count (New York: Cambridge University Press). 
Cox, Gary W. and Michael C. Munger (1989) 'Closeness, Expenditures and Turnout: the 1982 U.S. House Elections' American Political Science Review 83: 217-232.

Cox, Gary W. and Emerson Niou (1994) 'Seat Bonuses under the Single Non-Transferable Vote System: Evidence from Japan and Taiwan' Comparative Politics 26: 221-236.

Cox, Gary W., Frances Rosenbluth and Michael Thies (1998) 'Mobilization, Social Networks and Turnout: Evidence From Japan.' World Politics 50: 447-472.

Cox, Gary W., Frances Rosenbluth and Michael F. Thies (1999) 'Electoral Reform and the Fate of Factions: The Case of Japan's LDP' British Journal of Political Science 29: $33-56$.

Cox, Gary W. and Michael F. Thies (1998) 'The Cost of Intraparty Competition: The Single, Nontransferable Vote and Money Politics in Japan' Comparative Political Studies 31: 267-291.

Cox, Gary W. and Michael F. Thies (2000) 'How Much Does Money Matter? 'Buying Votes in Japan, 1967-1990' Comparative Political Studies 33: 37-57.

Cox, Karen and Leonard Schoppa (1998) 'The Consequences of 'Sticky Voting' in MixedMember Electoral' Paper Presented at the Annual Meeting of the American Political Science Association, Boston, Massachusetts, September 3-6.

Cox, Karen and Leonard Schoppa (2002) 'Interaction Effects in Mixed-Member Electoral Systems: Theory and Evidence from Germany, Japan and Italy' Comparative Politics 35: 1027-1053.

Curtis, Gerald L. (1988) The Japanese Way of Politics (New York: Columbia University Press).

Curtis, Gerald L. (1999) The Logic of Japanese Politics (New York: Columbia University Press).

Denver, David (1992) 'The Centre' in Anthony King et al. Britain at the Polls 1992 (Chatham, NJ: Chatham House Publishers).

Donovan, Mark (1995) 'The Politics of Electoral Reform in Italy' International Political Science Review 16: 47-64.

Downs, Anthony (1957) An Economic Theory of Democracy (New York: Harper and Row).

Duverger, Maurice (1954) Political Parties (New York: Wiley).

Farrell, Brian and David M. Farrell (1987) 'The General Election of 1987' in Howard R. Penniman and Brian Farrell (eds) Ireland at the Polls, 1981, 1982 and 1987 (Durham, NC: Duke University Press).

Flanagan, Scott C. (1968) 'Voting Behavior in Japan: The Persistence of Traditional Patterns' Comparative Political Studies (October) 399-401.

Flanagan, Scott C. (1984) 'Electoral Change in Japan: A Study of Secular Realignment' in Russel J. Dalton, Scott C. Flanagan and Paul Allen Beck (eds) Electoral Change in Advanced Industrial Democracies (Princeton, NJ: Princeton University Press)

Flanagan, Scott C. (1991) 'Mechanisms of Social Network Influence in Japanese Voting Behavior' in Flanagan et al. (eds) The Japanese Voter (New Haven, CN: Yale University Press).

Foster, James J. and Daniel J. Edelman (1982) 'Ghost-Hunting: The Organization of the Liberal Democratic Party in Hyogo Prefecture' Asian Survey 22: 843-857.

Gaines, Brian J. (1999) 'Duverger's Law and the Meaning of Canadian Exceptionalism' Comparative Political Studies 32: 835-861. 


\section{References}

Gelman, Andrew and Gary King (1993) 'Why are American Presidential Election Campaigns so Variable when Votes are so Predictable?' British Journal of Political Science 23: 409-451.

Grofman, Bernard and Arend Lijphart (eds) (1986) Electoral Laws and their Political Consquences (New York: Agathon Press).

Grofman, Bernard et al. (eds) (1999) Elections in Japan, Korea and Taiwan under the Single Non-Transferable Vote (Ann Arbor: The University of Michigan Press).

Herron, Erik S. and Misa Nishikawa (2001) 'Contamination Effects and the Number of Parties in Mixed-Superposition Electoral Systems’ Electoral Studies 20: 63-86.

Hrebenar, Ronald J. (1992a) 'The Democratic Socialist Party: Enigma of the Center' in Ronald J. Hrebenar (ed.) The Japanese Party System (Boulder, CO: Westview Press).

Hrebenar, Ronald J. (1992b) 'The Komeito: Party of Buddhist Democracy' in Ronald J. Hrebenar (ed.) The Japanese Party System (Boulder, CO: Westview Press).

Huckfeldt, Robert and John Sprague (1995) Citizens, Politics and Social Communication (Cambridge: Cambridge University Press).

Ishikawa Masumi and Hirose Michisada (1989) Jimintou: Chouki Shihai no Kouzou (LDP: The Structure of Long-Term Rule) (Tokyo: Iwanami Shinsho).

Iwai Tomoaki (1998a) Rippou Katei (The Legislative Process) (Tokyo: Tokyo University Press).

Iwai Tomoaki (1998b) 'The Political Impact of the New Regulations on Political Donations in Japan.' Paper presented at The Symposium for Political Reform in Japan, The German Institute for Japanese Studies, 17-18 July, Tokyo, Japan.

Iwai Tomoaki (1999) 'Hosokawa Naikaku' ('The Hosokawa Government') in Sasaki Takeshi (ed.) Seiji Kaikaku 1800-nichi no Shinjitsu (The 1,800 Days of Political Reform) (Tokyo: Kodansha).

Johnson, Stephen (2000) Opposition Politics in Japan (London: Routledge).

Kabashima Ikuo (1998) Seiken Koutai to Yuukensha no Taido Henyou (Changing Voter Attitudes and the Alternation in Power) (Tokyo: Bokutakusha).

Kabashima Ikuo (1999) '98-nen Sanninnsenn - Jimintou ha naze Maketa ka?' ('The Upper House Election of 1998: How the LDP Went Down to Defeat') Rebaiasan 25: 78-102.

Kabashima Ikuo (2000) 'Chiho Oukoku to Toshi no Hannran' ('The Rural Kingdom and the Revolt of the Cities') Chuиou Kouron (September) 130-143.

Kabashima, Ikuo and Ryousuke Imai (2002) 'Evaluation of Party Leaders and Voting Behaviour - An Analysis of the 2000 General Election' Social Science Japan Journal 5: 85-96.

Kabashima, Ikuo and Yoshito Ishio (1998) 'The Instability of Party Identification Among Eligible Japanese Voters' Party Politics 4: 149-174.

Kabashima Ikuo and Steven R. Reed (2000) 'Voter Reactions to 'Strange Bedfellows': The Japanese Voter Faces a Kaleidoscope of Changing Coalitions' Japanese Journal of Political Science 1: 229-248.

Kato Junko (1998) 'When the Party Breaks Up: Exit and Voice among Japanese Legislators' American Political Science Review 92: 857-70.

Katou Kunihiko (1985) Hekichi no jimintou-dono: touhyouritsu 90\% o koeru to nani ga okiru ka - saa Amami (Backwater LDP: What Happens When Turnout Surpasses 90\%? This is Amami) (Tokyo: Jouhou Sentaa Shuppankyoku).

Katz, Richard S. (1986) 'Intraparty Preference Voting' in Bernard Grofman and Arend Lijphart (eds) Electoral Laws and Their Political Consequences (New York: Agathon Press). 
Katz, Richard S. (2001) 'Reforming the Italian Electoral Law, 1993' in Matthew Soberg Shugart and Martin P. Wattenberg (eds) Mixed-Member Electoral Systems: The Best of Both Worlds? (Oxford: Oxford University Press) 96-122.

Kawato Sadafumi (2000) 'Strategic Contexts of the Vote on Political Reform Bills' Japanese Journal of Political Science 1: 23-52.

Kohno, Masaru (1997) Japan's Postwar Party Politics (Princeton, NJ: Princeton University Press).

Krauss, Ellis S. (1984) 'Conflict in the Diet: Toward Conflict Managment in Parliamentary Politics' in Ellis S. Krauss, Thomas P. Rohlen and Patricia G. Steinhoff (eds) Conflict in Japan (Honolulu: University of Hawaii Press).

Kusunoki Seiichirou (1997) 'Shousenkyokusei Houan no Zassetsu' ('The Failure of the Small-District System Bills') in Takafusa Nakamura and Masayasu Miyazai (eds) Kadoki toshite no 1950 nendai (The 1950: Japan's Decade of Transition) (Tokyo: Tokyo University Press) 47-72.

Laakso, Markku and Rein Taagepera (1979) 'The Effective Number of Parties: A Measure with Application to Western Europe' Comparative Political Studies 12: 3-27.

Laver, Michael and Michael Marsh (1996) 'Parties and Voters' in John Coakley and Michael Gallagher (eds) Politics in the Republic of Ireland (Dublin: PSAI Press).

Lijphart, Arend (1999) Patterns of Democracy (New Haven, CN: Yale University Press).

Lodge, Milton, Marco Steenbergen and Shawn Brau (1995) 'The Responsive Voter: Campaign Information and the Dynamics of Candidate Evaluation' American Political Science Review 89: 309-326.

Maeda Yukio (1995) 'Rengou Seiken Kousou to Chiji Senkyo' ('Proposed Coalitions and Gubernatorial Elections' Kokka Gakkai Zasshi 108: 1329-1390.

Mair, Peter (1982) 'Muffling the Swing: STV and the Irish General Election of 1981' West European Politics 5: 1, 75-90.

Mair, Peter (1986) 'Districting Choices under the Single-Transferable Vote' in Bernard Grofman and Arend Lijphart (eds) Electoral Laws and their Political Consequences (New York: Agathon Press).

Matsusaka, J. and F. Palda (1993) 'The Downsian Voter Meets the Ecological Fallacy' Public Choice 77: 855-878.

Miyagawa Takayoshi (1994) Shousenkyoku Hanndobukku (SMD Handbook) (Tokyo: Seiji Kouhou Sentaa).

Miyake Ichiro (1991) 'Issues and Voting Behavior' in Scott C. Flanagan et al. (eds) The Japanese Voter (New Haven, CN: Yale University Press).

Miyake Ichiro (2001) Senkyo Seido Henkaku to Touhyou Koudou (Changing the Electoral System and Voting Behaviour) (Tokyo: Bokutakusha).

Miyake Ichiro, Yoshitaka Nishizawa and Masaru Kohno (2001) 55nen Taisei ka no Seiji to Keizai (Politics and Economics During the 1955 Party System) (Tokyo: Bokutakusha).

Mizusaki Tokifumi and Hiroki Mori (1998) 'Tokuhyou deeta kara mita Heiritsu-sei no

Mekanizumu' ('The Impact of the New Electoral System on Voting Behavior and Campaign Strategies in 1996') Senkyo Kenkyuu 13: 50-59.

Molinar, Juan (1991) 'Counting the Number of Parties: An Alternative Index' American Political Science Review 85: 1383-1392.

Muller, Wolfgang C. (1999) 'Decision for Opposition: The Austria Socialist Party's Abandonment of Government Participation in 1966' in Wolfgang C. Muller and Kaare Strom (eds) Policy, Office or Votes: How Political Parties in Western Europe Make Hard Decisions (Cambridge: Cambridge University Press). 
Nagayama Masao (1997) 'Shousenkyoku no Kako to Gen zai' ('The Present and Future of SMDs') paper presented at the 1997 annual conference of the Japan Political Science Association, Tokyo.

Nakgawa Tomoko (1998) Bikkuri (Surprise) (Tokyo: Gendai Shokan).

Nakai Ayumu (1997) “'Soto kara kita”Kaikakuha: Nihon Shintou to Hosokawa Morihiro' ('Reformers from 'the Outside': Hosokawa Morihiro and the Japan New Party') in Otake Hideo (ed.) Seikai Saihen no Kenkyuu (Tokyo: Yuugaikaku).

Newell, James (2000) 'Party Finance and Corruption: Italy' in Robert Williams (ed.) Party Finance and Political Corruption (London: Macmillan).

Niwa Isao (1997) 'Daikigyou Roushi to Senkyo' ('Big Business Management and Labour in the Election') in Otake Hideo (ed.) Seikai Saihen no Kenkyuu (Tokyo: Yuugaikaku).

Nonaka Naoto (1998) 'Senzogaeri? Renritsu Seiken Jidai ni okeru Seisaku Katei no Henyo' ('A Return to One's Roots? Changing Patterns of Policy Making in the Era of Coalition Governments') Rebaiasan, Special Issue, 37-67.

Otake Hideo (1997) 'Seiji Kaikaku wo mezashitta futatsu no Seiji Seiryoku: Jimintou Wakate Kaikakuha to Ozawa Guruupu' ('Two Political Forces for Reform: The Young LDP Reformers and the Ozawa Group') in Otake Hideo (ed.) Seikai Saihen no Kenkyuu (Tokyo: Yuuhikaku).

Otake Hideo (1999) Nihon Seiji no Tairitsujiku (The Cleavages of Japanese Politics) (Tokyo: Chuukou Shinsho).

Packard, George R., III (1966) Protest in Tokyo: The Security Treaty Crisis of 1960 (Princeton, NJ: Princeton University Press).

Page, Benjamin I. and Robert Y. Shapiro (1992) The Rational Public (Chicago: The University of Chicago Press).

Pasquino, Gianfranco and Patrick McCarthy (eds) (1993) The End of Post-War Politics in Italy: The Landmark 1992 Elections (Boulder, CO: Westview Press).

Pempel, T.J. (1975) 'The Dilemma of Parliamentary Opposition in Japan' Polity (Fall) 63-79.

Pharr, Susan J. (1982) 'Liberal Democrats in Disarray: Intergenerational Conflict in the Conservative Camp' in Terry Edward MacDougall (ed.) Political Leadership in Contemporary Japan (Ann Arbor, MI: Michigan Papers in Japanese Studies).

Popkin, Samuel L. (1991) The Reasoning Voter (Chicago: University of Chicago Press).

Reader, Ian (1991) Religion in Contemporary Japan (Honolulu: University of Hawaii Press).

Reed, Steven R. (1991) 'The 1990 General Election: Explaining the Historic Socialist Victory’ Electoral Studies 10: 3 (September) 244-255.

Reed, Steven R. (1994a) 'The Japanese General Election of 1993' Electoral Studies 13: 1 (March) 80-83.

Reed, Steven R. (1994b) 'The Incumbency Advantage in Japan' in Albert Somit et al. (eds) The Victorious Incumbent: A Threat to Democracy? (Aldershot, UK: Dartmouth Publishing Company).

Reed, Steven R. (1994c) 'Democracy and the Personal Vote: A Cautionary Tale from Japan' Electoral Studies 13: 17-28.

Reed, Steven R. (1994d) 'Paths to Reform' By the Way 4: 32-35.

Reed, Steven R. (1997a) 'The 1996 Japanese General Election' Electoral Studies 16: 1 (March) 121-125. 
Reed, Steven R. (1997b) 'A Story of Three Booms: From the New Liberal Club to the Hosokawa Coalition Government' in Purnendra Jain and Takashi Inoguchi (eds) Japanese Politics Today (South Melbourne: Macmillan Education Australia).

Reed, Steven R. (1999) 'Political Reform in Japan: Combining Scientific and Historical Analysis' Social Science Journal Japan 2: 177-193.

Reed, Steven R. (2001a) 'The 2000 General Election' Japanese Journal of Political Science 1: 337-339.

Reed, Steven R. (2001b) 'Duverger's Law is Working in Italy' Comparative Political Studies 34: 312-327.

Reed, Steven R. and Michael F. Thies (2001a) 'The Causes of Political Reform in Japan' in Matthew Soberg Shugart and Martin P. Wattenberg (eds) Mixed-Member Electoral Systems: The Best of Both Worlds? (Oxford University Press) 152-172.

Reed, Steven R. and Ethan Scheiner (forthcoming) 'Electoral Incentives and Policy Preferences: Mixed Motives Behind Party Defections In Japan', British Journal of Political Science.

Riker, W.H. (1986) 'Duverger's Law Revisited' in B. Grofman and A. Lijphart (eds) Electoral Systems and Their Political Consequences (New York: Agathon Press).

Rochon, Thomas R. and Roy Pierce (1985) 'Coalitions as Rivalries: French Socialists and Communists, 1967-1978' Comparative Politics 17: 437-451.

Rosenstone, Steven J. and John Mark Hansen (1993) Mobilization, Participation and Democracy in America (London: Macmillan).

Sakakibara Eisuke (1991) 'The Japanese Politico-Economic System and the Public Sector' in Samuel Kernell (ed.) Parallel Politics: Economic Policymaking in Japan and the United States (Washington, DC: Brookings Institution).

Sasaki Takeshi (ed.) (1999a) Seiji Kaikaku 1800-nichi no Shinjitsu (The 1,800 Days of Political Reform) (Tokyo: Kodansha).

Sasaki Takeshi (1999b) 'Seiji Kaikaku to ha Nan deattanoka?' ('What Was Political Reform?') in Sasaki Takeshi (ed.) Seiji Kaikaku 1800-nichi no Shinjitsu (The 1,800 Days of Political Reform) (Tokyo: Kodansha).

Scheiner, Ethan (1999) 'Urban Outfitters: City-Based Strategies and Success in Post-War Japanese Politics’ Electoral Studies 18: 179-198.

Scheiner, Ethan (2001) 'Democracy Without Competition: Opposition Failure in OneParty Dominant Japan' Unpublished doctoral dissertation, Duke University, Durham, NC.

Shinkawa Toshimitsu (2000) Sengo Nihon Seiji to Shakai Minshushugi (Postwar Politics and Social Democracy) (Tokyo: Houritsu Bunka Sha).

Shirakawa Katsuhiko (2000) Jijikou wo Hihan suru (A Critique of the LDP-Liberal-Koumei Coalition) (Tokyo: Kaden-sha).

Shugart, Matthew Soberg and Martin P. Wattenberg (eds) (2001) Mixed-Member Electoral Systems: The Best of Both Worlds? (Oxford: Oxford University Press).

Sinnott, Richard (1978) 'The Electorate' in Howard R. Penniman (ed.) Ireland at the Polls: The Dáil Elections of 1977 (Washington, DC: American Enterprise Institute).

Sniderman, Paul M. et al. (2000) The Outsider: Prejudice and Politics in Italy (Princeton, NJ: Princeton University Press).

Steel, Brent and Taketsugu Tsurutani (1986) 'From Consensus to Dissensus: Britain and Japan' Comparative Politics 18: 235-248.

Taagepera, Rein and Matthew Soberg Shugart (1989) Seats and Votes: The Effects and Determinants of Electoral Systems (New Haven, CN: Yale University Press). 


\section{References}

Tanaka, Aiji (1997) 'Seitou shiji nashi' sou no ishiki kouzou' ('The Belief Structures of Voters with No Party Identification') Rebaaisan 20: 101-129.

Tani Satomi (1998) 'Political Realignment in Hyogo and Okayama,' in Otake Hideo (ed.) How Electoral Reform Boomeranged (Tokyo: Japan Center for International Exchange).

Taniguchi Masaki (1999) 'Shakai, Koumei, Minsha, Kyousantou' ('The JSP, Koumei, DSP and JCP') in Sasaki Takeshi (ed.) Seiji Kaikaku 1800-nichi no Shinjitsu (The 1,800 Days of Political Reform) (Tokyo: Kodansha).

Thies, Michael F. (1995) 'The Japanese House of Councillors Election of 1995' Electoral Studies 14: 464-470.

Tsebelis, George (1988) 'Nested Games: The Cohesion of French Electoral Coalitions' British Journal of Political Science 18: 145-170.

Ushiro Fusao (1999) 'Minshutou: Niwaka Kettou no Senseki' ('The Democrats: The Effects of Forming a Party Under Time Pressure') in Sasaki Takeshi et al. (eds) Daigishi to Kane (Dietmen and Money) (Tokyo: Asahi Shinbun-sha).

Vowles, Jack (1995) 'The Politics of Electoral Reform in New Zealand' International Political Science Review 16: 95-115.

Watanuki Joji (1991) 'Social Structure and Voting Behavior' in Scott C. Flanagan et al. (eds) The Japanese Voter (New Haven, CN: Yale University Press).

Weiner, Robert (1998) 'Nomination Errors under Japanese SNTV and the Limits of Party Control.' Unpublished manuscript, University of California at Berkeley.

Weiner, Robert (2000) 'Duvergerian Forces Produce Non-competition, Not Duverger's Law.' Presented at the Annual Meeting of the American Political Science Association, Washington, DC.

White, James W. (1970) The Soka Gakkai and Mass Society (Palo Alto, CA: Stanford University Press).

Wildavsky, Aaron (1959) 'A Methodological Critique of Duverger's Political Parties' Journal of Politics 21: 303-318.

Woodall, Brian (1996) Japan Under Construction: Corruption, Politics, and Public Works (Berkeley: University of California Press).

Yamada, Masahiro (1997) 'Nousonkei Senkyoku ni okeru Seikai Saihen oyobi Senkyo Seido Kaikaku no Eigyou: Ibaraki shin 2-ku, Nukaga Fukushiro wo Rei to shite' ('Political Realignment in Rural Districts: The Case of Nukaga Fukushirou in Ibaraki New $2^{\text {nd }}$ District') in Otake Hideo (1997a) Seikai saihen no kenkyuu.

Yoshida Shinichi and Yamamoto Shuji (1999) 'Giin wo Umidasu Kosuto' ('The Cost of Being a Legislator') in Sasaki Takeshi et al. (eds) Daigishi to Kane (Diet Members and Money) (Tokyo: Asahi Sensho). 


\section{Index}

Adonis, A. 195

Agricultural Co-operative (Noukyou) 35-6

Aichi Kazuo 42, 43

Akaba Kazuyoshi 89, 90-1, 92

Akagi Munenori 110

Akagi Norihiko 109-11

Akamatsu Masao 100-1

allied vote $151-3,154-5,167-8$

Amami 124-5

Ampou cleavage 7-8, 175, 198

April Society 49, 52

Arikawa Seiji 125, 135

Asano Shirou 43

Aum Shinrikyou 36

Austria 32

base mobilisation 147-8, 149

Berton, P. 9

bipolar competition 187-92; calculating bipolarity 200-1

Brau, S. 4

Britain 195; Labour Party 148; Liberal Democratic Party 32

Bromhead, P. 148

Cain, B. 19

campaign expenditure $151-3,155-6,168$

campaign expenditure law 181-2

campaign strategies $147-50$

Campbell, A. 165

Campbell, J.C. 49

Canada 165, 187

candidate-centred politics 19-20

candidates, effective number of 188

candidate's vote: 1996 150-3; 2000 166-71

challengers, effective number of 188

Christensen, R. 8, 9, 10, 11, 148

Clarke, H.D. 165 cleavages $175-6,195-8$

closeness hypothesis 157

coalitions: decision making 32; JiJi 47-8, 162-3; JiJiKou 48-53, 162-3, 166, 177; 1993 election 14-15, 26-7; 1996 election 40-2; Obuchi's search for partners 46-8; partial 46-7

competition, bipolar 187-92, 200-1

consensus democracy 17-18

'conservative alliance' camp 40, 41

Conservative Party 52-3, 55, 59, 161, 192

co-operation, electoral see electoral cooperation

co-ordination among opposition parties $20-1,102$

corruption 57, 195-6; reducing costs of elections to combat $179-82$

Costa Rica arrangements 59-60, 106, 112, 132-3; 'Costa Rica' incumbents 168-9

costs, reducing 179-82

Cox, G.W. 17, 19, 20, 21, 179, 185, 187

Cox, K 138

cross-district linkage 187

Curtis, G.L. 5, 7, 10, 11, 14, 20, 29, 30, 31

decision making, in coalitions 32

democracy 3-4; majoritarian vs consensus $17-18$

Democratic Party of Japan (DPJ) 34, 37, 159, 192, 193, 194, 196; bipolar competition 189-91; break up of NFP 44-5, 176; district-level returns 153-7, 173-4; factions 186; Hyogo 86; Ibaraki 106-7, 108, 109, 119-20; and JiJiKou coalition 51, 52; Kagoshima 137; leadership contest of 199950 ; Nagano 67, 69-70, 78-82, 82-3; 1996 election $38,41,149,153-7$; prospects for a two-party system 195; public opinion 
$164,165,166 ; 2000$ election 55-6, 57, 58, 60-1, 161, 173-4

Democratic Socialist Party (DSP) 8-9, 10, 13, 14, 29, 123

Demokurattsu (Democrats) 25-6, 30

Denver, D. 32

district level: bipolar competition 187-92; returns for 1996 153-7; returns for 2000 171-6

Doi Ryuichi 85-6, 92

Doi Takako 8, 40, 41, 86, 94, 96; Doi boom $10,11,156$

double candidacy 22-3

Downs, A. 157

Duverger's Law 17, 187, 188, 200

Eda Saburou 9-10

Edelman, D.J. 182

Ehime 60

electoral co-operation 21, 148, 149-50;

Hyogo 88-9; Ibaraki 105, 106; Nagano

69 ; negotiating $54-5$

electoral law violations $179-80$

electoral systems 16-23; changing the system 21-2; classifying 16-17; coordination among opposition parties 20-1; majoritarian vs consensus democracy 17-18; MMM see mixedmember majoritarian system; party or candidate 19-20

expenditure, campaign 151-3, 155-6, 168; law 181-2

factions $185-6$

Ferejohn, J. 19

Fiorina, M. 19

Five-Party Alliance (Rengou-Gotou) 84, $86,87-9,103$

Flanagan, S.C. 8,10

Foster, J.J. 182

France 148

Fujiki Youko 97-8

Fujimoto Kinzou 99

Fukasawa Kenichirou 78-80

Funada Hajime 37, 38

fund management organisations 181

Futami Nobuaki 107, 108, 114, 116

Future Party 29

Fuyushiba Tetsuzou 91, 94-5, 97-8

Germany 22, 196, 197

Gotou Shigeru 85, 100-2

Gotou Shigeyuki 75-6
Gotou Takeshi 100-2

Gotouda Masaharu 15

Grofman, B. 18

Gunji Akira 107, 108

Gunji Takao 110

Gunma 60

Hamada Ken'ichi 134-5

Hanashi Nobuyuki 111, 112-13

Hanashi Shingoro 112

Hara Kenzaburou 85, 98-9

Hashiguchi Ryouichi 136-7

Hashimoto Ryuutarou 15, 37, 185, 198-9; administration 38, 40, 41-2, 146, 161-2; resignation 46

Hashimoto Tomisaburou 111

Hata Bushirou 74

Hata Tsutomu 12, 33, 40-1; administration 29-30; Nagano 67, 68, 74-5, 82

Hata Yuichirou 78-80

Hatanaka Itsuo 97

'Hato-mander' 11

Hatoyama Ichiro 37

Hatoyama Kunio 37

Hatoyama Yukio 37, 50, 53, 164

Hirano Shigenobu 136-7

Hirata Shinichirou 132-3

Hirose Michisada 182

Honma Shuntarou 42-3

Horigomi Ikuo 74-5

Hosokawa Morihiro 12, 15, 32, 40-1, 153; administration 14, 26-8, 145-6

House of Councillors elections: Ibaraki 107-8, 119; Nagano 77-80; 1989 8, 11,$21 ; 1995$ 34-6, 77-8; 1998 45-6, $107-8,119,184-5$

Hyogo 65, 66, 84-104; new SMDs 89-103; 1996 election 84-7; 2000 election 87-9; first district 89-90; second district 90-1; third district 92; fourth district 92-3; fifth district 93-4; sixth district 94-6; seventh district 96; eighth district 97-8; ninth district 98-9; tenth district 99-100; eleventh district 100-2; twelfth district 102-3

Ibaraki 65, 66, 105-21; House of Councillors election 1998 107-8, 119; new SMDs 109-19; 1996 election 106-7, 118-19; 2000 election 108-9, 119; first district 109-11; second district 111-12; third district 112-13; fourth district 113-14; fifth district 
114-16; sixth district 116-17; seventh district 117-19

Ichikawa Ichirou 43

Ichimura Kouichirou 95-6

Ide Ichitarou 74

Ide Shouichi 68, 74

Igarashi Hiroko 116

Ikawa Hiromitsu 92

Ikeda Hayato 8

Imai Ryousuke 164

Imanishi Eiji 96

incumbency 151-3, 168-9

independent voters $147,164-5$

independents $45,61,183$

India 187

Inoue Kiichi 85, 93

Ireland 18, 148

Ishihara Shintarou 27, 131, 197

Ishii Hajime 89-90, 92

Ishii Ichiji 131

Ishii Ryouichi 86

Ishikawa Masumi 182

Ishio Yoshito 149

Italy $16,22,147,182,187,188$

Iwai Tomoaki 14, 24, 26, 28, 32, 179, 180

Iwanaga Hiromi 35-6

Iwasaki Tadao 74-5

Iwate 190

Japan Communist Party (JCP) 9;

Kagoshima 123; Nagano 69; 1993

election 13, 14; 1996 election 153,

153-7, 159; 2000 election 61, 161, $171,174-5$

Japan New Party (JNP) 12; failed merger with Sakigake 24-5; failed merger with Shinsei 28; 1993 election 12-13, 14; 1996 election 153; public opinion 146 Japan Socialist Party (JSP) 7-8, 24, 25 , 27, 29, 153; centre-left dream 10-11, 25-6; coalition with LDP and Sakigake 30-2, 33; House of Councillors election 1995 35; Ibaraki 105, 107, 108; Kagoshima 122, 123-4, 124-5, 137, 139; 'Murayama vision' 26; Nagano 70; name changed to SDP 34; 1993 election 13, 14, 15; public opinion 147

JiJi (LDP-Liberal) coalition 46-8, 162-3

JiJiKou (LDP-Liberal-Koumei) coalition 48-53, 162-3, 166, 177

Jiyuu Kenseikai 81

Juusen 38-9
Kabashima Ikuo 5, 13, 25, 46, 58, 149, 164

Kagoshima 65, 66, 122-39; Amami, early redistricting and 1990 Socialist boom 124-5; 1993 election 125-6; 1996 election 126-8, 129-31, 132-3, 134, 135-6; one-and-a-half party system 123-4; 2000 election 128-9, 131-2, 133-4, 135, 136-7; first district 126-9; second district 129-32; third district 132-4; fourth district 134-5; fifth district 135-7

Kaifu Toshiki 12, 30, 32, 44

Kajiwara Hirotoku 136-7

Kajiyama Hiroshi 113-14, 114-15

Kajiyama Seiroku 14, 46, 108, 113

Kakizawa Hiroharu 28

Kakizawa Kouji 38

Kamei Shizuka 40, 83, 96

Kamiyama Kazuto 128-9

Kan Naoto 37, 50, 93, 164

Kanakubo Yoshikazu 72

Kanemaru Shin 10, 11, 12

Kano Michihiko 29, 37, 44

Karasawa Shunjiro 72-3

Kato Junko 25, 128

Katou Eiichi 92

Katou Kouichi 36, 49-50, 52, 61, 137-8, 186, 193

Katou Kunihiko 124

Katou Mutsuki 185

Katou Takashi 76-7

Katz, R.S. 178

Kawauchi Hiroshi 126, 127-9

KenMin Club 81

Kenseikai 81

Kijima Hideo 75-6

Kimura Morio 190

Kishi Nobusuke 7-8

Kitagawa Renko 97-8

Kitazawa Seiko 72-3

Kitazawa Toshimi 78

Kobayashi Kunio 116

Kohno Masaru 165

Koike Yuriko 85, 94-6

Koizumi Junichirou 46, 162, 198-9

Koizumi Toshiaki 112-13

Konishi Toshiaki 93

Konoike Yoshitaka 85

Kornberg, A. 165

Kosaka Kenji 68, 71-2, 77

kouenkai (political machines) 20, 181, $182,182-3,183-4$ 


\section{Index}

Koumei (Clean Government Party) 9, 21, $35,36,41,161$; break up of NFP 44; electoral co-operation 54-5, 88-9, 109, 150; Hyogo 88-9, 91, 103; Ibaraki 109, 119; JiJiKou coalition 47-53, 162-3, 166, 177; Kagoshima 123; Nagano 69; 1993 election 13, 14; 1996 election 156-7, 158-9; obstacle to two-party system 192; public opinion 166; religious cleavage 196-7; ShinseiKoumei axis 28; 2000 election 55-6, 58-9, 168, 170, 176, 177

Koumoto Saburou 102-3

Koumoto Toshio 102

Kouno Tarou 151

Kouno Youhei 15, 24, 27, 29-30, 151

Koyama Mineo 77-8

Krauss, E.S. 46

Kubo Wataru 41, 123, 128

Kuno Kouichi 108

Kusunoki Seiichirou 11

Laakso-Taagepera index 188, 200

Laver, M. 19

Liberal Alliance (LA) 122, 130, 131

Liberal Democratic Party (LDP) 4, 7, 24, 33,183 ; alternatives to $7-11,15-16$; candidates' political machines 20; candidate's votes $152-3$; cleavages 195-6, 197; district-level returns 153-7, 171-3; electoral co-operation 54-5; factions 185-6; House of Councillors elections 21, 35, 45-6, 77-80, 108; Hyogo 84-5, 87; Ibaraki 105, 106-7, 108, 108-9, 118-20; JiJi coalition 46-8, 162-3; JiJiKou coalition 48-53, 162-3, 166, 177; Kagoshima 122, 123-4, 125-6, 137-8; Koizumi leadership 198-9; LDP-JSPSakigake coalition 30-2, 33; Nagano 77-83; 1993 election 12, 13, 14, 125-6; 1996 election 38, 40, 41-2, 84-5, 87, 106-7, 153-7, 159, 160; no confidence motion against Hata administration 29-30; party leadership elections 46, 49-50, 198-9; public opinion 146, 162, 164, 165-6; rice import liberalisation 25; turnout 159; two-party system 189-91, 192, 193; 2000 election 56-7, 58, 59-60, 88-9, 108-9, 161, 171-3, 177; urban LDP 27 Liberal Kinki 34, 85
Liberal Party (formed 1997) 44, 193; electoral co-operation 54-5; exit from JiJiKou coalition 52-3; JiJi coalition 46-8, 162-3; JiJiKou coalition 48-53, 162-3, 166, 177; 2000 election 57-8, $61,161,171,175$

Liberal Party (Jiyuutou) 28-9

Liberal Reform Alliance 32

Lijphart, A. 17, 18

Lockheed scandal 9

Lodge, M. 4

loophole 181-2, 185

Mair, P. 19, 194

majoritarian democracy 17-18

Marsh, M. 19

Matsumoto Jurou 100-2

Matsushita Tadahiro 132-4

McCarthy, P. 7

Mie 190

Miki Takeo 11

Minsei (Popular Government) 45

Minyuuren 44

mis-statements 54

mixed-member majoritarian system (MMM) 15, 22-3, 138; and bipolar competition 190-2; and factions 185 ;

Koumei and 48; party-centred campaigns 182-3; prospects for a twoparty system 194-5

mixed-member proportional representation (MMPR) 22

Miyagawa Takayoshi 151

Miyagi gubernatorial election 42-3

Miyaji Kazuaki 125-6, 132-4

Miyake Ichiro 3, 165, 182

Miyamato Ichizou 85, 87, 94-5, 98-9

Miyashita Souhei 75, 76-7

Miyazaki Moichi 126, 127

Miyazawa, Prime Minister 12

Miyazawa faction 185-6

Mochizuki Yuunai 73

Molinar index 188, 200

mobilisation hypothesis $157-8$

Mori Yoshirou 53-4, 59, 132, 164

Muller, W.C. 32

multimember districts (MMD) 4, 18, 19, 20, 21-2, 48, 194

Murai Jin $72-3$

Muraoka Masuo 184

Murasawa Maki 77-8 
Murayama Tomoichi 15, 26; administration 30,146 ; retirement 36-7

Muroi Kunihiko 97, 98

Nagai Takanobu 85-6, 99-100

Nagano 65, 66, 67-83; House of Councillors elections 77-80; 1996 election 71-2, 73, 74, 75, 76; 1999 byelection 78-80; prefectural assembly elections $81-2$; prefecture $68-70 ; 2000$ election 72, 73, 74-5, 76, 76-7; first district 71-2; second district 72-3; third district 74-5; fourth district 75-6; fifth district 75, 76-7

Nagano Sukenari 125, 127

Nagaoka Youji 109, 117-18

Nakagawa Tomoko 95-6

Nakai Ayumu 12

Nakajima Mamoru 75, 76

Nakajima Youjirou 180-1

Nakamura Kishirou 109, 116-18

Nakayama Eiichi 112

Nakayama Tarou 27

Nakayama Toshio 111-12, 112-13

national welfare tax 27-8

New Frontier Party (NFP) 33-4, 37, 149, 189, 190; break up of $44-5,189,192$; district-level returns 153-7; House of Councillors elections 34-5, 35-6; Ibaraki 106-7, 119, 120; Juusen problem 37-8; Nagano 67, 68-9; 1996 election 38, 40-1, 153-7, 159; Ozawa 33, 40, 43, 44; public opinion 146-7, $164 ; 2000$ election $167,170-1,176-7$

New Liberal Club (NLC) 9, 10, 147-8, 156

new-old cleavage 175-6

new parties 149; boom of 1993 11-15, 153; new new parties 1993-96 32-4

New Socialist Party (NSP) 34, 85

New Zealand 16, 22

Newell, J. 182

Nikaidou Susumu 123, 126, 135-7

1990 general election 21

1993 general election 4, 7-16, 65, 66; alternatives to LDP 7-11; forming a non-LDP government 14-15; Kagoshima 125-6; Reform Movement and the new parties 11-15; toward a new party system $15-16$

1996 election 4, 38-9, 40-2, 65, 66, 145-60; analysis of returns $150-9$; campaign strategies 147-50;

candidate's vote $150-3$; district-level returns 153-7; Hyogo 84-7; Ibaraki 106-7, 118-19; Kagoshima 126-8, 129-31, 132-3, 134, 135-6; Nagano 71-2, 74, 75, 76; public opinion between 1993 and 1996 elections 145-7; turnout 157-9

Niou, E. 19

Nishimura Yasutoshi 99

Nishizawa Yoshitaka 165

Niwa Isao 115

Niwa Kyoushirou 115

Niwa Yuuya 115-16

Noda Takeshi 49, 52-3

Nomura Itsuo 108, 118

Nonaka, LDP Secretary-General 53, 183

Nonaka Naoto 32

Nukaga Fukushirou 111-12

Nunome Yukio 79

Obuchi Keizou 49, 53, 54, 68, 132; leadership of LDP 46, 49-50; Obuchi faction of LDP 186; public support for Obuchi administration 162-4; search for coalition partners $46-8$

Ogawa Hajime 75-6

Okabe Hideo 115

Okazaki Hiromi 85, 92

Okinawa 38

Okutani Tooru 90-1

old-new cleavage 175-6

on-line model of voting behaviour 4

one-and-a-half party system 123-4

Oohata Akihiro 110, 114-15

Oota Seiichi 15, 28, 38

Oouchi Keigo 14, 29

Oowada Kiichi 114

Oozono Katsushi 133-4

opposition parties, co-ordination among 20-1, 102

Orange Friendly Society affair 41

Otake Hideo 9, 12, 28

Ougi Chikage 53

Ozato Sadatoshi 134-5, 137-8

Ozawa Ichirou 10, 24, 32, 68, 166, 190; Liberal advertisement for 2000 election 57-8; Miyagi gubernatorial election 42, 43; NFP 33, 40, 43, 44; non-LDP government 14,15 ; Reform 29; rivalry with Takemura 25, 31; Shinsei 12

Ozawa Teiko 72 


\section{Index}

partial coalitions 46-7

party branches $181-2$; stronger $183-5$

party-centred campaigns 19-20, 182-6

party identification hypothesis 165

party nominations $149-50$

Pasquino, G. 7

peace 198

Pempel, T.J. 21

Pharr, S.J. 9

political corruption see corruption

political reform 26-7

popular appeals 148

prefectural assembly elections 81-2

previous vote $151-3,154,167-8$

proportional representation (PR) 18, 19;

Ibaraki 119-20; PR incumbents 168-9;

reduction of PR section of MMM 48,

49, 51; tier in MMM 22-3, 190-1, 195;

2000 election $59-60$

public funding 180-1, 193

public opinion: between 1993 and 1996

elections 145-7; between 1996 and

2000 elections $161-6$

public works $56-7,83,197-8$

Recruit Scandal 11, 12

Reed, S.R. 5, 8, 9, 12, 18, 21, 25, 26, 41, $58,125,145,156,178,187,190,194$

Reform (Kaishin) 29, 31

Reform Club 44

Reform Movement 11-16

Reiyuukai 109

religion $36,49,52,55-6,196-7$

Rengou (trade union confederation) 8, 70, 86

Rengou-Gotou (five-party alliance) 84, 86, 87-9, 103

renza-sei 179-80

rice import liberalisation 25

Riker, W.H. 17

Risshou Kouseikai 109, 197

Rosenbluth, F. 185

rural-urban cleavage 153, 156-7, 176, 188-9, 198

Saga prefecture 35-6

Sagawa Kyuubin 11, 12, 28

Saitou Yoshiake 94

Saitou Zenichirou 113

Sakaue Yoshihide 95, 96

Sakigake (New Party Harbinger) 12; failed merger with JNP 24-5; LDP-JSP-

Sakigake coalition 30-2, 33; Nagano
68, 69; 1993 election 12-13, 14; 1996

election $38,40,153$

Sasaki Takeshi 5, 11

Satou Shinji 184-5

Satou Takayuki 42, 161-2, 196

Satou Yumi 110

Scheiner, E. 81, 156

Schoppa, L. 138

Sekido Hideko 110

Shimizu Isamu 71

Shimojou Mitsu 73

Shin Kenseikai 81

Shinkawa Toshimitsu 26

Shinsei 12, 33, 156, 190; failed merger with JNP 28; Nagano 67, 68, 81; 1993

election 12-13, 14; public opinion 146; Shinsei-Koumei axis 28

Shinto 54

Shiota Susumu 89, 93, 99-100

Shirakawa Katsuhiko 197

Shugart, M.S. 16, 18, 22, 194

single-member districts (SMDs) 17-18, 19; co-ordination among opposition parties 20, 21; SMD incumbency 168-9; tier in MMM 22-3, 194-5; 2000 election 59-60, 61

single non-transferable vote (SNTV) 18

single transferable vote (STV) 18, 19

Sniderman, P.M. 147

Social Democratic Liberal Party 28

Social Democratic Party of Japan (SDP) 34, 41, 190-1, 193; Hyogo 85; Nagano 69; 1996 election $38,40,153 ; 2000$ election 61, 161, 171, 175

Social Democratic League (SDL or Shaminren) 9-10

Society for Protecting the Separation of Religion and Politics (SBTK) 52, 56

Sonoda Shuukou 130-2, 137

Souka Gakkai 9, 36

Steenbergen, M. 4

strategic voting $17-18$

Sun Party 41

Sunada Keisuke 89-90

Sunada Shigetami 89

Suzuki Muneo 181

Taagepera Rein 16, 18, 194

Takami Yuuichi 85, 90-1

Takasawa Katsuichi 110

Takemura Masayoshi 12, 15, 24, 25, 28-9, 31

Takeshita faction 68 
Tanaka Aiji 165

Tanaka Kakuei 180

Tanaka Katsuya 117-18

Tanaka Makiko 162, 199

Tanaka Shuusei 68, 71

Tani Satomi 84, 89

Tani Youichi 94

Taniguchi Masaki 21, 25

Thies, M.F. 20, 26, 179, 185

Tochigi 190

Toida Saburou 100-1

Toida Tooru 101-2

Tokai Kisaburou 85, 99-100

Tokizaki Yuuji 110

Tokoi Yoshiharu 111-12

Tokuda Torao 124-5, 129-32

Tsuji Yasuhiro 100

Tsujimoto Kiyomi 181

Tsukada Enjuu 110

Tsukahara Shunpei 113, 114-15

Tsukahara Toshio 114

turnout 157-9

21st Century Club 183

two-party system 186-95; bipolar competition at district level 187-92; prospects for 194-5

2000 general election 4, 54-61, 161-77; analysing the returns $166-76$; candidate's vote 166-71; district-level returns 171-6; Hyogo 87-9; Ibaraki 108-9, 119; issues 55-8; Kagoshima 128-9, 131-2, 133-4, 135, 136-7; Nagano 72, 73, 74-5, 76, 76-7; negotiating electoral co-operation 54-5; public opinion between 1996 and 2000 elections $161-6$; results 58-61

United States 187; US-Japan Security Treaty $7-8$ urban-rural cleavage 153, 156-7, 176, 188-9, 198

Ushiro Fusao 37

violation of electoral law 179-80

Wakabayashi Masatoshi 71

Wakamiya Kiyoshi 98

Wakayama 191

Watanabe Michio 14, 15, 24, 27, 29

Watanuki Joji 9

Wattenberg, M.P. 22

Wearing, P. 165

Weiner, R. 125, 138

Yamada Masahiro 107, 111

Yamagishi Akira 10, 33

Yamaguchi Norihisa 79

Yamaguchi Tsuyoshi 102-3

Yamaguchi Wakako 73

Yamahama Sadao 10, 15, 33-4

Yamamoto Shuji 181

Yamanaka Sadanori 125, 126, 135-7

Yamazaki Taku 49-50

Yamazaki faction 193

Yanase Susumu 38

Yasu-Toku War 124-5

Yasuoka Okiharu 124-5, 126-9

YKK group 40, 41

Yokomichi Setsuo 50

Yokomichi Takahiro 26

Yonezawa Takashi 29

Yoshida Hiromi 83

Yoshida Shinichi 181

Yoshimura Seishi 93

Yoshioka Kenji 85-6, 94

Yuuai Kaigi 14 
